\title{
Evaluation of in vitro immunotoxicity tests using transcriptomics
}

Citation for published version (APA):

Schmeits, P. C. J. (2015). Evaluation of in vitro immunotoxicity tests using transcriptomics. [Doctoral Thesis, Maastricht University]. Uitgeverij BOXPress. https://doi.org/10.26481/dis.20151113ps

Document status and date:

Published: 01/01/2015

DOI:

10.26481/dis.20151113ps

Document Version:

Publisher's PDF, also known as Version of record

\section{Please check the document version of this publication:}

- A submitted manuscript is the version of the article upon submission and before peer-review. There can be important differences between the submitted version and the official published version of record.

People interested in the research are advised to contact the author for the final version of the publication, or visit the DOI to the publisher's website.

- The final author version and the galley proof are versions of the publication after peer review.

- The final published version features the final layout of the paper including the volume, issue and page numbers.

Link to publication

\footnotetext{
General rights rights.

- You may freely distribute the URL identifying the publication in the public portal. please follow below link for the End User Agreement:

www.umlib.nl/taverne-license

Take down policy

If you believe that this document breaches copyright please contact us at:

repository@maastrichtuniversity.nl

providing details and we will investigate your claim.
}

Copyright and moral rights for the publications made accessible in the public portal are retained by the authors and/or other copyright owners and it is a condition of accessing publications that users recognise and abide by the legal requirements associated with these

- Users may download and print one copy of any publication from the public portal for the purpose of private study or research.

- You may not further distribute the material or use it for any profit-making activity or commercial gain

If the publication is distributed under the terms of Article $25 \mathrm{fa}$ of the Dutch Copyright Act, indicated by the "Taverne" license above, 


\section{Evaluation of in vitro immunotoxicity tests using transcriptomics}

Peter Schmeits 
Peter Schmeits

Evaluation of in vitro immunotoxicity tests using transcriptomics

Thesis Maastricht University, Maastricht

ISBN 978-94-6295-277-5 


\title{
Evaluation of in vitro immunotoxicity tests using transcriptomics
}

\author{
PROEFSCHRIFT
}

Ter verkrijging van de graad van doctor aan de Universiteit Maastricht, op gezag van de Rector Magnificus, Prof. dr. L.L.G. Soete volgens het besluit van het College van Decanen, in het openbaar te verdedigen op vrijdag 13 november 2015 om 16.00 uur

Door

Peter Schmeits

Geboren te Oss op 24 maart 1986 


\section{Promotor}

Prof. dr. Henk van Loveren

\section{Co-promotor}

Dr. Ad Peijnenburg, RIKILT Wageningen UR

\section{Beoordelingscommissie}

Prof. dr. Bert Smeets (voorzitter)

Dr. Jan Damoiseaux

Prof. dr. ir. Ivonne Rietjens

Prof. dr. Jos Kleinjans

Prof. dr. Greet Schoeters

This research was financially supported by the Netherlands Toxicogenomics centre, the Netherlands Genomics Initiative 


\section{Contents}

Chapter 1 Introduction

Chapter 2 Detection of the mechanism of immunotoxicity of cyclosporine $\mathrm{A}$ in murine in vitro and in vivo models

Chapter 3 The effects of tributyltin oxide and deoxynivalenol on the transcriptome of the mouse thymoma cell line EL-4

Chapter 4 Assessment of the usefulness of the murine cytotoxic $\mathrm{T}$ cell line CTLL-2 for immunotoxicity screening by transcriptomics

Chapter 5 DON shares a similar mode of action as the ribotoxic stress inducer anisomycin while TBTO shares ER stress patterns with the ER stress inducer thapsigargin based on comparative gene expression profiling in Jurkat $\mathrm{T}$ cells

Chapter 6 Successful validation of genomic biomarkers for human immunotoxicity in Jurkat $\mathrm{T}$ cells in vitro

Chapter 7 Summary, general discussion and future perspectives

Chapter 8 Nederlandse samenvatting

Chapter 9 Valorisation Addendum

Dankwoord 



\section{Chapter 1}

\section{Introduction}




\section{The immune system}

The human immune system comprises specific organs and cells that work together to prevent or fight infections. Since the immune system protects the whole body it is spread over central and peripheral organs and sites, such as the bone marrow, thymus, spleen and lymph nodes (Fig. 1). Cells of the immune system are developing in the primary immune organs being the bone marrow and thymus. The development starts with a pluripotent haematopoietic stem cell in the bone marrow which is the 'mother'-cell of all leukocytes (white blood cells). This pluripotent haematopoietic stem cell differentiates into common lymphoid or common myeloid progenitor cells which further differentiate in the bone marrow. Common lymphoid progenitor cells give rise to B cell progenitor cells, $\mathrm{T}$ cell progenitor cells and natural killer cells. Common myeloid progenitor cells develop into megakaryocytes (that produce thrombocytes), erythrocytes, mast cells and myeloblasts. Myeloblasts further differentiate into granulocytes (basophils, neutrophils, eosinophils) and monocytes (macrophages) (Kozutsumi 1996).

The thymus lies in the thoracic cavity behind the sternum and in front of the heart. The most important functions of the thymus are the maturation of thymocytes into $\mathrm{T}$ cells and selection of those $\mathrm{T}$ cells and the generation of $\mathrm{T}$ cell receptors (Miller 2002). This process of $\mathrm{T}$ cell selection occurs in a phased manner. First, double positive (CD4+CD8+) thymocytes must recognise the human leukocyte antigen (HLA), or major histocompatibility complex (MHC) in most vertebrates including humans, that is expressed by thymic epithelial cells. Thymocytes that have at least a weak affinity for binding to MHC class I or II molecules will survive (positive selection). Those with no affinity will die, which concerns approximately $90 \%$ of the thymocytes ('death by neglect'). To avoid autoimmunity, thymocytes that have a high affinity for interacting with the HLA/MHC are forced into apoptosis (negative selection) (Baldwin et al. 2004; Palmer 2003). Positively selected (double positive) thymocytes mature into single positive thymocytes depending on the class of HLA/MHC that they bind to. Binding to HLA classes A, B or C (MHC class 1) results in CD8+ cytotoxic T cells, whereas binding to other HLA classes (MHC class 2) results in CD4+ T-helper cells. Since the majority of the population of T cells is generated early in life (until adolescence), the function of the thymus weakens and almost disappears in adult life as also seen in the decrease in size after puberty.

Secondary immune organs include the spleen, lymph nodes, Peyer's patches, the tonsils and tissues such as the lungs and skin. The spleen functions as a filter for blood and red blood cells that are also stored in there (Mebius and Kraal 2005). The human spleen is about the size of a fist and lies in the left part of the body next to the stomach. Lymph nodes are ovalshaped organs spread throughout the body that act as filters for particles from foreign origin. Lymph nodes, connected to each other by lymph vessels, have an important function in the immune system. Fluid inside these vessels contains lymphocytes that continuously travel along the lymphatic and blood vessels. Quite similar to lymph nodes, Peyer's patches are also oval shaped lymphoid organs. These are located in the intestine and more specifically in the ileum which is the part of the small intestine most distal from the 
stomach. The function of the Peyer's patches is to monitor and defuse pathogens that enter the human body through translocation across the small intestinal wall. Another lymphoid organ can be found in the pharynx and are called tonsils. These form a first barrier to pathogens that are either inhaled or ingested. The exact role of tonsils in the immune system is however not yet clear. The human body is further protected from inhaled pathogens by cells that produce mucus. These cells are lined in the respiratory system including the lungs and the mucus 'captures' the pathogens or dust particles that are moved away by cilia towards the throat and are coughed or sneezed out, or swallowed. Another important line of defence to pathogens concerns the skin. Dendritic cells (also called Langerhans cells) are present in the skin and take up antigens and present these to $\mathrm{T}$ cells. Another important organ in the human defence system is the liver containing large populations of lymphocytes and macrophages. The sinusoids of the liver are lined with Kupffer cells, specialised macrophages, that play an important role in the cleaning of the large volumes of blood passing through the liver. These Kupffer cells clear bacteria and endotoxins from the blood and phagocytose cellular debris.

\section{Innate and adaptive immune system}

The immune system can be divided into two sub-systems being the innate immune system (nonspecific white blood cells) and the adaptive (acquired; specific) immune system. Cells of the innate immune system include natural killer (NK) cells, mast cells, phagocytes (macrophages, dendritic cells, neutrophils) eosinophils and basophils. NK cells kill cells that have no or low levels of MHC class 1, which is the case in viral infected or tumour cells. When mast cells are activated, granules are released that contain large amounts of histamine and heparin. These cells are typically activated during allergic or anaphylactic reactions. Macrophages are leukocytes that are able to clear invading pathogens by a process called phagocytosis and are also particularly involved in removal of dead or dying cells. When activated, macrophages produce cytokines that attract other immune cells. Dendritic cells are present in almost any tissue. Dendritic cells are antigen presenting cells that phagocyte pathogens and present these as peptides to other cells of the immune system. Neutrophils are the most abundant type of phagocytes, normally representing 50 to $60 \%$ of the total circulating leukocytes. Neutrophils contain granules in their cytoplasm that contain substances to kill bacteria and fungi. Eosinophils and basophils also contain granules and therefore form, together with neutrophils, the group of granulocytes. Basophils release histamine upon contact to a pathogen and is especially involved in the defence against parasites and is known to play a role in allergies such as asthma. When eosinophils are activated they secrete a mixture of toxic proteins and free radicals (that lead to formation of reactive oxygen species (ROS)) which are highly effective in killing bacteria and parasites. Cells of the adaptive immune system include B lymphocytes and $\mathrm{T}$ lymphocytes. The main tasks of $\mathrm{B}$ cells is the production of antibodies. Antibodies, also named immunoglobulin (Ig), comprise five different types ( $\operatorname{Ig} A$, $\operatorname{IgD}, \operatorname{IgE}, \operatorname{IgG}, \operatorname{IgM}$ ). B cells are activated through their receptor, the $\mathrm{B}$ cell receptor $(\mathrm{BCR})$. Upon activation, $\mathrm{B}$ cells start to produce 
antibodies that have three functions: 1. Binding to specific pathogens (via its unique antigen) thereby prevent pathogens from entering or damaging cells, 2. Coating the pathogens to stimulate removal by macrophages and other cells and 3. Stimulate other immune responses, such as the complement pathway, for destruction of the pathogens. (Janeway 2001). The unique feature of the $\mathrm{T}$ cell is the $\mathrm{T}$ cell receptor (TCR). Different types of $\mathrm{T}$ cells are present in the human body including $\mathrm{T}$ helper cells, cytotoxic $\mathrm{T}$ cells and regulatory $\mathrm{T}$ cells. $\mathrm{T}$ helper cells express cluster of differentiation marker 4 (CD4) on their surface and their function includes the maturation of $\mathrm{B}$ cells to plasma cells or memory $\mathrm{B}$ cells and activation of cytotoxic $\mathrm{T}$ cells and macrophages. $\mathrm{T}$ helper cells become activated when their $\mathrm{T}$ cell receptor recognizes MHC class 2 antigens on antigen presenting cells (APCs). Cytotoxic T cells express marker CD8 on their cell surface and their main function is to destroy tumour cells and (virally) infected cells. Cytotoxic $\mathrm{T}$ cells become activated upon binding MHC class 1 molecules. Memory $\mathrm{T}$ cells (cytotoxic or helper $\mathrm{T}$ cells) are present long after an infection has been overcome and upon re-exposure these memory cells can quickly form large amounts of cytotoxic T cells (Bellantuono 2004; Kaech et al. 2002; Wherry and Ahmed 2004). Regulatory T cells prevent autoimmune diseases and other pathological self-reactivity by suppressing the activation of the immune system.

\section{Chemical immunotoxicity}

Immunotoxicity is defined as an adverse effect on the function of cells or organs of the immune system that is caused by exposure to chemicals. Immunotoxicity can be divided into direct immunotoxicity and indirect immunotoxicity. Indirect immunotoxicity includes the effects of haptens, which are considered incomplete antigens that need to bind to enzymes for instance. These hapten-enzyme complexes are first absorbed through skin or eyes, taken up by antigen presenting cells that present these haptens to the immune system where after a response is initiated (McFadden et al. 2011). These responses often include activation of inflammation leading to itches and rash.

Direct immunotoxicity includes the effects of chemicals on components of the immune system that results in an impaired immune system. Chemicals that can have immunotoxic effects include a variety of compound classes such as mycotoxins, insecticides, metals, pesticides, pharmaceutical drugs, and many more. Most of the chemicals that elicit direct immunotoxicity enter the human body through the consumption of food, air or water. After uptake (through the skin, lungs or into the bloodstream) these compounds can activate or suppress the immune system. Some of the chemicals can elicit immunotoxic effects only after biotransformation into a more toxic metabolite. These biotransformation reactions take place mainly in the liver. For in vitro experiments, biotransformation can be achieved by addition of liver S9 mix, usually from human or rat origin (Tucker et al. 1982). The S9 mix comprises of microsomes that are rich in Cytochrome P450 enzymes. These enzymes are the most important enzymes in converting compounds into metabolites. Examples of 
compounds that become (more) immunotoxic after metabolic activation include cyclophosphamide, benzo-a-pyrene and ochratoxin A.

\section{Immunotoxicity related diseases.}

In general the immune system functions to protect the human body from all threats foreign as well as domestic (as is the case for cancer cells). Several diseases are specifically related to immune dysfunction. These include infections, like the influenza virus, herpes simplex virus and acute otitis media, and allergies like eczema or childhood and occupational asthma. Next to those, Crohn's disease, Kawasaki disease, multiple sclerosis, rheumatoid arthritis and diabetes mellitus type 1 are all considered diseases related to a dysfunction of the immune system.

\section{Chemical immunotoxicity in humans}

Several immunotoxicity related incidents have occurred in men over the past years. Probably the most dramatic one is the case of TGN1412, an immunomodulatory drug also known as CD28 SuperMAB. This drug was developed for treatment of rheumatoid arthritis and B-cell leukaemia. During the first human clinical trial study using TGN1412 in London in 2006, this drug had to be withdrawn because of severe side effects leading to multiple organ dysfunction and hospitalisation of all six volunteers who received the drug in the clinical trial (Pearson 2006). This case is of course an extreme event.

In the field of organ transplantation, drugs are administered to suppress the immune system and prevent organ rejection and graft-versus-host disease. In these cases, the immunosuppression is not a side-effect but is the desired end point of the therapy. A wellknown immunosuppressant is cyclosporine A (CsA). Besides medical treatments, humans are primarily exposed to immunotoxic compounds through ingestion of contaminated water or feed, and inhalation. Next to that there is occupational exposure to compounds that can elicit immunotoxic effects. Trichloroethylene is for instance a water contaminant that suppresses the human and animal immune system (Veraldi et al. 2006). Benzene exposure occurs occupationally since it is used in paints, detergents and glues, or recreationally by exposure to tobacco smoke. Next to that benzene is also a component in gasoline. Benzene is proven to be immunotoxic in both mice (Farris et al. 1997) and human (Lisiewicz 1993). Another well-known immunotoxicant is TCDD, the most potent dioxin (Poland and Glover 1973a; Poland and Glover 1973b).

\section{Immunotoxic chemicals}

For some immunotoxicants the mechanism of action is quite well understood. For the organotin compound TBTO for instance, which is an environmental contaminant, it is known that it rapidly causes endoplasmic reticulum (ER) stress and calcium signalling, followed by a $\mathrm{T}$ cell activation response and eventually causes apoptosis (Katika et al. 2012a; Katika et al. 2011) Because TBTO is such a wide spread contaminant also other species besides humans are exposed to TBTO. TBTO was for instance detected in Japanese 
fish (Shimasaki et al. 2006) and measured in fish of the Finnish diet.(Airaksinen et al. 2010) Furthermore, organotin levels were detected in blood of human volunteers confirming uptake after human exposure to organotin compounds (Kannan 1999; Peters 2004; Whalen et al. 1999). Levels of TBTO in environment have decreased since the International Maritime Organisation (IMO) adopted a ban on the use of tributyl (TBT) compounds in ship paints in 2003.

Another example of an immunotoxicant with a known mode of action is the immunosuppressive drug cyclosporine A (CsA). This drug is used in clinic to prevent organ rejection and graft-versus-host disease after transplantation (Ponticelli 2005). CsA inhibits calcineurin (by binding to cyclophilin), a protein phosphatase that normally is activated by a prolonged intracellular calcium rise during $T$ cell activation (Sakuma et al. 2005). Calcineurin dephosphorylates nuclear factor of activated T cells (NFAT) that initiates interleukin-2 (IL-2) production. The end result of the inhibition of calcineurin by CsA is therefore a reduction in IL-2 production and T-cell activation (Ho et al. 1996; Stepkowski and Kirken 2000). Due to recent research on the organotin compound tributyltin oxide (TBTO) and the mycotoxin deoxynivalenol (DON), the modes of action of these immunotoxic compounds are also known. The mode of action of TBTO was already explained. DON, which is a trichothecene mycotoxin, is produced by certain fungi present on wheat, grain and corn. Because DON is very stable during the processing of food humans are almost continuously exposed to low levels of this immunotoxicant through their diet (Grove 1988). The first action of DON is considered to be the binding to ribosomes causing a so called ribotoxic stress (Iordanov et al. 1997; Zhou et al. 2005) response that leads to induction of ER stress, T cell activation and apoptosis (Katika et al. 2012b). These three compounds, CsA, TBTO and DON were used as immunotoxic model compounds.

Compounds for which the immunotoxic mechanisms are not (yet) established include among others the food contaminant 2,3-dichloro-1-propanol (2,3-DCP), the flame retardant Tetrabromobisphenol A (TBBPA) and the insecticide imidacloprid. An important issue in every experiment is the inclusion of negative controls. The search for compounds that are not immunotoxic was however rather difficult. Because of a publication bias (results of a positive correlation with immunotoxicity are much likely to be published whereas a negative correlation might not even be submitted), literature searches for non immunotoxic compounds had to be extended to governmental reports on food additives, herbicides, insecticides etc. The disadvantage of these resources is that the data presented in those reports is often limited to the exposure dose and the statement that no immunotoxicity was observed in rats and mice. Compounds for which no immunotoxicity could be found included several insecticides, fungicides, herbicides and drugs. 


\section{Approaches to immunotoxicity testing}

Several guidelines for (immuno)toxicity testing have been published since the start of this millennium. These guidelines cover testing on chemicals, such as the European REACH (Registration, Evaluation and Authorisation of Chemicals) and the United States Environmental Protection Agency (US EPA), or drugs as published by the US Food and Drug Administration (FDA) and the European Medicines Agency (EMEA). REACH was implemented as a new regulation in 2007 by the European Commission (EC 2006). Within this regulation, any chemical of which more than 1 tonne is produced or imported per year should be evaluated or re-evaluated for its toxicity risks. Since this includes almost all compounds, in vitro test alternatives should be developed to reduce the number of test animals, time and money that have to be spent (Hofer et al. 2004; Pedersen 2003). The number of animals that have to be used within the REACH initiative was estimated between 7.5 and 9 million and total costs was estimated at 1.6 billion Euro (Hofer et al. 2004; Pedersen 2003).

In a document called 'Guidance for Industry' published in 2002, the US Food and Drug Administration stated that immunotoxicity tests are mainly based on changes in organ weights in animal experiments, histopathology of those organs (spleen, thymus, bone marrow, lymph nodes) or by measuring serum parameters (ICCVAM 2002). The last paragraph of that document predicts that the new methods (at that time) e.g. genomics, proteomics, transgenic animals, will define useful endpoints in drug safety testing. EMA published a guideline on immunotoxicity studies for human pharmaceuticals (EMEA 2006). They suggested that further immunotoxicity testing is needed if signs of immunotoxicity are shown after evaluating weight of evidence of standard toxicity testing. Suggested additional immunotoxicity tests depend on the signs observed in standard toxicity tests. Options are the T-cell dependent antibody response (TDAR), immunophenotyping (identification of leukocyte subsets by using antibodies), natural killer cell activity assays, host resistance studies, macrophage/neutrophil function and cell-mediated immunity assays. Of these additional assays, the macrophage/neutrophil function assay can be performed in vitro, whereas the others use animals in vivo or for ex vivo measurements. The United States Environmental Protection Agency (US EPA) published a guidance on the data requirement in the pesticide program (EPA 2013). US EPA proposed to measure antibody production or $\mathrm{T}$ cell dependent antibody response in mice or rats after administration of sheep red blood cells. Next to that, measuring organ weights and (histo)pathology of immune system organs or tissues and white blood cell counts are performed as immunotoxic measures, however, these are often available from other toxicity tests in the testing battery.

The European Centre for the Validation of Alternative Methods (ECVAM), which main goal is to replace, reduce or refine the use of laboratory animals, held a workshop to assess the possibilities for in vitro immunotoxicity testing in 2005 (Gennari et al. 2005). The "future research needs" listed at the very end of the report suggested to use both animal and human cells, since the use of only human cells limits the extrapolation of previous 
performed toxicological studies in animals. In addition, the use of 'OMICS' techniques was considered for searching new endpoints in immunotoxicity testing. Following this workshop ECVAM joined forces with several toxicology departments throughout Europe to evaluate in vitro tests for immunotoxicity (Carfi et al. 2007). In that report using four immunotoxic model compounds and two control compounds, in vitro tests successfully distinguished the immunotoxic from non immunotoxic compounds.

The $7^{\text {th }}$ amendment of the cosmetics directive that was adopted by the European Union in 1976 states that a cosmetic product is considered as "any substance or preparation intended for placing in contact with the various external parts of the human body (epidermis, hair system, nails, lips and external genital organs) or with the teeth and the mucous membranes of the oral cavity with a view exclusively or principally to cleaning them, perfuming them or protecting them in order to keep them in good condition, change their appearance or correct body odours"(1976). In 2003 the European Parliament banned the use of animals in testing cosmetic products. A ban on the ingredients for cosmetic products was implemented in 2009. As a consequence, from 2009 onwards only in vitro methods are allowed to perform safety tests for cosmetic products and ingredients. Since implementation of the REACH initiative (Europe) (EC 2006) and publication of the vision and strategy on toxicity testing in the $21^{\text {st }}$ century (TOX21) from the National Research Council (2007), current immunotoxicogenomics procedures focus more and more on (human) primary cells or cell lines. Similar to the REACH objectives, TOX21 aims to use less animals, more highthroughput methods and test more compounds.

\section{In vitro methods and assays}

The state of the art of in vitro testing for direct immunotoxicity was summarised in 2010 (Lankveld et al. 2010). The testing strategy as suggested by the authors first focused on myelotoxicity, which is the ability of compounds to damage or destroy the bone marrow. Since all cells of the immune system arise from the bone marrow, compounds that induce myelotoxicity are automatically immunotoxic (Gennari et al. 2005). Compounds that are not myelotoxic can still induce immunotoxicity in one of the various differentiated immune cells. Therefore different assays are available to screen compounds that are potentially immunotoxic (Table 1). The human whole blood cytokine release assay measures the $\mathrm{IC}_{50}$ values of compounds in human whole blood based on production of interleukins IL-1 $\beta$ and IL-4 after stimulation with lipopolysaccharide or staphylococcal enterotoxin B (Langezaal et al. 2002). This test is the only one that is prevalidated for its use in in vitro immunotoxicity testing. Since cytokine production is one of the first steps in the immune response, changes in the levels of cytokines can be used as a measure for immunotoxicity. Reduced proliferation of lymphocytes is also an indication of immunosuppression, since the adaptive immune response requires lymphocyte proliferation. Proliferation of T cells can be measured in the lymphocyte proliferation assay by using labelled thymidine ( ${ }^{3} \mathrm{H}$-thymidine) after stimulation with phytohaemagglutinin (PHA), concanavalin A (Con A) or a combination of anti-CD3 and anti-CD28 (stimulation and co-stimulation). In the case of B- 
cell proliferation, lipopolysaccharide (LPS), S. typhimiurim mitogen (STM) or a combination of anti-CD40 and IL-4 are used as stimulus. These assays can be applied using primary cells of rodent or human origin. Human lymphocytes have the advantage that species differences are avoided, however, the variations between donors (intraspecies) is bigger in humans than in inbred laboratory animals. The mixed lymphocyte reaction (MLR) is also used for evaluation of immunotoxicity. This test uses $\mathrm{T}$ lymphocytes that are cocultured with the same cells originating from a different individual (allogeneic) or genetically identical cells (syngeneic). In the case of an allogeneic co-culture one expects $\mathrm{T}$ lymphocytes to proliferate, which is measured with ${ }^{3} \mathrm{H}$-thymidine. The outcome measure is the difference in ${ }^{3} \mathrm{H}$-thymidine incorporation between allogeneic and syngeneic cultured lymphocytes. In the cytotoxic T lymphocyte (CTL) assay $\mathrm{T}$ lymphocytes differentiate into cytotoxic $\mathrm{T}$ cells $\left(\mathrm{CD}^{+}\right)$. The assay measures CTL function to evaluate effects of different test compounds on cell-mediated immunity. Conventionally, rodents are exposed in vivo to test compounds where after splenocytes are collected and co-cultured for 5 days with P815 mastocytoma cells to allow $\mathrm{T}$ cells to differentiate to cytotoxic $\mathrm{T}$ cells. Then the cytotoxic $\mathrm{T}$ cells are collected from the spleens and added to new ${ }^{51} \mathrm{Cr}$-labelled P815 cells. As the cytotoxic T cells lyse ${ }^{51} \mathrm{Cr}$-labeled P815 cells, the measurement of ${ }^{51} \mathrm{Cr}$ in centrifuged supernatant is used as a measure for the cytotoxicity. This method was simplified in such a way that the exposure can also be performed after isolation of primary splenocytes (House 1995) or using peripheral blood mononuclear cells (PBMCs) of rodent or even human origin. Similar to the CTL assay, the natural killer (NK) cell assay also uses ${ }^{51} \mathrm{Cr}$ measurement as read out for cytolytic activity. NK cells are selected from isolated human PBMCs that were treated with test compound and mixed with human K562 erythroleukemia cells. After $4 \mathrm{~h}$ of incubation the amount of ${ }^{51} \mathrm{Cr}$ in the supernatant is measured reflecting the lysis of the target cells by natural killer cells (Cederbrant et al. 2003).

One of the challenges within immunotoxicity testing is that due to the large variety in cells and organs within the immune system, there is not one perfect cell line for in vitro toxicity testing. Most immunotoxicity tests have been performed in animal in vivo studies or using primary cells of animal or human origin (e.g. PBMCs). Endpoints of these studies were mostly cytokine production, antibody responses, cytotoxicity or measuring organ weights and pathology of immune tissues. Another challenge is that cell lines that are available only cover a small part of the immune system, for instance a single T cell, NK cell or B cell.

\section{Toxicogenomics}

Transcription of genes produces a single stranded messenger RNA (mRNA) copy of the DNA and this process takes place in the nucleus. The mRNA is transported to the cytoplasm where it is translated to proteins by ribosomes. The common term for studying properties of the genomes of related organisms is genomics. Toxicogenomics can be best characterized as a high throughput method that combines toxicology and genomics. In the field of immunotoxicity, toxicogenomics approaches are used to discriminate immunotoxic 
from non-immunotoxic substances using gene biomarkers, or to elucidate mechanisms of immunotoxicity of a substance. Before the implementation of toxicogenomics, the toxic effects of substances were tested using Q-RT-PCRs. These assays are still used as confirmation assays or as high-throughput screenings on limited number of genes, as these are quicker and less time and money consuming with respect to toxicogenomics approaches.

\section{Microarray}

Since the introduction of DNA microarray techniques at the end of the previous millennium (DeRisi et al. 1996; Marshall and Hodgson 1998; Schena et al. 1995), research in genetics gained interest and importance. The principle behind the microarray technology is the hybridisation of oligonucleotides in the test sample to oligonucleotides that are present on the microarray on a solid matrix (Duggan et al. 1999). For each gene of the human or mouse genome, one or more probes are present on the array. Lots of new techniques for detecting differences in the genome or proteome have been developed since the introduction of microarrays which collectively are referred to as 'OMICS' technologies. One of the great advantages of these OMICS technologies is that it allows to investigate the action of a compound on the total genome. With increasing regulatory demands on using less animals but generating more toxicity data for safety evaluation of compounds, the combination of in vitro assays and OMICS techniques may prove a suitable strategy for testing large numbers of compounds with less animals as compared to classical approaches.

\section{Transcriptomics analysis}

The immune cells are exposed to either substances or solvent controls. Subsequently the RNA is labelled with fluorescent dyes and hybridized to the microarrays. Data files of the microarray hybridisations contain spot intensities of ten thousands of different probes or probe sets that correspond to the genome of approximately 22.000 genes. The biggest challenge within toxicogenomics research is to deal with the big datasets provided after scanning the microarrays. There are many options to analyse the data, therefore only the methods used in this thesis are given hereafter. The (technical) basics of the analyses that were used are presented in short. As a first step the raw data is normalised for correction of inter array and labelling differences and for differences in the amount of RNA initially loaded onto the microarray chips. Flooring of the data is often performed to set a certain background intensity level. For example, spots that have a value of 5 in the control samples and 20 in the exposed samples would be 4 times upregulated in exposed samples. Biologically, however, these spots code for genes that are probably expressed at a low level in the cell line and are not distinguished from background noise. The term flooring points at the process of setting this background at for a certain level. All spots with lower intensities are put to this level, so the biologically irrelevant up and downregulation of genes is filtered out of the data. After flooring, the spot intensities are converted to $2 \log$ ratios relative to the average of the controls. Files containing the normalised $2 \log$ ratios versus the average of 
the controls then can be used in various bioinformatics tools including clustering and pathway analysis and gene set enrichment analysis.

In clustering analysis, genes are selected based on a chosen threshold (often $2 \log$ ratio of 0.7 in at least three arrays) and clustered on the resemblance in gene expression relative to all arrays in the selection. The colours red and green indicate up- and downregulation of genes, respectively. Subsets of genes belonging to the same cluster can then be uploaded to an online pathway analysis tool such as MetaCore. Tools like MetaCore link gene names to processes, pathways and diseases as found in published abstracts in PubMed. These tools are used for a quick analysis in what process or pathway subclusters of genes are involved in, however, one must keep in mind that there is some form of publication bias. Not all genes will be annotated to functions and some very common processes will link to a huge amount of genes.

For further analysis other programs such as Gene set enrichment analysis (GSEA) are used that detect differences in up- and downregulation of genes belonging to specific sets. GSEA is a statistical analysis tool for microarray data that can be used to give insight into the affected molecular mechanisms and to detect biological processes affected. The first step in GSEA is ranking the total set of genes as based on their expression ratios. Then this list is compared to a subset of genes that is specific for a certain process or pathway and determines whether these genes are more at the top (upregulated), at the bottom (downregulated) or randomly distributed (unaffected) of the ranked gene list (Subramanian et al. 2005). This enables detection of significantly affected gene sets, while the fold change of expression of individual genes can be relatively modest.

All in all, these bioinformatics tools aid in the understanding or unravelling the mode of action of compounds. In addition, when microarray data of one compound is similar (to a great extent) to microarray data of another compound in the same study, the compounds likely act via a similar mode of action (Fielden et al. 2011; Lamb et al. 2006).

\section{Objective of the thesis}

Since conventional immunotoxicity screens require animals that make these tests timeconsuming and expensive, in vitro alternatives are needed. The main objective of this thesis was to assess, using toxicogenomics, two mouse cell lines and one human cell line for their suitability for immunotoxicity testing. The first mouse cell line, EL-4, is derived from a thymoma of a C57BL/6 mouse (Gorer 1950) which is an often used mouse strain in drug research in general. EL-4 cells express CD3 molecules, but no CD4 or CD8 (Skinner et al. 1992; Varga et al. 1999). Therefore, these cells might be considered early thymocytes. The second mouse cell line tested in this thesis is the cytotoxic T cell line CTLL-2. These cells contain CD8 molecules and also originated from a C57BL/6 mouse. The human cell line used was the Jurkat $\mathrm{T}$ cell line originating from peripheral blood of a 14 year old boy suffering from $\mathrm{T}$ cell leukaemia (Schneider et al. 1977). A second aim was to validate genomic biomarkers for human immunotoxicity using a high throughput PCR method. For this purpose, human Jurkat $\mathrm{T}$ cells were exposed to a variety of chemicals and the changes 
in gene expression in a vast set of markers was assessed. A schematic overview of the experiments performed as part of this thesis is given in Table 2.

\section{Outline of the thesis}

In the first experiments performed as part of this thesis and described in Chapter 2, the immunosuppressive drug cyclosporine A was the central model compound that was tested in four different mouse models. These models included the thymoma cell line EL-4, the cytotoxic T cell line CTLL-2, primary splenocytes obtained from C57BL6 mice that were exposed in vitro, and spleens of C57BL6 mice exposed in vivo. The overlap in response to cyclosporine A between the four different mouse models was investigated by comparing individual genes as well as pathways and processes that were affected by CsA. The suitability of EL-4 cells for immunotoxicity research was then further investigated in Chapter 3 by comparing transcriptomics data of the mycotoxin DON and organotin compound TBTO with microarray data previously obtained after exposure of human Jurkat and mouse CTLL-2, primary splenocytes and spleens in vivo to DON and TBTO. In Chapter 4, using a similar set-up, the suitability of the mouse CTLL-2 cell line was assessed by comparing the gene expression profiles of CTLL-2 cells exposed to DON and TBTO to the expression profiles of thymuses of mice exposed in vivo, mice thymocytes and human Jurkat $\mathrm{T}$ cells exposed in vitro. The DON and TBTO Jurkat transcriptome data were generated in a previous $\mathrm{PhD}$ study by Katika (Katika et al. 2012a; Katika et al. 2012b; Katika et al. 2011). On the basis of the outcome of this latter study it was proposed that the primary mechanism of action of DON and TBTO includes the induction of ribotoxic stress and ER stress, respectively. For verification of this finding, Chapter $\mathbf{5}$ entails a mechanistic comparison of the gene expression profiles of DON and TBTO with those of positive controls of ribotoxic stress, endoplasmic reticulum stress and $\mathrm{T}$ cell activation in human Jurkat T cells. Anisomycin, thapsigargin and ionomycin were chosen as positive controls for ribotoxic stress, endoplasmic reticulum stress and $\mathrm{T}$ cell activation, respectively.

Recent transcriptomics experiments in which the Jurkat cell line was exposed to a large set of (non-) immunotoxic compounds, including CsA, TBTO, and DON, resulted in the identification of 25 mRNA potential biomarkers of direct immunotoxicity (Shao et al. 2014; Shao et al. 2013). These 25 mRNA biomarkers were further validated in Chapter 6 exposing Jurkat cells to a new set of chemicals including known immunotoxicants, known non-immunotoxicants and chemicals for which it is unknown if they exert any immunotoxic action. This validation study used a multiplex PCR method for rapid testing of the biomarkers in all samples. Chapter 7 presents the general discussion on the search for biomarkers for in vitro immunotoxicity and identification of modes of action using transcriptomics approaches.

\section{Netherlands Toxicogenomics Centre}

The research as described in this thesis was financially supported by the Netherlands Toxicogenomics Centre (NTC). This consortium aimed to use toxicogenomics tools to 
decipher the mechanistic and biological pathways that drive toxicity that will be used to build a suite of "systems toxicology" models as a basis for the development of expertise and aiding mechanistic and predictive toxicology. The ambition of NTC was to have genomics-based predictive models validated and framed within guidelines on chemical safety assessment protocols, thereby also inducing that toxicogenomics is an accepted factor in toxicological risk assessment.' Different Dutch research institutes (RIKILT, RIVM, TNO) and universities (Maastricht, Wageningen, Leiden, Erasmus Rotterdam) worked together to achieve these goals and ambitions of the NTC.

\begin{tabular}{|c|c|c|}
\hline Technique & Cell system & Endpoint \\
\hline Cytokine release assay & Human whole blood & IL-1 $\beta$ and IL-4 production, IC F0 \\
\hline Lymphocyte proliferation assay & Human peripheral lymphocytes & $\begin{array}{c}\text { Incorporation of radiolabelled } \\
\text { thymidine }\end{array}$ \\
\hline Mixed lymphocyte reaction & T lymphocytes & $\begin{array}{c}\text { Incorporation of radiolabelled } \\
\text { thymidine }\end{array}$ \\
\hline Cytotoxic T-lymphocyte assay & T lymphocytes & ${ }^{51} \mathrm{Cr}$ release \\
\hline Natural killer cell assay & NK cells & ${ }^{51} \mathrm{Cr}$ release \\
\hline
\end{tabular}

Table 1. Overview of in vitro immunotoxicity assays. 


\begin{tabular}{|c|c|c|c|c|}
\hline & Species / cells & $\begin{array}{c}\text { In vitro, in } \\
\text { vivo, primary } \\
\text { cells }\end{array}$ & Compounds & Tool \\
\hline Chapter 2 & $\begin{array}{l}\text { Mouse CTLL-2, EL-4, } \\
\text { primary mouse } \\
\text { splenocytes, spleens in } \\
\text { vivo }\end{array}$ & $\begin{array}{l}\text { In vitro, in vivo, } \\
\text { primary cells }\end{array}$ & CsA & Microarray \\
\hline Chapter 3 & Mouse EL-4 cells & In vitro & TBTO, DON & Microarray \\
\hline Chapter 4 & Mouse CTLL-2 cells & In vitro & TBTO, DON & $\begin{array}{l}\text { Microarray, } \\
\text { Q-RT-PCR }\end{array}$ \\
\hline Chapter 5 & Human Jurkat T cells & In vitro & $\begin{array}{c}\text { anisomycin, DON, } \\
\text { ionomycin, TBTO, } \\
\text { thapsigargin }\end{array}$ & Microarray \\
\hline Chapter 6 & Human Jurkat T cells & In vitro & $\begin{array}{l}21 \text { different } \\
\text { compounds }\end{array}$ & $\begin{array}{l}\text { Fluidigm } \\
\text { RT-PCR }\end{array}$ \\
\hline
\end{tabular}

Table 2. Overview Thesis Chapters.

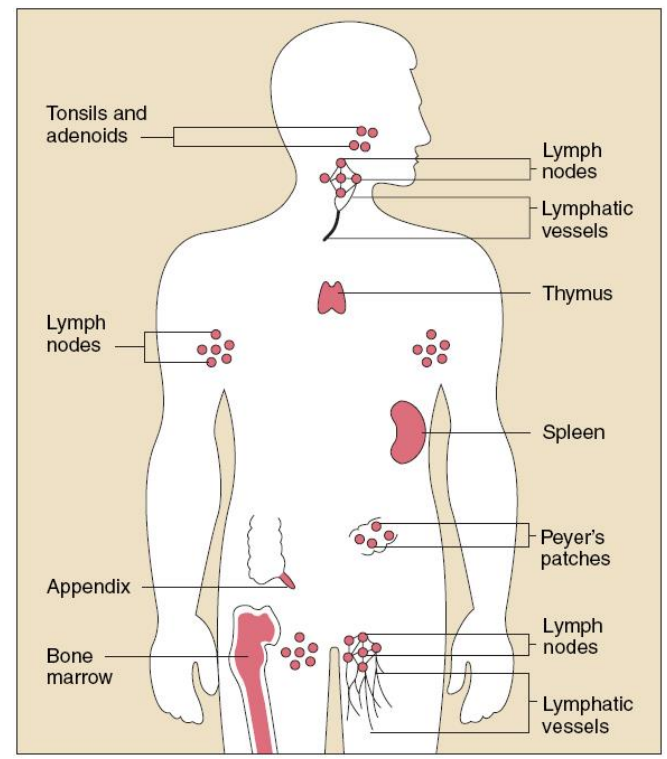

Figure 1. Overview of different parts of the immune system. Artwork originally created for the National Cancer Institute by Jeanne Kelly. Reprinted with permission of the artist. Copyright 2013. 
References

(1976) Council Directive 76/768/EEC of 27 July 1976 on the approximation of the laws of the Member States relating to cosmetic products. vol 31976L0768, Official Journal L, p 0169 - 0200

(2007) Toxicity Testing in the 21st Century: A Vision and a Strategy. The National Academies Press

Airaksinen R, Rantakokko P, Turunen AW, et al. (2010) Organotin intake through fish consumption in Finland. Environmental research 110(6):544-7 doi:10.1016/j.envres.2010.06.004

Baldwin TA, Hogquist KA, Jameson SC (2004) The fourth way? Harnessing aggressive tendencies in the thymus. Journal of immunology 173(11):6515-20

Bellantuono I (2004) Haemopoietic stem cells. The international journal of biochemistry \& cell biology 36(4):60720 doi:10.1016/j.biocel.2003.10.008

Carfi M, Gennari A, Malerba I, et al. (2007) In vitro tests to evaluate immunotoxicity: a preliminary study.

Toxicology 229(1-2):11-22 doi:10.1016/j.tox.2006.09.003

Cederbrant K, Marcusson-Stahl M, Condevaux F, Descotes J (2003) NK-cell activity in immunotoxicity drug evaluation. Toxicology 185(3):241-50

DeRisi J, Penland L, Brown PO, et al. (1996) Use of a cDNA microarray to analyse gene expression patterns in human cancer. Nature genetics 14(4):457-60 doi:10.1038/ng1296-457

Duggan DJ, Bittner M, Chen Y, Meltzer P, Trent JM (1999) Expression profiling using cDNA microarrays. Nature genetics 21(1 Suppl):10-4 doi:10.1038/4434

EC (2006) Regulation (EC) No 1907/2006 of the European Parliament and of the Council of 18 December 2006 concerning the Registration, Evaluation, Authorisation and Restriction of Chemicals (REACH), establishing a European Chemicals Agency, amending Directive 1999/45/EC and repealing Council Regulation (EEC) No 793/93 and Commission Regulation (EC) No 1488/94 as well as Council Directive 76/769/EEC and Commission Directives 91/155/EEC, 93/67/EEC, 93/105/EC and 2000/21/EC. In: EC (ed). OJ L, p 1-849 EMEA (2006) NOTE FOR GUIDANCE ON IMMUNOTOXICITY STUDIES FOR HUMAN PHARMACEUTICALS. In: Agency EM (ed) ICH Topic S 8 Immunotoxicity Studies for Human Pharmaceuticals. vol CHMP/167235/2004, p 13

EPA (2013) Part 158 Toxicology Data Requirements: Guidance for Neurotoxicity Battery, Subchronic Inhalation, Subchronic Dermal and Immunotoxicity Studies. In: Office of Pesticide Programs USEPA (ed). p 11

Farris GM, Robinson SN, Wong BA, Wong VA, Hahn WP, Shah R (1997) Effects of benzene on splenic, thymic, and femoral lymphocytes in mice. Toxicology 118(2-3):137-48

Fielden MR, Adai A, Dunn RT, 2nd, et al. (2011) Development and evaluation of a genomic signature for the prediction and mechanistic assessment of nongenotoxic hepatocarcinogens in the rat. Toxicological sciences : an official journal of the Society of Toxicology 124(1):54-74 doi:10.1093/toxsci/kfr202

Gennari A, Ban M, Braun A, et al. (2005) The Use of In Vitro Systems for Evaluating Immunotoxicity: The Report and Recommendations of an ECVAM Workshop. Journal of immunotoxicology 2(2):61-83

doi:10.1080/15476910590965832

Gorer PA (1950) Studies in antibody response of mice to tumour inoculation. British journal of cancer 4(4):372-9 Grove JF (1988) Non-macrocyclic trichothecenes. Natural product reports 5(2):187-209

Ho S, Clipstone N, Timmermann L, et al. (1996) The mechanism of action of cyclosporin A and FK506. Clinical immunology and immunopathology 80(3 Pt 2):S40-5

Hofer T, Gerner I, Gundert-Remy U, et al. (2004) Animal testing and alternative approaches for the human health risk assessment under the proposed new European chemicals regulation. Archives of toxicology 78(10):549-64 doi:10.1007/s00204-004-0577-9

House RVT, P. T. (1995) In vitro induction of cytotoxic T lymphocytes, vol 1. Wiley-Liss, New York ICCVAM (2002) Guidance for Industry - Immunotoxicology Evaluation of Investigational New Drugs. In: (CDER) USDoHaHSFaDACfDEaR (ed). ICCVAM, p 35

Iordanov MS, Pribnow D, Magun JL, et al. (1997) Ribotoxic stress response: activation of the stress-activated protein kinase JNK1 by inhibitors of the peptidyl transferase reaction and by sequence-specific RNA damage to the alpha-sarcin/ricin loop in the 28S rRNA. Molecular and cellular biology 17(6):3373-81 Janeway CT, P; Walport, M; Shlomchik, M (2001) Immunobiology, 5th edn. Garland Science, New York 


\section{Chapter 1}

Kaech SM, Wherry EJ, Ahmed R (2002) Effector and memory T-cell differentiation: implications for vaccine development. Nature reviews Immunology 2(4):251-62 doi:10.1038/nri778

Kannan K, Senthilkumar, K., Giesy, J.P., (1999) Occurrence of butyltin compounds in human blood.

Environmental Science \& Technology 33:1776-1779

Katika MR, Hendriksen PJ, de Ruijter NC, van Loveren H, Peijnenburg A (2012a) Immunocytological and biochemical analysis of the mode of action of bis (tri-n-butyltin) tri-oxide (TBTO) in Jurkat cells. Toxicology letters 212(2):126-36 doi:10.1016/j.toxlet.2012.05.010

Katika MR, Hendriksen PJ, Shao J, van Loveren H, Peijnenburg A (2012b) Transcriptome analysis of the human T lymphocyte cell line Jurkat and human peripheral blood mononuclear cells exposed to deoxynivalenol (DON): New mechanistic insights. Toxicology and applied pharmacology 264(1):51-64 doi:10.1016/j.taap.2012.07.017 Katika MR, Hendriksen PJ, van Loveren H, Peijnenburg A (2011) Exposure of Jurkat cells to bis (tri-n-butyltin) oxide (TBTO) induces transcriptomics changes indicative for ER- and oxidative stress, T cell activation and apoptosis. Toxicology and applied pharmacology 254(3):311-22 doi:10.1016/j.taap.2011.04.021

Kozutsumi H (1996) Special Education. The oncologist 1(1 \& 2):116-118

Lamb J, Crawford ED, Peck D, et al. (2006) The Connectivity Map: using gene-expression signatures to connect small molecules, genes, and disease. Science 313(5795):1929-35 doi:10.1126/science.1132939

Langezaal I, Hoffmann S, Hartung T, Coecke S (2002) Evaluation and prevalidation of an immunotoxicity test based on human whole-blood cytokine release. Alternatives to laboratory animals : ATLA 30(6):581-95

Lankveld DP, Van Loveren H, Baken KA, Vandebriel RJ (2010) In vitro testing for direct immunotoxicity: state of the art. Methods in molecular biology 598:401-23 doi:10.1007/978-1-60761-401-2_26

Lisiewicz J (1993) Immunotoxic and hematotoxic effects of occupational exposures. Folia medica Cracoviensia 34(1-4):29-47

Marshall A, Hodgson J (1998) DNA chips: an array of possibilities. Nature biotechnology 16(1):27-31 doi:10.1038/nbt0198-27

McFadden JP, Dearman RJ, White JM, Basketter DA, Kimber I (2011) The Hapten-Atopy hypothesis II: the 'cutaneous hapten paradox'. Clinical and experimental allergy : journal of the British Society for Allergy and Clinical Immunology 41(3):327-37 doi:10.1111/j.1365-2222.2010.03684.x

Mebius RE, Kraal G (2005) Structure and function of the spleen. Nature reviews Immunology 5(8):606-16 doi:10.1038/nri1669

Miller JF (2002) The discovery of thymus function and of thymus-derived lymphocytes. Immunological reviews 185:7-14

Palmer E (2003) Negative selection--clearing out the bad apples from the T-cell repertoire. Nature reviews Immunology 3(5):383-91 doi:10.1038/nri1085

Pearson H (2006) Tragic drug trial spotlights potent molecule. Nature doi:10.1038/news060313-17

Pedersen FdB, J.; Munn, S.; van Leeuwen, K. (2003) Assessment of additional testing needs under REACH

Effects of (Q)SARS, risk based testing and voluntary industry initiatives. In.

http://ec.europa.eu/enterprise/sectors/chemicals/files/reach/testing_needs-2003_10_29_en.pdf

Peters P (2004) Man-Made chemicals in human blood.

Poland A, Glover E (1973a) 2,3,7,8-Tetrachlorodibenzo-p-dioxin: a potent inducer of -aminolevulinic acid synthetase. Science 179(4072):476-7

Poland A, Glover E (1973b) Studies on the mechanism of toxicity of the chlorinated dibenzo-p-dioxins.

Environmental health perspectives 5:245-51

Ponticelli C (2005) Cyclosporine: from renal transplantation to autoimmune diseases. Annals of the New York Academy of Sciences 1051:551-8 doi:10.1196/annals.1361.099

Sakuma K, Nakao R, Aoi W, et al. (2005) Cyclosporin A treatment upregulates Id1 and Smad3 expression and delays skeletal muscle regeneration. Acta neuropathologica 110(3):269-80 doi:10.1007/s00401-005-1049-x

Schena M, Shalon D, Davis RW, Brown PO (1995) Quantitative monitoring of gene expression patterns with a complementary DNA microarray. Science 270(5235):467-70

Schneider U, Schwenk HU, Bornkamm G (1977) Characterization of EBV-genome negative "null" and "T" cell lines derived from children with acute lymphoblastic leukemia and leukemic transformed non-Hodgkin lymphoma. International journal of cancer Journal international du cancer 19(5):621-6 
Shao J, Berger LF, Hendriksen PJ, Peijnenburg AA, van Loveren H, Volger OL (2014) Transcriptome-based functional classifiers for direct immunotoxicity. Archives of toxicology 88(3):673-89 doi:10.1007/s00204-0131179-1

Shao J, Katika MR, Schmeits PC, et al. (2013) Toxicogenomics-based identification of mechanisms for direct immunotoxicity. Toxicological sciences : an official journal of the Society of Toxicology

doi:10.1093/toxsci/kft151

Shimasaki Y, Oshima Y, Inoue S, et al. (2006) Effect of tributyltin on reproduction in Japanese whiting, Sillago japonica. Marine environmental research 62 Suppl:S245-8 doi:10.1016/j.marenvres.2006.04.030

Skinner MA, Sambhara SR, Benveniste P, Miller RG (1992) Characterization of alpha beta+ CD4- CD8- CTL lines isolated from mixed lymphocyte cultures of adult mouse spleen cells. Cellular immunology 139(2):375-85 Stepkowski SM, Kirken RA (2000) The role of IL-2 in allograft rejection--a lesson learned from experimental work. Transplantation 69(12):2480-2

Subramanian A, Tamayo P, Mootha VK, et al. (2005) Gene set enrichment analysis: a knowledge-based approach for interpreting genome-wide expression profiles. Proceedings of the National Academy of Sciences of the United States of America 102(43):15545-50 doi:10.1073/pnas.0506580102

Tucker AN, Sanders VM, Hallett P, Kauffmann BM, Munson AE (1982) In vitro immunotoxicological assays for detection of compounds requiring metabolic activation. Environmental health perspectives 43:123-7

Varga G, Dreikhausen U, Kracht M, Appel A, Resch K, Szamel M (1999) Molecular mechanisms of T lymphocyte activation: convergence of T cell antigen receptor and IL-1 receptor-induced signaling at the level of IL-2 gene transcription. International immunology 11(11):1851-62

Veraldi A, Costantini AS, Bolejack V, Miligi L, Vineis P, van Loveren H (2006) Immunotoxic effects of chemicals: A matrix for occupational and environmental epidemiological studies. American journal of industrial medicine 49(12):1046-55 doi:10.1002/ajim.20364

Whalen MM, Loganathan BG, Kannan K (1999) Immunotoxicity of environmentally relevant concentrations of butyltins on human natural killer cells in vitro. Environmental research 81(2):108-16 doi:10.1006/enrs.1999.3968 Wherry EJ, Ahmed R (2004) Memory CD8 T-cell differentiation during viral infection. Journal of virology 78(11):5535-45 doi:10.1128/JVI.78.11.5535-5545.2004

Zhou HR, Jia Q, Pestka JJ (2005) Ribotoxic stress response to the trichothecene deoxynivalenol in the macrophage involves the SRC family kinase Hck. Toxicological sciences : an official journal of the Society of Toxicology 85(2):916-26 doi:10.1093/toxsci/kfi146 



\section{Chapter 2}

\section{Detection of the mechanism of immunotoxicity of cyclosporine $A$ in murine in vitro and in vivo models}

Peter C.J. Schmeits, Mirjam M Schaap, Mirjam Luijten, Eugene van Someren, André Boorsma, Henk van Loveren, Ad A C M Peijnenburg and Peter J M Hendriksen:

Archives of toxicology. 09/2014 


\begin{abstract}
Transcriptomics in combination with in vitro cell systems is a powerful approach to unravel modes of action of toxicants. An important question is to which extent the modes of action as revealed by transcriptomics depend on cell type, species and study type (in vitro or in vivo). To acquire more insight in this, we assessed the transcriptomic effects of the immunosuppressive drug cyclosporine A (CsA) upon 6 hours of exposure of the mouse cytotoxic T cell line CTLL-2, the thymoma EL-4 and primary splenocytes and compared these to the effects in spleens of mice orally treated with CsA for seven days. EL-4 and CTLL-2 cells showed the highest similarities in response. CsA affected many genes in primary splenocytes that were not affected in EL-4 or CTLL-2. Pathway analysis demonstrated that CsA upregulated the unfolded protein response, ER stress and NRF2 activation in EL-4 cells, CTLL-2 cells and primary mouse splenocytes but not in mouse spleen in vivo. As expected, CsA downregulated cell cycle and immune response in splenocytes in vitro, spleens in vivo as well as CTLL-2 in vitro. Genes up and downregulated in human Jurkat, HepG2 and renal proximal tubular cells were similarly affected in CTLL-2, EL-4 and primary splenocytes in vitro. In conclusion, of the models tested in this study, the known mechanism of immunotoxicity of CsA is best represented in the mouse cytotoxic T cell line CTLL-2. This is likely due to the fact that this cell line is cultured in the presence of a $\mathrm{T}$ cell activation stimulant (IL-2) making it more suitable to detect inhibitory effects on $\mathrm{T}$ cell activation.
\end{abstract}




\section{Introduction}

Whole genome transcriptomics analysis has been successfully applied to unravel modes of action of toxic compounds including immunotoxicants (Hochstenbach et al. 2010; Luebke et al. 2006; Schmeits et al. 2014a; Shao et al. 2013). Transcriptomics analysis has been employed both for in vitro and in vivo exposure studies. An important question is to what extent the modes of action as revealed by transcriptomics depend on the type of cell, the species, and the study type (in vitro or in vivo). In a previous study we assessed the usefulness of the mouse T cell line CTLL-2 cells for immunotoxicity testing by comparing the effects of deoxynivalenol (DON) and tributyltin oxide (TBTO) on the transcriptomes of CTLL-2 cells to that of human Jurkat cells and mouse thymocytes in vitro or thymus in vivo (Schmeits et al. 2013). Although CTLL-2 cells, Jurkat cells and the mouse thymus in vivo shared most pathways, CTLL-2 cells were not able to activate ER stress in response to DON exposure. Based on the transcriptomics response to DON and TBTO, the mouse thymoma cell line EL-4 was also not able to detect all processes induced by DON and TBTO in vivo (Schmeits et al. 2014b). The present study aimed to provide more insight into this issue by determining the most optimal system to recognise Cyclosporine A (CsA) induced immunotoxicity. CsA was selected as model compound since its mechanism in relation to immunotoxicity has been well described. The primary pharmacological response of lymphocytes to CsA exposure is an inhibition of NFAT-mediated transcription by complex formation of $\mathrm{CsA}$ and $\mathrm{CyP}-\mathrm{A} / \mathrm{CyP}-\mathrm{B}$, subsequently leading to inhibition of calcineurin (Bram et al. 1993; Clipstone and Crabtree 1992; Galat and Bua 2010). The mechanism by which CsA exerts its immunotoxic effects includes an inhibitory effect on $\mathrm{T}$ cell activation, an induction of the unfolded protein response (UPR) and endoplasmic reticulum (ER) stress, (mitochondrial) oxidative stress and eventually apoptosis (de Arriba et al. 2013; Halestrap et al. 1997; Hama et al. 2013; Hibino et al. 2011; Ho et al. 1996; Sakuma et al. 2005).

Cyclosporine A (CsA) is a fungal cyclic polypeptide which is used as an immunosuppressive drug in the clinic to prevent organ rejection and graft-versus-host disease in organ acceptors (Ponticelli 2005). CsA inactivates its target protein calcineurin. Calcineurin is activated by a sustained rise in intracellular $\mathrm{Ca}^{2+}$ levels (Sakuma et al. 2005), as is the case during $\mathrm{T}$ cell activation. Calcineurin then dephosphorylates NFAT, which binds to the promoter regions of its target genes including the cytokine interleukin 2 (IL-2) initiating the production of IL-2. The net effect of inhibition of calcineurin by CsA is thus a reduced T-cell activation response (Baken et al. 2008; Cristillo and Bierer 2002; Ho et al. 1996; Johnson et al. 2003; Mascarell and Truffa-Bachi 2003; Stepkowski and Kirken 2000). Next to its immunosuppressive effects, CsA can also cause hepatotoxicity (cholestasis), neurotoxicity, renal toxicity and carcinogenesis (de Arriba et al. 2013; Deters et al. 2003; Erdem et al. 2011; Klawitter et al. 2010; Kuschal et al. 2012).

CsA has been shown to induce growth arrest at the $G_{0} / G_{1}$ cell cycle phase of renal, glioma and immune cells (Gottschalk et al. 1994; Jeon et al. 2005; Kahl and Means 2004; YonishRouach et al. 1991; Zupanska et al. 2005), and at $G_{1} / S$ or $G_{2} / M$ checkpoints in renal cells 
(Lally et al. 1999; Wolf et al. 1995). Induction of cell cycle arrest by CsA was also detected in a transcriptomics study on the mouse spleen in vivo (Baken et al. 2008). CsA also inhibits DNA synthesis in mouse 3T3 fibroblasts (Tomono et al. 1996). In addition, CsA modulates expression of extracellular matrix genes (Baken et al. 2008) and induces oxidative stress (O'Connell et al. 2012), ER stress and UPR (Hama et al. 2013). Induction of nephrotoxicity by CsA is presumed to be due to the generation of reactive oxygen species causing oxidative stress (Tariq et al. 1999). In the liver, CsA causes cholestasis by inhibition of the bile salt export pump and thus impairing bile flow (Kienhuis et al. 2013). The current method for testing chemicals and drugs for immunotoxicity is based on rodent in vivo exposures. Alternative in vitro assays are considered because the animal models have many drawbacks including ethical concerns, labour intensiveness, and costs (Corsini and Roggen 2009). A challenge within immunotoxicity testing is that the immune system comprises many different cell types and interactions. One of the most important questions, therefore, is how many different cell types are required to predict the immunotoxic potential of a chemical.

In the present work, a comparative transcriptomics study has been performed to examine the effects of cyclosporine A (CsA) in different test models, including CTLL-2 cells and EL-4 cells (in vitro), primary mouse splenocytes (in vitro) and mouse spleens (in vivo). Moreover, to get more insight into possible different interspecies responses to CsA exposure, the mouse microarray data were compared to those previously obtained with human T (Jurkat), liver (HepG2) and renal (RPTEC/TERT1) cell lines exposed in vitro to CsA.

\section{Materials and Methods}

\section{Cells and chemicals}

CTLL-2 cells and EL-4 cells were purchased from the American Type Culture Collection (ATCC) and cultured in RPMI 1640 medium, containing HEPES with 10\% heat-inactivated Fetal Bovine Serum, $100 \mathrm{U} / \mathrm{ml}$ Penicillin, $100 \mu \mathrm{g} / \mathrm{ml}$ streptomycin, 1\% sodium pyruvate, $1 \%$ non-essential amino acids (Invitrogen Life Science, Breda, The Netherlands). For CTLL-2 cells, $10 \%$ rat IL-2 with ConA (T-STIM) was added to the medium (BD Bioscience, Breda, The Netherlands). Cells were cultured in $75 \mathrm{~cm}^{2}$ flasks at $37{ }^{\circ} \mathrm{C}(5 \%$ $\mathrm{CO}_{2}, 20 \% \mathrm{O}_{2}$ ) and medium was refreshed three times a week. Cyclosporine A (CsA; CAS 59865-13-3) was ordered from Sigma (Zwijndrecht, The Netherlands) for the in vitro studies and DMSO (CAS 67-68-5) was obtained from Merck (Amsterdam, The Netherlands). For the in vivo exposure study, CsA was kindly provided by Novartis (Basel, Switzerland).

\section{Animals}

Six-week-old male wild type mice (C57BL/6J, $n=4$ per group) were acclimated for two weeks and subsequently exposed to $500 \mathrm{ppm}$ CsA through feed for seven days or given a 
control diet. The dose of CsA was based on previously performed dose range finding studies (van Kreijl et al. 2001). Assuming the mice ate 5-10\% of their weight daily, this would lead to a daily exposure of 25 to $50 \mathrm{ppm}$. A previous study has shown that oral administration of 2-10 ppm CsA (once daily) inhibited the sheep red blood cell (SRBC)induced delayed type hypersensitivity (DTH) response (Ohga et al. 2008).

From the day of weaning, the health status of the mice was monitored daily and mice were weighed weekly starting at acclimation. Control animals showed a small increase in average weight gain $(+5.53 \%)$ while the weight of CsA exposed animals decreased $(-4.90$ $\%)$. Animals were kept in the same stringently controlled (specific pathogen-free, spf) environment, fed ad libitum and kept under a normal day/night rhythm. After seven days of exposure, mice were sacrificed at a fixed time of the day. During autopsy, spleens were isolated and stored according to manufacturer's protocol using RNAlater (Qiagen, Venlo, The Netherlands).

\section{Primary cell isolation}

Seven-week-old C57Bl/6 mice were obtained from the Wageningen University breeding colony and sacrificed by $\mathrm{CO}_{2}$ without any treatment. The protocol was approved by the ethics committee for animal experiments (Wageningen UR). Spleens were excised and put in $3 \mathrm{~mL}$ RPMI 1640 (standard) medium. Organs were pressed through a $70 \mu \mathrm{M}$ nylon cell strainer (Falcon, Franklin Lakes, NJ) to prepare single cell suspensions. Cells of two spleens were combined to obtain one sample. The suspensions were centrifuged (10 min, $4^{\circ}$ $\mathrm{C}, 1200 \mathrm{rpm})$ and resuspended in $5 \mathrm{~mL}$ red blood cell lyses buffer $\left(\mathrm{NH}_{4} \mathrm{Cl} 155 \mathrm{mM}\right.$, $\mathrm{KHCO}_{3} 10 \mathrm{mM}$, EDTA $1 \mathrm{mM}$; pH 7.4) and incubated for five minutes on ice. After washing the cells with medium $\left(10 \mathrm{~min}, 4^{\circ} \mathrm{C}, 1200 \mathrm{rpm}\right)$, the cell suspensions were adjusted to $5.0 \times 10^{6}$ cells $/ \mathrm{mL}$ using standard RPMI 1640 medium.

\section{Exposures}

Viability of CTLL-2 and EL-4 cells was determined using ATPlite assay (PerkinElmer/NEN Life Sciences, Boston, MA) according to manufacturer's instructions. Doses that caused a decrease of $20 \%$ or less after $24 \mathrm{~h}$ exposure were selected for $6 \mathrm{~h}$ exposures for transcriptomics analysis. Viability of CTLL-2 cells that were exposed to 7.5 and $15 \mu \mathrm{M}$ CsA were 87 and $81 \%$ respectively. Viability of EL-4 cells that were exposed to $1.5 \mu \mathrm{M}$ CsA was $80 \%$. For CTLL-2, $7.5 \mu \mathrm{M}$ and $15 \mu \mathrm{M}$ were selected and for EL-4 cells $1.5 \mu \mathrm{M}$ was selected. Concentrations for primary splenocytes were based on CTLL-2 viability results, thus 7.5 and $15 \mu \mathrm{M}$ CsA. These concentrations did not induce cytotoxicity in primary splenocytes after $6 \mathrm{~h}$ (data not shown).

CTLL-2 and EL-4 cells were seeded one day before the exposure at a concentration of 0.25 x $10^{6}$ cells $/ \mathrm{ml}$ in a 6-well plate with $2.7 \mathrm{~mL}$ per well. Primary splenocytes were seeded and exposed directly after isolation at a concentration of $5.0 \times 10^{6}$ cells $/ \mathrm{ml}$ in 6-well plates with $2.7 \mathrm{~mL}$ per well. Just prior to exposure, "CsA in DMSO" or pure DMSO were diluted with standard medium to 100 -fold stock solutions and $300 \mu \mathrm{L}$ of these solutions were added to 
the cells. The final DMSO concentration therefore did not exceed $0.1 \%$, which has no effect on cell viability. The cells were placed in an incubator $\left(5 \% \mathrm{CO}_{2}, 20 \% \mathrm{O}_{2}\right)$ at $37{ }^{\circ} \mathrm{C}$ for $6 \mathrm{~h}$. Exposures were performed in quadruplicate.

\section{RNA isolation}

After exposure the cells were centrifuged for five minutes at $1600 \mathrm{rpm}$ and $4{ }^{\circ} \mathrm{C}$ and the pellet was resuspended in $600 \mu \mathrm{L}$ RLT buffer (Qiagen) containing 1\% $\beta$-Mercaptoethanol ( $\beta$-ME, Invitrogen Life Science) and stored at $-80^{\circ} \mathrm{C}$ until RNA isolation. Samples in RLT buffer were put on QIAshredder columns (Qiagen) and centrifuged for $2 \mathrm{~min}$ at $15000 \mathrm{~g}$. The flow through was mixed and homogenized with $70 \%$ ethanol and put onto miRNeasy columns (Qiagen). RNA isolation including DNase treatment was performed according to manufacturer's protocol (Qiagen). RNA was eluted with warmed $\left(45^{\circ} \mathrm{C}\right) \mathrm{RNase}$ free water. RNA concentration, integrity and purity were assessed spectrophotometrically at wavelengths of 230, 260 and $280 \mathrm{~nm}$ (Nanodrop, Wilmington, DE) and by virtual gel electrophoresis (Experion, Biorad, Veenendaal, The Netherlands). One sample (EL-4) did not meet the quality criteria and was therefore excluded from further analysis.

Total RNA of the in vivo spleens was isolated using the miRNeasy kit and the QIAcube (Qiagen) according to the manufacturer's instructions. All samples passed RNA quality control using capillary gel electrophoresis (RIN > 7.3; Bioanalyzer 2100, Agilent Technologies, Amstelveen, the Netherlands).

\section{Microarray analysis}

For all samples, mRNA was amplified and labeled with the GeneChip Expression 3'Amplification One-Cycle cDNA Synthesis Kit and GeneChip Expression 3'-Amplification Reagents for IVT Labeling according to the manufacturer's instructions (Eukaryotic Sample and Array Processing 701025 Rev.5; Affymetrix). Amplified materials were hybridized to Affymetrix Mouse Genome 4302.0 Arrays for $16 \mathrm{~h}$ at $45^{\circ} \mathrm{C}$, subsequently washed and stained with the EukGE-WS2v5_450 protocol. The array plates were scanned using the Affymetrix GeneTitan scanner. Image generation and feature extraction were performed using Affymetrix GCOS Software v1.4.0.036.

\section{Data Analysis}

Custom CDF files were generated from the raw data by using the $\mathrm{R}$ package available at http://brainarray.mbni.med.umich.edu/Brainarray/Database/CustomCDF/14.1.0/entrezg.asp - Robust multichip average (RMA) normalization was applied to the complete dataset (BioConductor). Quality control was applied to the microarray data by using BioConductor packages (www.arrayanalysis.org). Spot intensities were floored and $2 \log$ ratios were calculated versus the DMSO control of the same biological replicate. Hereby, all DMSO control values were set to zero.

Gene expression data of the in vivo samples were successively subjected to quality control and correction of significant hybridization and experimental blocking effects, annotation, 
RMA normalization and subsequent data analysis, as previously described (Schaap et al. 2012). Hierarchical clustering on the average of each treatment group was performed with the programs Cluster (uncentered correlation; average linkage clustering) and Treeview (Eisen et al. 1998). Pathway analysis on subclusters of genes was performed using MetaCore (GeneGo, St. Joseph, MI).

\section{Gene Set Enrichment Analysis}

Gene Set Enrichment Analysis (GSEA) is a statistical analysis tool for microarray data, used to detect biological processes affected and to provide insight into the affected molecular mechanisms. GSEA makes use of predefined gene sets that are based on previous experimental results and literature. GSEA ranks all the genes on their expression ratios and determines whether a particular gene set is significantly enriched at the top or the bottom of the ranked list (Subramanian et al. 2005). The following gene set collections were used in this study: KEGG, Lymphocyte database (Shaffer et al. 2001), Gene Ontology (http://www.geneontology.org/), Tox action (self-made), unfolded protein response (Civelek et al. 2009; Kuny et al. 2012), cell cycle (Bar-Joseph et al. 2008; Whitfield et al. 2002) and blood cell type specific (created from literature (Du et al. 2006; Lyons et al. 2007; Su et al. 2004)).

In addition, gene sets were created from CsA exposure data on human HepG2 cells (Magkoufopoulou et al. 2011) and human renal tubular cells (RPTEC/TERT1) (Wilmes et al. 2013) to assess the interspecies and intertissue overlap in response to CsA.

\section{Heat maps of gene sets}

We visualized the expression of genes involved in $\mathrm{T}$ cell activation, NRF2 activation, unfolded protein response including ER stress, and apoptosis using the programs Cluster and Treeview (Eisen et al. 1998). Genes that were related to NRF2 activation were taken from KEGG, Biocarta and from literature mining. The gene set containing genes that were involved in the $\mathrm{T}$ cell activation response originated from the lymphocyte signature database (Shaffer et al. 2001) and apoptosis related genes were derived from Gene Ontology. Genes involved in the UPR and ER stress were taken from literature (Civelek et al. 2009; Kuny et al. 2012). Genes which have multiple functions or a function important for multiple processes can therefore be present in more than one figure. Expression of genes in these various processes was shown in mouse CTLL-2, EL-4, primary splenocytes, mouse spleens in vivo and human Jurkat cells $(8 \mu \mathrm{M})$. Data on CsA exposed human Jurkat cells were derived from a previous study of our group (Shao et al. 2013). Genes that were $\geq 1.6$ fold up- or down regulated vs. the average of the controls in at least 3 of 27 arrays were included in the heat maps 


\section{Results}

Hierarchical clustering and pathway analysis

Unsupervised hierarchical clustering was used to visualise genes that on average were more than 1.6 ( $2 \log 0.7$, arbitrary chosen value) times up- or downregulated versus the average of the controls (Fig. 1). In total 547 genes were selected that were distributed by the cluster program over six clusters. MetaCore was applied to assess the most significantly represented pathways per cluster. The first cluster, containing 37 genes upregulated by CsA in CTLL-2, is linked to ER stress induction and the unfolded protein response. A subset of these genes was also upregulated in EL-4 cells and primary mouse splenocytes. Genes in cluster 2 were mainly upregulated by CsA exposure in primary splenocytes and are involved in apoptosis and stress response. Cluster 3 contains genes that were upregulated in the mouse spleen in vivo and not affected in other cell types. The genes in this cluster are related to $\mathrm{T}$ cell chemotaxis. Genes in cluster 4 were predominantly downregulated in vivo and are linked to cell cycle and mitosis. Cluster 5 contains genes that were downregulated in primary splenocytes and are related to immune response and stress response. The 14 genes in cluster 6 were downregulated in CTLL- 2 cells and are related to apoptosis. Based on the unsupervised clustering of individual genes there is no overlap between the in vivo and the in vitro systems apart from a small group $(\mathrm{n}=22)$ of cell cycle related genes that are downregulated by $\mathrm{CsA}$ in the spleen in vivo and in primary thymocytes (at the top of cluster 4 in Figure 1). Principle component analysis on all genes corroborated the finding that hardly any overlap is present between in vivo and in vitro (Suppl. Fig. 1). 


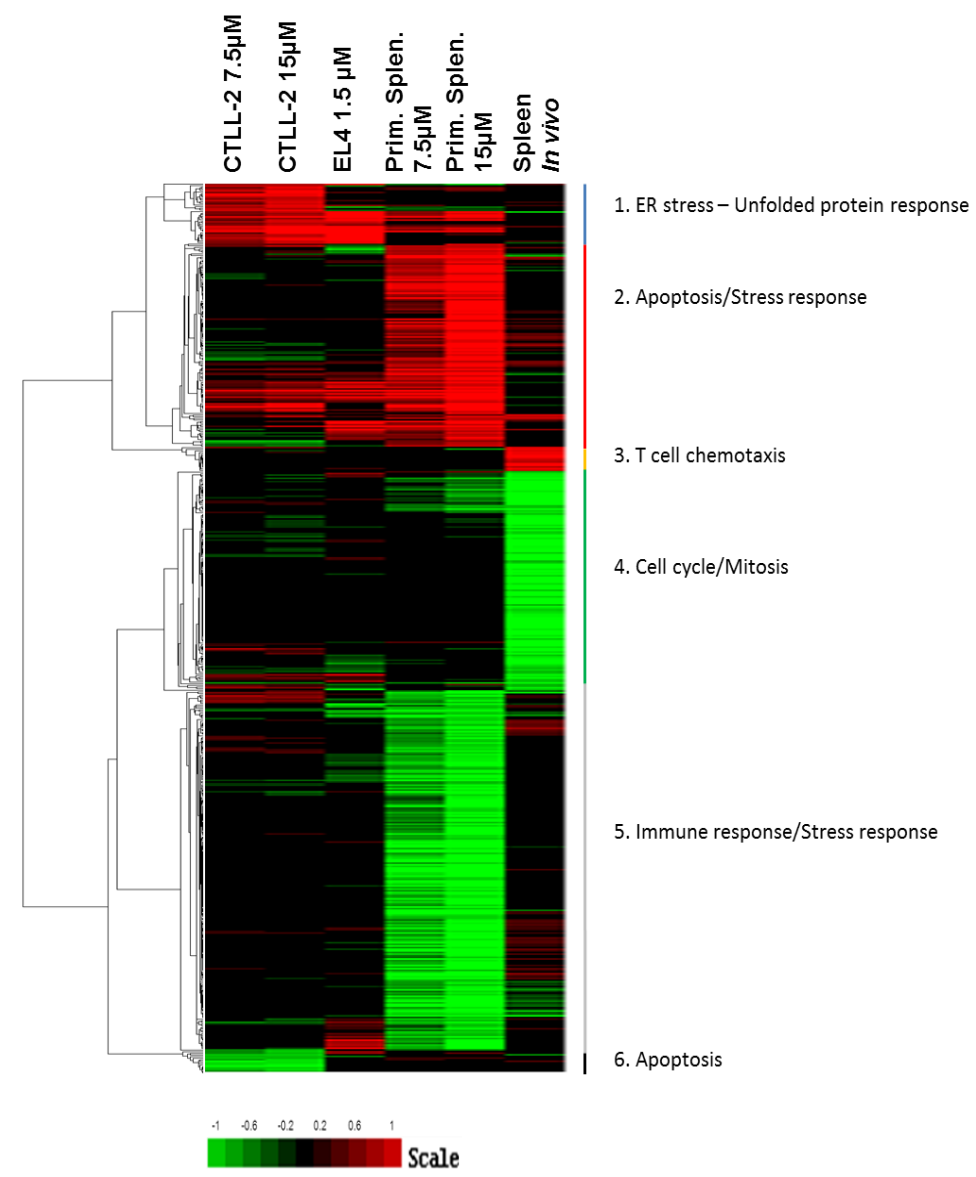

Figure 1. Hierarchical clustering of cyclosporine A responsive genes in four different mouse models. Gene selection is based on an average fold change of $\geq 1.6(2 \operatorname{LogRatio} \geq 0.7)$ in at least one of the cell types leading to a total of 547 genes. Green represents down-regulation, red represents up-regulation and black no effect; scale is shown at the right bottom of the figure. Subclusters of genes were uploaded in MetaCore to assess the processes affected by the different subclusters.

Gene set enrichment analysis (GSEA)

GSEA was then applied for each of the treatment groups in relation to the respective control samples. This allows comparing our data to gene sets that were published in literature or created by our own group (see Methods section 2.8). GSEA enables to assess similarities in effects on pathways and processes instead of on individual genes. The outcome of GSEA was visualized in heat maps.

A clear difference between primary splenocytes and the cell lines CTLL-2 and EL-4 was found for oxidative stress target genes that were upregulated in CTLL-2 and EL-4 cells, but downregulated in primary splenocytes (Fig. 2A). Endoplasmic reticulum (ER) stress response was induced in primary splenocytes $(7.5 \mu \mathrm{M})$, CTLL-2 and EL-4 cells. Target 
genes of $X B P 1$, that induce ER stress through the unfolded protein response (UPR) (Iwakoshi et al. 2003), were also upregulated in CTLL-2, EL-4, primary splenocytes (7.5 $\mu \mathrm{M})$ as well as in spleens in vivo. Target genes for $\mathrm{NF \kappa B}$ were upregulated in primary splenocytes whereas they were downregulated in CTLL-2 cells. Cell cycle and DNA repair were downregulated in CTLL-2 cells and spleens in vivo, and to a lesser extent in EL-4 cells as well.

Due to the effect of CsA on ER stress, XBPI target genes and the UPR, we investigated the expression of genes in the different stages of the UPR and ER stress. Gene sets related to the different stages of the UPR were upregulated in CTLL-2 cells, EL-4 cells and to a lesser extent in primary mouse splenocytes but not in the mouse spleen in vivo (Fig. 2B). Ubiquitination was upregulated in EL-4 cells and in primary splenocytes but not in CTLL-2 cells. Overall this shows that CsA upregulates genes at all stages of the unfolded protein response, except ubiquitination, in CTLL-2 cells and EL-4 cells while CsA upregulates genes at only a few stages of the unfolded protein response in primary mouse splenocytes (e.g. ubiquitination and protein disulphide isomerisation) and none in the spleen in vivo.

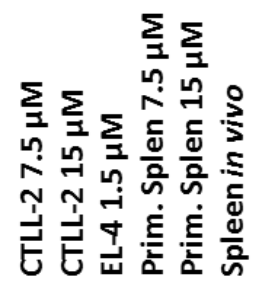

\begin{tabular}{ll}
\hline GENE SET & GENE SET COLLECTION \\
\hline OXIDATIVE STRESS UP & TOX ACTION \\
\hline OXIDATIVE PHOSPHORYLATION & KEGG \\
\hline BIOSYNTHESIS OF STEROIDS & KEGG \\
\hline ENDOPLASMIC RETICULUM STRESS RESPONSE & TOX ACTION \\
\hline XBP1 TARGET GENES & LYMPHOCYTE DB \\
\hline PPAR-ALPHA TARGET GENES & TOX ACTION \\
\hline NFKB TARGET GENES & LYMPHOCYTE DB \\
\hline T CELL & LYMPHOCYTE DB \\
\hline T CELL ACTIVATION & GO Biol ProcesS \\
\hline LYMPHOCYTE ACTIVATION & GO Biol ProcesS \\
\hline RNA BIOSYNTHESIS & GO Biol ProcesS \\
\hline APOPTOSIS & GO Biol Process \\
\hline DNA REPAIR & GO Biol ProcesS \\
\hline CELL CYCLE & Cell cycle \\
\hline
\end{tabular}




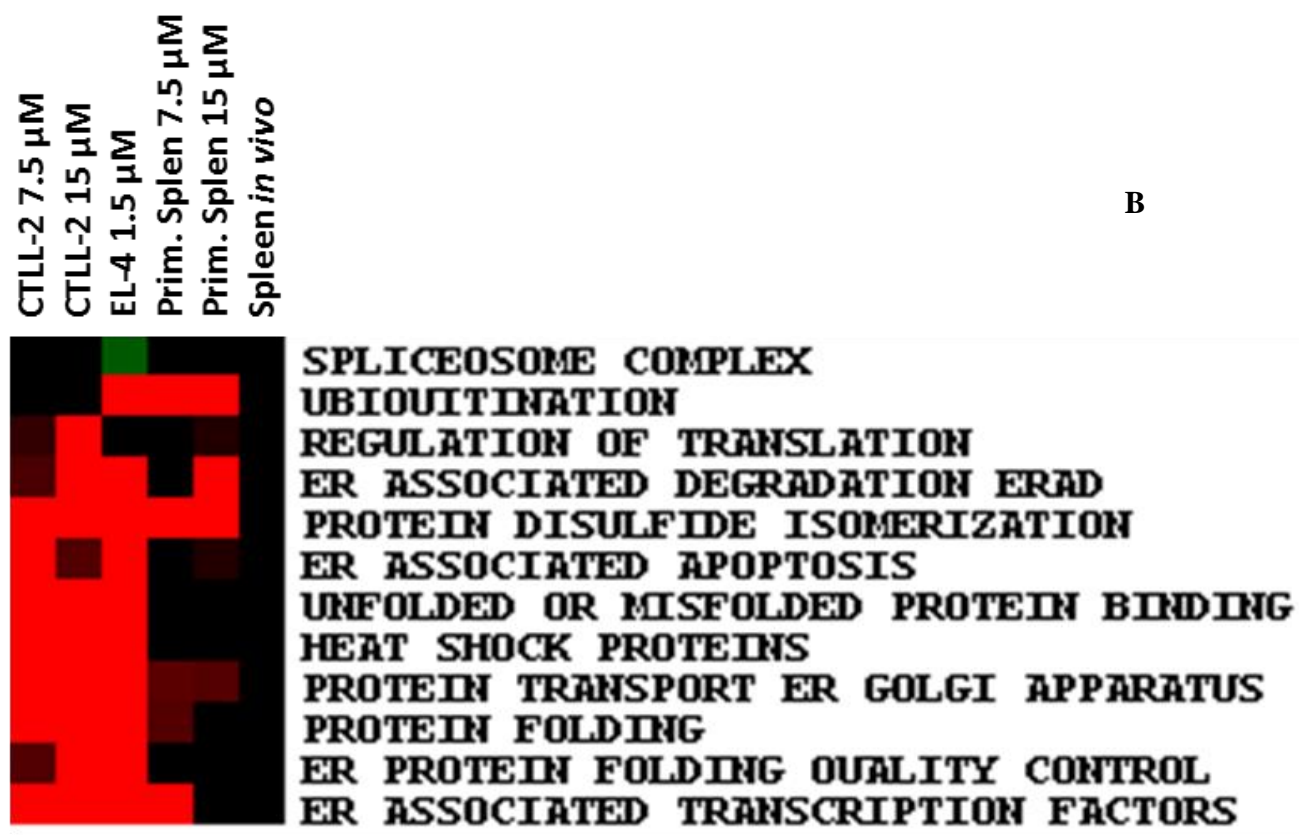

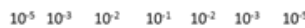

\section{Scale}

Figure 2. Heatmap of processes significantly affected by cyclosporine A exposure.

Overview of the effects of CsA on, (A) a selection of gene sets, and (B) unfolded protein response related gene sets, that were run in GSEA (selection; p value < 0.01, FDR < 0.25). Each line represents one gene set. Each column represents the average gene expression per cell type. Scale indicates statistical significance (p-value) of the gene set. Green represents downregulation, red upregulation and black no effect.

Heat maps of genes involved in T cell activation, NRF2 activation, unfolded protein response, ER stress, and apoptosis

The effects of CsA on the repression of $\mathrm{T}$ cell activation and the induction of oxidative stress, ER stress and apoptosis (Fig. 2A) prompted us to assess the effects of CsA on the individual genes involved in these processes (Fig. 3). This comparison also included the effects of CsA on the human Jurkat $\mathrm{T}$ cell line which is a cell line often used for immunotoxicity testing (Shao et al. 2013).

Overall, relative few genes were affected in the spleen in vivo in all of the processes. The transcriptomics data do therefore not yield indications that any of the four processes are induced in the spleen in vivo. CsA is considered to decrease activation of $\mathrm{T}$ cells which agreed with the downregulation of T cell activation related genes, such as JUN and RGS2, in CTLL-2 cells (Fig. 3A). In marked contrast, CD69, which is considered to be an early marker gene acting as co-stimulant for T cell activation (Ziegler et al. 1994), is upregulated by CsA in CTLL-2 cells, primary splenocytes and spleen in vivo, but not in EL-4 cells. CD69 was downregulated in human Jurkat cells (Fig. 3A). 
Transcription factor NRF2 plays a crucial role in the response of cells to oxidative stress (Ma 2013). NRF2 target genes were mainly upregulated in CTLL-2 and EL-4 cells. In primary splenocytes and spleen in vivo more NRF2 target genes were downregulated than upregulated. CsA affected very few NRF2 target genes in Jurkat cells (Fig. 3B). HMOX1, which is considered as an important marker for oxidative stress (Tyrrell and Basu-Modak 1994), was upregulated in CTLL-2 and EL-4 cells, but not affected in primary splenocytes, spleen in vivo or Jurkat T cells.

As shown in Fig 3C, CsA induced the expression of many genes involved in unfolded protein response and ER stress in CTLL-2 and EL-4 cells while less genes were upregulated in primary mouse splenocytes. CsA hardly induced any of the UPR/ER stress related genes in the spleen in vivo and induced a limited number of genes in Jurkat cells.

CsA eventually induces apoptosis (Strauss et al. 2002). Remarkably, three genes that are related to apoptosis were downregulated in the spleen in vivo (Fig. 3D) while none were upregulated. Compared to the other cell systems, CsA induced the highest number of apoptosis-related genes in EL-4 and CTLL-2 cells. In primary splenocytes the number of genes upregulated equals the number of genes that were downregulated. The effect of CsA on apoptosis genes in Jurkat cells was very limited. 

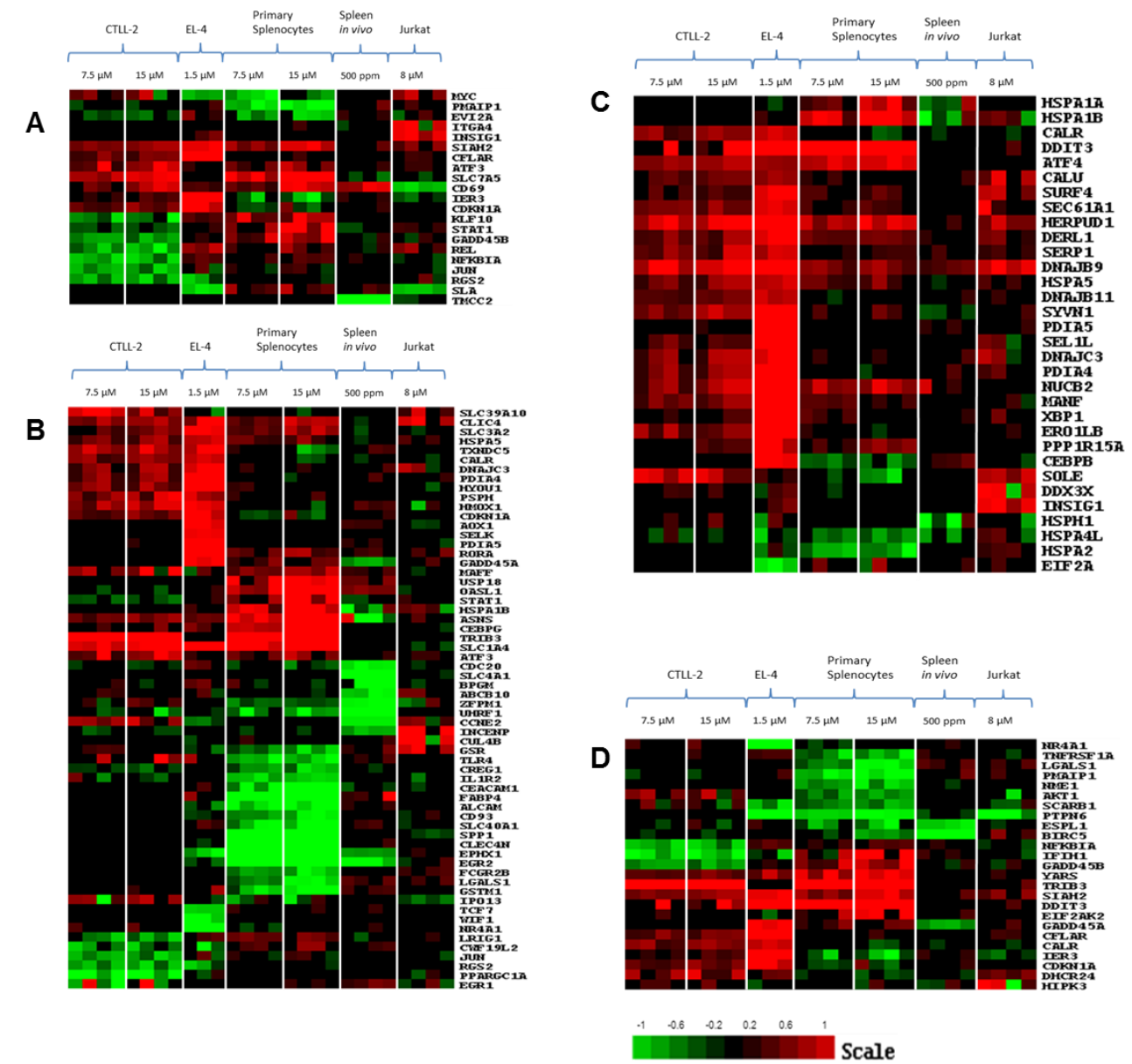

Figure 3. mRNA expression levels of individual genes involved in $\mathrm{T}$ cell activation, apoptosis, mitochondria or NRF2 activation.

Genes known to be involved in T cell activation (A), NRF2 activation (B), Unfolded protein response including ER stress (C) or apoptosis (D) were filtered for being affected by exposure to CsA in the present study (selection criterion: $\geq 1$.6-fold up or downregulated in at least 3 of 28 arrays). Scale is displayed in bottom right corner; green represents downregulation, red upregulation and black means no effect.

\section{Analysis on genes up- or downregulated in Jurkat}

Since the genes involved in the mechanism of immunotoxicity of CsA were limitedly affected in the human Jurkat cell line (Fig. 3 and (Shao et al. 2013)) we used GSEA to investigate if genes that are up- or downregulated by CsA in the Jurkat cell line were also up- or downregulated in the mouse systems (Fig. 4). Genes that were downregulated in Jurkat cells after exposure to CsA were also downregulated in EL-4 cells. However, these genes were upregulated in CTLL-2 cells $(15 \mu \mathrm{M})$ and not affected in the primary splenocytes or spleens in vivo. Genes upregulated in Jurkat cells were also upregulated in CTLL-2, EL-4 and primary splenocytes, but not in spleens in vivo. 

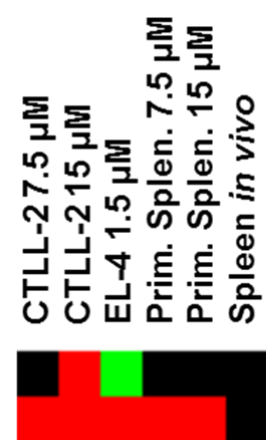

\section{Genes Downregulated in Jurkat Cells} Genes Upregulated in Jurkat Cells

\section{$\begin{array}{lllllll}10^{-5} & 10^{-3} & 10^{-2} & 10^{-1} & 10^{-2} & 10^{-3} & 10^{-5}\end{array}$ \\ Scale}

Figure 4. GSEA using genes up and downregulated in human Jurkat T cells.

Overview of the effects of CsA on gene sets that were run in GSEA (selection; $p$ value $<0.01$, FDR $<0.25$ ). Each line represents a set of genes that were either up- or down-regulated by CsA in Jurkat cells. Each column represents the average gene expression of CTLL-2 exposed to CsA 7.5 or $15 \mu \mathrm{M}$, EL-4 cells exposed to $1.5 \mu \mathrm{M}$, primary splenocytes exposed to $7.5 \mu \mathrm{M}$ or $15 \mu \mathrm{M}$, and spleens exposed to CsA in vivo. Green represents downregulation, red upregulation and black no effect. The more brighter the colours, the higher statistical significant (p-value) the effect is.

\section{Effect on immune cell type specific genes}

A plausible explanation for the fact that CsA hardly affects T cell activation or ER stress in the spleen in vivo is that apoptotic $\mathrm{T}$ cells are known to be quickly removed by phagocytosis by macrophage-like cells (Hochreiter-Hufford and Ravichandran 2013). We therefore used GSEA to investigate which immune cell types are affected by CsA using the gene set collection 'blood cell type specific' created manually from literature data sets (Du et al. 2006; Lyons et al. 2007; Su et al. 2004). These gene sets contain genes that are highly expressed in certain blood cell types.

A significant proportion of genes that are highly expressed in Natural Killer (NK) cells were upregulated by $\mathrm{CsA}$ in spleen in vivo (Fig. 5). Part of the genes expressed in monocytes were also upregulated in EL-4 and CTLL-2 $(7.5 \mu \mathrm{M})$. Also genes highly expressed in monocytes were upregulated in spleen in vivo, while these genes were downregulated in primary splenocytes in vitro. However, the monocyte specific marker CD14 was upregulated in spleen in vivo but not upregulated in CTLL-2 and EL-4. 


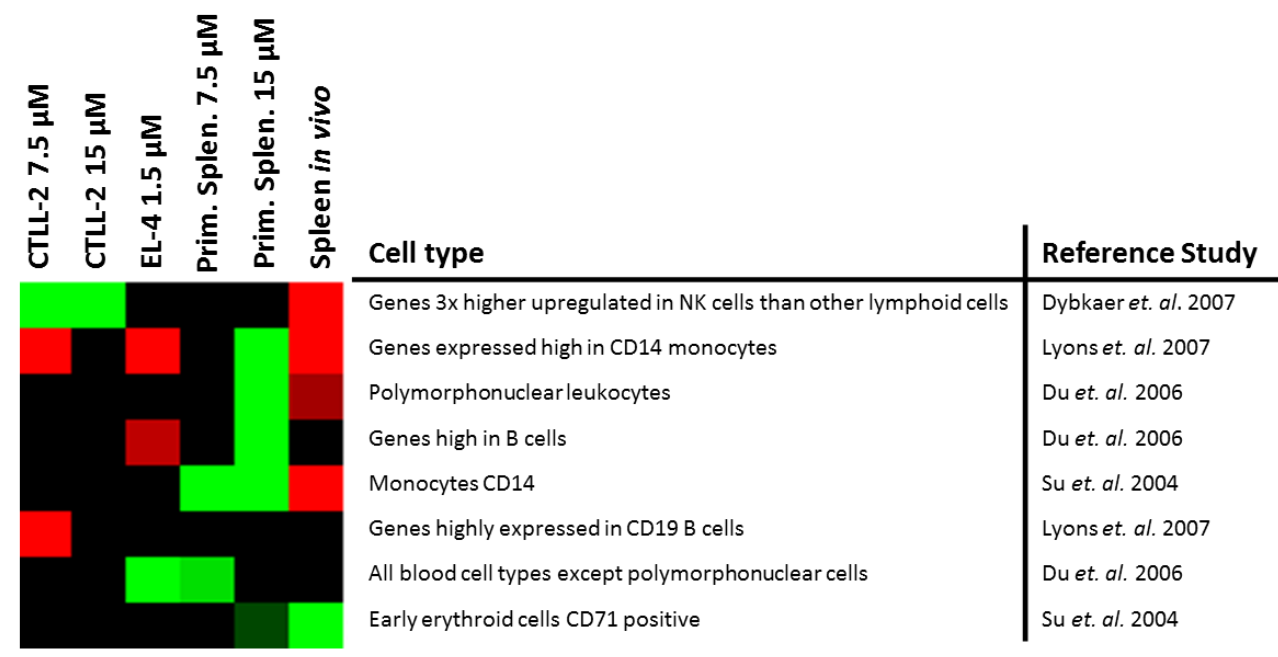

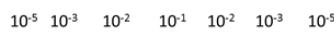

Figure 5. Expression of blood cell type specific genes.

Overview of the expression of genes involved in specific blood cell types in CsA exposed CTLL-2 cells, EL-4 cells, primary splenocytes in vitro and spleens in vivo. Each column represents the average gene expression of one exposure model. Each line represents one gene set from the collection Tissue specific blood cell types. Green represents downregulation, red upregulation and black no effect. The more brighter the colours, the higher statistical significant (p-value) the effect is.

\section{Interspecies comparison using transcriptomics data of human cell lines}

The present microarray data were then compared to data obtained from literature on effects of CsA exposure on HepG2 cells (Magkoufopoulou et al. 2011). Gene sets were created based on the HepG2 data separating up and downregulated genes for each time point. Those gene sets were then used to compare to the transcriptomics data of CTLL-2, EL-4, primary mouse splenocytes and spleens in vivo (Fig. 6A).

A significant proportion of genes that were upregulated by CsA in HepG2 cells were also upregulated in CTLL-2, EL-4, primary mouse splenocytes and spleens in vivo. Genes that were downregulated in HepG2 cells $(12,24$ or $48 \mathrm{~h}$ ) were also downregulated in mouse spleens in vivo. Genes downregulated in HepG2 cells after $24 \mathrm{~h}$ but not after 12 or $48 \mathrm{~h}$ were also downregulated in primary splenocytes. Genes that were downregulated in HepG2 cells after $48 \mathrm{~h}$ were also downregulated in EL-4 cells, CTLL-2 cells $(15 \mu \mathrm{M})$ and spleen in vivo.

In addition, gene sets were created from a study on human RPTEC/TERT1 proximal tubule epithelial cells that were exposed to CsA (Wilmes et al. 2013), Fig. 6B. Genes upregulated by CsA in human RPTEC cells were also upregulated in CTLL-2 cells, EL-4 cells and primary splenocytes, but not in spleens in vivo. Genes that were downregulated in RPTEC 


\section{Chapter 2}

cells were also downregulated in spleens in vivo (except $5 \mu \mathrm{M}, 14$ days) and primary splenocytes in vitro.

These comparisons to CsA data obtained in human liver cells (HepG2) and human renal tubular cells indicate that CsA causes effects on gene expression that are shared between different cell types and species (human and mouse).

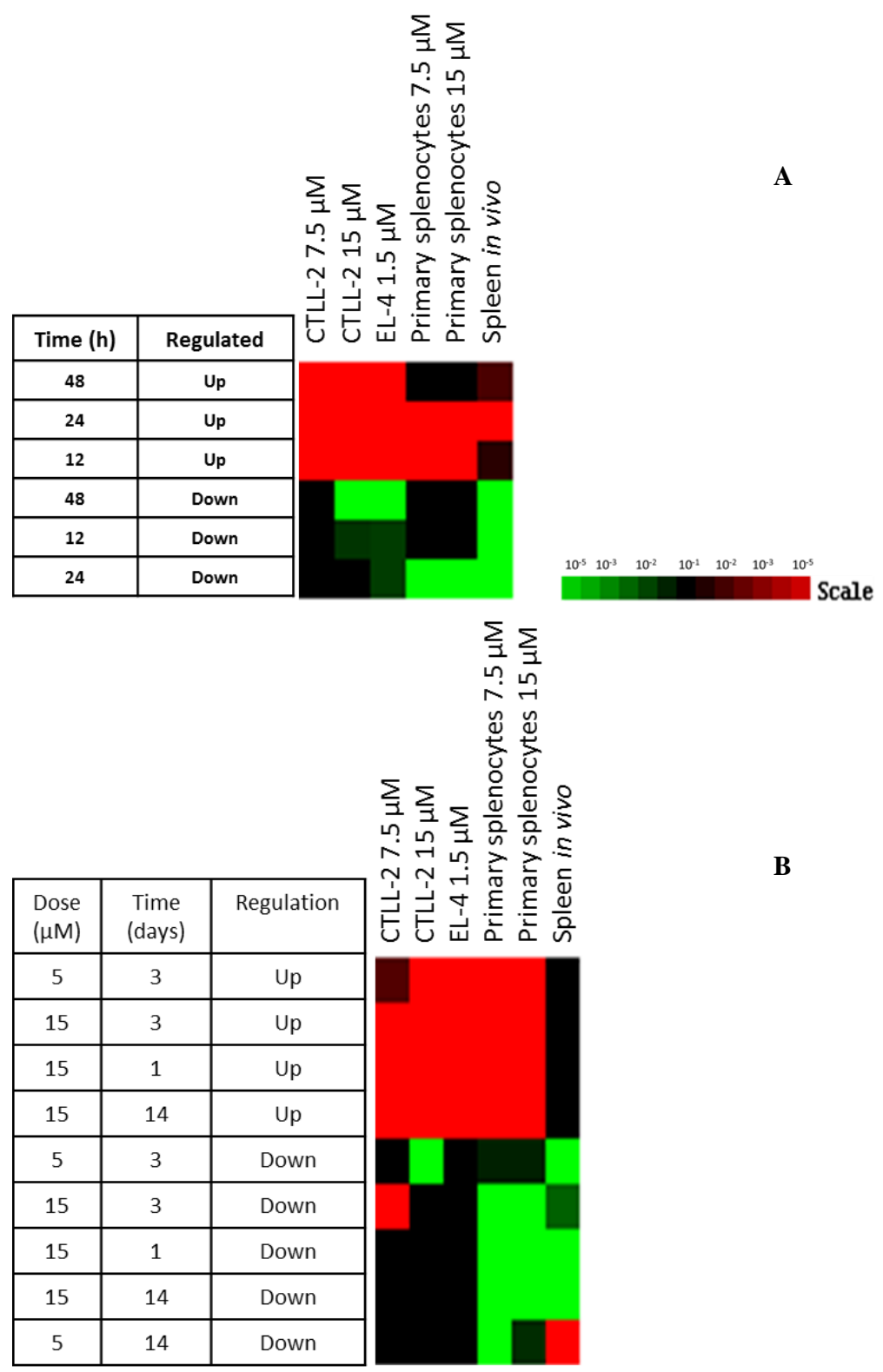


Figure 6. Comparison of genes up and down regulated in human HepG2 cells exposed to CsA and human RPTEC/TERT1 proximal tubule epithelial cells.

Overview of the effects of CsA on gene sets that were run in GSEA (selection; $p$ value $<0.01$, FDR $<0.25$ ). Each line represents a set of genes that were either up- or down-regulated by CsA exposure in (A) human HepG2 cells and (B) human RPTEC/TERT1 cells . Each column represents the average gene expression of CTLL-2 exposed to CsA 7.5 or $15 \mu \mathrm{M}$, EL-4 cells exposed to $1.5 \mu \mathrm{M}$, primary splenocytes exposed to $7.5 \mu \mathrm{M}$ or $15 \mu \mathrm{M}$, and spleens exposed to CsA in vivo. Green represents downregulation, red upregulation and black no effect. The more brighter the colours, the higher statistical significant (p-value) the effect is.

Genes commonly up- or downregulated by CsA in multiple cell systems

It is particularly interesting to search for genes that are up- or downregulated in all or in most of the cell systems examined in this study. We therefore selected genes that were upor downregulated with 2-log ratio $|0.7|$ in at least 15 out of 36 arrays. This cut-off value was chosen arbitrarily. Cell types that were included were CTLL-2, EL-4, primary splenocytes, spleen in vivo, human Jurkat, and human HepG2 cells. This analysis resulted in five genes that were downregulated, being PTPN6, EGR2, DGAT2 (upregulated in primary splenocytes), CCL24 and PLIN2 (Fig. 7A). However, these genes were hardly affected in CTLL-2 cells. MetaCore analysis on the five downregulated genes did not result in any significant process, which is probably due to the low number of genes.

Furthermore, 14 genes were upregulated in most cell types which are visualised in Fig. 7B. These genes were downregulated in HepG2 cells exposed to CsA for $48 \mathrm{~h}$, and unaffected in spleen in vivo. MetaCore analysis on these 14 genes revealed these genes to be involved in ER stress and the unfolded protein response (UPR).

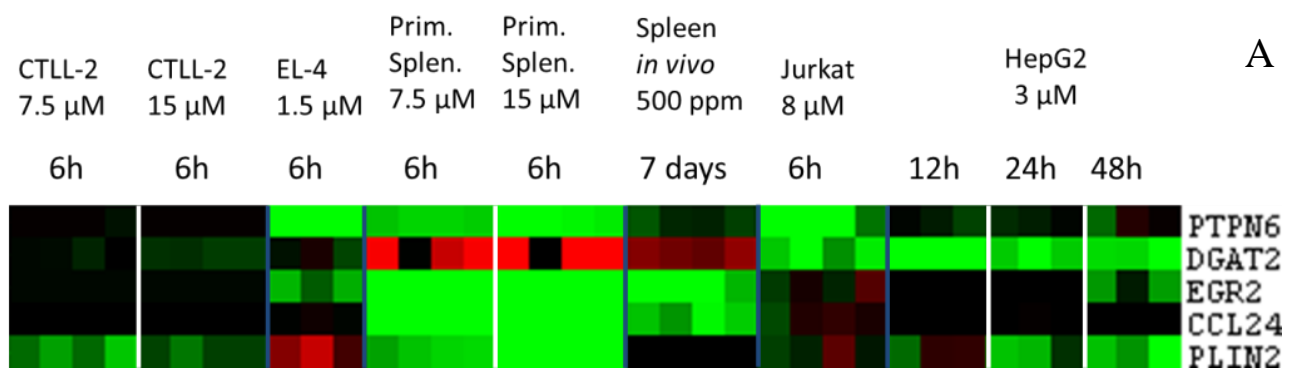




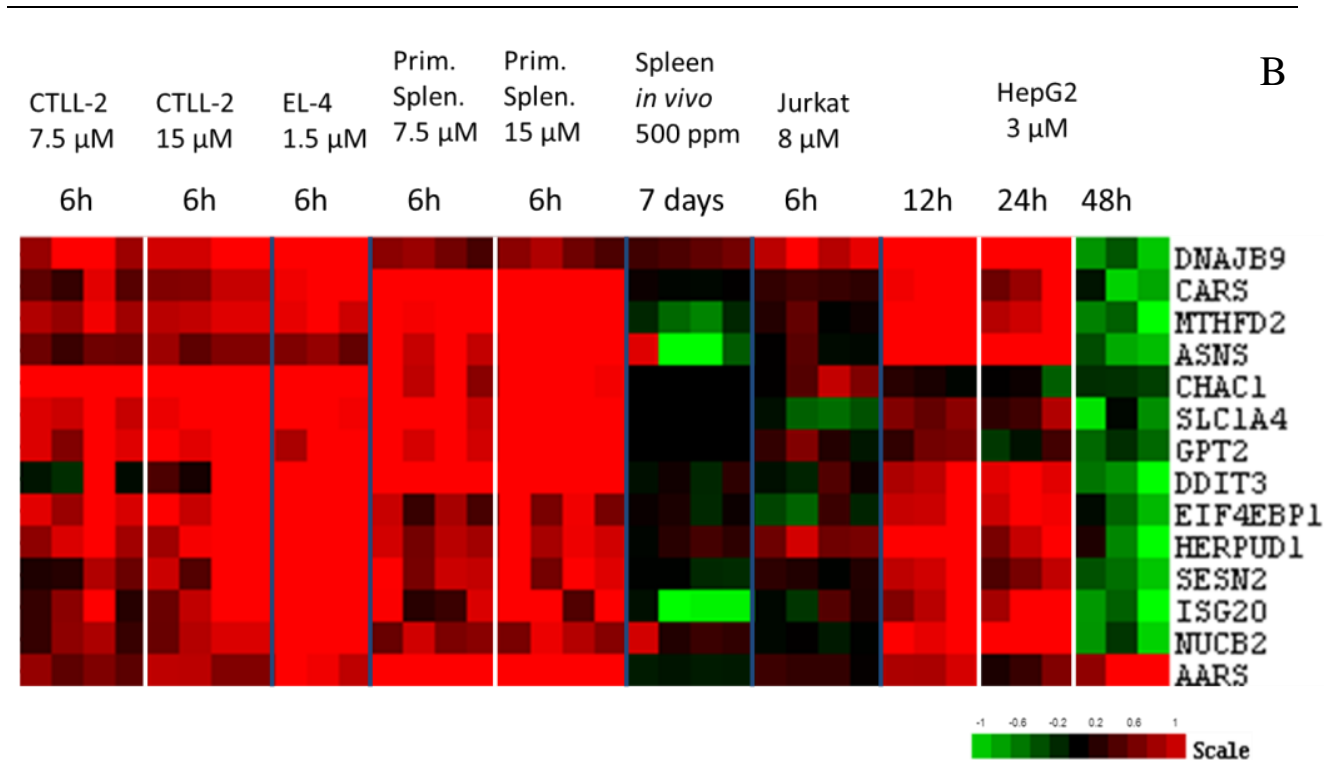

Figure 7. Genes commonly up- or downregulated by CsA.

Selection of genes that are either downregulated (A) or upregulated (B) by CsA in multiple exposure settings. Genes were selected on fold change $\geq 1.6(2 \operatorname{LogRatio} \geq 0.7)$ in at least 15 out of 36 arrays. Scale is displayed in bottom right corner; green represents downregulation, red upregulation and black means no effect.

\section{Discussion}

In this study we assessed the transcriptomics response of mouse CTLL-2 cells, EL-4 cells, primary splenocytes in vitro and spleens in vivo to the immunosuppressive drug CsA. In addition, we took advantage of the availability of microarray data of human Jurkat $\mathrm{T}$ cells, liver HepG2 cells and renal proximal tubular cells (RPTEC/TERT1) exposed to CsA. A main goal was to assess to which extent the modes of action as revealed by transcriptomics would depend on the cell type, the species and the study type (in vitro or in vivo).

CsA responsive genes in the different cell models were compared by means of hierarchical clustering and MetaCore pathway analysis. Most of the genes that are up- or downregulated in spleens of mice exposed in vivo to CsA were not affected in the other cell systems (Fig. 1). Furthermore, most of the genes that were affected in vivo were downregulated while relatively few genes were upregulated. The lack of overlap in response between in vivo and in vitro may be due to a difference in the concentration of CsA at the site of action. Genes that were regulated in spleens in vivo and not regulated in the in vitro cell systems may also be secondary to effects that occurred in other organs. In primary splenocytes the number of up and downregulated genes was approximately equal while in EL-4 cells and CTLL-2 cells more genes were upregulated than downregulated. Processes that were upregulated in CTLL-2 cells and EL-4 cells based on MetaCore analysis included ER stress, the unfolded protein response and some apoptosis related genes. GSEA analysis confirmed induction of ER stress and unfolded protein response in CTLL-2 and EL-4 cells and indicated ER stress and unfolded protein response (gene set XBP1 target genes) to be induced in primary 
splenocytes as well (Fig. 2A). We then assessed the effects on sets of genes involved in the different stages of the UPR (Fig. 2B). Almost all processes involved in the UPR were upregulated in EL-4 and CTLL-2 cells. In primary splenocytes, some of the processes that are involved in early stages of the UPR (ubiquitination, protein disulphide isomerization) were upregulated. In contrast, none of these UPR and ER stress related gene sets were affected in the spleen in vivo. The induction of UPR by CsA has been reported before in human renal tissue and renal tubular cell cultures (Du et al. 2009; Hama et al. 2013; Wilmes et al. 2013).

The mouse cell lines CTLL-2 and EL-4 and mouse primary splenocytes differ from mouse in vivo and human Jurkat in vitro in their mRNA expression response to CsA for genes involved in the processes of $\mathrm{T}$ cell activation, activation of the oxidative stress transcription factor NRF2, UPR and ER stress and apoptosis (Fig. 3). T cell activation was most convincingly downregulated in CTLL-2 cells (Fig. 2A and 3A). Although some $\mathrm{T}$ cell activation genes were upregulated in EL-4 cells and primary splenocytes (Fig. 3A), the gene set as a whole was not affected (Fig. 2A). An important difference between CTLL-2 cells and the other cell systems is that CTLL-2 cells are cultured in the presence of T-cell activating cytokines. (T-STIM, rat IL-2 factor) inducing a $\mathrm{T}$ cell activation response. This likely makes CTLL-2 cells more suitable to detect inhibition of T cell activation than the other cell systems. The $\mathrm{T}$ cell activation response is also constitutively activated in EL-4 cells due to a mutation in the calcineurin gene (Schmeits et al. 2014b) which is most probably the reason that the expression of the important pathways in CTLL-2 and EL-4 are alike (Fig. 3).

In agreement to previously published results on human and rat renal tubular cells (Shin et al. 2010; Wilmes et al. 2013), CsA activates NRF2 in CTLL-2 cells and EL-4 cells (Fig. 3B). In primary splenocytes, more NRF2 target genes were downregulated than upregulated. Genes involved in the UPR were convincingly upregulated in CTLL-2 and EL-4 cells (Fig. 3C), confirming this mechanism of CsA. CsA has also been reported to induce apoptosis (Strauss et al. 2002). In the present study, this was confirmed in EL-4 and CTLL-2 cells and to lesser extent in primary splenocytes but not in the spleen in vivo and Jurkat T cells (Fig. 2A and 3D).

We then compared to what extent the effects caused by CsA in other cell types correlated with the data obtained in the mouse systems used in the present study. Data were obtained from human liver HepG2 cells (Magkoufopoulou et al. 2011) and human renal tubular cells (Wilmes et al. 2013). Based on these comparisons we conclude that the transcriptomics response of different cell lines and spleen in vivo upon exposure to CsA have only few genes in common. We then searched for individual genes that are up- or downregulated by CsA irrespective of the cell system. Five genes were identified that are downregulated, although these genes were less affected in CTLL-2 cells (Fig. 7A). Next to those genes, fourteen genes were identified that are upregulated in most of the CsA exposed cell systems (Fig. 7B). These genes were convincingly upregulated in CTLL-2, EL-4, primary splenocytes and HepG2 cells (except 48 h). In Jurkat cells and spleens in vivo these 
fourteen genes were less severely affected. MetaCore analysis revealed that these genes function in unfolded protein response and ER stress. It is of great interest to test if these genes are also up- or downregulated in CsA exposures performed in other cell types.

An important issue when comparing the in vivo and in vitro situation is that the spleen in vivo contains a variety of different cell types and that influx of phagocytic cells and removal of affected cells can occur. This is supported by the finding of increased expression of genes related to NK cells and monocytes in the spleen indicating infiltration of phagocytic cells (Fig. 5). A similar observation has been reported in mice thymuses exposed to the immunotoxicant deoxynivalenol (van Kol et al. 2011). So, the cells that became apoptotic may have been removed already at the time of sacrifice. Therefore, it can be concluded that in vivo exposure to $500 \mathrm{ppm}$ CsA for seven days is not very informative for identification of acute immunotoxic mode of actions. Presumably, a higher dose and a shorter exposure duration would have yielded more suitable mechanistic data.

Of the mouse systems tested, CTLL-2 cells reflected the known mechanisms of CsA the best. CsA exposure in CTLL-2 cells downregulated T cell activation and induced oxidative stress, unfolded protein response leading to ER stress, and apoptosis (Fig. 2 and 3). There are some differences in the results obtained after GSEA and individual gene selection. Those differences might be caused by the fact that no initial filtering of data is applied in the procedure of GSEA (Subramanian et al. 2005), while in the process of selecting significant genes a threshold is chosen. Therefore some minor effects on the expression of genes belonging to one particular set can still lead to a significant result on the whole gene set in GSEA while these genes did not pass the threshold for being included in the heat maps.

The main immunotoxic action of CsA, as described in literature, is the suppression of the T cell activation response and induction of ER stress and oxidative stress leading to apoptosis of T cells (Hama et al. 2013; Ho et al. 1996; O'Connell et al. 2012; Stepkowski and Kirken 2000). Of the in vitro models tested in this study (CTLL-2, EL-4, primary splenocytes, and Jurkat) CTLL-2 cells performed best in detecting the mechanism underlying immunotoxicity of CsA. EL-4 cells were less suitable in detecting inhibition of $\mathrm{T}$ cell activation. Interestingly, hardly any effect on T cell activation, NRF2 activation, UPR and apoptosis was observed in the human Jurkat $\mathrm{T}$ cell line. Jurkat cells do not have a constitutively activated $\mathrm{T}$ cell response and previous studies demonstrated this cell line to be very well suited to detect induction of the T cell activation response (Katika et al. 2011; Schmeits et al. 2014a). One lesson from the present study, therefore, is that in vitro assays on effects on $\mathrm{T}$ cell activation require at least two immune cell systems, one with an activated and one with a non-activated $\mathrm{T}$ cell activation response, to detect both inactivating and activating effects.

\section{Conflict of interest statement}

The authors declare that there are no conflicts of interest. 
Detection of the mechanism of immunotoxicity of cyclosporine A in murine in vitro and in vivo models

\section{Acknowledgements}

This study was financially supported by the Netherlands Genomics Initiative, the Netherlands Organisation for Scientific Research, and the Netherlands Toxicogenomics Centre (grant number 05060510). 


\section{Chapter 2}

\section{References}

Baken KA, Pennings JL, Jonker MJ, et al. (2008) Overlapping gene expression profiles of model compounds provide opportunities for immunotoxicity screening. Toxicology and applied pharmacology 226(1):46-59 doi:10.1016/j.taap.2007.08.026

Bar-Joseph Z, Siegfried Z, Brandeis M, et al. (2008) Genome-wide transcriptional analysis of the human cell cycle identifies genes differentially regulated in normal and cancer cells. Proceedings of the National Academy of Sciences of the United States of America 105(3):955-60 doi:10.1073/pnas.0704723105

Bram RJ, Hung DT, Martin PK, Schreiber SL, Crabtree GR (1993) Identification of the immunophilins capable of mediating inhibition of signal transduction by cyclosporin A and FK506: roles of calcineurin binding and cellular location. Molecular and cellular biology 13(8):4760-9

Civelek M, Manduchi E, Riley RJ, Stoeckert CJ, Jr., Davies PF (2009) Chronic endoplasmic reticulum stress activates unfolded protein response in arterial endothelium in regions of susceptibility to atherosclerosis.

Circulation research 105(5):453-61 doi:10.1161/CIRCRESAHA.109.203711

Clipstone NA, Crabtree GR (1992) Identification of calcineurin as a key signalling enzyme in T-lymphocyte activation. Nature 357(6380):695-7 doi:10.1038/357695a0

Corsini E, Roggen EL (2009) Immunotoxicology: opportunities for non-animal test development. Alternatives to laboratory animals : ATLA 37(4):387-97

Cristillo AD, Bierer BE (2002) Identification of novel targets of immunosuppressive agents by cDNA-based microarray analysis. The Journal of biological chemistry 277(6):4465-76 doi:10.1074/jbc.M108598200

de Arriba G, Calvino M, Benito S, Parra T (2013) Cyclosporine A-induced apoptosis in renal tubular cells is related to oxidative damage and mitochondrial fission. Toxicology letters 218(1):30-38

doi:10.1016/j.toxlet.2013.01.007

Deters M, Klabunde T, Meyer H, Resch K, Kaever V (2003) Effects of curcumin on cyclosporine-induced cholestasis and hypercholesterolemia and on cyclosporine metabolism in the rat. Planta medica 69(4):337-43 doi:10.1055/s-2003-38870

Du J, Yu Y, Tu H, et al. (2006) New insights on macrophage migration inhibitory factor: based on molecular and functional analysis of its homologue of Chinese amphioxus. Molecular immunology 43(13):2083-8 doi:10.1016/j.molimm.2005.12.007

Du S, Hiramatsu N, Hayakawa K, et al. (2009) Suppression of NF-kappaB by cyclosporin a and tacrolimus (FK506) via induction of the C/EBP family: implication for unfolded protein response. Journal of immunology 182(11):7201-11 doi:10.4049/jimmunol.0801772

Eisen MB, Spellman PT, Brown PO, Botstein D (1998) Cluster analysis and display of genome-wide expression patterns. Proceedings of the National Academy of Sciences of the United States of America 95(25):14863-8 Erdem SR, Emre-Aydingoz S, Atilla P, et al. (2011) Cyclosporine A-induced acute hepatotoxicity in guinea pigs is associated with endothelin-mediated decrease in local hepatic blood flow. Life sciences 88(17-18):753-60 doi:10.1016/j.1fs.2011.02.015

Galat A, Bua J (2010) Molecular aspects of cyclophilins mediating therapeutic actions of their ligands. Cellular and molecular life sciences : CMLS 67(20):3467-88 doi:10.1007/s00018-010-0437-0

Gottschalk AR, Boise LH, Thompson CB, Quintans J (1994) Identification of immunosuppressant-induced apoptosis in a murine B-cell line and its prevention by bcl-x but not bcl-2. Proceedings of the National Academy of Sciences of the United States of America 91(15):7350-4

Halestrap AP, Connern CP, Griffiths EJ, Kerr PM (1997) Cyclosporin A binding to mitochondrial cyclophilin inhibits the permeability transition pore and protects hearts from ischaemia/reperfusion injury. Molecular and cellular biochemistry 174(1-2):167-72

Hama T, Nakanishi K, Mukaiyama H, et al. (2013) Endoplasmic reticulum stress with low-dose cyclosporine in frequently relapsing nephrotic syndrome. Pediatric nephrology doi:10.1007/s00467-012-2403-6

Hibino M, Sugiura K, Muro Y, Shimoyama Y, Tomita Y (2011) Cyclosporin A induces the unfolded protein response in keratinocytes. Archives of dermatological research 303(7):481-9 doi:10.1007/s00403-010-1099-3 Ho S, Clipstone N, Timmermann L, et al. (1996) The mechanism of action of cyclosporin A and FK506. Clinical immunology and immunopathology 80(3 Pt 2):S40-5 


\section{Detection of the mechanism of immunotoxicity of cyclosporine A in murine in vitro}

and in vivo models

Hochreiter-Hufford A, Ravichandran KS (2013) Clearing the dead: apoptotic cell sensing, recognition, engulfment, and digestion. Cold Spring Harbor perspectives in biology 5(1):a008748

doi:10.1101/cshperspect.a008748

Hochstenbach K, van Leeuwen DM, Gmuender H, et al. (2010) Transcriptomic profile indicative of immunotoxic exposure: in vitro studies in peripheral blood mononuclear cells. Toxicological sciences : an official journal of the Society of Toxicology 118(1):19-30 doi:10.1093/toxsci/kfq239

Iwakoshi NN, Lee AH, Vallabhajosyula P, Otipoby KL, Rajewsky K, Glimcher LH (2003) Plasma cell differentiation and the unfolded protein response intersect at the transcription factor XBP-1. Nature immunology 4(4):321-9 doi:10.1038/ni907

Jeon SH, Piao YJ, Choi KJ, et al. (2005) Prednisolone suppresses cyclosporin A-induced apoptosis but not cell cycle arrest in MDCK cells. Archives of biochemistry and biophysics 435(2):382-92

doi:10.1016/j.abb.2005.01.003

Johnson EN, Lee YM, Sander TL, et al. (2003) NFATc1 mediates vascular endothelial growth factor-induced proliferation of human pulmonary valve endothelial cells. The Journal of biological chemistry 278(3):1686-92 doi:10.1074/jbc.M210250200

Kahl CR, Means AR (2004) Calcineurin regulates cyclin D1 accumulation in growth-stimulated fibroblasts. Molecular biology of the cell 15(4):1833-42 doi:10.1091/mbc.E03-10-0730

Katika MR, Hendriksen PJ, van Loveren H, Peijnenburg A (2011) Exposure of Jurkat cells to bis (tri-n-butyltin) oxide (TBTO) induces transcriptomics changes indicative for ER- and oxidative stress, T cell activation and apoptosis. Toxicology and applied pharmacology 254(3):311-22 doi:10.1016/j.taap.2011.04.021

Kienhuis AS, Vitins AP, Pennings JL, et al. (2013) Cyclosporine A treated in vitro models induce cholestasis response through comparison of phenotype-directed gene expression analysis of in vivo Cyclosporine A-induced cholestasis. Toxicology letters 221(3):225-36 doi:10.1016/j.toxlet.2013.06.236

Klawitter J, Gottschalk S, Hainz C, Leibfritz D, Christians U, Serkova NJ (2010) Immunosuppressant neurotoxicity in rat brain models: oxidative stress and cellular metabolism. Chemical research in toxicology 23(3):608-19 doi:10.1021/tx900351q

Kuny S, Gaillard F, Sauve Y (2012) Differential gene expression in eyecup and retina of a mouse model of Stargardt-like macular dystrophy (STGD3). Investigative ophthalmology \& visual science 53(2):664-75 doi:10.1167/iovs.11-8418

Kuschal C, Thoms KM, Schubert S, et al. (2012) Skin cancer in organ transplant recipients: effects of immunosuppressive medications on DNA repair. Experimental dermatology 21(1):2-6 doi:10.1111/j.16000625.2011.01413.x

Lally C, Healy E, Ryan MP (1999) Cyclosporine A-induced cell cycle arrest and cell death in renal epithelial cells. Kidney international 56(4):1254-7 doi:10.1046/j.1523-1755.1999.00696.x

Luebke RW, Holsapple MP, Ladics GS, et al. (2006) Immunotoxicogenomics: the potential of genomics technology in the immunotoxicity risk assessment process. Toxicological sciences : an official journal of the Society of Toxicology 94(1):22-7 doi:10.1093/toxsci/kfl074

Lyons PA, Koukoulaki M, Hatton A, et al. (2007) Microarray analysis of human leucocyte subsets: the advantages of positive selection and rapid purification. BMC genomics 8:64 doi:10.1186/1471-2164-8-64

Ma Q (2013) Role of nrf2 in oxidative stress and toxicity. Annual review of pharmacology and toxicology 53:40126 doi:10.1146/annurev-pharmtox-011112-140320

Magkoufopoulou C, Claessen SM, Jennen DG, Kleinjans JC, van Delft JH (2011) Comparison of phenotypic and transcriptomic effects of false-positive genotoxins, true genotoxins and non-genotoxins using HepG2 cells.

Mutagenesis 26(5):593-604 doi:10.1093/mutage/ger021

Mascarell L, Truffa-Bachi P (2003) New aspects of cyclosporin a mode of action: from gene silencing to gene upregulation. Mini reviews in medicinal chemistry 3(3):205-14

O'Connell S, Tuite N, Slattery C, Ryan MP, McMorrow T (2012) Cyclosporine A--induced oxidative stress in human renal mesangial cells: a role for ERK 1/2 MAPK signaling. Toxicological sciences : an official journal of the Society of Toxicology 126(1):101-13 doi:10.1093/toxsci/kfr330

Ohga K, Takezawa R, Arakida Y, Shimizu Y, Ishikawa J (2008) Characterization of YM-58483/BTP2, a novel store-operated $\mathrm{Ca} 2+$ entry blocker, on $\mathrm{T}$ cell-mediated immune responses in vivo. International immunopharmacology 8(13-14):1787-92 doi:10.1016/j.intimp.2008.08.016 


\section{Chapter 2}

Ponticelli C (2005) Cyclosporine: from renal transplantation to autoimmune diseases. Annals of the New York Academy of Sciences 1051:551-8 doi:10.1196/annals.1361.099

Sakuma K, Nakao R, Aoi W, et al. (2005) Cyclosporin A treatment upregulates Id1 and Smad3 expression and delays skeletal muscle regeneration. Acta neuropathologica 110(3):269-80 doi:10.1007/s00401-005-1049-x Schaap MM, Zwart EP, Wackers PF, et al. (2012) Dissecting modes of action of non-genotoxic carcinogens in primary mouse hepatocytes. Archives of toxicology 86(11):1717-27 doi:10.1007/s00204-012-0883-6

Schmeits PC, Katika MR, Peijnenburg AA, van Loveren H, Hendriksen PJ (2014a) DON shares a similar mode of action as the ribotoxic stress inducer anisomycin while TBTO shares ER stress patterns with the ER stress inducer thapsigargin based on comparative gene expression profiling in Jurkat T cells. Toxicology letters 224(3):395-406 doi:10.1016/j.toxlet.2013.11.005

Schmeits PC, Volger OL, Zandvliet ET, van Loveren H, Peijnenburg AA, Hendriksen PJ (2013) Assessment of the usefulness of the murine cytotoxic T cell line CTLL-2 for immunotoxicity screening by transcriptomics. Toxicology letters 217(1):1-13 doi:10.1016/j.toxlet.2012.12.005

Schmeits PCJ, van Kol S, van Loveren H, Peijnenburg AACM, Hendriksen PJM (2014b) The effects of tributyltin oxide and deoxynivalenol on the transcriptome of the mouse thymoma cell line EL-4. Toxicology Research doi:10.1039/C3TX50100K

Shaffer AL, Rosenwald A, Hurt EM, et al. (2001) Signatures of the immune response. Immunity 15(3):375-85 Shao J, Katika MR, Schmeits PC, et al. (2013) Toxicogenomics-based identification of mechanisms for direct immunotoxicity. Toxicological sciences : an official journal of the Society of Toxicology 135(2):328-46 doi:10.1093/toxsci/kft151

Shin DH, Park HM, Jung KA, et al. (2010) The NRF2-heme oxygenase-1 system modulates cyclosporin Ainduced epithelial-mesenchymal transition and renal fibrosis. Free radical biology \& medicine 48(8):1051-63 doi:10.1016/j.freeradbiomed.2010.01.021

Stepkowski SM, Kirken RA (2000) The role of IL-2 in allograft rejection--a lesson learned from experimental work. Transplantation 69(12):2480-2

Strauss G, Osen W, Debatin KM (2002) Induction of apoptosis and modulation of activation and effector function in T cells by immunosuppressive drugs. Clinical and experimental immunology 128(2):255-66

Su AI, Wiltshire T, Batalov S, et al. (2004) A gene atlas of the mouse and human protein-encoding transcriptomes. Proceedings of the National Academy of Sciences of the United States of America 101(16):6062-7

doi:10.1073/pnas.0400782101

Subramanian A, Tamayo P, Mootha VK, et al. (2005) Gene set enrichment analysis: a knowledge-based approach for interpreting genome-wide expression profiles. Proceedings of the National Academy of Sciences of the United States of America 102(43):15545-50 doi:10.1073/pnas.0506580102

Tariq M, Morais C, Sobki S, Al Sulaiman M, Al Khader A (1999) N-acetylcysteine attenuates cyclosporininduced nephrotoxicity in rats. Nephrology, dialysis, transplantation : official publication of the European Dialysis and Transplant Association - European Renal Association 14(4):923-9

Tomono M, Toyoshima K, Ito M, Amano H (1996) Calcineurin is essential for DNA synthesis in Swiss 3T3 fibroblasts. The Biochemical journal 317 ( Pt 3):675-80

Tyrrell RM, Basu-Modak S (1994) Transient enhancement of heme oxygenase 1 mRNA accumulation: a marker of oxidative stress to eukaryotic cells. Methods in enzymology 234:224-35

van Kol SW, Hendriksen PJ, van Loveren H, Peijnenburg A (2011) The effects of deoxynivalenol on gene expression in the murine thymus. Toxicology and applied pharmacology 250(3):299-311

doi:10.1016/j.taap.2010.11.001

van Kreijl CF, McAnulty PA, Beems RB, et al. (2001) Xpa and Xpa/p53+/- knockout mice: overview of available data. Toxicologic pathology 29 Suppl:117-27

Whitfield ML, Sherlock G, Saldanha AJ, et al. (2002) Identification of genes periodically expressed in the human cell cycle and their expression in tumors. Molecular biology of the cell 13(6):1977-2000 doi:10.1091/mbc.02-020030 .

Wilmes A, Limonciel A, Aschauer L, et al. (2013) Application of integrated transcriptomic, proteomic and metabolomic profiling for the delineation of mechanisms of drug induced cell stress. Journal of proteomics 79:180-94 doi:10.1016/j.jprot.2012.11.022 
Detection of the mechanism of immunotoxicity of cyclosporine A in murine in vitro and in vivo models

Wolf G, Thaiss F, Stahl RA (1995) Cyclosporine stimulates expression of transforming growth factor-beta in renal cells. Possible mechanism of cyclosporines antiproliferative effects. Transplantation 60(3):237-41

Yonish-Rouach E, Kimchi A, Rubinstein M (1991) The antiproliferative effect of cyclosporine on hematopoietic and lymphoblastoid cell lines--common mechanistic elements with interferon-alpha. Transplantation 51(6):127682

Ziegler SF, Ramsdell F, Alderson MR (1994) The activation antigen CD69. Stem cells 12(5):456-65 doi:10.1002/stem.5530120502

Zupanska A, Dziembowska M, Ellert-Miklaszewska A, Gaweda-Walerych K, Kaminska B (2005) Cyclosporine a induces growth arrest or programmed cell death of human glioma cells. Neurochemistry international 47(6):43041 doi:10.1016/j.neuint.2005.05.010 



\section{Chapter 3}

\section{The effects of tributyltin oxide and deoxynivalenol on the transcriptome of the mouse thymoma cell line EL-4}

Peter C J Schmeits, Sandra van Kol, Henk van Loveren, Ad Peijenburg, and Peter Hendriksen

Toxicology Research. 02/2014

Supplementary material can be found at:

http:/ / pubs.rsc.org/en/Content/ArticleLanding/2014/TX/c3tx50100k\#!d ivAbstract 


\begin{abstract}
The main goal of this study was to assess the potential of the mouse thymoma EL-4 cell line in screening for chemical induced immunotoxicity. Therefore, EL-4 cells were exposed to two well-known immunotoxicants, organotin compound tributyltin oxide (TBTO, 0.5 and $1 \mu \mathrm{M}$ for 3 or $6 \mathrm{~h}$ ) and the mycotoxin deoxynivalenol (DON, 0.25, 0.5 and $1 \mu \mathrm{M}$ for 3 , 6 or $11 \mathrm{~h}$ ). Previous studies in human Jurkat T cells and mouse thymus in vivo showed that the primary mode of action of TBTO is induction of endoplasmic reticulum (ER) stress, T cell activation and apoptosis. DON induces ribotoxic stress and, similarly to TBTO, induces ER stress, T cell activation and apoptosis. In the present study, the effects of TBTO and DON on EL-4 mRNA expression were assessed by whole genome microarray analysis. The microarray data were then compared to those obtained with mouse thymuses in vivo, mouse thymocytes in vitro, and CTLL-2 cells and human Jurkat cells in vitro exposed to TBTO or DON. Analysis at the level of gene sets revealed that part of the previously detected modes of action of TBTO and DON were not observed in the EL-4 cell line. In EL-4 cells, TBTO induced genes involved in calcium signalling and ER stress but did not induce genes involved in $\mathrm{T}$ cell activation and apoptosis. DON induced RNA related processes and ribosome biogenesis. Furthermore, DON downregulated ER stress, T cell activation and apoptosis which is opposite to the mechanism of DON observed in the mouse thymus in vivo and in Jurkat T cells in vitro. Apparently, EL-4 cells lack factors that are important to link ribotoxic stress to ER stress. In addition, of the lack of $\mathrm{T}$ cell activation response of EL-4 cells to TBTO is likely due to the fact that these cells are in a constitutively activated state already. Based on the results obtained for TBTO and DON, it can be concluded that the EL-4 cell line has limited value for immunotoxicogenomics based screening.
\end{abstract}




\section{Introduction}

REACH, the European regulation community on chemicals and their safe use, aims to test all new and existing chemicals for toxicity of which the yearly production exceeds one tonne (Hofer et al. 2004; Pedersen 2003). In immunotoxicity testing the current strategy is heavily relying on animal models. Since testing all new and almost all existing chemicals would require enormous amounts of animals, money and time, in vitro alternatives are urgently needed (Corsini and Roggen 2009). Some recent studies mainly used human Jurkat T cells as a model for immunotoxicity (Katika et al. 2012b; Katika et al. 2011; Shao et al. 2013). However, because the immune system comprises multiple organs and multiple cell types, a battery of in vitro tests with a diversity of cell lines may be useful as screening tool for the prediction of immunotoxicity. In this study we followed a toxicogenomics approach to assess the usefulness of mouse thymoma EL-4 cells as a potential in vitro system to screen compounds for immunotoxicity.

EL-4 cells were derived from a thymoma of a C57BL/6 mouse more than sixty years ago (Gorer 1950). These cells express CD3 but they do not express CD4 or CD8 molecules on their surface (Skinner et al. 1992; Varga et al. 1999). All T cells including progenitor cells express CD3 and during development in the thymus they will become double positive thymocytes expressing both CD4 and CD8 at positive selection (Bommhardt et al. 2004). Further development into CD4+ or CD8+ T cells occurs in the thymic medulla in a process called negative selection, where $\mathrm{T}$ cells with high affinity for the interaction with Major Histocompatibility Complex (MHC) undergo apoptosis to prevent autoreactivity (Bommhardt et al. 2004). Since EL-4 cells contain CD3 molecules but no CD4 or CD8 they can be classified as early thymocytes (Neumann and Martin 2001).

In the present study, EL-4 cells were treated with two well-known immunotoxicants, the mycotoxin deoxynivalenol (DON) and the organotin compound tributyltin oxide (TBTO) and were subsequently subjected to DNA microarray analysis. Both compounds have been used before in human and rodent transcriptomics studies (Baken et al. 2007; Baken et al. 2006; Baken et al. 2008; Katika et al. 2012a; Katika et al. 2012b; Katika et al. 2011; Schmeits et al. 2013; van Kol et al. 2012; van Kol et al. 2011).

TBTO is an organotin compound that has been applied for various industrial purposes. It was for instance utilized as marine anti-fouling agent in ship paint, as a wood preservative and in production of plastic floor tiles. Because of its extensive use, TBTO is a wide spread environmental contaminant.(Hoch 2001) Humans can be exposed to organotin compounds through inhalation, absorption and consumption of contaminated food and water (De Santiago and Aguilar-Santelises 1999). In the period before the ban on TBTs, human blood butyltin concentrations ranging from 21 to $155 \mathrm{ng} / \mathrm{m}$ were measured in volunteers in Michigan (Kannan 1999; Whalen et al. 1999). More recently, a Dutch study in 2004 detected butyltin levels higher than $0.1 \mathrm{ng} / \mathrm{ml}$ in only six out of hundred blood samples (Peters 2004). Furthermore, in a Finnish study, none of 300 blood samples contained more than $1 \mathrm{ng}$ butyltin per $\mathrm{ml}$ (Rantakokko et al. 2008). The differences are probably caused by restrictions in the use of organotin compounds and due to regional differences. 
TBTO causes peripheral $\mathrm{T}$ cell depletion in its main target organ the thymus by inhibition of proliferation and induction of apoptosis (Krajnc et al. 1984). Recently, it has been shown that TBTO induces ER stress, affects calcium homeostasis, induces T cell activation and apoptosis in human Jurkat T cells (Katika et al. 2012a; Katika et al. 2011). In vivo, mouse microarray data indicated that TBTO induces oxidative stress and apoptosis in the thymus (Baken et al. 2008). In mouse primary thymocytes TBTO upregulates genes that are involved in ER stress, NFKB and TNF $\alpha$ pathways, DNA damage, p53 signalling and apoptosis (van Kol et al. 2012).

DON belongs to a class of mycotoxins, trichothecenes, and is a common contaminant of wheat and corn (Bimczok et al. 2007; Rasmussen et al. 2003; Severino et al. 2006). DON, which is a hydroxylated form of nivalenol, is produced by the fungi Fusarium sp. and is a commonly found mycotoxin in food and feed (Isebaert et al. 2005; Lombaert et al. 2003; Rasmussen et al. 2003; Tutelyan 2004). DON is chemically very stable during food processing (Grove 1988) and as a result humans are almost continuously exposed to low levels of this mycotoxin in their diet. Although data on human blood levels of DON are lacking, estimations for a tolerable daily intake range from 1 to $1000 \mu \mathrm{g} / \mathrm{kg}$ body weight per day (Canady 2001; FAO/WHO 2010; Pestka 2010). DON has been shown to cause a series of toxic effects in animals including immunomodulation (Pestka et al. 2005). The primary action of DON is the interference with the active site of peptidyltransferase on ribosomes (Shifrin and Anderson 1999; Ueno 1987; Zhou et al. 2003), leading to inhibition of protein synthesis (Rocha et al. 2005). This triggers a so called ribotoxic stress response (Iordanov et al. 1997; Zhou et al. 2003) that in human Jurkat cells is followed by induction of endoplasmic reticulum stress, $\mathrm{T}$ cell activation and apoptosis (Katika et al. 2012b). A recent microarray study on the thymuses of mice that were fed different concentrations of DON for 3, 6 and 24 hours showed that DON induces cellular effects that also occur during $\mathrm{T}$ cell activation (van Kol et al. 2011). On the basis of this finding it was postulated that these processes led to negative selection of the activated thymocytes and removal of apoptotic cells out of the thymus by phagocytosis (van Kol et al. 2011).

The microarray data of the present work of EL-4 cells exposed to two well-known immunotoxicants TBTO and DON were compared to transcriptome data from previous studies that examined the effects of TBTO and DON on murine thymus, mouse primary thymocytes and the human Jurkat T cell line (Baken et al. 2006; Katika et al. 2012b; Katika et al. 2011; van Kol et al. 2012; van Kol et al. 2011). These comparisons were performed to investigate the feasibility of using EL-4 cells as part of an in vitro strategy for immunotoxicity testing. To our knowledge, this is the first study that performed transcriptomics on murine EL-4 cells.

\section{Materials and Methods}

\section{Cell culture and chemicals}

EL-4 cells (ATCC; TIB-39) were cultured in RPMI 1640 medium (Invitrogen Life Science, Breda, The Netherlands) supplemented with $10 \%$ heat inactivated Fetal Bovine Serum (FBS) $100 \mathrm{U} / \mathrm{ml}$ Penicillin, and $100 \mu \mathrm{g} / \mathrm{ml}$ streptomycin (Invitrogen Life Science). Medium 
was refreshed three times a week. TBTO and DON (Sigma-Aldrich, Zwijndrecht, the Netherlands) were solved in absolute DMSO, diluted in standard medium and added to the culture wells in different concentrations. The final DMSO concentration in the culture wells was $0.1 \%$, which had no effect on the cell viability.

\section{Cell viability Assay}

Cell viability was determined using the water-soluble tetrazolium salt (WST-1) assay (Roche Diagnostics, Mannheim, Germany). This assay is based on the reduction of WST-1 to formazan that is mainly dependent on NADH and NADPH produced by viable cells. The reaction induces a colour change proportional to the mass of living cells in the culture medium. Cells were seeded into 96-well microtiter plates at a concentration of $5 \times 10^{5}$ cells/well and in triplicate per condition. Solutions of TBTO, DON or DMSO or medium (controls) were added to a total volume of $100 \mu \mathrm{l}$. Cells were incubated for $24 \mathrm{~h}$ and $10 \mu \mathrm{l}$ WST-1 assay mix was added during the last $2 \mathrm{~h}$. The amount of WST-1 converted to formazan was quantified at $450 \mathrm{~nm}$ using a microplate reader (Synergy ${ }^{\mathrm{TM}}$ HT MultiDetection Microplate Reader, Bio-teck instruments). Relative viability was measured by comparing the mean optical density of the TBTO and DON exposed cells with the mean optical density of the control cells. Subcytotoxic concentrations were defined as those concentrations leading to a decrease of $20 \%$ viability or less after $24 \mathrm{~h}$. These concentrations were then used in exposure experiments that were subsequently used for microarray hybridisations.

\section{Exposures}

EL-4 cells were seeded in six-well plates at a concentration of $5 \times 10^{5}$ cells/well and in triplicate per condition. Twenty hours after seeding, exposure was initiated by adding DON $(0.25 \mu \mathrm{M}, 0.5 \mu \mathrm{M}$ for 3,6 and $11 \mathrm{~h}$, and $1 \mu \mathrm{M}$ for $6 \mathrm{~h})$ or TBTO $(0.5 \mu \mathrm{M}$ and $1 \mu \mathrm{M}$ for 3 or $6 \mathrm{~h}$ ) to the EL-4 cells. The maximum DMSO concentration did not exceed $0.1 \%$ that had no effect on viability of EL-4 cells. These exposures were performed with three different passages of EL-4 cells.

\section{RNA isolation}

After exposure, cells were harvested and washed with PBS (10 min, $\left.1200 \mathrm{rpm}, 4^{\circ} \mathrm{C}\right)$. The cell pellets were resuspended in $600 \mu \mathrm{RLT}$ lysis buffer containing $1 \% \beta$-mercaptoethanol (Qiagen, Venlo, the Netherlands). The samples were stored at $-80^{\circ} \mathrm{C}$ until RNA isolation. Total RNA was isolated using RNeasy mini kits including DNase treatment (Qiagen) according to the manufacturer's instructions. RNA concentrations were determined by measuring absorbance at 260 and $280 \mathrm{~nm}$ and purity was estimated by 260/280 nm absorbance ratio (Nanodrop technologies, Wilmington, DE).

\section{Microarray hybridizations}

RNA was amplified and purified using the Agilent low RNA input fluorescent amplification kit protocol (Agilent Technologies, Palo Alto, CA). $1 \mu \mathrm{g}$ of each of the linearly amplified cRNA preparations was labelled by incorporation of Cy5-CTP (PerkinElmer/NEN Life Sciences, Boston, MA). Stratagene Universal Mouse Reference RNA 
(Agilent Technologies, La Jolla, CA) was used and labelled with fluorescent Cy3 dye (Perkin-Elmer/NEN). Each of the Cy5 labelled experimental cRNA samples was combined with an equal amount of the Cy3 labelled reference cRNA and hybridized on 44K whole mouse genome oligo microarrays (Agilent Technologies) following the Agilent two-colour microarray-based gene expression analysis protocol. The microarrays were hybridized for $17 \mathrm{~h}$ at $65^{\circ} \mathrm{C}$ in Agilent microarray hybridization chambers. Upon hybridization, the microarrays were washed and dried at room temperature following the instructions of the supplier. Arrays were scanned using an Agilent microarray scanner (G2565B). The fluorescent readings from the scanner were converted to quantitative files using Feature Extraction 9.1 software (Agilent Technologies). Quality check of the arrays was performed using software package LimmaGUI in R version 2.3.1. Data were imported in GeneMaths XT 1.5 (Applied Maths, St. MartensLatem, Belgium) and signals below two times background were excluded from subsequent analysis.

\section{Data analysis}

As a first step in the microarray data analysis, data were log transformed and normalized as described by Pellis (2003). In short, first, the Cy5 values were corrected using values of the Cy3 labelled internal standard to correct for possible differences in hybridization conditions between slides. Second, the median of the adjusted Cy5 signals was used to correct for possible differences between experiments with respect to the efficiency of probe labelling and amount of probe labelled.

Hierarchical clustering of the data was performed using the programs Cluster and Treeview (Eisen et al. 1998). An online software suite MetaCore (GeneGo Inc., St. Joseph, MI) was used to identify statistically significantly affected pathways for the subclusters of genes identified in hierarchical clustering.

\section{Comparative data analysis}

Gene Set Enrichment Analysis (GSEA) is a statistical analysis tool for microarray data and is used to detect the affected biological processes and to provide insight into the affected molecular mechanisms. GSEA uses predefined gene sets that are based on literature or previous experimental results. GSEA has the advantage over other statistical tools that no initial filtering is applied to the dataset to select for significantly differentially expressed genes. GSEA first ranks all the genes of the microarray data on their expression ratios and then determines whether a particular gene set is significantly enriched at the top or the bottom of the ranked list, or whether genes are randomly distributed (Subramanian et al. 2005). This enables detection of significantly affected gene sets, while the fold change of expression of the individual genes can be relatively modest (Subramanian et al. 2005).

In addition, gene sets were manually created based on the present EL-4 microarray data. Spots that were up- or downregulated with a fold change of $>1.6$ in at least two out of three arrays were included. This selection was performed for up- and downregulated spots separately per time point.

We then tested whether these EL-4 responsive gene sets were also affected in previous microarray studies on mouse thymuses exposed in vivo to TBTO (Baken et al. 2006) or 
DON (van Kol et al. 2011), mouse thymocytes exposed to TBTO in vitro (van Kol et al. 2012), mouse CTLL-2 cells exposed to TBTO and DON in vitro (Schmeits et al. 2013) and human Jurkat T cells exposed to TBTO and DON (Katika et al. 2012b; Katika et al. 2011). Results of these comparisons are visualized in heat maps of gene sets in which red and green indicate up and downregulation, respectively. Brighter colours represent a higher significance level. A full green or red colour indicates $\mathrm{p}<0.0001$. Gene sets used to identify biological pathways and processes affected by TBTO and DON were derived from:

1. Lymphocyte database, containing genes upregulated during $\mathrm{T}$ cell activation (Feske et al. 2001; Shaffer et al. 2001).

2. Gene Ontology: gene sets were downloaded from the Gene Ontology consortium (http://www.geneontology.org/) including molecular function and biological process.

3. Tox action (self-made)

4. Genes affected by TBTO or DON in other studies (Baken et al. 2006; Katika et al. 2012b; Katika et al. 2011; Schmeits et al. 2013; van Kol et al. 2012; van Kol et al. 2011).

Genes involved in ribosomal function, ER stress, $T$ cell activation and apoptosis

We then investigated how individual genes that play a role in the modes of action of TBTO and DON respond in EL-4 cells. Genes involved in RNA biosynthesis were taken from Reactome (www.reactome.org), genes involved in ER stress were taken from Kyoto Encyclopaedia of Genes and Genomes (KEGG), Biocarta and from literature mining and a set of apoptosis-related genes was taken from Gene Ontology. Genes upregulated during T cell activation were taken from the lymphocyte database (Feske et al. 2001; Shaffer et al. 2001). Separately for TBTO and DON, the effects on expression of genes involved in the mechanisms of action in EL-4 cells were compared to the expression of those genes in CTLL-2 cells, Jurkat T cells and for TBTO also in primary mouse thymocytes. This was performed using the programs Cluster and Treeview (Eisen et al. 1998). Red and green indicate up- and down-regulation vs. the average of the control samples. The threshold for up- and downregulation was set on a $2 \log$ ratio of 0.7 (numerical ratio 1.6).

\section{Results and Discussion}

\section{Time and dose selection}

Viability of EL-4 cells was determined using the WST-1 assay which is based on formazan formation by living cells. Viability of EL-4 cells was increased to $180 \%$ and $140 \%$ when exposed to 0.25 or $0.5 \mu \mathrm{M}$ TBTO for $6 \mathrm{~h}$, while viability was decreased to 83 and $102 \%$ after $24 \mathrm{~h}$ exposure, respectively (Fig. 1a). This might be an example of stimulation of various processes at lower concentrations of the toxicants, which is not unexpected. In previous experiments using TBTO, viability of Jurkat and CTLL-2 cells also increased after $6 \mathrm{~h}$ and then decreased after $24 \mathrm{~h}$, although viability was not increased to levels higher than 
$120 \%$ (Schmeits et al. 2014; Schmeits et al. 2013). Such stimulatory effects were also observed with respect to the generation of reactive oxygen species after in vitro exposure of oyster blood phagocytes to tributyltin at the lower concentrations (Anderson et al. 1997). Possibly, the early, increased proliferation might be induced by the $\mathrm{T}$ cell activation response while at later time points the proliferation is reduced due to the ribotoxic stress or ER stress response leading to apoptosis. Exposure to 1 and $2 \mu \mathrm{M}$ TBTO for $6 \mathrm{~h}$ resulted in a viability of 67 and $43 \%$, respectively. Exposure of EL-4 cells to 1 and $2 \mu \mathrm{M}$ TBTO reduced the viability to less than $25 \%$ after $24 \mathrm{~h}$.

The viability of EL-4 cells exposed to DON was almost unchanged by $0.25 \mu \mathrm{M}$ at any time point and gradually decreased from $0.5 \mu \mathrm{M}$ onwards (Fig. 1b). Exposure for 24 h to 0.5 and $1.0 \mu \mathrm{M}$ DON reduced the viability to $78 \%$ and $57 \%$ respectively. 24 h exposure to 2 or 4 $\mu \mathrm{M}$ DON resulted in $38 \%$ viability.
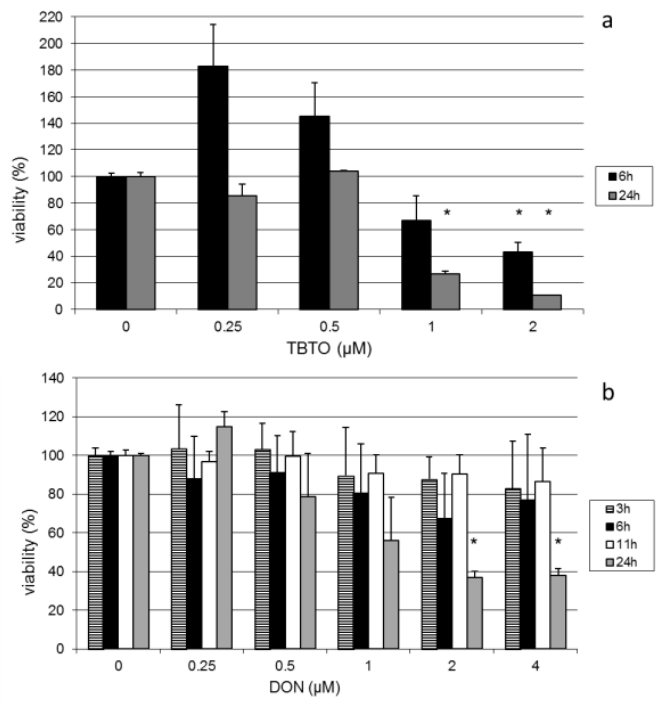

Fig. 1 Average viability of EL-4 cells exposed to (a) TBTO and (b) DON. Viability results reflect the average \pm $\mathrm{SD}$ of three independent measurements presented as percentage relative to solvent control DMSO at the same time point. * $\mathrm{P} \leq 0.01$ compared to solvent control DMSO (Student's T test).

The criterion for selecting doses for microarray exposures was the same as used before (Katika et al. 2011; Schmeits et al. 2013; van Kol et al. 2011). Doses were selected that resulted in a decrease in viability of less than $20 \%$ after $24 \mathrm{~h}$ exposure. Furthermore, for both compounds one dose resulting in a more than $20 \%$ reduction in cell viability was selected to assess the gene expression profile at cytotoxic conditions. For TBTO, $0.5 \mu \mathrm{M}$ and $1 \mu \mathrm{M}$ were chosen as subcytotoxic and cytotoxic doses, respectively. These doses were 2.5 to 5 times higher than the highest concentrations found in human blood samples (Kannan 1999; Whalen et al. 1999). For DON, 0.25 and $0.5 \mu \mathrm{M}$ were selected as subcytotoxic and $1 \mu \mathrm{M}$ was selected as cytotoxic doses. No data could be obtained on human blood concentrations of DON. The tolerable daily intake (TDI) of DON in humans 
varies between 1 and $1000 \mu \mathrm{g} / \mathrm{kg}$ bodyweight/day (0.003375 to $3.37 \mu \mathrm{M})$ (Canady 2001; FAO/WHO 2010; Pestka 2010). The concentrations of DON as used in the present study are thus within the range of the TDI of DON.

To study the effects of TBTO and DON in time, EL-4 cells were exposed for 3 and $6 \mathrm{~h}$. The effect of DON was also examined upon $11 \mathrm{~h}$ exposure since it was shown in a DON in vivo study that the number of differentially expressed genes decreased with longer exposure times (van Kol et al. 2011).

\section{Hierarchical clustering and pathway analysis}

Transcriptomics was performed on RNA from triplicate exposures. However, for $3 \mathrm{~h}$ and 6 $\mathrm{h}$ exposure to $1 \mu \mathrm{M}$ TBTO and $6 \mathrm{~h}$ exposure to $1 \mu \mathrm{M}$ DON only duplicates were obtained since three samples did not meet the quality control criteria.

Unsupervised hierarchical clustering was performed to visualise genes that were affected by TBTO (Fig. 2a) or DON (Fig. 2b). Genes were selected on > 1.6 fold up- or downregulation in $\geq 3$ arrays. This resulted in two large subclusters for TBTO and three subclusters for DON. These subclusters of genes were uploaded to MetaCore for identification of the most significantly represented pathways and biological processes in these clusters. Genes that were upregulated by TBTO corresponded to the processes of apoptosis and stress response (Fig. 2a). The apoptosis-related genes included AP1, CHAC1, GADD34, GADD45, NUR77 and PUMA. The genes downregulated by TBTO were related to regulation of molecular function, signal transduction and metabolic process. These downregulated genes thus are involved in some common processes that are not specific for immunotoxicity or the mechanism of TBTO. One of the three subclusters affected by DON consisted of genes that were specifically upregulated by DON after $11 \mathrm{~h}$ and a significant number of genes of this cluster are involved in cell cycle and DNA packaging (Fig. 2b). The second subcluster contained genes that were upregulated at all time points at DON concentrations of $0.5 \mu \mathrm{M}$ or higher and these genes are related to RNA processing, metabolism and biosynthesis, which is in line with the reported primary mechanism of action of DON (Katika et al. 2012b; van Kol et al. 2011). The third subcluster contained genes that were downregulated upon DON exposure and these genes are related to unfolded protein response (UPR), ER stress and cholesterol biosynthesis. The genes per cluster including the expression data for both TBTO and DON can be found in supplementary tables 1 and 2, respectively. A clustering on $>1.6$ fold up- or downregulation in $\geq 2$ arrays is also visualized as supplementary figure 1 . Spots that were up- or downregulated by $1 \mu \mathrm{M}$ TBTO were also up- or downregulated by $0.5 \mu \mathrm{M}$ TBTO. Spots that were affected by $1 \mu \mathrm{M}$ DON were similarly affected by $0.5 \mu \mathrm{M}$ but with a lower ratio. 


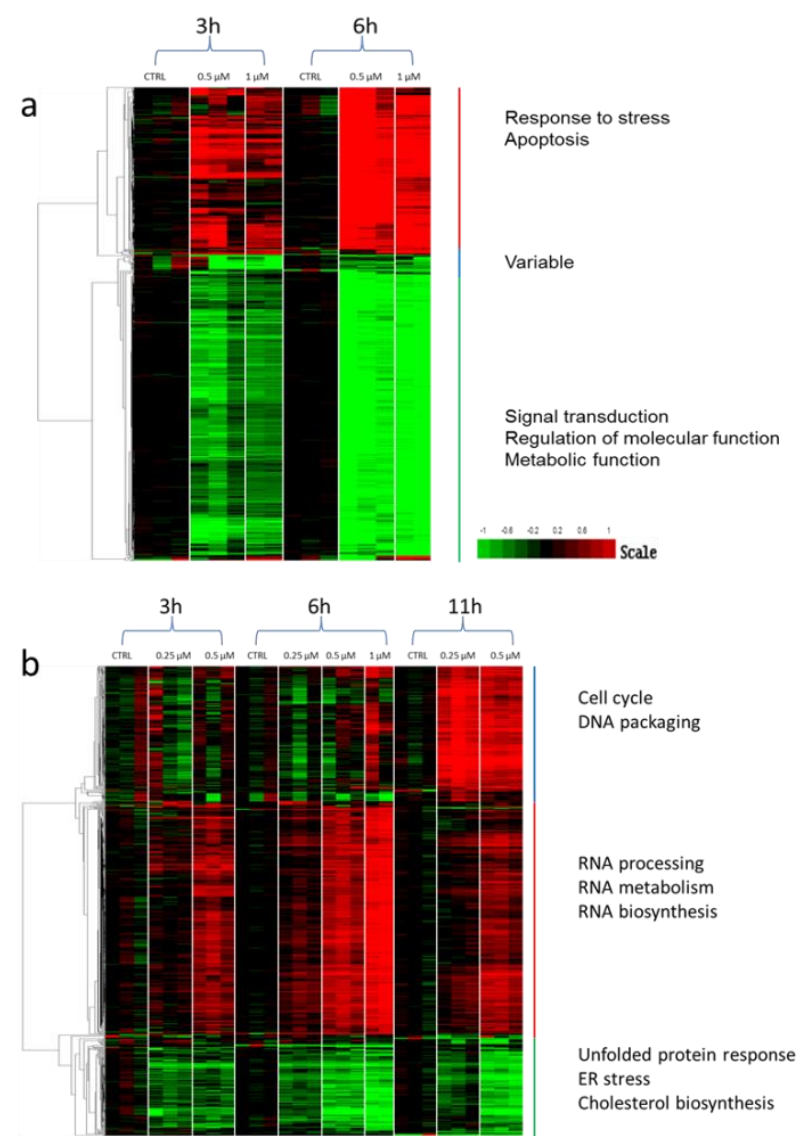

Fig. 2. Unsupervised hierarchical clustering of spots altered by TBTO or DON exposure in EL-4 cells. (a) This heat map contains 708 spots that were > 1.6 times up or downregulated by TBTO in EL-4 cells in at least 3 out of 16 arrays. (b) This heatmap contains 717 spots that were $>1.6$ times up or downregulated by DON in EL-4 cells in at least 3 out of 29 arrays. For each of the subclusters the corresponding biological processes are indicated at the right based on Metacore analysis. Scale is displayed in bottom right corner. Green represents downregulation, red represents upregulation and black represents no effect.

Gene set enrichment analysis (GSEA)

GSEA was used as a complementary tool, next to hierarchical clustering and MetaCore analysis, to identify which pathways and processes were affected by TBTO and DON in EL-4 cells. GSEA enabled us to compare the present EL-4 microarray data to gene sets that are publically available (see methods section 'comparative data analysis'). GSEA was performed separately for TBTO and DON and results were compared to the time matched controls. The GSEA output was then converted to a heat map for the gene sets that were significantly $(\mathrm{P} \leq 0.01$ and FDR $\leq 0.25)$ up- or downregulated (Fig. 3). Genes involved in calcium signalling were upregulated by exposure for $3 \mathrm{~h}$ to 0.5 and $1 \mu \mathrm{M}$ TBTO and $6 \mathrm{~h}$ to $1 \mu \mathrm{M}$ TBTO and downregulated after exposure for $3 \mathrm{~h}$ to $0.5 \mu \mathrm{M}$ DON. The increase in calcium signalling by TBTO agrees with the results obtained in previous experiments using 
Jurkat cells (Katika et al. 2012a). However, in Jurkat cells TBTO and DON also induced T cell activation and apoptosis. ${ }^{5,15}$ GSEA does not provide evidence for T cell activation or apoptosis induction after TBTO or DON exposure in EL-4 cells. Genes involved in the process of apoptosis and programmed cell death were downregulated by $1 \mu \mathrm{M}$ TBTO (3 and $6 \mathrm{~h}$ ) and $3 \mathrm{~h}$ DON exposure $(0.25$ and $0.5 \mu \mathrm{M})$. Since genes involved in $\mathrm{T}$ cell activation were not affected it is not shown in Figure 3. Genes involved in the cell cycle and RNA related processes were downregulated by TBTO, while these were upregulated by DON after 6 or $11 \mathrm{~h}$. Genes involved in the ER stress response were upregulated by TBTO exposure to $0.5 \mu \mathrm{M}$ and downregulated at all time points and by all, except one $(11 \mathrm{~h} 0.25$ $\mu \mathrm{M})$, concentrations of DON. Oxidative stress was downregulated by $3 \mathrm{~h}$ TBTO exposure, and 3 or $6 \mathrm{~h}$ DON exposure. The induction of the gene sets 'ribosome biogenesis and assembly', 'RNA processing' and 'mRNA metabolic process' by DON is visualised in heat maps showing the expression levels of the individual genes (Suppl. Fig. 2a-c). These heat maps convincingly show the upregulation of genes involved in the structure and function of ribosomes and RNA related processes. This holds true for subcytotoxic concentrations after $6 \mathrm{~h}(0.5 \mu \mathrm{M})$ and $11 \mathrm{~h}(0.25$ and $0.5 \mu \mathrm{M})$ as well as $6 \mathrm{~h}$ exposure to $1 \mu \mathrm{M}$ DON, a concentration that is cytotoxic after $24 \mathrm{~h}$ (Fig. 1). The upregulation of genes involved in ribosome biogenesis and assembly, RNA processing and metabolism and mRNA metabolic process was expected since these are known ribotoxic stress responses (Iordanov et al. 1997; Shifrin and Anderson 1999).
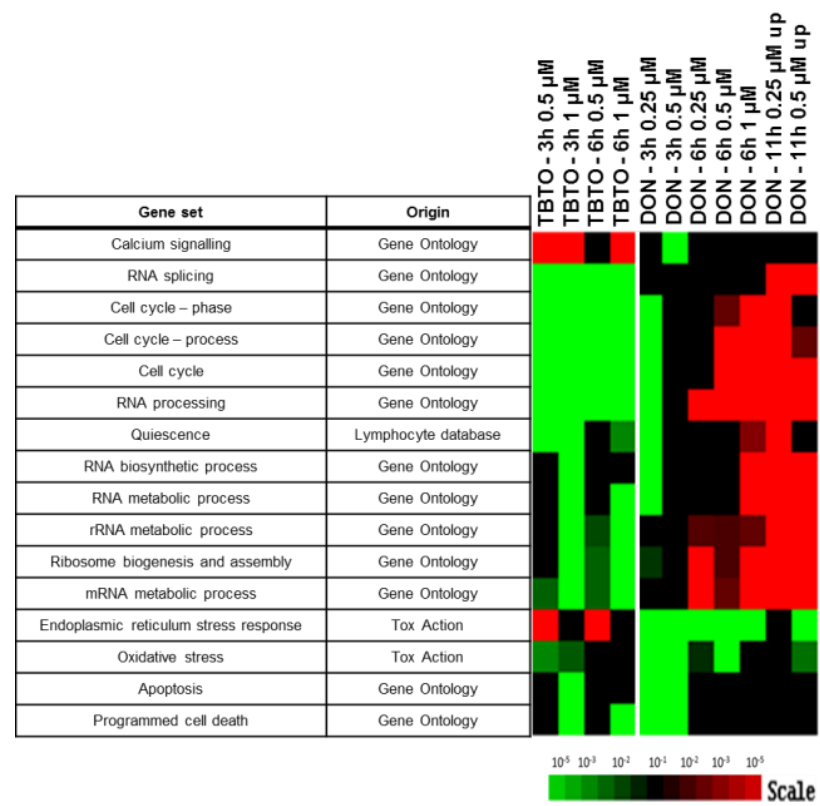

Fig. 3 Heat map of processes significantly affected ( $p$ value $\leq 0.01$, FDR $\leq 0.25$ ) in the EL-4 cell line showing an overview of the effects of TBTO and DON exposure on a selection of gene sets that were run in GSEA. Each line represents one gene set. Scale indicates statistical significance (p-value) of the gene sets. Green represents downregulation, red upregulation and black no effect. 


\section{Comparative data analysis}

We investigated whether the genes that were affected by TBTO and DON in the present EL-4 study were similarly affected in the mouse thymus in vivo (TBTO and DON), mouse primary thymocytes in vitro (TBTO), and the mouse CTLL-2 and human Jurkat cell lines in vitro (TBTO and DON). To that end, we used microarray data obtained from experiments performed before (Baken et al. 2006; Katika et al. 2012b; Katika et al. 2011; Schmeits et al. 2013; van Kol et al. 2012; van Kol et al. 2011). GSEA statistics was then used to test whether genes affected in the current study using EL-4 cells were similarly affected in previous experiments.

For TBTO, a heat map of this comparison is depicted in Fig. 4a. The sets containing genes that were downregulated by TBTO in EL-4 cells were also downregulated by TBTO in 1) the mouse

thymus in vivo, 2) mouse thymocytes exposed in vitro, 3) Jurkat cells exposed for $6 \mathrm{~h}$ to 0.5 $\mu \mathrm{M}$ TBTO, and 4) CTLL-2 cells exposed for $6 \mathrm{~h}$ to $0.2 \mu \mathrm{M}$ TBTO. Gene sets that were upregulated by TBTO in EL-4 cells were not significantly affected by TBTO in the mouse thymus in vivo (Fig. 4a). This is likely a result of the depletion of thymocytes out of the thymus after exposure to TBTO in combination with a relatively long exposure time of three days (Krajnc et al. 1984). Upregulation of these gene sets occurred in mouse thymocytes exposed to TBTO in vitro, except for those exposed for 3 or $11 \mathrm{~h}$ to $0.1 \mu \mathrm{M}$ TBTO. Gene sets upregulated by TBTO in EL-4 cells were also upregulated by TBTO in Jurkat cells exposed to $0.2 \mu \mathrm{M}$ for $3 \mathrm{~h}$ and $0.5 \mu \mathrm{M}$ for 3 and $6 \mathrm{~h}$, but not $0.2 \mu \mathrm{M}$ for $6 \mathrm{~h}$. Genes upregulated in EL-4 cells were also upregulated in CTLL-2 cells exposed to $0.2 \mu \mathrm{M}$ TBTO and oppositely regulated in CTLL-2 cells exposed to $0.1 \mu \mathrm{M}$ TBTO. Overall, there is a significant overlap in genes that are up- or down-regulated by TBTO exposure in EL-4 cells to genes that are up- or downregulated in other mouse and human models.

Genes downregulated by DON in EL-4 cells were also downregulated in DON exposed mouse thymus in vivo, in Jurkat cells and in CTLL-2 cells (Fig. 4b). Genes that were upregulated by DON in EL-4 cells were also upregulated after 3 and $6 \mathrm{~h}$, but not $24 \mathrm{~h}$ exposures in vivo. Thus, with longer in vivo exposure time the overlap to genes affected in EL-4 cells decreased. This is likely due to the fact that the number of genes affected by DON in the mouse thymus in vivo is much lower after $24 \mathrm{~h}$ than after $6 \mathrm{~h}$ which is related to the rapid excretion of DON and the recovery of the thymus (van Kol et al. 2011). Genes upregulated in EL-4 cells were also upregulated in mouse thymus, Jurkat T cells and CTLL-2 cells.

In general, genes affected by TBTO and DON in EL-4 cells are affected in the same direction in other mouse (in vitro) and human lymphocytes and thymocytes. 
a

\begin{tabular}{|c|c|c|}
\hline Species - system & Time & Dose \\
\hline Mouse - in vivo - thymus & $14 \mathrm{~d}$ & $300 \mathrm{mg} / \mathrm{Kg}$ \\
\hline Mouse - in vivo- thymus & $7 \mathrm{~d}$ & $300 \mathrm{mg} / \mathrm{Kg}$ \\
\hline Mouse - in vivo - thymus & $3 d$ & $300 \mathrm{mg} / \mathrm{Kg}$ \\
\hline Mouse - in vitro - thymocytes & $11 \mathrm{~h}$ & $0.5 \mu \mathrm{M}$ \\
\hline Mouse - in vitro - thymocytes & $11 \mathrm{~h}$ & $0.1 \mu \mathrm{M}$ \\
\hline Mouse - in vitro-thymocytes & $6 \mathrm{~h}$ & $1 \mu \mathrm{M}$ \\
\hline Mouse - in vitro- thymocytes & $6 \mathrm{~h}$ & $0.5 \mu \mathrm{M}$ \\
\hline Mouse - in vitro - thymocytes & $6 \mathrm{~h}$ & $0.1 \mu \mathrm{M}$ \\
\hline Mouse - in vitro - thymocytes & $3 \mathrm{~h}$ & $1 \mu \mathrm{M}$ \\
\hline Mouse - in vitro-thymocytes & $3 \mathrm{~h}$ & $0.5 \mu \mathrm{M}$ \\
\hline Mouse - in vitro- thymocytes & $3 \mathrm{~h}$ & $0.1 \mu \mathrm{M}$ \\
\hline Human - in vitro - Jurkat & $6 \mathrm{~h}$ & $0.5 \mu \mathrm{M}$ \\
\hline Human - in vitro - Jurkat & $6 \mathrm{~h}$ & $0.2 \mu \mathrm{M}$ \\
\hline Human - in vitro - Jurkat & $3 \mathrm{~h}$ & $0.5 \mu \mathrm{M}$ \\
\hline Human - in vitro - Jurkat & $3 \mathrm{~h}$ & $0.2 \mu \mathrm{M}$ \\
\hline Mouse - in vitro- CTLL-2 & $6 \mathrm{~h}$ & $0.2 \mu \mathrm{M}$ \\
\hline Mouse - in vitro - CTLL-2 & $6 \mathrm{~h}$ & $0.1 \mu \mathrm{M}$ \\
\hline
\end{tabular}

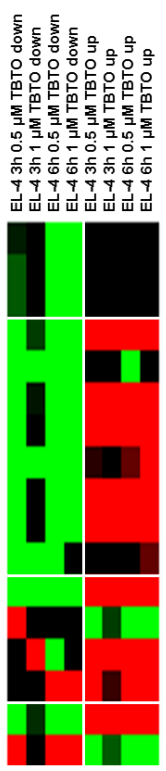

Fig. 4 A significant proportion of genes affected by TBTO or DON in EL-4 cells are also affected by TBTO and DON in the mouse thymus, mouse CTLL-2 cells and in human Jurkat T cells. Sets of genes up- or downregulated by TBTO (a) and DON (b) in EL-4 cells were selected from the present study. Thereafter, GSEA statistics was used to assess whether these gene sets were significantly affected by TBTO or DON in the mouse thymus in vivo or in vitro, mouse CTLL-2 cells and Jurkat cells in vitro using microarray data of previous studies. Scale indicates statistical significance (p-value) of the gene set. Green represents downregulation, red upregulation and black no effect.

\section{Genes involved in ER stress, $T$ cell activation and apoptosis}

The mode of action of TBTO, as identified in human Jurkat T cells (Katika et al. 2012a; Katika et al. 2011) and primary mouse thymocytes (van Kol et al. 2012) includes induction of ER stress, T cell activation and apoptosis. The mode of action of DON as identified in mouse thymus in vivo (van Kol et al. 2011) and Jurkat $\mathrm{T}$ cells includes the induction of ribotoxic stress and RNA related processes followed by ER stress, T cell activation and apoptosis (Katika et al. 2012b; Pestka et al. 2005; Shifrin and Anderson 1999). As summarized in Table 1, TBTO induces ER stress and DON induces ribotoxic stress in EL-4 cells but both compounds do not induce the downstream processes. It is therefore of interest to assess the effects of TBTO and DON on the individual genes of these processes in EL-4 cells and to compare these to the effects in CTLL-2, human Jurkat T cells and for TBTO also in primary mouse thymocytes. 
Table 1. Overview of processes affected by TBTO and DON in this study and previous transcriptomics studies.

\begin{tabular}{c|c|c|c|c}
\hline TBTO & EL-4 (this study) & CTLL-2 & Jurkat & Primary thymocytes \\
\hline ER stress & + & + & + & + \\
\hline T cell activation & 0 & + & + & + \\
\hline Apoptosis & 0 & + & + & + \\
\hline DON & EL-4 (this study) & CTLL-2 & Jurkat & Thymus in vivo \\
\hline Ribotoxic stress & + & + & + & + \\
\hline ER stress & - & - & + & + \\
\hline T cell activation & 0 & - & + & +
\end{tabular}

+ upregulated, - downregulated, 0 not regulated.

As shown in Figure 5a, TBTO affects less genes involved in ER stress, T cell activation or apoptosis in EL-4 cells than in Jurkat cells and primary thymocytes. However, those genes that are affected in EL-4 cells are often affected in the same direction in Jurkat cells and primary thymocytes although most often with a higher induction or repression value. TBTO upregulated the early ER stress marker HERPUD1 (Schulze et al. 2005) in EL-4, CTLL-2 and Jurkat cells, as well as in primary mouse thymocytes (Fig. 5a, panel 1). Other ER stress genes that were convincingly upregulated by TBTO in each of the four cell types were TRIB3, DNA damage inducible transcript 3 (DDIT3, also involved in apoptosis), EIF2AK3, EGR1 and a heat shock protein HSPA4L. Other ER stress genes, like ATF3 and GADD45B, were upregulated in CTLL-2, Jurkat and primary mouse thymocytes but not in EL-4 cells. Only a limited number of genes related to $\mathrm{T}$ cell activation were upregulated in EL-4 cells (BCL6, GEM, FOS, JUN, FOSL2, DUSP1, CD69, CCL4, KLF6, REL, CXCL10 and EGR1) of which CD69 is considered to be an early response T cell activation marker (Ziegler et al. 1994). More genes were upregulated in CTLL-2 and Jurkat cells while TBTO affected the highest number of $\mathrm{T}$ cell activation genes in primary thymocytes. In the process of apoptosis, the number of genes upregulated by TBTO in EL-4 cells was limited to five (NFKBIA, DDIT3, TRIB3, CHAC1 and TNFAIP3). These genes were also upregulated in CTLL-2 $(0.2 \mu \mathrm{M})$, Jurkat $(0.5 \mu \mathrm{M})$ and primary thymocytes $(0.5$ and $1 \mu \mathrm{M})$. Similar to ER stress and T cell activation, TBTO affected more apoptosis-related genes in Jurkat and primary thymocytes than in EL-4 and CTLL-2 cells. The response of the different cell types to TBTO is however more alike than the response to DON.

EL-4, CTLL-2 cells and Jurkat cells differ much more in their response to DON than to that of TBTO (Fig. 5b vs. 5a). The effect of DON on the expression of genes involved in RNA biosynthesis was limited in EL-4 as compared to Jurkat (Fig.5b, panel 1). Two genes that were convincingly upregulated in EL-4 cells are DDX20 and NUPL2. DDX20 was upregulated in all cell models and is involved in alteration of RNA secondary structure (Schutz et al. 2010). Gene NUPL2 is mostly upregulated in EL-4 cells and functions as exporter of mRNA from nucleus to cytoplasm (Narayanan et al. 2011). Genes involved in ER stress were mostly downregulated in EL-4 and CTLL-2 cells. Among the downregulated genes are HERPUD1 and XBP1, that are also downregulated in Jurkat cells. 
Both HERPUD1 and XBP1 are known to be induced by the unfolded protein response (Iwakoshi et al. 2003; Ma and Hendershot 2004; Yoshida et al. 2001). This indicates that the induction of ER stress by DON in Jurkat cells is independent of the unfolded protein response. DDIT3 is the only ER stress related gene that was upregulated by DON in EL-4 cells. In contrast to EL-4 and CTLL-2 cells, multiple ER stress genes were upregulated in Jurkat $\mathrm{T}$ cells. Two genes with the highest upregulation in Jurkat cells were Activating Transcription Factor 3 (ATF3) and Early Growth Factor 1 (EGR-1). ATF3 is induced after ER stress induction and then blocks the cell cycle (Cai et al. 2000). EGR-1 encodes for a transcription factor that is transiently induced after ER stress (Reimertz et al. 2003). This activation then results into cell death by apoptosis (Muthukkumar et al. 1995).

Of the genes involved in T cell activation, only two, KLF10 and TSC22D3, were induced by DON in EL-4 cells. In marked contrast, DON induced approximately half of the genes related to $\mathrm{T}$ cell activation in Jurkat cells. The early $\mathrm{T}$ cell activation marker CD69 was upregulated in Jurkat cells and downregulated in EL-4 and CTLL-2 cells. Most of the genes involved in apoptosis were not affected in EL-4 cells. Exceptions were TRIB3 and CHAC1 that were downregulated and DDIT3 that was upregulated in EL-4 cells. In CTLL-2 cells more apoptosis-related genes were downregulated and only GADD45B was upregulated. The highest number of apoptosis-related genes was upregulated in Jurkat cells. Of these genes HRK, MRPS30 and GZMB are induced by the highest factors. HRK encodes for a protein that induces apoptosis and interacts with the BCL2 survival gene (Inohara et al. 1997). MRPS30 is a mitochondrial ribosomal protein that is associated with programmed cell death (Cavdar Koc et al. 2001a; Cavdar Koc et al. 2001b; Sun et al. 1998). Granzyme B (GZMB) encodes for a serine proteinase that activates cell death pathways (Pinkoski et al. 2001).

Supplementary Figure 3 shows the effects of TBTO on genes involved in ER stress, T cell activation and apoptosis using the same selection criteria as used for DON ( 3 arrays $\geq 2 \log$ 0.7). It is evident that TBTO affects a larger number of genes involved in these processes as compared to DON. Similar as shown in Fig. 5a, the effect on genes involved in ER stress, T cell activation and apoptosis remains limited in EL-4 cells also when using a less stringent cut-off value. 
Chapter 3

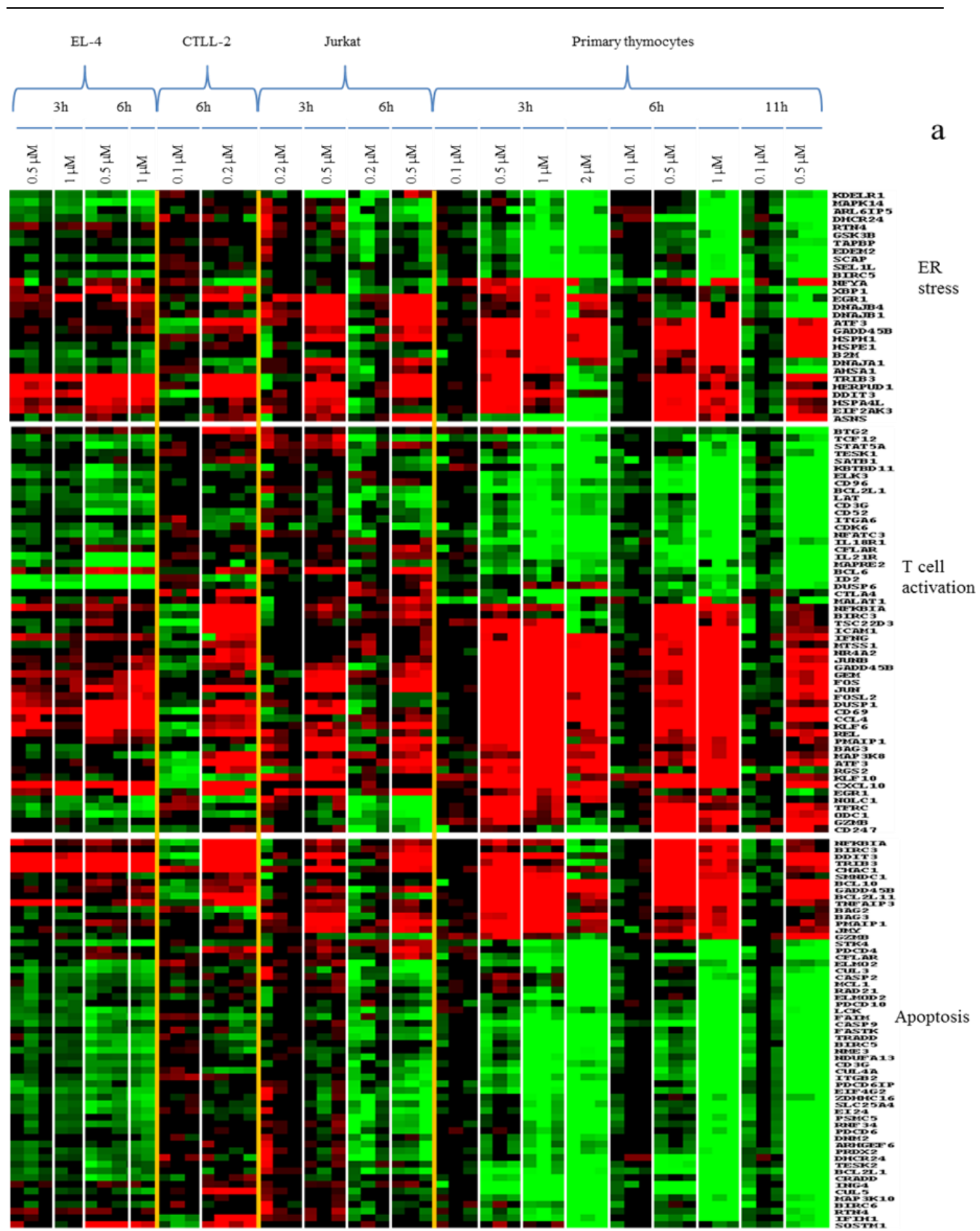


The effects of tributyltin oxide and deoxynivalenol on the transcriptome of the mouse thymoma cell line EL-4

EL-4
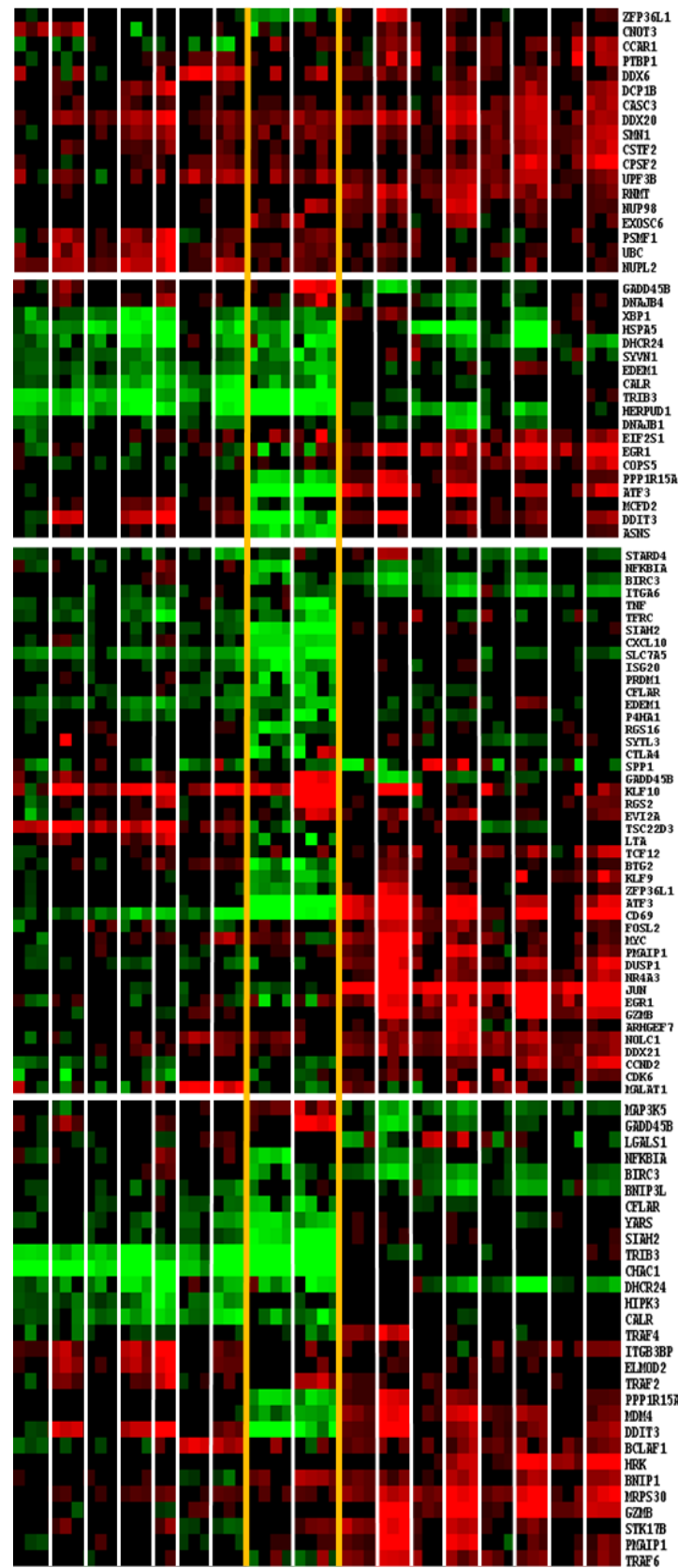

$\mathrm{b}$

RNA biosynthesis

ER stress

$\mathrm{T}$ cell activation

Apoptosis

DHCR24

CBLR

TRRFA
ITCB 3BP

ITCB 3BP
EDIOOD2

TRRF2

PPPIR1

DDIT3

BCLAF1

MRK
BRIP1
BNI

BMIP1
MRPS30

GAB

STK1B 
Fig. 5 Overview of the expression of genes involved in the modes of action of TBTO and DON.

(a) Effect of TBTO on mRNA expression of genes involved in ER stress, T cell activation and apoptosis in mouse EL-4, CTLL-2, human Jurkat, and mouse primary thymocytes. (b) Effect of DON on mRNA expression of genes involved in RNA biosynthesis, ER stress, T cell activation and apoptosis in mouse EL-4, CTLL-2 and human Jurkat T cells. Genes were selected based on a 2 fold up- or downregulation in at least nine arrays (TBTO) or on a 1.6 fold up- or downregulation in at least three arrays (DON). Scale is displayed in bottom right corner of figure 5 b; green: downregulation, red: upregulation, black: no effect.

\section{Overview of the mode of actions of TBTO and DON in EL-4 cells}

As shown in Figure 4, a significant proportion of the genes up or downregulated by TBTO and DON in EL-4 cells were often also up or downregulated by these compounds in the mouse thymus in vivo, mouse thymocytes in vitro and human Jurkat cells. However, pathways that were affected by TBTO in mouse thymus in vivo, mouse thymocytes in vitro and human Jurkat cells were not similarly affected in EL-4 cells. ER stress, oxidative stress, $\mathrm{T}$ cell activation and apoptosis were induced by TBTO in mouse thymus and Jurkat T cells in vivo, but not in EL-4 cells, except the induction of ER stress after $0.5 \mu \mathrm{M}$ TBTO (Fig. 3) (Katika et al. 2012b; van Kol et al. 2011). GSEA showed that DON induces genes that are involved in ribosome biogenesis and assembly and RNA processing in EL-4 cells (Fig. 3, Supplementary Fig. 2), which fits with the classification of DON as a ribotoxic stress inducer (Iordanov et al. 1997; Schmeits et al. 2013; Shifrin and Anderson 1999; van Kol et al. 2011). The induction values of RNA biosynthesis genes is still less convincing as compared to Jurkat cells (Fig. 5b).

The difference between GSEA and individual gene presentation is due to the detection of more subtle effects by GSEA since no initial data filtering is applied. Also, heat maps of GSEA results show the relative expression of the genes without presenting information on the magnitude of the response. The lack of $\mathrm{T}$ cell activation and apoptosis induction for both TBTO and DON, and the lack of ER stress induction in DON exposed EL-4 cells is contrary to previous findings in Jurkat cells and mice experiments (Katika et al. 2012b; Katika et al. 2011; Pestka et al. 2005; van Kol et al. 2012; van Kol et al. 2011). Apparently, DON exposure in EL-4 cells does not induce ER stress related genes which might be due to a lack of molecular hubs that link ribotoxic stress to ER stress. However, it cannot be excluded that DON and TBTO induce ER stress in EL-4 cells at the (post-)translational level. In this regard it is noteworthy that DON induces degradation of HSPA5 protein (alias GRP78) in mouse macrophages (Shi et al. 2009). HSPA5 triggers the UPR that would prevent ER stress (Falahatpisheh et al. 2007). We found HSPA5 to be downregulated as well but at the mRNA level by DON exposure in EL-4 cells, but not by TBTO exposure (Fig 5). However, HSPA5 mRNA is also downregulated by DON in CTLL-2 and Jurkat cells (Fig. 5b) and can thus not explain the fact that ER stress was upregulated in DON exposed Jurkat cells, whereas it was downregulated in EL-4 exposed cells. It can be envisaged that due to this absence of ER stress, the intracellular calcium level does not raise and $\mathrm{T}$ cell activation is averted after exposure to DON. In contrast, TBTO does induce ER stress in EL-4 cells which is due to a direct effect on the ER (Schmeits et al. 2014). However, the ER stress did not proceed into T cell activation and apoptosis in EL-4 cells. 
This is very likely due to the fact that the $\mathrm{T}$ cell activation response is constitutively activated in EL-4 cells due to a mutation in the calcineurin gene (Fruman et al. 1995). The $\mathrm{T}$ cell activation response is also found to be constitutively activated in CTLL-2 cells but this can be attributed to the presence of ConA and IL-2 in the medium. Under this culture condition also this cell line is not able to induce a $\mathrm{T}$ cell activation response upon exposure to DON or TBTO (Schmeits et al. 2013).

\section{Conclusions}

In conclusion, the experiments performed in the present study indicated that there is a substantial overlap in genes affected by TBTO and DON in EL-4 cells with genes affected by these compounds in human Jurkat $\mathrm{T}$ cells, mouse CTLL-2 cells and thymocytes that were exposed in vivo or in vitro (Fig. 4). Nevertheless, more detailed pathway analysis indicated that TBTO and DON induced less processes in EL-4 cells than in Jurkat cells and primary mouse thymocytes. Similar to Jurkat cells and mouse primary thymocytes, TBTO upregulated genes involved in calcium signalling and ER stress in EL-4 cells. However, oxidative stress and apoptosis were downregulated which is contrary to the effects of TBTO in Jurkat cells and primary mouse thymocytes.

DON upregulated cell cycle, RNA related processes and ribosome biogenesis in EL-4 cells, which is indicative for ribotoxic stress induction, and downregulated ER stress, oxidative stress and apoptosis related pathways. The EL-4 results are very similar to those obtained in DON exposed CTLL-2 cells. Before (Schmeits et al. 2013), we hypothesized that CTLL-2 cells might lack genes that play a role in the connection between ribotoxic stress and ER stress. Likely, EL-4 cells lack these genes as well. In addition, both cell lines have a constitutively activated $\mathrm{T}$ cell activation response.

Since the immune system consists of multiple organs and cell types it is of relevance to assess the immunotoxicity of new and existing compounds with a battery of complementary cell systems. Based on the data presented in this study it can be postulated that the mouse thymoma EL-4 cell line model has limited value for in vitro immunotoxicity testing. However, to make a definite decision on the use of EL-4 cells in immunotoxicity testing, more compounds with different modes of action should be screened.

\section{Acknowledgments}

The study is supported by a grant (MFA 6809) that the University of Maastricht received from the Dutch Technology Foundation STW and the Netherlands Toxicogenomics Centre (grant number 05060510). 


\section{Chapter 3}

References

Anderson RS, Brubacher LL, Calvo LM, Burreson EM, Unger MA (1997) Effect of in vitro exposure to tributyltin on generation of oxygen metabolites by oyster hemocytes. Environmental research 74(1):84-90

Baken KA, Arkusz J, Pennings JL, Vandebriel RJ, van Loveren H (2007) In vitro immunotoxicity of bis(tri-nbutyltin)oxide (TBTO) studied by toxicogenomics. Toxicology 237(1-3):35-48 doi:10.1016/j.tox.2007.04.018

Baken KA, Pennings JL, de Vries A, Breit TM, van Steeg H, van Loveren H (2006) Gene expression profiling of Bis(tri-n-butyltin)oxide (TBTO)-induced immunotoxicity in mice and rats. Journal of immunotoxicology 3(4):227-44 doi:10.1080/15476910601023602

Baken KA, Pennings JL, Jonker MJ, et al. (2008) Overlapping gene expression profiles of model compounds provide opportunities for immunotoxicity screening. Toxicol Appl Pharmacol 226(1):46-59

doi:10.1016/j.taap.2007.08.026

Bimczok D, Doll S, Rau H, et al. (2007) The Fusarium toxin deoxynivalenol disrupts phenotype and function of monocyte-derived dendritic cells in vivo and in vitro. Immunobiology 212(8):655-66 doi:S0171-2985(07)00068-X [pii] 10.1016/j.imbio.2007.05.002

Bommhardt U, Beyer M, Hunig T, Reichardt HM (2004) Molecular and cellular mechanisms of T cell development. Cellular and molecular life sciences : CMLS 61(3):263-80 doi:10.1007/s00018-003-3224-3

Cai Y, Zhang C, Nawa T, et al. (2000) Homocysteine-responsive ATF3 gene expression in human vascular endothelial cells: activation of c-Jun NH(2)-terminal kinase and promoter response element. Blood 96(6):2140-8

Canady RA, Coker, R.D., Egan, S.K., Krska, R., Kuiper-Goodman, T., Olsen, M (2001) Deoxynivalenol. Safety evaluation of certain mycotoxins in food. . Joint Expert Committee on Food Additives (JECFA) : WHO Food Additives Series 47

Cavdar Koc E, Burkhart W, Blackburn K, Moseley A, Spremulli LL (2001a) The small subunit of the mammalian mitochondrial ribosome. Identification of the full complement of ribosomal proteins present. The Journal of biological chemistry 276(22):19363-74 doi:10.1074/jbc.M100727200

Cavdar Koc E, Ranasinghe A, Burkhart W, et al. (2001b) A new face on apoptosis: death-associated protein 3 and PDCD9 are mitochondrial ribosomal proteins. FEBS letters 492(1-2):166-70

Corsini E, Roggen EL (2009) Immunotoxicology: opportunities for non-animal test development. Alternatives to laboratory animals : ATLA 37(4):387-97

De Santiago A, Aguilar-Santelises M (1999) Organotin compounds decrease in vitro survival, proliferation and differentiation of normal human B lymphocytes. Human \& experimental toxicology 18(10):619-24

Eisen MB, Spellman PT, Brown PO, Botstein D (1998) Cluster analysis and display of genome-wide expression patterns. Proc Natl Acad Sci U S A 95(25):14863-8

Falahatpisheh H, Nanez A, Montoya-Durango D, Qian Y, Tiffany-Castiglioni E, Ramos KS (2007) Activation profiles of HSPA5 during the glomerular mesangial cell stress response to chemical injury. Cell stress \& chaperones 12(3):209-18

FAO/WHO (2010) Summary Report of the 72nd Meeting of the Joint FAO/WHO Expert Committee on Food Additives (JECFA).

Feske S, Giltnane J, Dolmetsch R, Staudt LM, Rao A (2001) Gene regulation mediated by calcium signals in T lymphocytes. Nature immunology 2(4):316-24 doi:10.1038/86318

Fruman DA, Pai SY, Burakoff SJ, Bierer BE (1995) Characterization of a mutant calcineurin A alpha gene expressed by EL4 lymphoma cells. Molecular and cellular biology 15(7):3857-63

Gorer PA (1950) Studies in antibody response of mice to tumour inoculation. British journal of cancer 4(4):372-9 Grove JF (1988) Non-macrocyclic trichothecenes. Nat Prod Rep 5(2):187-209

Hoch M (2001) Organotin compounds in the environment - an overview. Appl Geochem 16(7-8):719-743

Hofer T, Gerner I, Gundert-Remy U, et al. (2004) Animal testing and alternative approaches for the human health risk assessment under the proposed new European chemicals regulation. Archives of toxicology 78(10):549-64 doi:10.1007/s00204-004-0577-9

Inohara N, Ding L, Chen S, Nunez G (1997) harakiri, a novel regulator of cell death, encodes a protein that activates apoptosis and interacts selectively with survival-promoting proteins Bcl-2 and Bcl-X(L). The EMBO journal 16(7):1686-94 doi:10.1093/emboj/16.7.1686 
Iordanov MS, Pribnow D, Magun JL, et al. (1997) Ribotoxic stress response: activation of the stress-activated protein kinase JNK1 by inhibitors of the peptidyl transferase reaction and by sequence-specific RNA damage to the alpha-sarcin/ricin loop in the 28S rRNA. Molecular and cellular biology 17(6):3373-81

Isebaert S, Haesaert G, Devreese R, Maene P, Fremaut F, Vlaemynck G (2005) Fusarium spp. and Fusarium mycotoxins in maize: a problem for Flanders? Commun Agric Appl Biol Sci 70(3):129-36

Iwakoshi NN, Lee AH, Vallabhajosyula P, Otipoby KL, Rajewsky K, Glimcher LH (2003) Plasma cell differentiation and the unfolded protein response intersect at the transcription factor XBP-1. Nature immunology 4(4):321-9 doi:10.1038/ni907

Kannan K, Senthilkumar, K., Giesy, J.P., (1999) Occurrence of butyltin compounds in human blood. Environmental Science \& Technology 33:1776-1779

Katika MR, Hendriksen PJ, de Ruijter NC, van Loveren H, Peijnenburg A (2012a) Immunocytological and biochemical analysis of the mode of action of bis (tri-n-butyltin) tri-oxide (TBTO) in Jurkat cells. Toxicology letters 212(2):126-36 doi:10.1016/j.toxlet.2012.05.010

Katika MR, Hendriksen PJ, Shao J, van Loveren H, Peijnenburg A (2012b) Transcriptome analysis of the human T lymphocyte cell line Jurkat and human peripheral blood mononuclear cells exposed to deoxynivalenol (DON): New mechanistic insights. Toxicology and applied pharmacology 264(1):51-64 doi:10.1016/j.taap.2012.07.017 Katika MR, Hendriksen PJ, van Loveren H, Peijnenburg A (2011) Exposure of Jurkat cells to bis (tri-n-butyltin) oxide (TBTO) induces transcriptomics changes indicative for ER- and oxidative stress, $\mathrm{T}$ cell activation and apoptosis. Toxicology and applied pharmacology 254(3):311-22 doi:10.1016/j.taap.2011.04.021

Krajnc EI, Wester PW, Loeber JG, et al. (1984) Toxicity of bis(tri-n-butyltin)oxide in the rat. I. Short-term effects on general parameters and on the endocrine and lymphoid systems. Toxicol Appl Pharmacol 75(3):363-86

Lombaert GA, Pellaers P, Roscoe V, Mankotia M, Neil R, Scott PM (2003) Mycotoxins in infant cereal foods from the Canadian retail market. Food Addit Contam 20(5):494-504 doi:10.1080/0265203031000094645 G55W0EN8C29E44LN [pii]

Ma Y, Hendershot LM (2004) Herp is dually regulated by both the endoplasmic reticulum stress-specific branch of the unfolded protein response and a branch that is shared with other cellular stress pathways. The Journal of biological chemistry 279(14):13792-9 doi:10.1074/jbc.M313724200

Muthukkumar S, Nair P, Sells SF, Maddiwar NG, Jacob RJ, Rangnekar VM (1995) Role of EGR-1 in thapsigargin-inducible apoptosis in the melanoma cell line A375-C6. Molecular and cellular biology 15(11):626272

Narayanan MS, Kushwaha M, Ersfeld K, Fullbrook A, Stanne TM, Rudenko G (2011) NLP is a novel transcription regulator involved in VSG expression site control in Trypanosoma brucei. Nucleic acids research 39(6):2018-31 doi:10.1093/nar/gkq950

Neumann D, Martin MU (2001) Interleukin-12 upregulates the IL-18Rbeta chain in BALB/c thymocytes. Journal of interferon \& cytokine research : the official journal of the International Society for Interferon and Cytokine Research 21(8):635-42 doi:10.1089/10799900152547902

Pedersen FdB, J.; Munn, S.; van Leeuwen, K. (2003) Assessment of additional testing needs under REACH Effects of (Q)SARS, risk based testing and voluntary industry initiatives. In. http://ec.europa.eu/enterprise/sectors/chemicals/files/reach/testing_needs-2003_10_29_en.pdf Pellis L, Franssen-van Hal NLW, Burema J, Keijer J (2003) The intraclass correlation coefficient applied for evaluation of data correction, labeling methods, and rectal biopsy sampling in DNA microarray experiments. Physiol Genomics 16(1):99-106 doi:10.1152/physiolgenomics.00111.2003

Pestka JJ (2010) Deoxynivalenol: mechanisms of action, human exposure, and toxicological relevance. Archives of toxicology 84(9):663-79 doi:10.1007/s00204-010-0579-8

Pestka JJ, Uzarski RL, Islam Z (2005) Induction of apoptosis and cytokine production in the Jurkat human T cells by deoxynivalenol: role of mitogen-activated protein kinases and comparison to other 8-ketotrichothecenes.

Toxicology 206(2):207-19 doi:S0300-483X(04)00566-9 [pii] 10.1016/j.tox.2004.08.020

Peters P (2004) Man-Made chemicals in human blood.

Pinkoski MJ, Waterhouse NJ, Heibein JA, et al. (2001) Granzyme B-mediated apoptosis proceeds predominantly through a Bcl-2-inhibitable mitochondrial pathway. The Journal of biological chemistry 276(15):12060-7 doi:10.1074/jbc.M009038200 


\section{Chapter 3}

Rantakokko P, Turunen A, Verkasalo PK, Kiviranta H, Mannisto S, Vartiainen T (2008) Blood levels of organotin compounds and their relation to fish consumption in Finland. The Science of the total environment 399(1-3):90-5 doi:10.1016/j.scitotenv.2008.03.017

Rasmussen PH, Ghorbani F, Berg T (2003) Deoxynivalenol and other Fusarium toxins in wheat and rye flours on the Danish market. Food Addit Contam 20(4):396-404 doi:10.1080/0265203031000082495

W2CODNRN91MGQP2E [pii]

Reimertz C, Kogel D, Rami A, Chittenden T, Prehn JH (2003) Gene expression during ER stress-induced apoptosis in neurons: induction of the BH3-only protein Bbc3/PUMA and activation of the mitochondrial apoptosis pathway. The Journal of cell biology 162(4):587-97 doi:10.1083/jcb.200305149

Rocha O, Ansari K, Doohan FM (2005) Effects of trichothecene mycotoxins on eukaryotic cells: a review. Food Addit Contam 22(4):369-78 doi:RJ50431603572613 [pii]

$10.1080 / 02652030500058403$

Schmeits PC, Katika MR, Peijnenburg AA, van Loveren H, Hendriksen PJ (2014) DON shares a similar mode of action as the ribotoxic stress inducer anisomycin while TBTO shares ER stress patterns with the ER stress inducer thapsigargin based on comparative gene expression profiling in Jurkat T cells. Toxicol Lett 224(3):395-406 doi:10.1016/j.toxlet.2013.11.005

Schmeits PC, Volger OL, Zandvliet ET, van Loveren H, Peijnenburg AA, Hendriksen PJ (2013) Assessment of the usefulness of the murine cytotoxic T cell line CTLL-2 for immunotoxicity screening by transcriptomics. Toxicol Lett 217(1):1-13 doi:10.1016/j.toxlet.2012.12.005

Schulze A, Standera S, Buerger E, et al. (2005) The ubiquitin-domain protein HERP forms a complex with components of the endoplasmic reticulum associated degradation pathway. Journal of molecular biology 354(5):1021-7 doi:10.1016/j.jmb.2005.10.020

Schutz P, Wahlberg E, Karlberg T, et al. (2010) Crystal structure of human RNA helicase A (DHX9): structural basis for unselective nucleotide base binding in a DEAD-box variant protein. Journal of molecular biology 400(4):768-82 doi:10.1016/j.jmb.2010.05.046

Severino L, Luongo D, Bergamo P, Lucisano A, Rossi M (2006) Mycotoxins nivalenol and deoxynivalenol differentially modulate cytokine mRNA expression in Jurkat T cells. Cytokine 36(1-2):75-82 doi:S1043-

4666(06)00314-0 [pii]

10.1016/j.cyto.2006.11.006

Shaffer AL, Rosenwald A, Hurt EM, et al. (2001) Signatures of the immune response. Immunity 15(3):375-85

Shao J, Katika MR, Schmeits PC, et al. (2013) Toxicogenomics-based identification of mechanisms for direct immunotoxicity. Toxicological sciences : an official journal of the Society of Toxicology

doi:10.1093/toxsci/kft151

Shi Y, Porter K, Parameswaran N, Bae HK, Pestka JJ (2009) Role of GRP78/BiP degradation and ER stress in deoxynivalenol-induced interleukin-6 upregulation in the macrophage. Toxicological sciences : an official journal of the Society of Toxicology 109(2):247-55 doi:10.1093/toxsci/kfp060

Shifrin VI, Anderson P (1999) Trichothecene mycotoxins trigger a ribotoxic stress response that activates c-Jun Nterminal kinase and p38 mitogen-activated protein kinase and induces apoptosis. The Journal of biological chemistry 274(20):13985-92

Skinner MA, Sambhara SR, Benveniste P, Miller RG (1992) Characterization of alpha beta+ CD4- CD8- CTL lines isolated from mixed lymphocyte cultures of adult mouse spleen cells. Cellular immunology 139(2):375-85 Subramanian A, Tamayo P, Mootha VK, et al. (2005) Gene set enrichment analysis: A knowledge-based approach for interpreting genome-wide expression profiles. Proceedings of the National Academy of Sciences of the United States of America 102(43):15545-15550 doi:10.1073/pnas.0506580102

Sun L, Liu Y, Fremont M, et al. (1998) A novel $52 \mathrm{kDa}$ protein induces apoptosis and concurrently activates c-Jun N-terminal kinase 1 (JNK1) in mouse C3H10T1/2 fibroblasts. Gene 208(2):157-66

Tutelyan VA (2004) Deoxynivalenol in cereals in Russia. Toxicol Lett 153(1):173-9

doi:10.1016/j.toxlet.2004.04.042

S0378427404002577 [pii]

Ueno Y (1987) Trichothecenes in food Mycotoxin in food. Academic press, New York, p 123-147 
van Kol SW, Hendriksen PJ, van Loveren H, Peijnenburg A (2012) Transcriptomics analysis of primary mouse thymocytes exposed to bis(tri-n-butyltin)dioxide (TBTO). Toxicology 296(1-3):37-47

doi:10.1016/j.tox.2012.03.002

van Kol SWM, Hendriksen PJM, van Loveren H, Peijnenburg A (2011) The effects of deoxynivalenol on gene expression in the murine thymus. Toxicology and applied pharmacology 250(3):299-311

Varga G, Dreikhausen U, Kracht M, Appel A, Resch K, Szamel M (1999) Molecular mechanisms of T

lymphocyte activation: convergence of T cell antigen receptor and IL-1 receptor-induced signaling at the level of IL-2 gene transcription. International immunology 11(11):1851-62

Whalen MM, Loganathan BG, Kannan K (1999) Immunotoxicity of environmentally relevant concentrations of butyltins on human natural killer cells in vitro. Environmental research 81(2):108-16 doi:10.1006/enrs.1999.3968 Yoshida H, Matsui T, Yamamoto A, Okada T, Mori K (2001) XBP1 mRNA is induced by ATF6 and spliced by IRE1 in response to ER stress to produce a highly active transcription factor. Cell 107(7):881-91

Zhou HR, Islam Z, Pestka JJ (2003) Rapid, sequential activation of mitogen-activated protein kinases and transcription factors precedes proinflammatory cytokine mRNA expression in spleens of mice exposed to the trichothecene vomitoxin. Toxicological sciences : an official journal of the Society of Toxicology 72(1):130-42 Ziegler SF, Levin SD, Johnson L, et al. (1994) The mouse CD69 gene. Structure, expression, and mapping to the NK gene complex. Journal of immunology 152(3):1228-36 



\section{Chapter 4}

\section{Assessment of the usefulness of the murine cytotoxic $T$ cell line CTLL-2 for immunotoxicity screening by transcriptomics}

Peter C J Schmeits, Oscar L Volger, Ella T Zandvliet, Henk van Loveren, Ad A C M Peijnenburg, and Peter J M Hendriksen

Toxicology Letters 12/2012

Supplementary material can be found at:

http://www.sciencedirect.com/science/article/pii/S0378427412014233 


\begin{abstract}
A toxicogenomics approach was applied to assess the usefulness of the mouse cytotoxic $\mathrm{T}$ cell line CTLL-2 for in vitro immunotoxicity testing. CTLL-2 cells were exposed for six hours to two model immunotoxic compounds: 1) the mycotoxin deoxynivalenol (DON, 1 and $2 \mu \mathrm{M}$ ), a ribotoxic stress inducer, and 2) the organotin compound tributyltin oxide (TBTO, 100 and $200 \mathrm{nM}$ ), an endoplasmic reticulum (ER) stress inducer. Effects on wholegenome mRNA expression was assessed by microarray analysis. The biological interpretation of the microarray data indicated that TBTO $(200 \mathrm{nM})$ induced genes involved in $\mathrm{T}$ cell activation, ER stress, NFאB activation and apoptosis, which agreed very well with results obtained before on TBTO exposed Jurkat cells and mouse primary thymocytes. Remarkably, DON $(2 \mu \mathrm{M})$ downregulated genes involved in $\mathrm{T}$ cell activation, ER stress and apoptosis, which is opposite to results obtained before for DON-exposed Jurkat cells and mouse primary thymocytes. Furthermore, the results for DON in CTLL-2 cells are also opposite to the results obtained for TBTO in CTLL-2 cells. In agreement with the lack of induction of ER stress and apoptosis, viability assays showed that CTLL-2 cells are much more resistant to the toxicity of DON than Jurkat cells and primary thymocytes. We propose that CTLL-2 cells lack the signal transduction that induces ER stress and apoptosis in response to ribotoxic stress. Based on the results for TBTO and DON, the CTLL-2 cell line does not yield an added value for immunotoxicity compared to the human Jurkat $\mathrm{T}$ cell line.
\end{abstract}




\section{Introduction}

Animal models are presently used as the first choice in regulatory immunotoxicity testing. REACH, the European Community Regulation on Chemicals and their safe use, aims to collect information about new chemicals, and re-evaluate all existing chemicals for their toxicity risks. Since animal experiments in vivo have ethical concerns, are labour- and timeintensive, expensive and have a limited predictability for human toxicity, the focus within current immunotoxicity research lies on developing in vitro alternatives (Corsini and Roggen, 2009). The FDA defines immunotoxicity as unintended immunosuppression or enhancement of the immune system (Food and Drug Administration, 2006). In a recent paper, the state of the art of testing of toxicity of chemicals to the immune system is discussed, advocating the use of 'omics' techniques in in vitro testing (Lankveld et al., 2010). The immunological response involves many different cell types. An important question, therefore, is how many different immune cell types and cell lines have to be included for immunotoxicity testing to cover a wide range of immunotoxic modes of action. Therefore, it is important to explore the responses of different immune cell types to immunotoxic compounds. In previous studies we assessed the whole genome mRNA response of the human Jurkat $\mathrm{T}$ cell line, human PBMCs, mouse thymocytes in vitro as well as mouse and rat thymus in vivo to deoxynivalenol (DON) and/or tributyltin oxide (TBTO). The biological interpretation of these data put forward pathways and processes affected by DON and TBTO leading to more insight in the modes of actions of these toxicants (Baken et al., 2007; Baken et al., 2006; Baken et al., 2008; Katika et al., 2012a; Katika et al., 2012b; Katika et al., 2011; van Kol et al., 2011, 2012).

The present study aimed to test whether the mouse cytotoxic T cell line CTLL-2 is a useful additional model system to predict immunotoxicity of chemicals. The CTLL-2 cell line was selected for three reasons. Firstly, we anticipated that this cell line might produce responses that are specific for cytotoxic $\mathrm{T}$ lymphocytes or specific for this cell line due to (epi)genetic or chromosomal alterations. Secondly, the CTLL-2 cell line originates from a C57BL/6 mouse which is a commonly used mouse strain in animal testing. Thirdly, the inclusion of a mouse cell line enables to perform a so-called parallelogram approach. This parallelogram approach aims to predict human in vivo effects based on comparing mouse in vitro data with mouse in vivo and human in vitro data (Lankveld et al. (2010). The rationale is that when a compound elicits the same effects human in vitro, mouse in vitro and mouse in vivo, these effects will likely also be induced human in vivo. For these reasons, we exposed CTLL-2 cells to DON and TBTO followed by whole-genome transcriptomics analysis, and compared the effects on CTLL-2 cells to those on human immune cells in vitro, mouse or rat immune cells in vivo and mouse immune cells in vitro obtained previously (Baken et al., 2006; Katika et al., 2012b; Katika et al., 2011; van Kol et al., 2011, 2012). The availability of data of previous studies enabled to compare the effects of DON and TBTO on CTTL-2 cells vs. other immune cells both on mechanisms of action and on effects on individual genes. 
DON and TBTO are contaminants in food, and there is a continuous exposure to both. Whereas direct evidence of immunotoxic effects of exposure is lacking, due to the relatively low exposure and the limited number of epidemiological studies performed, there is abundant circumstantial information that the immune system in humans is influenced by these contaminants (Baken et al., 2007; Katika et al., 2012a; Katika et al., 2012b; Katika et al., 2011; van Kol et al., 2011, 2012). Higher levels of DON are also toxic to other cell types like liver or kidney, but immune cells are more sensitive (Dinu et al., 2011; Konigs et al., 2008).

DON is a common contaminant of wheat and corn causing humans to be almost continuously exposed to low levels of this mycotoxin through their diet (Bimczok et al., 2007; Rasmussen et al., 2003; Severino et al., 2006). DON acts on the cells of the spleen, thymus and bone marrow (Pestka et al., 2005; Pestka et al., 2004). Induction of apoptosis was reported in the Jurkat cell line by Pestka et al. (2005) and inhibition of proliferation was reported in human peripheral blood lymphocytes (Thuvander et al., 1999). Previous studies tested the effect of DON on the thymus of C57BL/6 mice in vivo (van Kol et al., 2011) and on human Jurkat T cells and PBMCs in vitro (Katika et al., 2012b). In the murine thymus, DON represses processes of proliferation, mitochondrial function, protein synthesis and ribosomal protein assembly and induces ER stress, T cell activation and apoptosis (van Kol et al., 2011). In Jurkat cells, DON upregulates genes involved in ER and oxidative stress, ribosome structure and function, calcium mediated signalling, mitochondrial function, $\mathrm{T}$ cell activation, apoptosis, RNA/protein synthesis and processing and NFAT and NFkB/TNF- $\alpha$ pathways (Katika et al., 2012b).

TBTO is an organotin compound which has been used extensively in industry for the preservation of wood and as anti-fouling agent in ship paint and is therefore a widespread environmental contaminant (Hoch, 2001). In rats, tributyltin has been classified as an immunotoxic agent (Snoeij et al., 1985). The thymus is the primary target organ of TBTO where it causes peripheral T-cell depletion due to inhibition of proliferation and induction of apoptosis (Krajnc et al., 1984). Inhibition of proliferation was also reported in human and mouse in vitro and mouse in vivo studies (Baken et al., 2006; Baken et al., 2008; Snoeij et al., 1988; Van Loveren et al., 1990; Vandebriel et al., 1998; Vos et al., 1984; Whalen et al., 2002). A number of studies have been performed to gain more insight into the mechanism by which TBTO induces apoptosis. Early studies described effects of organotin compounds on the inhibition of oxidative phosphorylation (Aldridge, 1958; Aldridge and Street, 1964, 1970; Evans et al., 1979; Rosenberg et al., 1984; Rosenberg et al., 1980). In rats in vivo, tributyltin causes DNA damage in blood cells and elevated reactive oxygen species levels in the liver (Liu et al., 2006). In human and rat thymocytes in vitro, TBTO causes inhibition of DNA synthesis (Seinen et al., 1979; Snoeij et al., 1986). More recently, microarray studies on mice showed that TBTO induces oxidative stress and apoptosis in the thymus in vivo (Baken et al., 2008) and upregulates genes involved in ER stress, NFkB and TNF $\alpha$ pathways, DNA damage, p53 signalling and apoptosis in mouse primary thymocytes in vitro (van Kol et al., 2012). TBTO also induces ER stress, oxidative stress, $\mathrm{T}$ cell 
activation and apoptosis in Jurkat cells as demonstrated by microarray analysis and biochemical experiments by Katika et al (2011).

Here we describe experiments using DNA microarrays on mRNA of CTLL-2 cells that were exposed to subcytotoxic concentrations of DON and TBTO. The responses in mRNA expression of the CTTL-2 cells were compared to expression data obtained in previous studies using mice thymuses in vivo (DON and TBTO) (Baken et al., 2006; van Kol et al., 2011), primary mouse thymocytes in vitro (TBTO) (van Kol et al., 2012) and human Jurkat T cells (DON and TBTO) (Katika et al., 2012b; Katika et al., 2011).

The goal of these experiments and comparisons was to assess the usefulness of the mouse CTLL-2 cell line for immunotoxicity research. To our knowledge, this is the first study to apply transcriptomics analysis to CTLL-2 cells.

\section{Materials and methods}

\section{Cell culture}

CTLL-2 cells were obtained from the American Type Culture Collection (ATCC) and cultured in RPMI 1640 medium, containing HEPES with 10\% heat-inactivated Fetal Bovine Serum (FBS), $100 \mathrm{U} / \mathrm{ml}$ Penicillin, and $100 \mu \mathrm{g} / \mathrm{ml}$ streptomycin, 1\% sodium pyruvate, $1 \%$ non-essential amino acids (Invitrogen Life Science, Breda, The Netherlands) and $10 \%$ rat IL-2 with ConA (BD Bioscience, Breda, The Netherlands). Cells were cultured in $75 \mathrm{~cm}^{2}$ flasks at a concentration of $2.0 \times 10^{5}$ cells $/ \mathrm{mL}$ in an incubator at $37^{\circ} \mathrm{C}\left(5 \% \mathrm{CO}_{2}\right.$, $20 \% \mathrm{O}_{2}$ ). Medium was refreshed three times a week.

\section{Viability assays}

Two assays were applied for determining the viability of CTLL-2 cells, based either on mitochondrial activity (WST-1, Roche Diagnostics GmbH, Germany) or on intracellular ATP content (ATPlite, Perkin Elmer). WST-1 (4-[3-(4-iodophenyl)-2-(4-nitrophenyl)-2H5-tetrazolio]-1,3-benzene disulfonate) is a water soluble tetrazonium salt which is cleaved by mitochondrial dehydrogenases to form a coloured formazan complex. The amount of formazan correlates to the viability of the cells. The WST-1 assay was performed as previously described (Katika et al., 2011), and the ATPLite assay was performed according to the manufacturer's protocol. Luminescence $(\lambda=590 \mathrm{~nm})$ and optical densities (450 and $630 \mathrm{~nm}$ ) were quantified as readouts for the ATPLite and WST-1 assays, respectively, by using a plate reader (Synergy ${ }^{\text {TM }}$ HT Multi-Detection Microplate Reader, BioTek instruments, Winooski, VT). Viability was measured after 6 or $24 \mathrm{~h}$ incubation and both WST-1 and ATPlite assays were performed at least three times.

\section{Chemical Exposures}

CTLL-2 cells were seeded one day before the exposure at a concentration of $0.25 \times 10^{6}$ cells/ml in a 6-well plate with $2.7 \mathrm{~mL}$ of cells per well. Just prior to the exposure, stock solutions of 1 or $2 \mathrm{mM}$ deoxynivalenol (CAS 51481-10-8, Sigma), 100 or $200 \mu \mathrm{M}$ bis [tri- 
n-butyltin] oxide (CAS 56-35-9, 96\% purity, Sigma) or pure Dimethylsulfoxide (DMSO, CAS 67-68-5, Merck) were diluted 100 times with medium and $300 \mu \mathrm{L}$ of these mixtures were added to the cells. The final DMSO concentration did not exceed $0.1 \%$ which has no effect on cell viability. CTLL-2 cells were exposed for $6 \mathrm{~h}$ in a $\mathrm{CO}_{2}$ incubator at $37{ }^{\circ} \mathrm{C}$. CTLL-2 cells were exposed at four different passage numbers (ranging between passages 11 to 18 ).

\section{RNA isolation}

After exposure the cells were centrifuged for $5 \mathrm{~min}$ at $1600 \mathrm{rpm}$ and $4{ }^{\circ} \mathrm{C}$, and the pellet was resuspended in $600 \mu \mathrm{L}$ RLT buffer (Qiagen, Venlo, the Netherlands) containing $1 \% \beta$ Mercaptoethanol ( $\beta$-ME, Invitrogen Life Science) and stored at $-80^{\circ} \mathrm{C}$ until RNA isolation. Samples in RLT buffer were put on QIAshredder columns (Qiagen) and centrifuged for 2 min at $15000 \mathrm{~g}$. The flow through was mixed and homogenized with $70 \%$ ethanol and put onto miRNeasy columns (Qiagen). RNA isolation including DNase treatment was performed according to manufacturer's protocol (Qiagen). RNA was eluted with warmed $\left(45{ }^{\circ} \mathrm{C}\right)$ RNase free water. RNA concentration, integrity and purity were assessed spectrophotometrically at wavelengths of 230, 260 and $280 \mathrm{~nm}$ (Nanodrop, Wilmington, DE) and by virtual gel electrophoresis (Experion, Biorad, Veenendaal, The Netherlands).

\section{Microarray analysis}

100 ng total RNA was used to synthesize biotin-labelled cRNA (3'IVT-Express Labelling Kit, Affymetrix). $7.5 \mu \mathrm{g}$ cRNA was used for fragmentation reactions and subsequently this cRNA was denaturized. The fragmented cRNA with a concentration of $0.0375 \mu \mathrm{g} / \mu \mathrm{l}$ was utilized for hybridization on Affymetrix Hy MG 430 array plates (HWS kit, Affymetrix). The array plates were scanned using the Affymetrix GeneTitan scanner. One sample (TBTO $100 \mathrm{nM}$, replicate 4) was taken out of the analysis due to technical failure.

\section{Data Analysis}

Custom CDF files were generated from the raw data by using the $\mathrm{R}$ package available at http://brainarray.mbni.med.umich.edu/Brainarray/Database/CustomCDF/14.1.0/entrezg.asp - Robust multichip average (RMA) normalization was applied to the complete dataset (BioConductor). Quality control was applied to the microarray data by using BioConductor packages (www.arrayanalysis.org). Spot intensities were floored to 12 and $2 \log$ ratios were calculated versus the DMSO control of the same biological replicate. Hereby, all DMSO control values were set to zero.

Limma analysis, as advocated by Jeanmougin et al. (2010), was used to assess the number of genes altered by each exposure condition. Gene expression changes were considered significant when q-value was $<0.01$ and fold change $>|1.4|$. Hierarchical clustering was performed with the programs Cluster (uncentered correlation; average linkage clustering) and Treeview (Eisen et al., 1998). Selection of genes for hierarchical clustering was based on fold change $>|1.6|$ vs. the respective control sample (0.1\% DMSO) in at least 3 out of 15 
arrays. Red and green indicate up- and down-regulation vs. average expression of control samples. Pathway analysis was performed on genes within clusters using Metacore software (GeneGo, St. Joseph, MI).

\section{Gene Set Enrichment Analysis}

Gene Set Enrichment Analysis (GSEA) is a statistical analysis tool for microarray data, used to detect biological processes affected and to provide insight into the affected molecular mechanisms. GSEA makes use of predefined gene sets that are based on previous experimental results and literature. GSEA ranks all the genes on their expression ratios and determines whether a particular gene set is significantly enriched at the top or the bottom of the ranked list (Subramanian et al., 2005). The following gene set collections were used in this study:

- Lymphocyte database: gene sets were taken over from Shaffer et al. (2001). A proportion of these gene sets are based on results from expression profiling studies on lymphocytes.

- Biocarta-2: publically available gene sets from (http://www.biocarta.com/).

- Gene Ontology: publically available gene sets from (http://www.geneontology.org/).

- Tox action (self-made): gene sets were selected from microarray studies on toxic action of compounds.

- Cell cycle: gene sets were taken from studies Bar-Joseph et al. and Whitfield et al. in which cells were first synchronized at the G0 phase and then stimulated to enter the cell cycle. Microarray analysis was performed to detect genes upregulated during certain cell cycle stages. Up- or down-regulation of these gene sets is indicative for a higher or lower proliferation rate (Bar-Joseph et al., 2008; Whitfield et al., 2002).

- DON in vivo: Genes up- or down-regulated by DON in the mouse thymus in vivo (van Kol et al., 2011).

Furthermore, gene sets were created from genes affected in the present CTLL-2 study according to limma analysis. Using GSEA statistics, we then tested whether these gene sets were also affected in previous microarray studies on primary mouse thymocytes exposed in vitro to TBTO (van Kol et al., 2012), mouse thymuses exposed in vivo to DON (van Kol et al., 2011) or TBTO (Baken et al., 2006) and Jurkat cells exposed in vitro to DON or TBTO (Katika et al., 2012a; Katika et al., 2011). The results of these comparisons are visualized in heat maps of gene sets in which green and red indicate downregulation and upregulation, respectively. Brighter colours represent a higher significance level. A full green or red colour indicates $\mathrm{p}<0.0001$. 


\section{Molecular Concept Analysis}

Molecular concept analysis enables to visualize networks in which the overlap between gene sets based on co-occurrence of genes is shown (Rhodes et al., 2007). This overlap was calculated based on the genes that were responsible for a gene set to be significantly affected. For this, either the top $10 \%$ of the genes upregulated or the top $10 \%$ of the genes downregulated was used. To reduce complexity of the figures, criteria for gene sets to be significant for molecular concepts mapping were more stringent than used for making heat maps. Gene sets were selected on a p value $<0.01$ in combination with an FDR value $<0.1$ according to GSEA statistics. In addition, gene sets containing $<7$ genes were excluded from the analysis. The significance of overlap between the gene sets was calculated based on the binomial distribution using Venn-Mapper (Smid et al., 2003). Gene sets showing significant overlap ( $Z$ value $\geq 3$ that is equal to $p<0.00001$ ) were connected in a network that was visualized using Cytoscape(Shannon et al., 2003). An overview of the gene sets used in molecular concept analysis, their gene set collection and the number of genes that are present in the CTLL-2 data from those gene sets is presented in Supplementary Table 1.

\section{Heat maps of effects on genes involved in Apoptosis, ER stress and T cell activation}

A set of apoptosis-related genes was taken from Gene Ontology (http://www.geneontology.org); a set of genes involved in ER stress was taken from KEGG, Biocarta and from literature mining. Genes upregulated during $\mathrm{T}$ cell activation were taken from the lymphocyte database (Feske et al., 2001; Shaffer et al., 2001). Genes were then filtered on $\geq 1$.6-fold up- or down regulation vs. the average of the controls in $\geq 3$ of 15 arrays in our CTLL-2 experiments. Per gene set, the effects of DON and TBTO in both CTLL-2 and Jurkat cells were visualized in one heat map using the programs cluster and Treeview (Eisen et al., 1998). Some genes are present in two or three of the processes and are therefore present in multiple heat maps. Red and green indicate up- and downregulation vs. the average of the control samples.

\section{Relative expression of genes in unexposed cells}

The relative expression in CTLL-2 cells and Jurkat cells of the genes in the processes of T cell activation were calculated using the average intensity of unexposed cells. Approximately $45 \%$ of the genes that were considered not expressed and floored were put on $0 \%$. The remaining $55 \%$ of the genes that are considered to be expressed were ranked on expression between 0 and $100 \%$. A difference in rank of $20 \%$ or more was taken as threshold for much higher or lower expression level between Jurkat and CTLL-2 cells. Genes upregulated during $\mathrm{T}$ cell activation were taken from the lymphocyte database (Tcell_PIind4x_Fig6_4xup_by_activ_after_3h) (Feske et al., 2001; Shaffer et al., 2001).

\section{$q R T-P C R$}

The expression levels of six genes were measured by qRT-PCR in CTLL-2 cells. Primers were designed using Beacon designer 7 (Premier Biosoft International, Palo Alto, CA), 
close to poly-A tails and intron spanning where possible. The primer sequences are given in Table 1. One microgram RNA was converted to cDNA using the miScript cDNA synthesis kit (Qiagen). A minus reverse transcriptase reaction was included as a control for genomic DNA contamination. qRT-PCR was performed on Bio-Rad CFX96 real time detection system (Veenendaal, the Netherlands). Reactions consisted of $2 \mu 1$ cDNA, $8.5 \mu 1$ SYBRgreen super mix, $2.5 \mu 1 \mathrm{RNase}$ free water, $1 \mu \mathrm{Fw}$ and $1 \mu 1 \mathrm{Rv}$ primer.qRT-PCR was performed as follows: $3 \mathrm{~min}$ at $95^{\circ} \mathrm{C}$ and 45 cycles of amplification. Settings were $10 \mathrm{sec}$ at $95^{\circ} \mathrm{C}, 30 \mathrm{sec}$ at $60{ }^{\circ} \mathrm{C}$. After the last cycle the PCR reaction was extended with $10 \mathrm{sec}$ at 95 ${ }^{\circ} \mathrm{C}$. Relative expression levels were calculated using Bio-Rad CFXmanager v2.0. Three reference genes were used, Actb, Hprt1 and Lgals1. These reference genes were not regulated upon exposure to DON or TBTO, as concluded from the microarray experiments. 
Table 1. Primer sequences for genes used in qRT-PCR verification experiments.

\begin{tabular}{|c|c|c|c|c|}
\hline $\begin{array}{c}\text { Accession } \\
\text { number }\end{array}$ & Gene & Gene Name & Sense primer $5^{\prime}-3^{\prime}$ & $\begin{array}{c}\text { Antisense } \\
\text { primer 5'-3, }\end{array}$ \\
\hline NM_007393 & Actb & Actin, beta & $\begin{array}{c}\text { TCCACACCCGCCACC } \\
\text { AGTTC }\end{array}$ & $\begin{array}{c}\text { CCTTCTGACC } \\
\text { CATTCCCACC } \\
\text { ATC }\end{array}$ \\
\hline NM_007498 & Atf3 & $\begin{array}{c}\text { Activating } \\
\text { transcription factor } 3\end{array}$ & $\begin{array}{c}\text { AATTGCTGCTGCCAA } \\
\text { GTGTCG }\end{array}$ & $\begin{array}{l}\text { CTCCGTGCCA } \\
\text { CCTCTGCTTA }\end{array}$ \\
\hline NM_026929 & Chac1 & $\begin{array}{l}\text { Cation transport } \\
\text { regulator-like } 1 \text { (E. } \\
\text { coli) }\end{array}$ & $\begin{array}{c}\text { GAGACACCTTCCATA } \\
\text { GGG }\end{array}$ & $\begin{array}{l}\text { GAACTTGGT } \\
\text { ATGCCACAC }\end{array}$ \\
\hline NM_007837 & Ddit3 & $\begin{array}{c}\text { DNA-damage } \\
\text { inducible transcript } 3\end{array}$ & $\begin{array}{c}\text { AGTCCCTGCCTTTCA } \\
\text { CCTTGG }\end{array}$ & $\begin{array}{c}\text { TGCTCTTCCT } \\
\text { CCTCTTCCTC } \\
\text { CTG }\end{array}$ \\
\hline NM_013556 & Hprt1 & $\begin{array}{c}\text { Hypoxanthine guanine } \\
\text { phosphoribosyl } \\
\text { transferase }\end{array}$ & $\begin{array}{c}\text { TGGGCTTACCTCACT } \\
\text { GCTTTCC }\end{array}$ & $\begin{array}{c}\text { CCTGGTTCAT } \\
\text { CATCGCTAAT } \\
\text { CACG }\end{array}$ \\
\hline NM_008495 & Lgals & $\begin{array}{l}\text { Lectin, galactose } \\
\text { binding, soluble } 1\end{array}$ & $\begin{array}{c}\text { CCCATAATCCAGCCC } \\
\text { TTTC } \\
\end{array}$ & $\begin{array}{l}\text { ATGTGTTCTT } \\
\text { GGTCTCAGTG }\end{array}$ \\
\hline NR_029382 & Mir17hg & $\begin{array}{c}\text { MIR17 host gene } 1 \\
\text { (non-protein coding) } \\
\text { (Mir17hg), non-coding } \\
\text { RNA }\end{array}$ & $\begin{array}{c}\text { ACCAGTGTTACGGAT } \\
\text { TGAATGCTAC }\end{array}$ & $\begin{array}{c}\text { AAGTGCGTT } \\
\text { GCTGCGTGA } \\
\text { AG }\end{array}$ \\
\hline NM_010907 & Nfikbia & $\begin{array}{l}\text { Nuclear factor of } \\
\text { kappa light } \\
\text { polypeptide gene } \\
\text { enhancer in B-cells } \\
\text { inhibitor }\end{array}$ & $\begin{array}{c}\text { CTTGGTGACTTTGGG } \\
\text { TGCTGATG }\end{array}$ & $\begin{array}{c}\text { GGGAGTAGC } \\
\text { CTTGGTAGGT } \\
\text { TAC }\end{array}$ \\
\hline NM_175093 & Trib3 & $\begin{array}{c}\text { Tribbles homolog } 3 \\
\text { (Drosophila) }\end{array}$ & $\begin{array}{c}\text { ATCCTACTCTGGCAA } \\
\text { AGC }\end{array}$ & $\begin{array}{l}\text { TCGTGGAAT } \\
\text { GGGTATCTG }\end{array}$ \\
\hline
\end{tabular}

\section{Results}

\section{Cell viability measurements}

Two assays were applied for determining the viability of CTLL-2 cells, based on either mitochondrial activity (WST-1) or intracellular ATP content (ATPlite). The most sensitive of the two assays is used to determine subcytotoxic concentrations of DON and TBTO in CTLL-2 cells. The viability of CTLL-2 cells was not affected by $6 \mathrm{~h}$ exposure to DON concentrations up to the highest dose of $5 \mu \mathrm{M}$ (Fig. 1a). Exposure for 24 h to $1 \mu \mathrm{M}$ DON induced a reduction of viability of approximately 20\%. Remarkably, viability did not reduce much further when CTLL-2 cells were exposed for $24 \mathrm{~h}$ to concentrations of DON up to $5 \mu \mathrm{M}$ DON according to both the ATPlite and WST-1 assay. For exposure to TBTO concentrations from $200 \mathrm{nM}$ onwards, the ATPlite assay determined lower viabilities than the WST-1 assay (Fig 1b). Exposure to $100 \mathrm{nM}$ TBTO did not affect the viability after $6 \mathrm{~h}$ and reduced the viability of CTLL-2 cells to approximately $80 \%$ (both WST-1 and ATPlite) 
after 24 h. $200 \mathrm{nM}$ TBTO reduced the viability to $80 \%$ after $6 \mathrm{~h}$ and $40 \%$ after $24 \mathrm{~h}$, as measured with ATPlite assays. However, based on WST-1 assays, $200 \mathrm{nM}$ TBTO did not change viability after $6 \mathrm{~h}$ and reduced viability to $64 \%$ after $24 \mathrm{~h}$.

Doses for exposures for microarray experiments were chosen on the same criteria as done in our previous experiments on Jurkat cells and primary thymocytes: the lower dose was selected on induction of approximately $20 \%$ decrease of viability after $24 \mathrm{~h}$ exposure, and a 2-fold higher concentration was taken as second dose (Katika et al., 2011; van Kol et al., 2011). Applying these criteria on the ATPlite and WST-1 results in CTLL-2 cells, we selected $1 \mu \mathrm{M}$ DON and $100 \mathrm{nM}$ TBTO as subcytotoxic concentrations ( $20 \%$ decrease of viability). For these conditions both ATPlite and WST-1 assay determined a similar viability of CTLL-2 cells. $2 \mu \mathrm{M}$ DON and $200 \mathrm{nM}$ TBTO were chosen as 2 -fold higher concentrations, which did not induce more than $20 \%$ decrease in viability after $6 \mathrm{~h}$ exposure. These four conditions were then selected for microarray analysis on $6 \mathrm{~h}$ exposed CTLL-2 cells. 

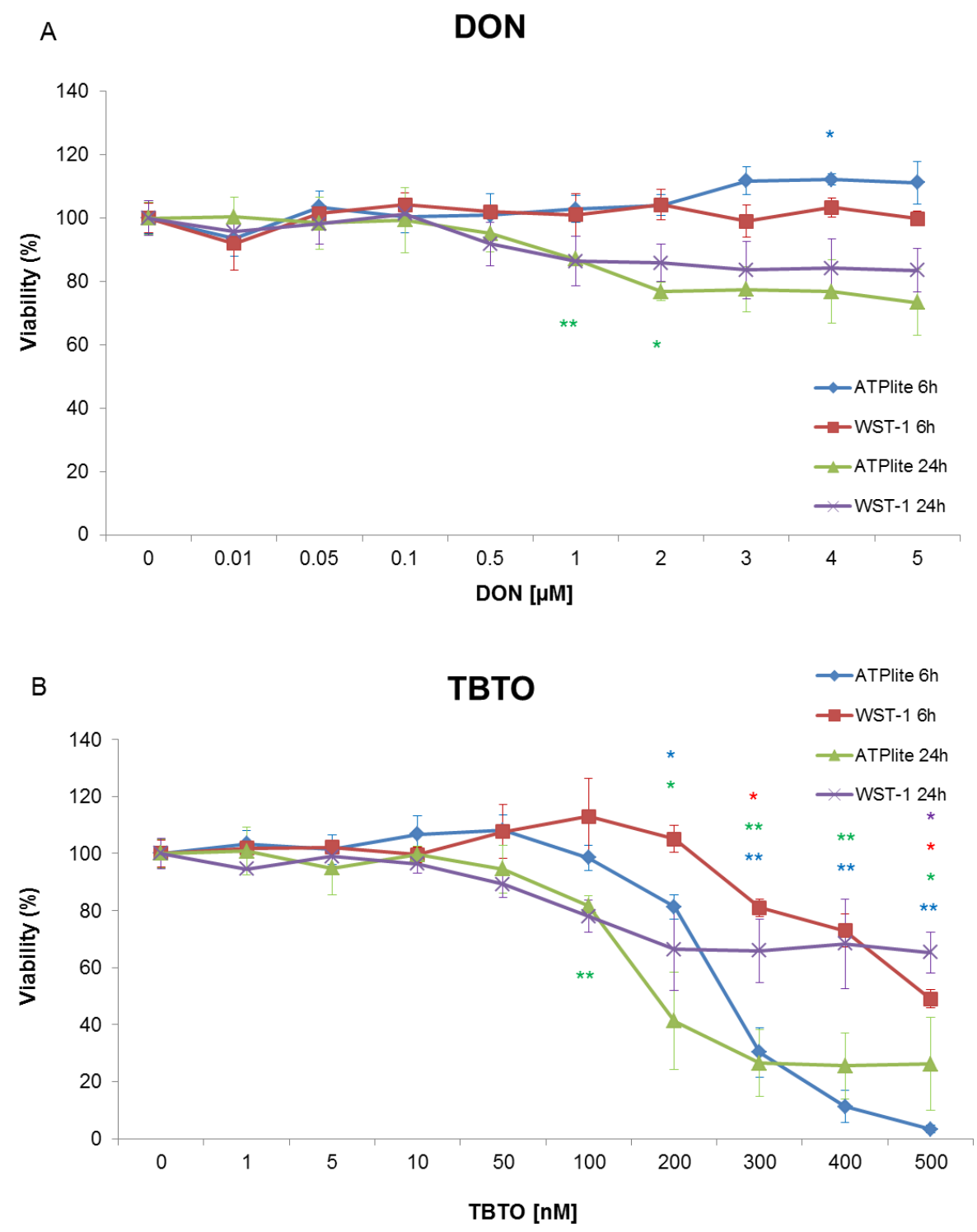

Fig. 1. Average viability of CTLL-2 cells exposed to DON or TBTO.

Viability of CTLL-2 cells exposed to DON (A) or TBTO (B) for 6 or $24 \mathrm{~h}$, measured by ATPlite or WST-1 assay. The relative viability after treatment is presented as percentage compared to the vehicle control DMSO at the same time point. Results shown are mean \pm SD of three independent measurements. *: $p<0.05$ and $* *$ : $p<0.01$ compared to control (Student's T test). For ATPlite $6 \mathrm{~h}$ these asterisks are blue, for WST-1 $6 \mathrm{~h}$ red, ATPlite $24 \mathrm{~h}$ green and for WST-1 24h these are purple. 
Hierarchical clustering and pathway analysis

Unsupervised hierarchical clustering was performed to visualize the effects of the DON and TBTO exposures on mRNA expression. Genes $(n=773)$ were selected on $>1.6$ fold up or down regulation in $\geq 3$ arrays, and the clustering resulted in six main subclusters (Fig. 2).

Metacore analysis was applied on the genes from the individual clusters to identify the most significantly represented pathways and biological processes. One main finding is that genes of two toxicity induced processes, the unfolded protein response and ER stress, were upregulated by $200 \mathrm{nM}$ TBTO and not affected or downregulated by $100 \mathrm{nM}$ TBTO and downregulated by both DON doses (Cluster 1). Genes involved in apoptosis and inflammation were also upregulated by $200 \mathrm{nM}$ TBTO but not regulated by the other exposures (Cluster 2). Genes involved in positive regulation of lymphocyte activation were mainly upregulated by the highest dose of both DON and TBTO (Cluster 3). Genes related to cell cycle were downregulated by $200 \mathrm{nM}$ TBTO (Cluster 4) which is in accordance with the impaired viability as determined by the viability assays. A main part of these cell cycle related genes were upregulated by $1 \mu \mathrm{M}$ DON and $100 \mathrm{nM}$ TBTO. Next to cell cycle related genes, $100 \mathrm{nM}$ TBTO upregulates genes involved in cholesterol biosynthesis while these genes were downregulated by both DON doses and $200 \mathrm{nM}$ TBTO (Cluster 5). Genes involved in lymphocyte and thymocyte migration were upregulated by 1 and $2 \mu \mathrm{M} D O N$, downregulated by $100 \mathrm{nM}$ TBTO and for a part up and other part downregulated by 200 nM TBTO (Cluster 6). 


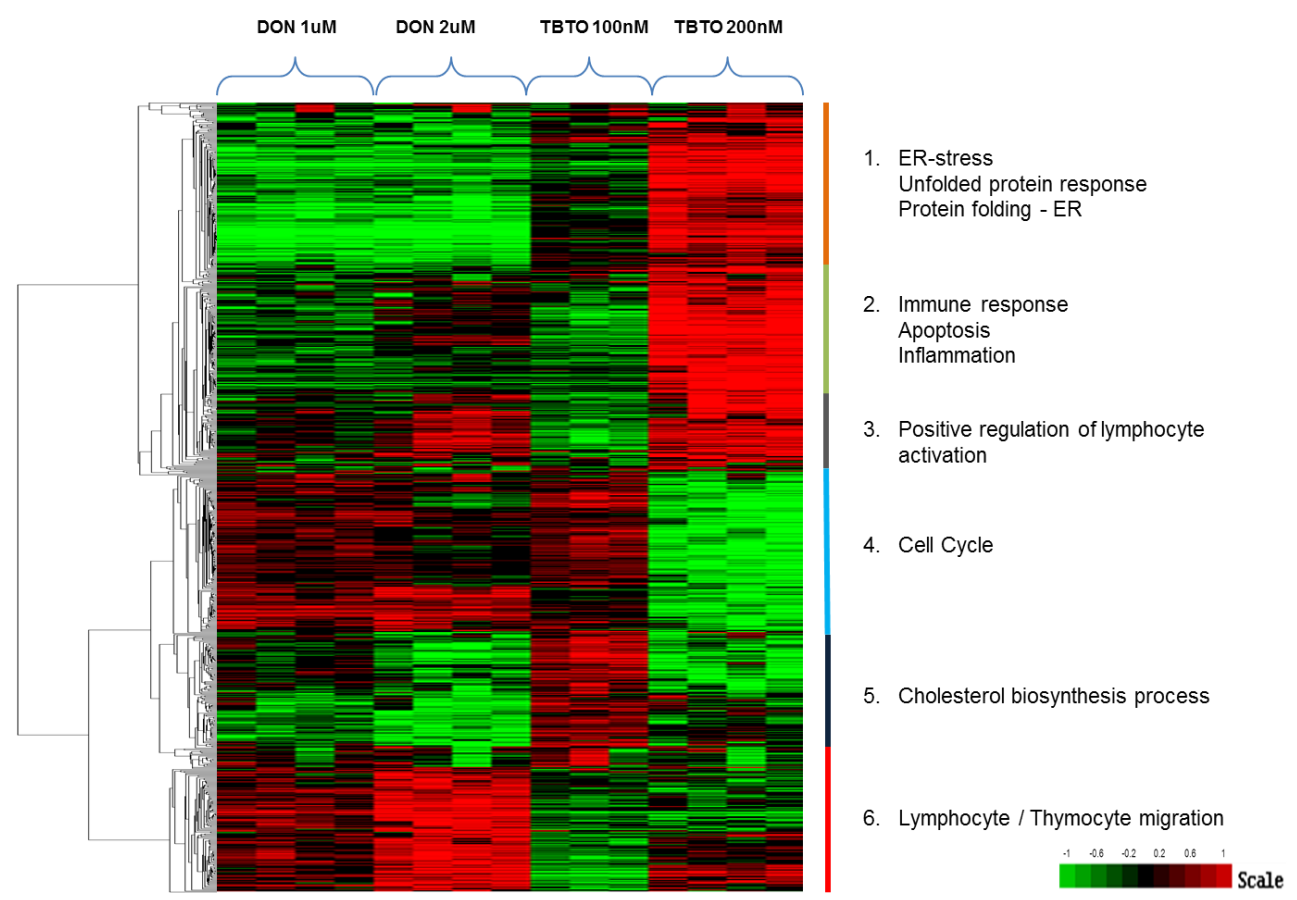

Fig. 2. Unsupervised hierarchical clustering of genes altered by DON and TBTO exposure in CTLL-2 cells. This heat map represents 773 genes that were > 1.6 times up- or downregulated by DON and TBTO in CTLL-2 in at least 3 out of 15 arrays. Data for each array is presented as $2 \log$ ratios versus the DMSO control within the same experiment. For the subclusters, the corresponding biological processes are indicated at the right based on Metacore analysis. Scale is displayed in bottom right corner. Green represents down-regulation, red represents upregulation and black represents no effect. The top 10 highest up- and downregulated genes for each subcluster are given in Supplementary Table 1. ER: endoplasmic reticulum.

\section{Significantly affected genes}

Limma analysis was used to assess the number of genes affected by 1 and $2 \mu \mathrm{M}$ DON, and 100 and $200 \mathrm{nM}$ TBTO on the transcriptome of CTLL-2 cells. A total of 866 genes were altered in CTLL-2 cells by DON and/or TBTO ( $>1.4$-fold; $\mathrm{q}<0.01)$. No genes were significantly affected by $100 \mathrm{nM}$ TBTO whereas the largest number of genes $(\mathrm{N}=663)$ were affected by $200 \mathrm{nM}$ TBTO. DON 1 and $2 \mu \mathrm{M}$ affected 53 and 289 genes, respectively. Venn analysis was used to determine the overlap of genes affected by DON ( 1 and $2 \mu \mathrm{M})$ and $200 \mathrm{nM}$ TBTO (Fig. 3). The majority of the genes regulated by $200 \mathrm{nM}$ TBTO (576 of 663 genes) and $2 \mu \mathrm{M}$ DON (185 of 289 genes) were not regulated by the other exposure conditions. Fifty-three genes were affected by $1 \mu \mathrm{M}$ DON and 49 of these genes were also affected in the same direction by $2 \mu \mathrm{M}$ DON. Twenty-eight genes were affected by each of the three conditions; remarkably 26 of these genes were downregulated by DON and upregulated by TBTO. Metacore analysis showed that a significant part of these 26 genes are involved in amino acid transport and ER stress/unfolded protein response pathway. One gene was downregulated by all three conditions: Thioredoxin domain-containing protein 1 
precursor, (Txndc11, alias Efp1). Eighty-three genes were affected by both $2 \mu \mathrm{M}$ DON and $200 \mathrm{nM}$ TBTO, of which 40 in the same direction and 43 in opposite direction. Metacore analysis on the genes shared by $2 \mu \mathrm{M}$ DON and $200 \mathrm{nM}$ TBTO did not result in statistically significant pathways.

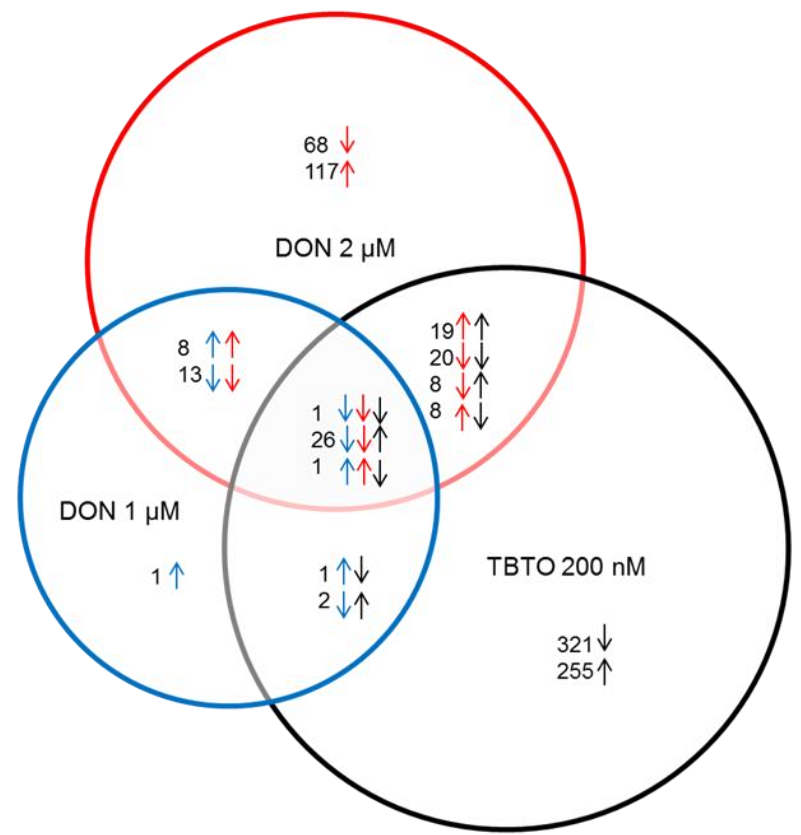

Fig. 3. Venn diagram of genes significantly regulated by DON ( 1 or $2 \mu \mathrm{M})$ or TBTO (200 nM) in CTLL-2 cells. CTLL-2 cells were exposed to DON or TBTO for $6 \mathrm{~h}$. Limma statistical analysis was used to determine the number of significant genes based on $\mathrm{q}<0.01$ and fold change $>|1.4|$. In total, 53 genes were regulated by DON 1 $\mu \mathrm{M}, 289$ genes by DON $2 \mu \mathrm{M}$ and 663 genes by TBTO $200 \mathrm{nM}$. No genes were found significantly affected by $100 \mathrm{nM}$ TBTO. Arrows indicate up- or downregulation; DON $2 \mu \mathrm{M}$ is displayed in red, DON $1 \mu \mathrm{M}$ in blue and TBTO $200 \mathrm{nM}$ in black.

\section{GSEA and Molecular Concept Analysis}

GSEA was applied for each of the four treatments using the six gene set collections listed in Materials and Methods. Molecular Concept analysis was used to visualize the overlap in genes between the pathways. We applied molecular concept analysis on the two treatments that affected the highest number of pathways, $2 \mu \mathrm{M}$ DON and $200 \mathrm{nM}$ TBTO. Gene sets upregulated by $2 \mu \mathrm{M}$ DON were mainly involved in the cell cycle (Fig. 4a). Gene sets downregulated by $2 \mu \mathrm{M}$ DON were involved in T cell activation, oxidative stress, ER stress, transport and metabolism (Fig. 4b). Figs $4 \mathrm{a}$ and $4 \mathrm{~b}$ also show a good correlation between the effects of DON in vitro and in vivo: Gene sets up- or downregulated by $6 \mathrm{~h}$ DON exposure in the mouse thymus in vivo were affected in the same direction in CTLL-2 cells in vitro. Gene sets upregulated by $200 \mathrm{nM}$ TBTO were involved in ER stress, T cell activation, NFKB activation and quiescence (Fig. 4c). Gene sets downregulated by $200 \mathrm{nM}$ TBTO were all involved in the cell cycle and proliferation (Fig. 4d). 


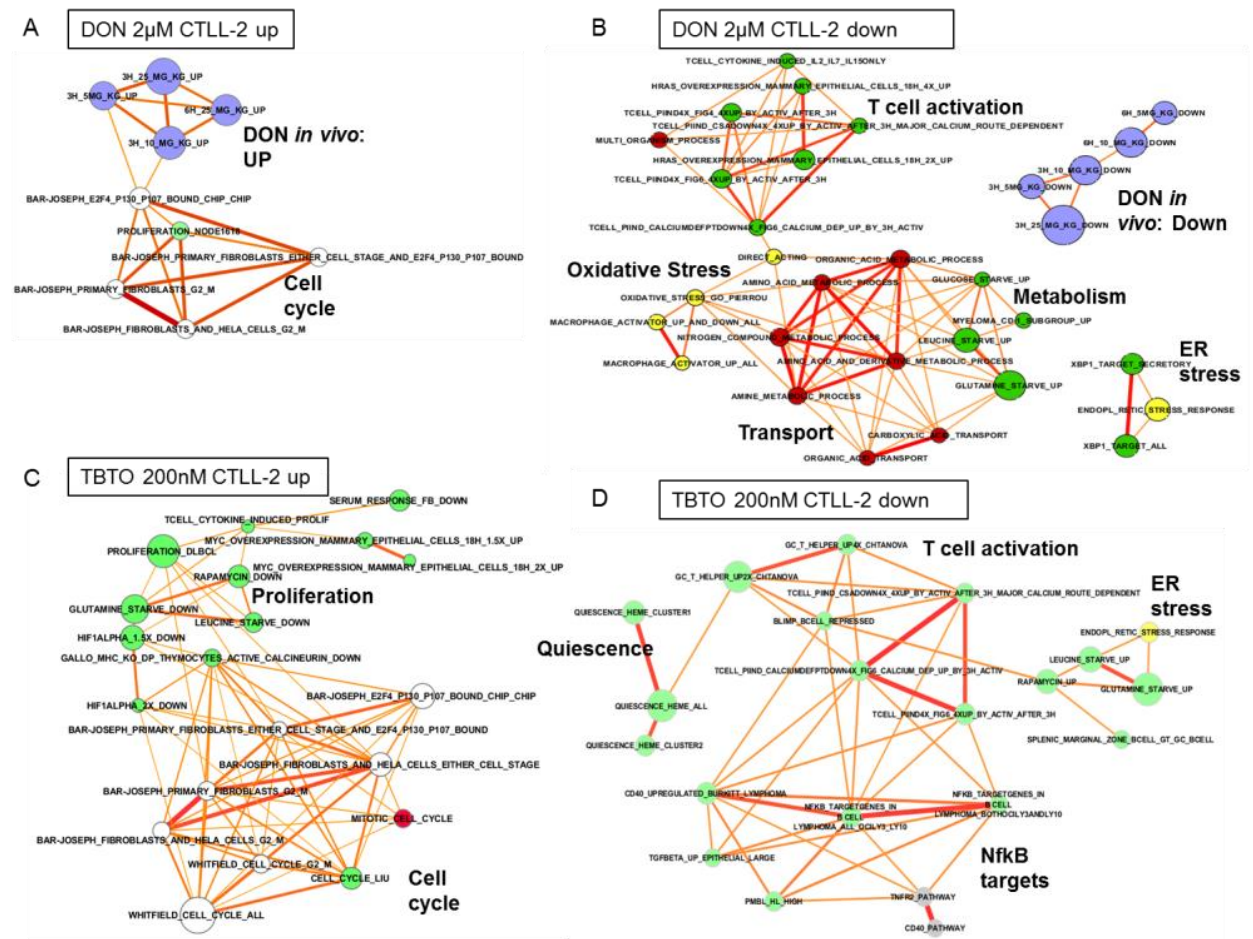

Fig. 4. Molecular concepts analysis of gene sets affected in CTLL-2 cells after $6 \mathrm{~h}$ exposure to $2 \mu \mathrm{M}$ DON or 200 nM TBTO.

Results of molecular concepts analysis are given for gene sets that are A) upregulated by DON, B) downregulated by DON, C) upregulated by TBTO, and D) downregulated by TBTO. The size of the nodes corresponds to the number of genes of the gene set. The width and boldness of the connecting lines indicate the degree of overlap between the gene sets. The colour of the nodes corresponds to the gene set collection from which the gene sets were taken: green: Lymphocyte signature database; white: Cell Cycle; purple: DON in vivo (van Kol et al., 2011). yellow: TOX action; red: GO_biological Processes and grey: Biocarta.

\section{$q R T-P C R$}

Six genes were selected to assess whether the effects of DON and TBTO as measured by microarray analysis can be confirmed by qRT-PCR. Atf3, Chac1, Ddit3, Mir17hg, Nfibia and Trib3 were selected on basis of a key role in T cell activation (Atf3, Nfikbia, and Trib3), ER stress response (Atf3, Chac1, Ddit3), apoptosis (Chac1, Ddit3, Nfibia, and Trib3), NFkB activation (Nfibia), unfolded protein response (Atf3 and Chac1) and the effect on microRNA cluster 17-92 (Mir17hg). The mRNA expression levels of these genes as quantified by microarray analysis and qRT-PCR are shown in Figure 5. The qRT-PCR analysis confirmed the microarray results for the effects of both DON and TBTO on Atf3, 
Chac1, Mir17hg and Trib3 as well as for the effect of $200 \mathrm{nM}$ TBTO on Nfikbia and Ddit3. qRT-PCR detected Nfikia to be upregulated by both 1 and $2 \mu \mathrm{M}$ DON and $100 \mathrm{nM}$ TBTO which was not detected by the microarray analysis. qRT-PCR did not confirm the downregulation of Ddit3 by 1 and $2 \mu \mathrm{M}$ DON.
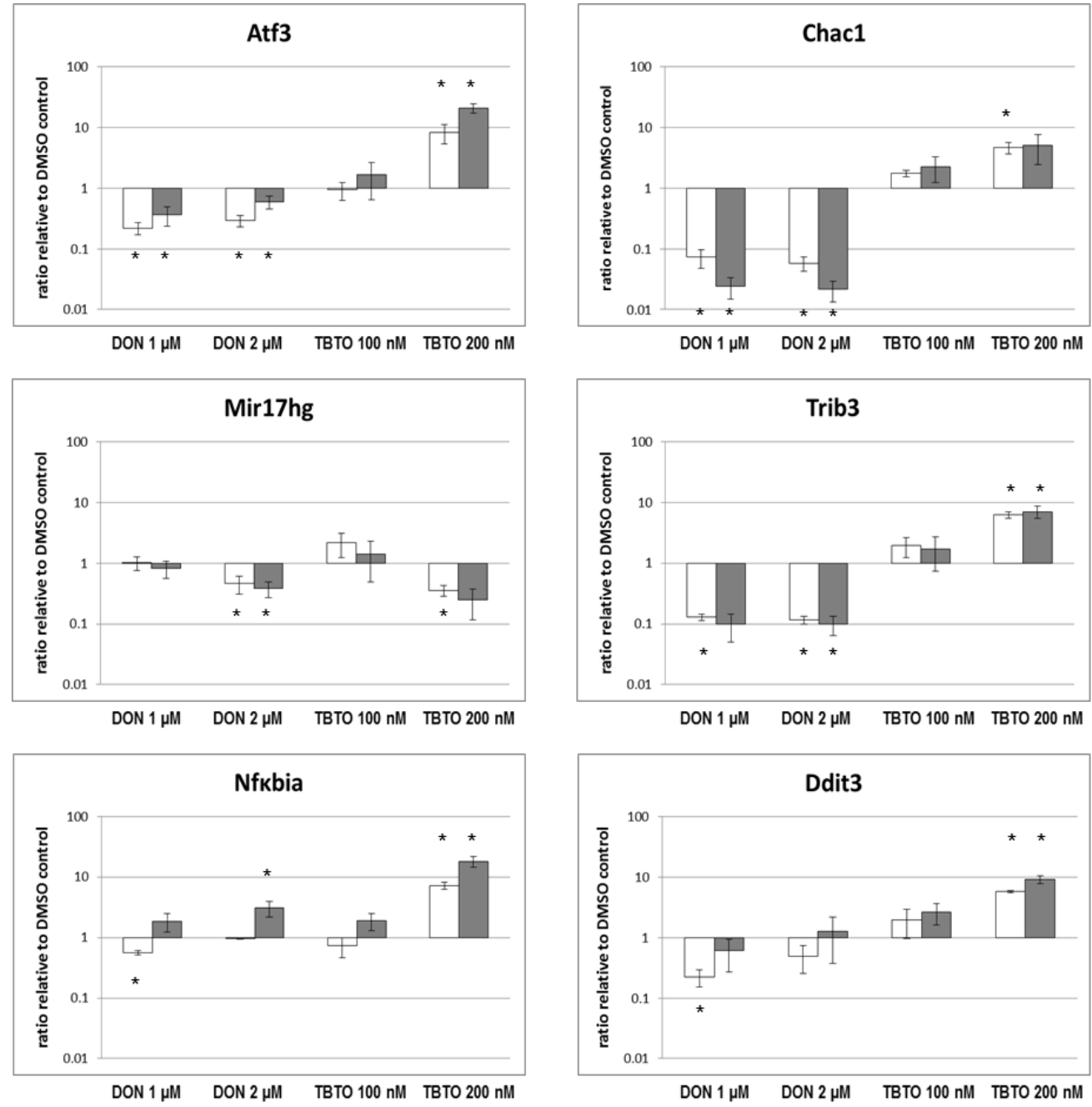

Fig. 5. Quantitative reverse transcriptase PCR confirmation of microarray data.

qRT-PCR was performed for Atf3, Chac1, Mir17hg, Trib3, Nfikbia, and Ddit3. Expression levels were compared to DMSO control and calculated using Hprt1, Lgals1 and Actb as reference genes. White bars represent microarray results, grey bars represent qRT-PCR results. Exposure conditions are presented at the bottom. Y-axis represents ratios compared to DMSO. Values are based on four biological replicates for which qRT-PCR was done in technical triplicates. * indicates p-value $\leq 0.01$ based on student's T-test for the comparison 
between DON or TBTO exposure and solvent control. Error bars represent the standard deviation of the gene expression calculated over the four biological replicates.

Are genes affected by DON and TBTO in CTLL-2 cells also affected in mouse thymocytes in vitro and in vivo, and in human Jurkat T cells in vitro?

We investigated whether the genes up- and downregulated by DON and TBTO in the present study, were also up- and downregulated in DON exposed mice thymus in vivo, DON or TBTO exposed human Jurkat T cells or mouse thymocytes in vitro. To this end we used microarray gene expression data from earlier studies with DON (Katika et al., 2012b; van Kol et al., 2011), or TBTO (Baken et al., 2006; Katika et al., 2011; van Kol et al., 2012). Gene sets were made from the genes significantly affected in CTLL-2 cells in the present microarray study according to limma analysis. An overview of the number of genes per gene set is given in Table 2 .

As shown in figure $6 \mathrm{a}$, the sets of genes up- or downregulated by $2 \mu \mathrm{M}$ DON in CTLL-2 cells were 1) also up- or downregulated in the thymus of mice exposed to DON for 3 or $6 \mathrm{~h}$, and 2) up- or downregulated by 0.25 and $0.5 \mu \mathrm{M}$ DON in Jurkat cells at most time points. The set of genes downregulated by $1 \mu \mathrm{M}$ DON in CTLL-2 cells was also downregulated in the mouse thymus after $12 \mathrm{~h}$ exposure to 5 an $10 \mathrm{mg} / \mathrm{kg}$ DON and in Jurkat cells after $6 \mathrm{~h}$ exposure to 0.25 and $0.5 \mu \mathrm{M}$ DON. The gene set upregulated by $1 \mu \mathrm{M}$ DON in CTTL-2 cells was only upregulated in the mouse thymus exposed for $3 \mathrm{~h}$ to $10 \mathrm{mg}$ DON. This limited correlation might be due to the low number of genes (11) in this gene set.

Similar comparisons were performed for genes that were affected by $200 \mathrm{nM}$ TBTO in CTLL-2 cells (Fig. 6b). Since $100 \mathrm{nM}$ TBTO did not result in significantly affected genes, comparisons with this condition could not be made. The sets of genes up- or downregulated by $200 \mathrm{nM}$ TBTO in CTLL-2 cells were also up- or downregulated by TBTO in Jurkat cells and by 0.5 and $1 \mu \mathrm{M}$ TBTO in primary mouse thymocytes. The set of genes downregulated by $200 \mathrm{nM}$ TBTO in CTLL-2 cells were also downregulated in the mouse thymus in vivo by 3 days exposure to $300 \mathrm{mg} / \mathrm{kg}$ TBTO. The set of genes upregulated by $200 \mathrm{nM}$ TBTO in CTLL-2 cells was not affected by TBTO exposure for 3,7 or $14 \mathrm{~d}$ in the mouse thymus in vivo. 
Assessment of the usefulness of the murine cytotoxic T cell line CTLL-2 for immunotoxicity screening by transcriptomics

Table 2. Number of genes affected by 6 h exposure to DON or TBTO in CTLL-2 cells ${ }^{a}$

\begin{tabular}{ccc}
\hline Gene set name & Up & Down \\
\hline CTLL-2 DON $1 \mu \mathrm{M}$ & 11 & 42 \\
CTLL-2 DON $2 \mu \mathrm{M}$ & 153 & 136 \\
CTLL-2 TBTO $100 \mathrm{nM}$ & 0 & 0 \\
CTLL-2 TBTO $200 \mathrm{nM}$ & 311 & 352 \\
\hline
\end{tabular}

${ }^{a}$ Significance was determined by limma analysis. Fold change $>1.4, \mathrm{q}<0.01$

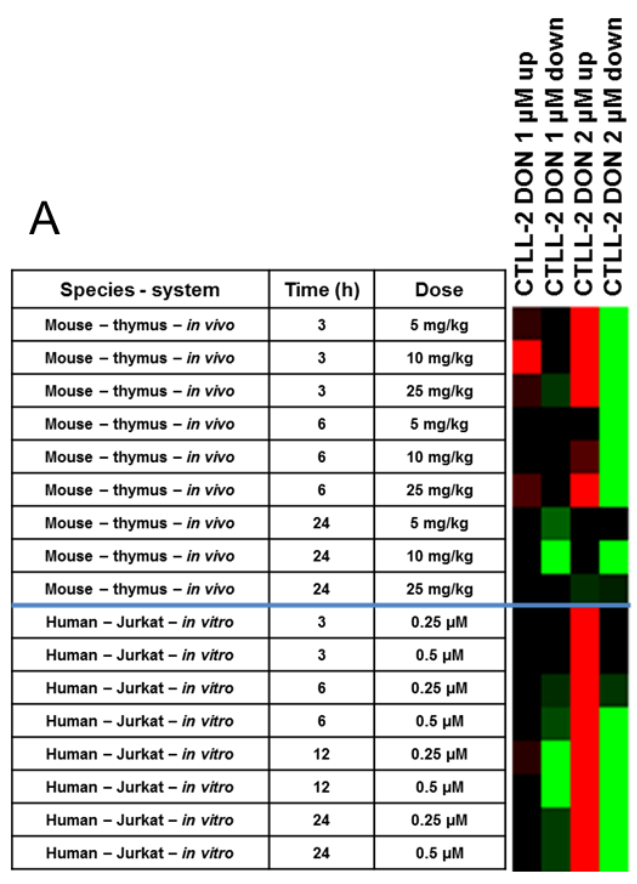

\begin{tabular}{|c|c|c|}
\hline Species - system & Time & Dose \\
\hline Mouse-in vivo-thymus & 3 days & $300 \mathrm{mg} / \mathrm{kg}$ \\
\hline Mouse - in vivo-thymus & 7 days & $300 \mathrm{mg} / \mathrm{kg}$ \\
\hline Mouse-invivo-thymus & 14 days & $300 \mathrm{mg} / \mathrm{kg}$ \\
\hline Mouse - in vitro- thymocyte & $3 \mathrm{~h}$ & $0.1 \mu \mathrm{M}$ \\
\hline Mouse - in vitro- thymocyte & $3 \mathrm{~h}$ & $0.5 \mu \mathrm{M}$ \\
\hline Mouse - in vitro- thymocyte & $3 \mathrm{~h}$ & $1 \mu \mathrm{M}$ \\
\hline Mouse - in vitro- thymocyte & $3 \mathrm{~h}$ & $2 \mu \mathrm{M}$ \\
\hline Mouse - in vitro- thymocyte & $6 \mathrm{~h}$ & $0.1 \mu \mathrm{M}$ \\
\hline Mouse - in vitro-thymocyte & $6 \mathrm{~h}$ & $0.5 \mu \mathrm{M}$ \\
\hline Mouse - in vitro- thymocyte & $6 \mathrm{~h}$ & $1 \mu \mathrm{M}$ \\
\hline Mouse - in vitro- thymocyte & $11 \mathrm{~h}$ & $0.1 \mu \mathrm{M}$ \\
\hline Mouse - in vitro- thymocyte & $11 \mathrm{~h}$ & $0.5 \mu \mathrm{M}$ \\
\hline Human-in vitro-Jurkat & $3 \mathrm{~h}$ & $0.2 \mu \mathrm{M}$ \\
\hline Human - in vitro-Jurkat & $3 \mathrm{~h}$ & $0.5 \mu \mathrm{M}$ \\
\hline Human - in vitro-Jurkat & $6 \mathrm{~h}$ & $0.2 \mu \mathrm{M}$ \\
\hline Human - in vitro-Jurkat & $6 \mathrm{~h}$ & $0.5 \mu \mathrm{M}$ \\
\hline
\end{tabular}

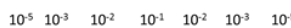

Scale

Fig. 6. Genes affected by DON or TBTO in CTLL-2 cells are also affected by DON and TBTO in the mouse thymus and in the human Jurkat T lymphocyte cell line.

Sets of genes up- or downregulated by DON and TBTO in CTLL-2 cells were selected from the present study. Thereafter, GSEA statistics was used to assess whether these gene sets were significantly affected by DON or TBTO in the mouse thymus in vivo or in vitro and Jurkat cells in vitro using microarray data of previous studies (Baken et al., 2006; Katika et al., 2011; van Kol et al., 2011; Katika et al., 2012b; van Kol et al., 2012). Scale indicates statistical significance (p-value) of the gene set. green represents downregulation, red upregulation and black no effect. 
Genes involved in Apoptosis, ER stress and T cell activation

Apoptosis, ER stress and T cell activation are affected by DON and TBTO in CTTL-2 cells in the present study and in Jurkat cells and primary thymocytes in our previous studies (Katika et al., 2012b; Katika et al., 2011). It is of interest to know whether 1) the same genes of these processes are affected in CTLL-2 cells and in Jurkat cells, and 2) whether DON and TBTO affect the same genes within these processes. Therefore, heat maps were created showing the effects of DON and TBTO on individual genes involved in apoptosis, ER stress and T cell activation in CTLL-2 and Jurkat cells. In concordance with results of hierarchical clustering and molecular concept mapping, many of the genes involved in these three processes are upregulated by TBTO and downregulated by DON in CTLL-2 cells (Fig. 7). A few genes are downregulated by TBTO and upregulated or not affected by DON. A comparison between the cell lines demonstrates that most of the genes upregulated by $200 \mathrm{nM}$ TBTO in CTLL-2 are also upregulated by $0.5 \mu \mathrm{M}$ TBTO in Jurkat cells. Apoptosis, ER stress and T cell activation-related genes downregulated by DON in CTLL-2 cells are unaffected or upregulated by DON in Jurkat cells (Fig. 7). Taken together, DON and TBTO have opposite effects on genes involved in apoptosis, ER stress and $\mathrm{T}$ cell activation in CTLL-2 cells but mostly similar effects in Jurkat cells. 
Assessment of the usefulness of the murine cytotoxic T cell line CTLL-2 for immunotoxicity screening by transcriptomics
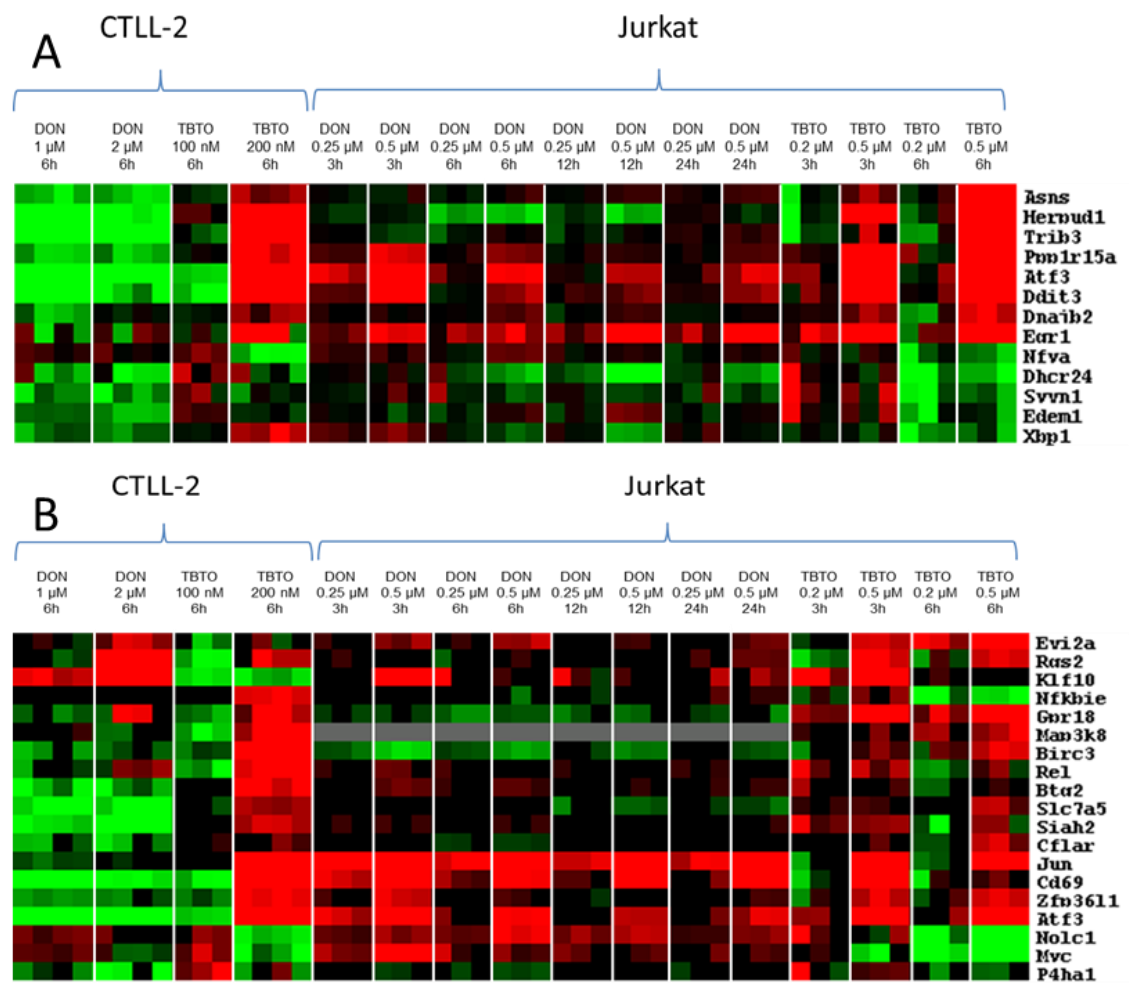

\section{CTLL-2 Jurkat}

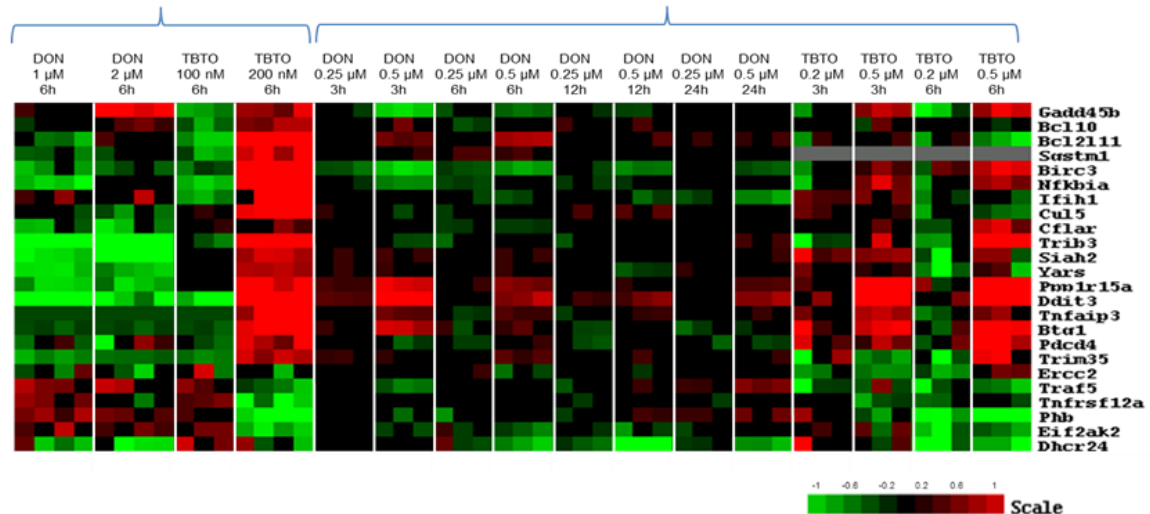

Fig. 7. Effects of DON and TBTO on genes involved in ER stress (A), T cell activation (B) and apoptosis (C) in CTLL-2 and Jurkat cells.

Genes known to involved in T cell activation, ER stress and apoptosis were filtered for being affected by $6 \mathrm{~h}$ exposure to DON $(1$ or $2 \mu \mathrm{M})$ or TBTO $(100$ or $200 \mathrm{nM})$ in the present study (selection criterion: >1.6-fold up or downregulated in at least 3 of 12 arrays). Effects on these genes are shown for DON and TBTO on CTLL- 2 cells in the present study and on Jurkat cells in a previous study (Katika et al., 2011; Katika et al., 2012b). Scale is displayed in bottom right corner; green: downregulation, red: upregulation, black: no effect, grey: gene not present on the array. 


\section{Expression of genes upregulated during $T$ cell activation}

Since CTLL-2 cells are continuously activated by ConA and IL-2, we hypothesized that a subset of T-cell activation-related genes are higher expressed in CTTL-2 cells than in Jurkat cells. Therefore, we assessed the expression levels of genes previously been reported to be upregulated during the T cell activation response in human T cells (Feske et al., 2001). The 12 genes that were not present on the CTLL-2 array were excluded. Of the genes uniquely expressed in either CTTL-2 or Jurkat cells, more genes are expressed in CTLL-2 than in Jurkat cells (15 vs. 13 genes, see Supplementary Table 2). Of the genes expressed both in CTLL-2 and Jurkat cells, 14 genes were much higher expressed in CTTL-2 and 7 genes much higher in Jurkat cells.

Many of the genes highly expressed in CTLL-2 cells are involved in the MAP kinase pathway (Myc, Dusp6, Dusp2, Ier3) or in TNF activation (Mapkap2, Map3k8, TNF), both processes are known to be activated during T cell activation (Ashwell, 2006; Huang et al., 2009; Tsai et al., 1996). CTTL-2 cells also highly express other genes that are known to be involved in $\mathrm{T}$ cell activation response (Lta, Cd96). Genes highly expressed in Jurkat cells include genes known to negatively regulate $\mathrm{T}$ cell receptor signalling (Sla, Nfikbia) (Sosinowski et al., 2000).

\section{Discussion}

For immunotoxicity testing, there is a big demand to replace animal testing by in vitro experiments. Whole genome mRNA expression analysis on cells exposed to test chemicals in vitro promises to be a valuable option for this aim. Genes of which mRNA levels are affected by certain compounds can be used as biomarkers. Moreover, biological interpretation of the expression data may provide information about the processes and receptors affected by compounds. The immunological response involves many different cell types which makes it important to assess how many different immune cell types and cell lines have to be included for immunotoxicity testing to cover a wide range of immunotoxic modes of action. In this study, the value of the mouse CTLL-2 cell line as an in vitro screening model for immunotoxicity was assessed using two immunotoxic model compounds, DON and TBTO. The transcriptome responses of CTLL-2 cells were compared to that of other immune cells obtained from previous in vitro and in vivo studies.

A first interesting observation came from the viability assays which indicated that CTLL-2 cells are much more resistant to DON than Jurkat cells and primary thymocytes (Supplementary Table 3). In previous studies subcytotoxic doses of DON were assessed at $0.5 \mu \mathrm{M}$ for primary thymocytes, $0.25 \mu \mathrm{M}$ for Jurkat cells and $0.5 \mu \mathrm{M}$ for the mouse thymoma cell line EL4(Katika et al., 2012b; Osman et al., 2010; van Kol et al., 2011). Exposure for $24 \mathrm{~h}$ to $1 \mu \mathrm{M}$ DON reduced the viability of CTLL-2 cells to approximately $80 \%$. Remarkably, viability did not reduce much further when CTLL-2 cells were exposed for $24 \mathrm{~h}$ to concentrations up to $5 \mu \mathrm{M}$ DON. Exposure for $24 \mathrm{~h}$ to $5 \mu \mathrm{M}$ DON reduced the viability of EL4 cells to less than $35 \%$ (unpublished data) and exposure to $1 \mu \mathrm{M}$ DON reduced the viability of Jurkat cells to $50 \%$ (Katika et al., 2012b). In contrast, TBTO 
reduced the viability of CTLL-2 cells to below $80 \%$ from $100 \mathrm{nM}$ onwards which is lower than the subcytotoxic doses determined before for primary thymocytes and Jurkat cells (Katika et al., 2011; van Kol et al., 2012). The relative high resistance of CTLL-2 cells to DON is also reflected by the lower number of genes significantly affected by $2 \mu \mathrm{M}$ DON compared to $200 \mathrm{nM}$ TBTO: 289 vs. 663 genes, respectively (Table 2).

The modes of action of DON and TBTO have been investigated in several types of cells and tissues including primary thymocytes, Jurkat cells, the thymus in vivo, EL4 cells and RAW264.7 cells (Dong et al., 1994; Katika et al., 2012b; Katika et al., 2011; van Kol et al., 2011, 2012; Wang et al., 2012). The main cellular target of DON is the ribosome. Binding of DON to ribosomes causes ribotoxic stress that in turn leads to ER stress, induction of processes related to protein synthesis (e.g. mRNA formation and translation), inhibition of proliferation, and eventually induces apoptosis (Iordanov et al., 1997; Katika et al., 2012b; Pestka, 2008; Shifrin and Anderson, 1999; van Kol et al., 2011). ER stress also induces leakage of calcium from the ER leading to activation of NFkB, calcineurin and NFAT that induces oxidative stress and $\mathrm{T}$ cell activation in primary thymocytes and Jurkat cells and ultimately leads to apoptosis as well (Katika et al., 2012b; van Kol et al., 2011). There are strong indications that TBTO acts directly on the endoplasmic reticulum inducing a raise of intracellular $\mathrm{Ca} 2+$ release from the ER leading to the same calcium induced responses as mentioned above for DON (Aw et al., 1990; Bissonnette et al., 2010; Chow et al., 1992; Grundler et al., 2001; Kass and Orrenius, 1999; Katika et al., 2012b; Lane et al., 2009).

Biological interpretation of the present mRNA expression data was conducted using three methods: 1) Metacore analysis on groups of genes significantly affected according to limma, 2) Metacore analysis on clusters after hierarchical clustering, and 3) GSEA analysis on the entire microarray dataset followed by Molecular Concepts analysis. These analyses indicated that the processes of ER stress, protein synthesis, NFkB activation, oxidative stress, T cell activation, cell cycle and apoptosis were affected in the present study as well. Effects of both DON and TBTO on ER stress were supported by each of these three methods. A significant part of the 26 genes that according to limma analysis were downregulated by DON $(1$ and $2 \mu \mathrm{M})$ and upregulated by TBTO $(200 \mathrm{nM})$ were involved in the ER stress/unfolded protein response pathway next to amino acid synthesis. The only gene that according to limma analysis was downregulated by $200 \mathrm{nM}$ TBTO as well as 1 and $2 \mu \mathrm{M}$ DON is Txndc11, alias Efp1. Txndc11 is known to be upregulated during ER stress, binds to Par-4 and therewith inhibits Par-4 mediated apoptosis (Appel et al., 2009). Downregulation of ER stress-related genes by DON and upregulation by $200 \mathrm{nM}$ TBTO was also evident from the hierarchical clustering analysis (Fig. 2, cluster 1), molecular concepts mapping (Figs $4 \mathrm{~b}$ and 5c), and the heatmap of ER stress related genes (Fig. 7a). ER stress specific genes Herpud1 and Edem1 were downregulated by both concentrations of DON and upregulated by $200 \mathrm{nM}$ TBTO in CTLL-2 cells (Olivari et al., 2006; Schulze et al., 2005). In addition, qRT-PCR confirmed elevated expression the ER stress related gene Atf3 and Ddit3 by $200 \mathrm{nM}$ TBTO (Fig 6). Atf3 and Chac1 were downregulated by 1 
and $2 \mu \mathrm{M}$ DON (Fig 6). To our knowledge, this is the first study to report chemically induced down regulation of the ER stress response.

The effects of DON and TBTO on T cell activation and apoptosis were like those on ER stress: downregulated by 1 and $2 \mu \mathrm{M}$ DON, and upregulated by $200 \mathrm{nM}$ TBTO (T cell activation: Fig. 2: cluster 3, Figs 4b, 4c and 7b; apoptosis: Fig. 2, cluster 2 and Fig. 7c). T cell activation related genes Atf3, Nfikbia and Trib3 were significantly upregulated by 200 nM TBTO. Atf3 and Trib3 were significantly downregulated by 1 and $2 \mu \mathrm{M}$ DON (Fig. 6). Nfikbia, Ddit3 and Trib3 are also related to apoptosis and were all upregulated by $200 \mathrm{nM}$ TBTO.

In addition, cell cycle and proliferation related genes were downregulated by $200 \mathrm{nM}$ TBTO and upregulated by both DON doses (Figs. 2, cluster 4, 4a and 4d). Genes involved in quiescence and NFאB target genes are uniquely upregulated by $200 \mathrm{nM}$ TBTO (Fig. 4c). Gene Mir17hg, downregulated by $2 \mu \mathrm{M}$ DON and $200 \mathrm{nM}$ TBTO, is host gene for microRNA cluster17-92 that functions on cell survival, proliferation, differentiation and angiogenesis (de Pontual et al., 2011; Mendell, 2008). A recent publication showed that Mir17hg is also downregulated in acute lymphocytic leukaemia (ALL) cells following glucocorticoid treatment that results into upregulation of Bim (alias Bcl2111) and induction of apoptosis (Harada et al., 2012). Bim was upregulated by $200 \mathrm{nM}$ TBTO in CTLL-2 but not regulated by DON (Fig. 7c).

The induction of $\mathrm{T}$ cell activation, ER stress and apoptosis by TBTO in CTLL-2 cells agrees with results previously obtained by our group using Jurkat cells (shown in Fig. 7) and primary rat and mouse thymocytes (Baken et al., 2007; Katika et al., 2011; van Kol et al., 2012) and apoptosis was observed in rats and mice in vivo (Baken et al., 2006). However, the downregulation of genes involved in ER stress, and T cell activation by DON is surprising and oppose results from previous studies on the human Jurkat cells (shown in Fig. 7), human PBMCs, and mouse thymus in vivo (Iordanov et al., 1997; Katika et al., 2012b; Pestka, 2008; Shifrin and Anderson, 1999; van Kol et al., 2011).

An important difference between CTLL-2 cells and previously studied immune cells is that CTLL-2 cells lack the ability to produce IL-2 and are therefore cultured in the presence of ConA and IL-2 to maintain cell growth. The relative basal expression of unexposed CTLL2 cells showed that $\mathrm{T}$ cell activation responsive genes are constitutively activated in CTLL2 cells, as compared to Jurkat cells. This makes it harder to further induce a $\mathrm{T}$ cell activation response although this is succeeded by $200 \mathrm{nM}$ TBTO. T cell activation also leads to apoptosis in mouse thymocytes in vitro and in vivo and in Jurkat cells (Katika et al., 2012b; Pestka et al., 2005; van Kol et al., 2011).

Since not all genes are annotated to functions, we also compared the response of CTLL-2 cells to DON vs. the in vivo response of the mouse thymus on the level of genes instead of on the level of pathways. For this, GSEA statistics was used to assess whether genes significantly affected by 3,6 and 24 h exposure to 5,10 and $25 \mathrm{mg} / \mathrm{kg}$ DON in the mouse thymus were also significantly affected by $6 \mathrm{~h}$ exposure to $2 \mu \mathrm{M}$ DON in CTLL- 2 cells. This demonstrated that gene sets that were up- or downregulated by DON exposure in vivo 
were affected in the same direction by DON exposure in CTLL-2 cells (Fig. 4a and 4b). The other way around, gene sets up- or downregulated by $2 \mu \mathrm{M}$ DON exposure in CTLL-2 cells were significantly up- and down-regulated by DON in the mouse thymus in vivo and Jurkat cells in vitro (Fig. 6a). This indicates that DON affects many genes in the same direction (up- or downregulation) in CTLL-2 cells and the mouse thymus in vivo that are not annotated yet into processes or pathways. Gene sets up- or downregulated by $1 \mu \mathrm{M}$ DON in CTLL-2 cells were up- or downregulated in Jurkat cells in only a few exposure conditions, which is likely due to the limited number of genes in these gene sets (11 and 42 genes for up- and downregulation).

Gene sets up- or downregulated by 200nM TBTO exposure in CTLL-2 cells were affected by TBTO in the same direction in human Jurkat $\mathrm{T}$ lymphocyte cell line and mouse thymocytes exposed in vitro (Fig. 6b). The same gene sets were not significantly affected in the mouse thymus in vivo by 3,7 or $14 \mathrm{~d}$ treatment with $300 \mathrm{mg} / \mathrm{kg}$ TBTO with exception of genes downregulated after $3 \mathrm{~d}$ (Fig. 6b). This limited correlation is likely due to the long exposure times causing depletion of the thymocytes from the thymus in vivo.

Exposure for $24 \mathrm{~h}$ to $1 \mu \mathrm{M}$ DON impairs the viability of CTLL-2 cells with 20\%, while concentrations up to $5 \mu \mathrm{M}$ do not further reduce the viability. This is remarkable since 5 $\mu \mathrm{M}$ DON is highly cytotoxic for other cell types. DON is known to bind ribosomes and this is expected to occur in CTLL-2 cells as well which might explain the $20 \%$ reduction of viability by DON concentrations from $1 \mu \mathrm{M}$ onwards. Ribotoxic stress is known to induce ER stress (Iordanov et al., 1997; Katika et al., 2012b; Pestka et al., 2004; Shifrin and Anderson, 1999). Therefore, the most plausible explanation for the resistance of CTLL-2 cells to higher concentrations of DON is that these cells miss the link between ribotoxic stress and ER stress. This agrees with the lack of induction of ER stress related genes by DON. In contrast to DON, TBTO, which directly affects the ER, does induce ER stress in CTLL-2 cells indicating that this response is functional in CTLL-2 cells. Candidate genes that are involved in the link between ribotoxic stress and ER stress are glucose related protein 78 (Grp78, alias Hspa5), hematopoietic cell kinase (Hck) and phosphor kinase (Pkr, alias Eif2ak2) (Bae et al., 2010; Pestka, 2010). In CTLL-2 cells, Hck is not present and Hspa5 and Pkr were not affected. Because Hck is present in Jurkat $\mathrm{T}$ cells and primary mouse thymocytes, the lack of this gene might contribute to the absence of ER stress in DON exposed CTLL-2 cells. However, at this point we cannot exclude other genes as the exact mechanism is not fully understood.

In conclusion, the present findings indicate that TBTO induces ER stress, $\mathrm{T}$ cell activation, $\mathrm{NFKB}$ and apoptosis in the CTLL-2 cell line, which corresponds to previous findings on other immune cell types. DON exposure, however, downregulates the processes of ER stress and $\mathrm{T}$ cell activation which is opposite to results obtained before on other immune cells including Jurkat cells, PBMCs and the mouse thymus in vivo. It is relevant to be aware that two cell lines can give opposite responses to the same toxicant. This opposite response of CTLL-2 cells might be caused by 1) the lack of expression or non-functionality of genes involved in linking ribotoxic stress to ER stress, and 2) continuously activation of the T cell 
activation response by ConA and IL-2. The present results are of interest for the selection of types of immune cells for immunotoxicity testing by transcriptomics. Based on the results for the model compounds TBTO and DON, the CTLL-2 cell line does not yield an added value for immunotoxicity compared to the human Jurkat $\mathrm{T}$ cell line.

\section{Conflict of interest statement}

The authors declare that there are no conflicts of interest.

\section{Acknowledgements}

This study was financially supported by the Netherlands Genomics Initiative, the Netherlands Organisation for Scientific Research, and the Netherlands Toxicogenomics Centre (grant number 05060510). 


\section{References}

Aldridge, W.N., 1958. The biochemistry of organotin compounds: trialkyltins and oxidative phosphorylation. Biochem J 69, 367-376.

Aldridge, W.N., Street, B.W., 1964. Oxidative phosphorylation. Biochemical effects and properties of trialkyltins. Biochem J 91, 287-297.

Aldridge, W.N., Street, B.W., 1970. Oxidative phosphorylation. The specific binding of trimethyltin and triethyltin to rat liver mitochondria. Biochem J 118, 171-179.

Appel, S., Vetterkind, S., Koplin, A., Maertens, B., Boosen, M., Preuss, U., 2009. EFP1 is an ER stress-induced glycoprotein which interacts with the pro-apoptotic protein Par-4. Cell Health and Cytoskeleton 1, 16.

Ashwell, J.D., 2006. The many paths to p38 mitogen-activated protein kinase activation in the immune system. Nature reviews Immunology 6, 532-540.

Aw, T.Y., Nicotera, P., Manzo, L., Orrenius, S., 1990. Tributyltin stimulates apoptosis in rat thymocytes. Archives of biochemistry and biophysics $283,46-50$.

Bae, H., Gray, J.S., Li, M., Vines, L., Kim, J., Pestka, J.J., 2010. Hematopoietic cell kinase associates with the 40S ribosomal subunit and mediates the ribotoxic stress response to deoxynivalenol in mononuclear phagocytes.

Toxicol Sci 115, 444-452.

Baken, K.A., Arkusz, J., Pennings, J.L., Vandebriel, R.J., van Loveren, H., 2007. In vitro immunotoxicity of bis(tri-n-butyltin)oxide (TBTO) studied by toxicogenomics. Toxicology 237, 35-48.

Baken, K.A., Pennings, J.L., de Vries, A., Breit, T.M., van Steeg, H., van Loveren, H., 2006. Gene expression profiling of Bis(tri-n-butyltin)oxide (TBTO)-induced immunotoxicity in mice and rats. J Immunotoxicol 3, 227 244.

Baken, K.A., Pennings, J.L., Jonker, M.J., Schaap, M.M., de Vries, A., van Steeg, H., Breit, T.M., van Loveren, H., 2008. Overlapping gene expression profiles of model compounds provide opportunities for immunotoxicity screening. Toxicol Appl Pharmacol 226, 46-59.

Bar-Joseph, Z., Siegfried, Z., Brandeis, M., Brors, B., Lu, Y., Eils, R., Dynlacht, B.D., Simon, I., 2008. Genomewide transcriptional analysis of the human cell cycle identifies genes differentially regulated in normal and cancer cells. Proceedings of the National Academy of Sciences of the United States of America 105, 955-960.

Bimczok, D., Doll, S., Rau, H., Goyarts, T., Wundrack, N., Naumann, M., Danicke, S., Rothkotter, H.J., 2007. The Fusarium toxin deoxynivalenol disrupts phenotype and function of monocyte-derived dendritic cells in vivo and in vitro. Immunobiology 212, 655-666.

Bissonnette, S.L., Haas, A., Mann, K.K., Schlezinger, J.J., 2010. The role of CaMKII in calcium-activated death pathways in bone marrow B cells. Toxicological sciences : an official journal of the Society of Toxicology 118 , 108-118.

Chow, S.C., Kass, G.E., McCabe, M.J., Jr., Orrenius, S., 1992. Tributyltin increases cytosolic free Ca2+ concentration in thymocytes by mobilizing intracellular $\mathrm{Ca} 2+$, activating a $\mathrm{Ca} 2+$ entry pathway, and inhibiting Ca2+ efflux. Archives of biochemistry and biophysics 298, 143-149.

Corsini, E., Roggen, E.L., 2009. Immunotoxicology: opportunities for non-animal test development. Alternatives to laboratory animals : ATLA 37, 387-397.

de Pontual, L., Yao, E., Callier, P., Faivre, L., Drouin, V., Cariou, S., Van Haeringen, A., Genevieve, D., Goldenberg, A., Oufadem, M., Manouvrier, S., Munnich, A., Vidigal, J.A., Vekemans, M., Lyonnet, S., HenrionCaude, A., Ventura, A., Amiel, J., 2011. Germline deletion of the miR-17 approximately 92 cluster causes skeletal and growth defects in humans. Nat Genet 43, 1026-1030.

Dinu, D., Bodea, G.O., Ceapa, C.D., Munteanu, M.C., Roming, F.I., Serban, A.I., Hermenean, A., Costache, M., Zarnescu, O., Dinischiotu, A., 2011. Adapted response of the antioxidant defense system to oxidative stress induced by deoxynivalenol in Hek-293 cells. Toxicon 57, 1023-1032.

Dong, W., Azcona-Olivera, J.I., Brooks, K.H., Linz, J.E., Pestka, J.J., 1994. Elevated gene expression and production of interleukins 2, 4, 5, and 6 during exposure to vomitoxin (deoxynivalenol) and cycloheximide in the EL-4 thymoma. Toxicol Appl Pharmacol 127, 282-290.

Eisen, M.B., Spellman, P.T., Brown, P.O., Botstein, D., 1998. Cluster analysis and display of genome-wide expression patterns. Proceedings of the National Academy of Sciences of the United States of America 95, 1486314868. 
Evans, W.H., Cardarelli, N.F., Smith, D.J., 1979. Accumulation and excretion of [1-14C]bis(tri-n-butyltin) oxide in mice. J Toxicol Environ Health 5, 871-877.

Feske, S., Giltnane, J., Dolmetsch, R., Staudt, L.M., Rao, A., 2001. Gene regulation mediated by calcium signals in T lymphocytes. Nat Immunol 2, 316-324.

Food, Drug Administration, H.H.S., 2006. International Conference on Harmonisation; Guidance on S8 Immunotoxicity Studies for Human Pharmaceuticals; availability. Notice. Federal register 71, 19193-19194. Grundler, W., Dirscherl, P., Beisker, W., Marx, K., Stampfl, A., Maier, K., Zimmermann, I., Nusse, M., 2001. Early functional apoptotic responses of thymocytes induced by Tri-n-butyltin. Cytometry 44, 45-56.

Harada, M., Pokrovskaja-Tamm, K., Soderhall, S., Heyman, M., Grander, D., Corcoran, M., 2012. Involvement of miR17 pathway in glucocorticoid-induced cell death in pediatric acute lymphoblastic leukemia. Leukemia \& lymphoma 53, 2041-2050.

Hoch, M., 2001. Organotin compounds in the environment - an overview. Appl Geochem 16, 719-743.

Huang, G., Shi, L.Z., Chi, H., 2009. Regulation of JNK and p38 MAPK in the immune system: signal integration, propagation and termination. Cytokine 48, 161-169.

Iordanov, M.S., Pribnow, D., Magun, J.L., Dinh, T.H., Pearson, J.A., Chen, S.L., Magun, B.E., 1997. Ribotoxic stress response: activation of the stress-activated protein kinase JNK1 by inhibitors of the peptidyl transferase reaction and by sequence-specific RNA damage to the alpha-sarcin/ricin loop in the $28 \mathrm{~S}$ rRNA. Mol Cell Biol 17, 3373-3381.

Jeanmougin, M., de Reynies, A., Marisa, L., Paccard, C., Nuel, G., Guedj, M., 2010. Should we abandon the t-test in the analysis of gene expression microarray data: a comparison of variance modeling strategies. PloS one 5, e12336.

Kass, G.E.N., Orrenius, S., 1999. Calcium signaling and cytotoxicity. Environmental Health Perspectives 107, 25 35.

Katika, M.R., Hendriksen, P.J., De Ruijter, N.C., van Loveren, H., Peijnenburg, A., 2012a. Immunocytological and biochemical analysis of the mode of action of bis (tri-n-butyltin) tri-oxide (TBTO) in Jurkat cells. Toxicol Lett.

Katika, M.R., Hendriksen, P.J., Shao, J., van Loveren, H., Peijnenburg, A., 2012b. Transcriptome analysis of the human $\mathrm{T}$ lymphocyte cell line Jurkat and human peripheral blood mononuclear cells exposed to deoxynivalenol (DON): New mechanistic insights. Toxicol Appl Pharmacol.

Katika, M.R., Hendriksen, P.J., van Loveren, H., Peijnenburg, A., 2011. Exposure of Jurkat cells to bis (tri-nbutyltin) oxide (TBTO) induces transcriptomics changes indicative for ER- and oxidative stress, T cell activation and apoptosis. Toxicology and applied pharmacology 254, 311-322.

Konigs, M., Schwerdt, G., Gekle, M., Humpf, H.U., 2008. Effects of the mycotoxin deoxynivalenol on human primary hepatocytes. Molecular nutrition \& food research 52, 830-839.

Krajnc, E.I., Wester, P.W., Loeber, J.G., van Leeuwen, F.X., Vos, J.G., Vaessen, H.A., van der Heijden, C.A., 1984. Toxicity of bis(tri-n-butyltin)oxide in the rat. I. Short-term effects on general parameters and on the endocrine and lymphoid systems. Toxicology and applied pharmacology 75, 363-386.

Lane, R., Ghazi, S., Whalen, M., 2009. Increases in Cytosolic Calcium Ion Levels in Human Natural Killer Cells in Response to Butyltin Exposure. Arch Environ Contam Toxicol 57, 816-825.

Lankveld, D.P., Van Loveren, H., Baken, K.A., Vandebriel, R.J., 2010. In vitro testing for direct immunotoxicity: state of the art. Methods in molecular biology 598, 401-423.

Liu, H.G., Wang, Y., Lian, L., Xu, L.H., 2006. Tributyltin induces DNA damage as well as oxidative damage in rats. Environmental toxicology 21, 166-171.

Mendell, J.T., 2008. miRiad roles for the miR-17-92 cluster in development and disease. Cell 133, 217-222.

Olivari, S., Cali, T., Salo, K.E., Paganetti, P., Ruddock, L.W., Molinari, M., 2006. EDEM1 regulates ER-

associated degradation by accelerating de-mannosylation of folding-defective polypeptides and by inhibiting their covalent aggregation. Biochem Biophys Res Commun 349, 1278-1284.

Osman, A.M., Pennings, J.L., Blokland, M., Peijnenburg, A., van Loveren, H., 2010. Protein expression profiling of mouse thymoma cells upon exposure to the trichothecene deoxynivalenol (DON): implications for its mechanism of action. J Immunotoxicol 7, 147-156.

Pestka, J.J., 2008. Mechanisms of deoxynivalenol-induced gene expression and apoptosis. Food Addit Contam Part A Chem Anal Control Expo Risk Assess 25, 1128-1140. 
Pestka, J.J., 2010. Deoxynivalenol-induced proinflammatory gene expression: mechanisms and pathological sequelae. Toxins 2, 1300-1317.

Pestka, J.J., Uzarski, R.L., Islam, Z., 2005. Induction of apoptosis and cytokine production in the Jurkat human T cells by deoxynivalenol: role of mitogen-activated protein kinases and comparison to other 8-ketotrichothecenes. Toxicology 206, 207-219.

Pestka, J.J., Zhou, H.R., Moon, Y., Chung, Y.J., 2004. Cellular and molecular mechanisms for immune modulation by deoxynivalenol and other trichothecenes: unraveling a paradox. Toxicol Lett 153, 61-73.

Rasmussen, P.H., Ghorbani, F., Berg, T., 2003. Deoxynivalenol and other Fusarium toxins in wheat and rye flours on the Danish market. Food Addit Contam 20, 396-404.

Rhodes, D.R., Kalyana-Sundaram, S., Tomlins, S.A., Mahavisno, V., Kasper, N., Varambally, R., Barrette, T.R., Ghosh, D., Varambally, S., Chinnaiyan, A.M., 2007. Molecular concepts analysis links tumors, pathways, mechanisms, and drugs. Neoplasia 9, 443-454.

Rosenberg, D.W., Anderson, K.E., Kappas, A., 1984. The potent induction of intestinal heme oxygenase by the organotin compound, bis(tri-n-butyltin)oxide. Biochemical and biophysical research communications 119, 10221027.

Rosenberg, D.W., Drummond, G.S., Cornish, H.C., Kappas, A., 1980. Prolonged induction of hepatic haem oxygenase and decreases in cytochrome P-450 content by organotin compounds. Biochem J 190, 465-468. Schulze, A., Standera, S., Buerger, E., Kikkert, M., van Voorden, S., Wiertz, E., Koning, F., Kloetzel, P.M., Seeger, M., 2005. The ubiquitin-domain protein HERP forms a complex with components of the endoplasmic reticulum associated degradation pathway. Journal of molecular biology 354, 1021-1027.

Seinen, W., Vos, J.G., Brands, R., Hooykaas, H., 1979. Lymphocytotoxicity and immunosuppression by organotin compounds. Suppression of graft-versus-host reactivity, blast transformation, and E-rosette formation by di-nbutyltindichloride and di-n-octyltindichloride. Immunopharmacology 1, 343-355.

Severino, L., Luongo, D., Bergamo, P., Lucisano, A., Rossi, M., 2006. Mycotoxins nivalenol and deoxynivalenol differentially modulate cytokine mRNA expression in Jurkat T cells. Cytokine 36, 75-82.

Shaffer, A.L., Rosenwald, A., Hurt, E.M., Giltnane, J.M., Lam, L.T., Pickeral, O.K., Staudt, L.M., 2001.

Signatures of the immune response. Immunity 15, 375-385.

Shannon, P., Markiel, A., Ozier, O., Baliga, N.S., Wang, J.T., Ramage, D., Amin, N., Schwikowski, B., Ideker, T., 2003. Cytoscape: a software environment for integrated models of biomolecular interaction networks. Genome Res 13, 2498-2504.

Shifrin, V.I., Anderson, P., 1999. Trichothecene mycotoxins trigger a ribotoxic stress response that activates c-Jun N-terminal kinase and p38 mitogen-activated protein kinase and induces apoptosis. J Biol Chem 274, 13985 13992.

Smid, M., Dorssers, L.C., Jenster, G., 2003. Venn Mapping: clustering of heterologous microarray data based on the number of co-occurring differentially expressed genes. Bioinformatics 19, 2065-2071.

Snoeij, N.J., Penninks, A.H., Seinen, W., 1988. Dibutyltin and tributyltin compounds induce thymus atrophy in rats due to a selective action on thymic lymphoblasts. Int J Immunopharmacol 10, 891-899.

Snoeij, N.J., van Iersel, A.A., Penninks, A.H., Seinen, W., 1985. Toxicity of triorganotin compounds: comparative in vivo studies with a series of trialkyltin compounds and triphenyltin chloride in male rats. Toxicol Appl Pharmacol 81, 274-286.

Snoeij, N.J., Vanrooijen, H.J.M., Penninks, A.H., Seinen, W., 1986. Effects of Various Inhibitors of OxidativePhosphorylation on Energy-Metabolism, Macromolecular-Synthesis and Cyclic-Amp Production in Isolated Rat Thymocytes - a Regulating Role for the Cellular-Energy State in Macromolecular-Synthesis and Cyclic-Amp Production. Biochimica Et Biophysica Acta 852, 244-253.

Sosinowski, T., Pandey, A., Dixit, V.M., Weiss, A., 2000. Src-like adaptor protein (SLAP) is a negative regulator of T cell receptor signaling. J Exp Med 191, 463-474.

Subramanian, A., Tamayo, P., Mootha, V.K., Mukherjee, S., Ebert, B.L., Gillette, M.A., Paulovich, A., Pomeroy, S.L., Golub, T.R., Lander, E.S., Mesirov, J.P., 2005. Gene set enrichment analysis: a knowledge-based approach for interpreting genome-wide expression profiles. Proc Natl Acad Sci U S A 102, 15545-15550.

Thuvander, A., Wikman, C., Gadhasson, I., 1999. In vitro exposure of human lymphocytes to trichothecenes: individual variation in sensitivity and effects of combined exposure on lymphocyte function. Food Chem Toxicol 37, 639-648. 
Tsai, E.Y., Jain, J., Pesavento, P.A., Rao, A., Goldfeld, A.E., 1996. Tumor necrosis factor alpha gene regulation in activated T cells involves ATF-2/Jun and NFATp. Mol Cell Biol 16, 459-467.

van Kol, S.W., Hendriksen, P.J., van Loveren, H., Peijnenburg, A., 2011. The effects of deoxynivalenol on gene expression in the murine thymus. Toxicology and applied pharmacology 250, 299-311.

van Kol, S.W., Hendriksen, P.J., van Loveren, H., Peijnenburg, A., 2012. Transcriptomics analysis of primary mouse thymocytes exposed to bis(tri-n-butyltin)dioxide (TBTO). Toxicology.

Van Loveren, H., Krajnc, E.I., Rombout, P.J., Blommaert, F.A., Vos, J.G., 1990. Effects of ozone,

hexachlorobenzene, and bis(tri-n-butyltin)oxide on natural killer activity in the rat lung. Toxicology and applied pharmacology 102, 21-33.

Vandebriel, R.J., Meredith, C., Scott, M.P., Roholl, P.J., Van Loveren, H., 1998. Effects of in vivo exposure to bis(tri-n-butyltin)oxide, hexachlorobenzene, and benzo(a)pyrene on cytokine (receptor) mRNA levels in cultured rat splenocytes and on IL-2 receptor protein levels. Toxicology and applied pharmacology 148, 126-136.

Vos, J.G., de Klerk, A., Krajnc, E.I., Kruizinga, W., van Ommen, B., Rozing, J., 1984. Toxicity of bis(tri-nbutyltin)oxide in the rat. II. Suppression of thymus-dependent immune responses and of parameters of nonspecific resistance after short-term exposure. Toxicology and applied pharmacology 75, 387-408.

Wang, X., Liu, Q., Ihsan, A., Huang, L., Dai, M., Hao, H., Cheng, G., Liu, Z., Wang, Y., Yuan, Z., 2012.

JAK/STAT pathway plays a critical role in the proinflammatory gene expression and apoptosis of RAW264.7 cells induced by trichothecenes as DON and T-2 toxin. Toxicol Sci 127, 412-424.

Whalen, M.M., Williams, T.B., Green, S.A., Loganathan, B.G., 2002. Interleukins 2 and 12 produce recovery of cytotoxic function in tributyltin-exposed human natural killer cells. Environ Res 88, 199-209.

Whitfield, M.L., Sherlock, G., Saldanha, A.J., Murray, J.I., Ball, C.A., Alexander, K.E., Matese, J.C., Perou, C.M., Hurt, M.M., Brown, P.O., Botstein, D., 2002. Identification of genes periodically expressed in the human cell cycle and their expression in tumors. Molecular biology of the cell 13, 1977-2000. 
Chapter 5

\begin{abstract}
DON shares a similar mode of action as the ribotoxic stress inducer anisomycin while TBTO shares ER stress patterns with the ER stress inducer thapsigargin based on comparative gene expression profiling in Jurkat $T$ cells
\end{abstract}

Peter C J Schmeits, Madhumohan R Katika, Ad A C M Peijnenburg, Henk van Loveren, Peter J M Hendriksen

Toxicology Letters 11/2013;

Supplementary material can be found at: http://www.sciencedirect.com/science/article/pii/S0378427413013969 


\begin{abstract}
Previously, we studied the effects of deoxynivalenol (DON) and tributyltin oxide (TBTO) on whole genome mRNA expression profiles of human $\mathrm{T}$ lymphocyte Jurkat cells. These studies indicated that DON induces ribotoxic stress and both DON and TBTO induced ER stress which resulted into T-cell activation and apoptosis. The first goal of the present study was to provide final proof for these mode of actions by comparing the effects of $6 \mathrm{~h}$ exposure to DON and TBTO on mRNA expression to those of positive controls of ribotoxic stress (anisomycin), ER stress (thapsigargin) and $\mathrm{T}$ cell activation (ionomycin). Genes affected by anisomycin and the majority of genes affected by thapsigargin were affected in the same direction by DON and TBTO respectively, confirming the expected modes of action. Pathway analysis further sustained that DON induces ribotoxic stress and both DON and TBTO induce unfolded protein response (UPR), ER stress, T cell activation and apoptosis. The second goal was to assess whether DON and/or TBTO affect other pathways above those detected before. TBTO induced groups of genes that are involved in DNA packaging and heat shock response that were not affected by thapsigargin. DON did not affect other genes than anisomycin indicating the effect of DON to be restricted to ribotoxic stress. This study also demonstrates that comparative gene expression analysis is a very promising tool for the identification of modes of action of immunotoxic compounds.
\end{abstract}


DON shares a similar mode of action as the ribotoxic stress inducer anisomycin while TBTO shares ER stress patterns with the ER stress inducer thapsigargin based on comparative gene expression profiling in Jurkat T cells

\section{Introduction}

Deoxynivalenol (DON) is a mycotoxin produced by Fusarium species, which grow on agricultural products. Humans are primarily exposed to DON through consumption of food (Rotter et al., 1996). It has been proposed that DON binds to the 3 '-end of the $28 \mathrm{~S}$ ribosomal RNA (rRNA) and inhibiting protein synthesis and leading to the induction of ribotoxic stress (Iordanov et al., 1997). One target organ is the thymus in which DON mainly affects the early precursor thymocytes (Pestka et al., 2004; van Kol et al., 2011). Before, we showed that DON downregulates genes involved in mitochondria, proliferation, protein synthesis and ribosomal proteins in the mouse thymus in vivo (van Kol et al., 2011). Furthermore, DON causes apoptosis in human Jurkat T cells (Katika et al., 2012b). Proteomic analysis of mouse thymoma EL-4 cells showed that DON $(0.5 \mu \mathrm{M})$ affected protein folding and degradation, chaperones and key metabolic enzymes (Osman et al., 2010).

Tributyltin oxide (TBTO) is an organotin product that has been widely used as biocide in agriculture, as catalyst in polyurethane industry and as antifouling agent in paints. As a result, TBTO is a widespread environmental contaminant (Hoch, 2001). TBTO has been shown to be immunotoxic by induction of depletion of thymocytes and causes thymus atrophy in rodents (Baken et al., 2007; Van Loveren et al., 1990). TBTO has also been shown to reduce macrophage and natural killer (NK) cell activity and differentiation of Tcells (Kergosien and Rice, 1998; Van Loveren et al., 1990; Vos et al., 1990). Using gene expression analysis, we recently reported that TBTO induces endoplasmic reticulum (ER) stress, T cell activation, oxidative stress and apoptosis in mouse thymocytes (Katika et al., 2011; van Kol et al., 2012). Proteomic analysis of mouse EL-4 cells indicated that TBTO affects the expression of proteins involved in energy sensor pathways and proliferation (Osman and van Loveren, 2012).

In this study we compared the effects of DON and TBTO to model compounds for ER stress (thapsigargin), ribotoxic stress (anisomycin) and $\mathrm{T}$ cell activation (ionomycin). Thapsigargin is a non-competitive inhibitor of the protein class SERCA (sarco/endoplasmic reticulum Ca2+ ATPase) (Rogers et al., 1995). This compound, derived from the plant Thapsia garganica, is known to induce an ER stress response by triggering calcium efflux from the ER leading to apoptosis (Scheuner and Kaufman, 2008). Induction of ER stress and apoptosis by thapsigargin has been demonstrated in several cell types such as rat lymphocytes, thymocytes, in mouse primary T cells, and in mice in vivo (Liu et al., 2001; Mason et al., 1991; Pino et al., 2008). The induction of ER stress and apoptosis by thapsigargin was functionally assayed by using an siRNA library against apoptotic genes in human colorectal carcinoma cells (Futami et al., 2005). The ionophore ionomycin, produced by Streptomyces conglobatus, raises calcium levels via release of calcium from intracellular pools and subsequently acts as a T cell activator (Imboden et al., 1985). Ionomycin induced activation of protein kinase $\mathrm{C}$ and phosphorylation of target proteins CD4 and CD8 in human T cells thereby inducing T cell activation (Chatila et al., 1989). Anisomycin is produced by Streptomyces griseolus and is a well-known protein synthesis 
inhibitor (Grollman, 1967). Anisomycin binds to the 28S rRNA, as measured by rRNA footprinting (Rodriguez-Fonseca et al., 1995) and triggers a ribotoxic stress response (Iordanov et al., 1997). The binding of anisomycin to ribosomes was also tested in a binding assay using ribosomes from Chinese Hamster Ovary cells (Middlebrook and Leatherman, 1989).

In previous in vitro work we studied the effect of DON and TBTO on gene expression in the human Jurkat $\mathrm{T}$ cell line using whole genome microarrays. These studies revealed that DON upregulates ribosomal genes and genes involved in RNA/protein biosynthesis which indicates the induction of ribotoxic stress (Katika et al., 2011). In turn, this ribotoxic stress induces ER stress. TBTO induces ER stress as well but in contrast to DON likely via a direct effect on the ER (Katika et al., 2012b; Katika et al., 2011).

One key event in the process of ER stress is the leakage of calcium from the ER that in turn leads to a larger calcium influx through calcium channels in the plasma membrane. Of importance, these same events also occur during a normal $\mathrm{T}$ cell activation response. The rise in intracellular calcium activates calcineurin that in turn induces nuclear translocation of NFATC1 leading to a T cell activation response and apoptosis in Jurkat cells (Katika et al., 2012a). In addition, we showed that TBTO induces oxidative stress as indicated by activation of NRF2 (Katika et al., 2011).

Since it is well described that compounds with similar modes of actions induce similar changes in gene expression (Fielden et al., 2011; Lamb et al., 2006), we compared the effects of TBTO and DON on the transcriptome of Jurkat cells to those of positive controls for ER stress (thapsigargin), ribotoxic stress (anisomycin) and T cell activation (ionomycin) within one experiment. Bioinformatics analysis of the array data aimed to compare the effects both at the level of individual genes and at the level of biological processes. This approach was followed for two aims: 1) to provide final proof for the previously described modes of action of TBTO and DON, and 2) to assess whether DON and/or TBTO affect other pathways above those detected before. This study successfully confirmed the modes of action of DON and TBTO following comparative gene expression analyses and demonstrated effects of TBTO on DNA condensation and heat shock proteins that were not described before. To our knowledge this is the first time such a comparative method is used to determine modes of action of immunotoxic compounds.

\section{Materials and methods}

\section{Chemicals}

Tributyltin oxide (TBTO), deoxynivalenol (DON), thapsigargin, anisomycin and ionomycin were purchased from Sigma Aldrich Company (Zwijndrecht, The Netherlands).

\section{Cell culture}

The human T-lymphocyte cell line (Jurkat) was obtained from the American Type Culture Collection (ATCC). Jurkat cells were cultured in RPMI-1640 medium supplemented with 
DON shares a similar mode of action as the ribotoxic stress inducer anisomycin while TBTO shares ER stress patterns with the ER stress inducer thapsigargin based on comparative gene expression profiling in Jurkat T cells

$10 \%$ FCS, $2 \mu \mathrm{M}$ L-glutamine, $100 \mathrm{U} / \mathrm{ml}$ penicillin, $100 \mu \mathrm{g} / \mathrm{ml}$ streptomycin (Invitrogen Life Science, Breda, the Netherlands). Cells were cultured at $37{ }^{\circ} \mathrm{C}$ with $5 \% \mathrm{CO} 2$ in a humidified atmosphere. The medium was refreshed three times a week.

\section{Cell viability}

The mitochondrial WST-1 assay was used to determine the viability of Jurkat cells after DON, TBTO, anisomycin, thapsigargin and ionomycin exposures (Roche diagnostics, Germany). Cell viability was determined based on the ability of viable cells to metabolize and convert the water soluble tetrazolium salt (WST-1) to a yellow coloured formazan by the mitochondrial dehydrogenases. The amount of formazan correlates to the viability of the cells. The assay was performed as described previously (Katika et al., 2011). As readout, optical density was measured at $450 \mathrm{~nm}$ in a colorimetric microplate reader (Synergy ${ }^{\mathrm{TM}}$ HT Multi-Detection Microplate Reader, BioTek instruments, Winooski, VT). TBTO, DON, thapsigargin and ionomycin were dissolved in DMSO. Anisomycin was dissolved in water. Stock solutions were diluted in RPMI-1640 medium without FCS. The final DMSO concentration in the medium controls was less than $0.1 \%$ which exerted no effect on cell viability. Relative viability was measured as a percentage of the vehicle controls. Concentrations were considered subcytotoxic when at least $80 \%$ of the Jurkat cells was viable after $24 \mathrm{~h}$ exposure.

\section{Exposures}

On the basis of the results of the cell viability measurements, appropriate sub-cytotoxic concentrations were selected for microarray experiments. Jurkat cells were cultured in six well plates overnight and exposed for $6 \mathrm{~h}$ to $0.25 \mu \mathrm{M}$ anisomycin, $0.5 \mu \mathrm{M}$ DON, $1 \mu \mathrm{M}$ ionomycin, $0.2 \mu \mathrm{M}$ TBTO, $0.5 \mu \mathrm{M}$ thapsigargin or DMSO (thus a total of six treatment groups). Exposures were performed in triplicate in three independent experiments and Jurkat cells were used between passage 15 and 20. Triplicate samples from the same day were combined to obtain one sample per independent experiment.

\section{Total RNA isolation}

After exposure of the Jurkat cells, cells were collected by centrifugation (10 min, 1200rpm, $4{ }^{\circ} \mathrm{C}$ ) and washed with phosphate buffered saline (PBS). The cell pellets were lysed in 600 $\mu 1$ RLT buffer (Qiagen, Venlo, The Netherlands) with $1 \% \beta$-mercaptoethanol and stored immediately at $-80{ }^{\circ} \mathrm{C}$. Total RNA was isolated using the RNeasy kit (Qiagen) following manufacturer's instructions. RNA concentration and purity were determined using Nanodrop apparatus (Nanodrop technologies, Wilmington, DE) by measuring absorption ratios at 260/280 and 230/280 $\mathrm{nm}$. The integrity of the RNA samples was examined using BioRad Experion chips (Veenendaal, The Netherlands). 
Microarray hybridization

Gene expression profiling was performed using Affymetrix U133 Plus 2.0 Arrays (Affymetrix, Santa Clara, CA). For each RNA sample, complementary cDNA was synthesized by using $5 \mu \mathrm{g}$ of total RNA and subsequent biotin-labelled cRNA was synthesized using Gene Chip One-Cycle Target Labelling and control reagents including the One-Cycle cDNA synthesis kit, Poly-A RNA control kit, sample clean-up module, IVT labelling kit, and hybridization control kit (Affymetrix) according to the manufacturer's protocol. The yield of cRNA was measured spectrophotometrically (Nanodrop) and the integrity was determined using the Bio Analyzer (Agilent) before and after fragmentation of $15 \mu \mathrm{g}$ of the labelled cRNA. Fragmented samples were hybridized on the array chips for $16 \mathrm{~h}$ at $45^{\circ} \mathrm{C}$ (GeneChip Hybridization Oven 640, Affymetrix), after which the chips were washed and stained using the GeneChip hybridization, wash and stain kit and the GeneChip Fluidics Station 450 (Affymetrix). Chips were then scanned using the Affymetrix GeneChip Scanner 3000 7G, and raw data were extracted using the GeneChip Operating Software (Affymetrix).

\section{Data Analysis}

Quality control of the microarray data was performed using Bioconductor packages (including simpleaffy and affyplm), through the $\mathrm{R}$ pipeline, which can be accessed via Gene Pattern (Reich et al., 2006). Gene pattern was used for pre-processing of the microarray data. The scaling factor, background, percentage present spots, and housekeeping controls were checked for each chip. Arrays were normalized using Robust Multichip Average (RMA), employing the Expression File Creator module (Grundler et al., 2001). RMA is a common algorithm for converting raw Affymetrix data to gene expression values. In addition, the MBNI Custom CDF, which contains updated probe set definitions for Entrez Gene IDs, was applied(http://brainarray.mbni.med.umich.edu/Brainarray/Database/CustomCDF/11.0.1/ent rezg.asp). After normalisation, 2log-ratios were created for each probe set, followed by correcting the value for each sample by the average of the DMSO control.

\section{Hierarchical clustering and pathway analysis}

Hierarchical clustering was performed using the programs Cluster (uncentered correlation; average linkage clustering) and Treeview (Eisen et al., 1998). For genes within the subclusters of the hierarchical cluster heat map, pathway analysis was done using Metacore. This is an online program used for functional and biological interpretation of gene expression data. Overrepresentation of genes from signalling and metabolic pathways is assessed by hypergeometric distribution (Ekins et al., 2006). Pathways with a p value $\leq 10$ 5 were considered significant. 
DON shares a similar mode of action as the ribotoxic stress inducer anisomycin while TBTO shares ER stress patterns with the ER stress inducer thapsigargin based on comparative gene expression profiling in Jurkat T cells

Gene set enrichment analysis (GSEA)

GSEA is a statistical analysis tool for microarray data that is used to detect biological processes affected and to provide insight into the affected molecular mechanisms. GSEA makes use of predefined gene sets that are based on previous experimental results and literature. GSEA has the advantage over other statistical tools that no initial filtering is applied to the dataset to select significantly differentially expressed genes. GSEA ranks all the genes based on their expression ratios and determines whether genes from a particular gene set are significantly enriched at the top or the bottom of the ranked list (Subramanian et al., 2005). This enables detection of significantly affected gene sets, while the fold change of expression of individual genes can be relatively modest. GSEA was performed for all treatment groups vs. controls at the same time point. Gene sets with a $p$ value $\leq 0.05$ and a false discovery rate (FDR) $\leq 0.25$ were considered being significantly affected. For GSEA analyses we used gene sets from various sources:

1. Lymphocyte database: gene sets were taken from a database published by Shaffer et al. (2001).

2. Tox-action (self-made). Gene sets were created from Gene Ontology, REACTOME and literature. For literature references see Supplementary file (Tox action references).

3. Biocarta-2: gene sets were downloaded from Biocarta database.

(http://www.biocarta.com/).

4. Transcription factor targets: Gene sets were selected from microarray studies on a) toxic action of compounds or b) target genes of toxicity-related transcription factors.

5. Gene Ontology (GO): gene sets were downloaded from the Gene Ontology consortium (http://www.geneontology.org/) including molecular function, biological process and cellular components.

\section{Heat maps of gene sets}

We made selections of genes indicative for a process or pathway and visualized the expression of those genes using the programs Cluster and Treeview (Eisen et al., 1998). The genes of the gene sets involved in ribosome function, RNA transcription and apoptosis were taken from Gene Ontology (http://www.geneontology.org/). The genes of the gene sets that were involved in oxidative stress, mitochondrion function and NRF2 activation were taken from KEGG, Biocarta and from literature mining. The gene set of genes upregulated during $\mathrm{T}$ cell activation was taken from the lymphocyte database (Shaffer et al., 2001). Genes involved in the different stages of the unfolded protein response (UPR) were taken from Civelek et al. (2009) and Kuny et al. (2012). Genes were selected for visualisation using the criteria $\geq 1$.7-fold up-or down regulated vs. the average of the controls in $\geq 3$ of 15 arrays. Genes that are involved in multiple processes are presented in multiple figures. 


\section{Results}

\section{Cell viability}

Figure 1 shows the effects of the compounds on cell viability that were determined by measuring mitochondrial activity (WST-1 assay). The criterion for selecting subcytotoxic doses for microarray experiments was similar to that applied in our previous experiments. Exposure doses were selected that induce approximately $20 \%$ reduction in cell viability after 24 h exposure (Katika et al., 2011; Schmeits et al., 2013; van Kol et al., 2011). Based on this criterion, Jurkat cells were exposed for $6 \mathrm{~h}$ to $0.25 \mu \mathrm{M}$ anisomycin, $0.5 \mu \mathrm{M}$ DON, 1 $\mu \mathrm{M}$ ionomycin, $0.2 \mu \mathrm{M}$ TBTO, and $0.5 \mu \mathrm{M}$ thapsigargin.
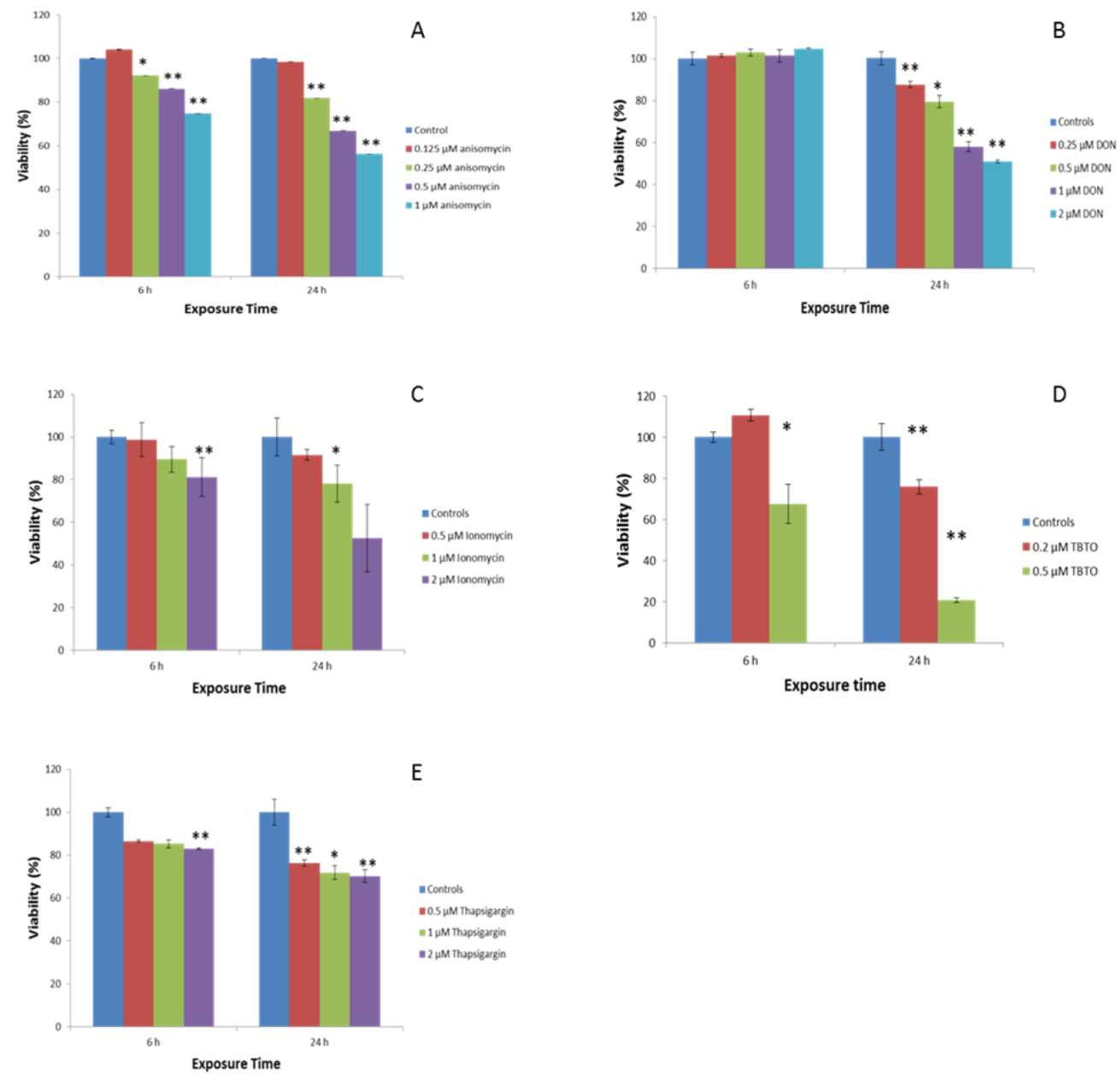

Fig. 1. Average viability of Jurkat T cells after 6 or $24 \mathrm{~h}$ exposure to Anisomycin (A), DON (B), Ionomycin (C), TBTO (D) or Thapsigargin (E), based on WST-1 measurements. The relative viability after treatment is presented as percentage compared to the vehicle control DMSO at the same time point. Results shown are mean \pm SD of three independent measurements. *: $\mathrm{p}<0.05$ and ${ }^{* *}: \mathrm{p}<0.01$ compared to control (Student's T test). 
DON shares a similar mode of action as the ribotoxic stress inducer anisomycin while TBTO shares ER stress patterns with the ER stress inducer thapsigargin based on comparative gene expression profiling in Jurkat T cells

\section{Hierarchical clustering and pathway analysis}

Unsupervised hierarchical clustering was performed for genes that were $\geq 1.7$ fold up- or downregulated versus the average of the controls in at least 3 out of 15 arrays. As shown in Fig. 2, sixteen main gene clusters could be distinguished and were further examined for overrepresentation of genes involved in signalling pathways or biological processes using Metacore analysis. The sixteenth cluster did not result in any significant pathways and was therefore not assigned a letter. In all clusters, similar results were obtained for the genes affected by anisomycin and DON. A high proportion of the genes in clusters A-C was related to transcription, RNA processing and ribosomes, which were upregulated by anisomycin and DON, which very well suits the hypothesis that DON is a ribotoxic stress inducer. Other genes that were upregulated by anisomycin and DON were involved in ER stress (cluster F) and DNA dependent transcription, cell cycle and regulation of metabolic processes (cluster G). Clusters of genes that were downregulated were involved in protein modification, purine nucleotide biosynthesis, negative regulation of apoptosis and RNA splicing (cluster K), stress response, anti-apoptosis, protein folding and cell death (cluster $\mathrm{L}$ ), cell-cell signalling (cluster $\mathrm{M}$ ), sterol metabolism (cluster $\mathrm{N}$ ) and cellular migration and cytokine secretion (cluster $\mathrm{O}$ ).

Similarities, but also some clear differences were seen when the expression profile of TBTO was compared to thapsigargin. Genes related to ribosome biogenesis, RNA metabolic process and RNA and rRNA processing (clusters A and B) were downregulated by TBTO, whereas they were almost unaffected by thapsigargin. Genes in cluster D were involved in protein folding ER and T cell activation and were upregulated by thapsigargin whereas they were less affected by TBTO as compared to thapsigargin. Consistent with the mode of action for endoplasmic reticulum stress induction, genes in clusters $\mathrm{E}$ and $\mathrm{F}$ (Protein folding and ER stress pathway) mostly were upregulated by both TBTO and thapsigargin. Genes involved in DNA dependent transcription, cell cycle and regulation of metabolic processes (cluster G) were upregulated by TBTO and to lesser extent also by thapsigargin. Genes involved in amino acid processing and tRNA amino acetylation (cluster $\mathrm{H}$ ) were also upregulated by TBTO and thapsigargin, whereas genes involved in DNA packaging and nucleosome assembly (Cluster I) were uniquely upregulated by TBTO. A heat map of the 88 genes of this cluster is given in Supplementary Figure 1. This cluster includes eight genes encoding histones and several genes coding for heat shock proteins (e.g. HSPA6, HSPA1a and DNAJb14) that are co-chaperones involved in protein folding (Nollen et al., 1999). Genes that were downregulated by TBTO and thapsigargin were involved in RNA processing, protein modification and cellular migration and cytokine secretion (clusters J, K and O). Opposite effects for TBTO and thapsigargin was found for genes involved in cell-cell signalling and neurotransmitter transport (cluster M). TBTO upregulated and thapsigargin downregulated these genes, respectively.

Ionomycin induced expression of genes that were related to protein folding ER and $\mathrm{T}$ cell activation (cluster D), which is in agreement with its use as positive control for $\mathrm{T}$ cell activation. Genes in this cluster were also upregulated by thapsigargin, but much less or not 


\section{Chapter 5}

affected by TBTO and in part downregulated by anisomycin and DON. This is the only cluster of genes that was convincingly affected by ionomycin. A heat map of the 95 genes of cluster $\mathrm{D}$ is given in supplementary figure 2 . Some minor other effects include a slight upregulation of genes involved in cluster E (protein folding ER, ER induced apoptosis) and cluster $\mathrm{H}$ (amino acid processing). Genes involved in cellular migration and cytokine secretion (cluster $\mathrm{O}$ ) were partly downregulated by ionomycin. Genes in the sixteenth cluster were not involved in a specific pathway.

\begin{tabular}{|c|c|c|c|c|c|}
\hline ANISO & DON & ION & ТВTO & TG & \\
\hline & & & & & A. TH17 chemotaxis, RNA metablic process \\
\hline & & & & & B. Ribosome biogenesis, RNA and rRNA processing, \\
\hline & & & & & C. Regulation of transcription, RNA biosynthesis process \\
\hline & & & & & D. Protein folding ER, $T$ cell activation \\
\hline & & & & & E. Protein folding ER, ER stress induced apoptosis \\
\hline & $=$ & & & & $\begin{array}{l}\text { F. ER stress induced apoptosis, ER unfolded protein response, ER } \\
\text { nucleus signaling pathway. }\end{array}$ \\
\hline
\end{tabular}

G. DNA dependent transcription, Cell cycle, regulation of metabolic process

H. Amino acid processing, tRNA aminoacetylation,

I. DNA packaging, nucleosome assembly

J. RNA processing, rRNA and tRNA processing, ribosome biogenesis

K. Protein modification process, purine nucleotide biosynthesis, negative regulation of apoptosis, RNA splicing

L. Stress response, anti-apoptosis, protein folding, cell death

M. Cell-cell signaling, neurotransmitter transport

N. Lipid/sterol metabolic process

O. Cellular migration, cytokine secretion

Scale

Fig. 2. Unsupervised hierarchical clustering of genes altered by anisomycin, DON, ionomycin, TBTO or thapsigargin exposure in Jurkat T cells. This heat map contains 2557 genes that were $>1.7$ times (2Log ratio > 0.8) up- or downregulated versus the average of the controls in Jurkat cells in at least 3 of 15 arrays. Data for each array is presented as $2 \mathrm{Log}$ ratios versus the average of the controls. The corresponding biological processes according to Metacore analysis are indicated per subcluster. Green is downregulation, red is upregulation and black represents no effect. 
DON shares a similar mode of action as the ribotoxic stress inducer anisomycin while TBTO shares ER stress patterns with the ER stress inducer thapsigargin based on comparative gene expression profiling in Jurkat T cells

\section{Gene set enrichment analysis}

Gene set enrichment analysis (GSEA) was used for the identification of gene sets affected by the exposures in Jurkat cells. As a first step, genes are ranked on their expression ratios and GSEA then determines whether genes from a particular gene set are significantly enriched at the top or the bottom of the ranked list. The advantage of this method over the method of hierarchical clustering is that no initial filtering of the data is performed. GSEA enabled us to compare our microarray results with data published in literature or put forward by other microarray studies. GSEA was performed on each of the five treatments in comparison to the control samples. Gene sets were taken from five different collections (see section 2.9). The GSEA results were visualized in a heat map, Fig. 3.

Anisomycin upregulated expression of genes mainly involved in RNA and ribosomal processes and also induced ER stress and apoptosis. In total, sixteen gene sets were upregulated by anisomycin of which protein transport is the only one that was not also upregulated by DON. Anisomycin downregulated one gene set that was also downregulated by DON. Thus, the effect of anisomycin on these gene sets is shared by DON in sixteen out of seventeen gene sets which very well suits our hypothesis that DON and anisomycin have a similar mode of action. Gene sets that were upregulated by DON and not by anisomycin included genes upregulated after activation of NRF2 or NFKB, T cell activation, DNA repair, mitochondrion and translation.

Thapsigargin significantly affected gene sets linked to ER stress, T cell activation and protein transport and processing and downregulated genes related to immune response and RNA. Two of the four gene sets that were upregulated by thapsigargin were also upregulated by TBTO, being ER stress and T cell activation. Next to these, TBTO also upregulated other gene sets such as apoptosis, NRF2, NFкB and mitochondrion. Similar to thapsigargin, TBTO also downregulated gene sets related to RNA and ribosomes, although more gene sets were downregulated by TBTO than by thapsigargin.

As expected, the ionophore ionomycin upregulated calcium related processes. Ionomycin, DON as well as TBTO upregulated ER stress, apoptosis, T cell activation, NRF2 and NFkB. Gene sets related to RNA and transcription were downregulated by ionomycin.

Based on the GSEA analysis, anisomycin and DON show more overlap in their response then TBTO and thapsigargin. Differences between the ribotoxic and ER stress inducers lie mainly in the RNA and ribosome associated processes. To assess the genes responsible for enrichment of the gene sets, heat maps showing the effects on the individual genes within the main gene sets are given in the following sections. 

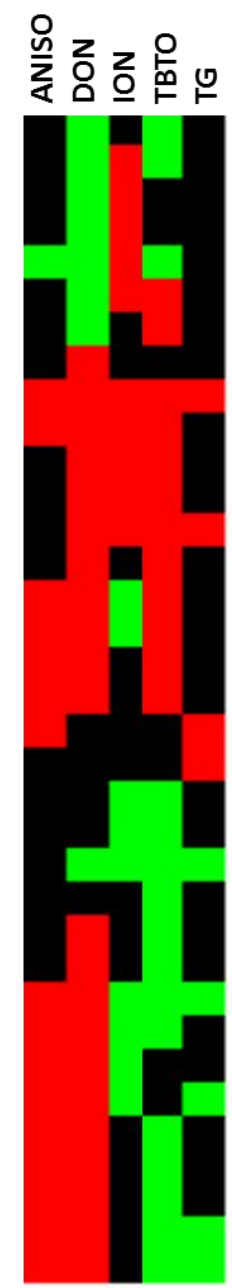

\section{IOH BRIDTHG}

CALCTUM IOH BTIDTIG

LIPID METABOLIC PROCESS

IOH TRANSPORT

CATIOH TRANSMEMBRAKE TRANSPORTER ACTIVITY

RESPOHSE TO STRESS

PROTEIT MODIFICATIOH PROCESS

DHA REPAIR

EHDOPL RETIC STRESS RESPOHSE

APOPTOSIS GO

HIRF 2 UP

HFKB UP

T CELL ACTIUATION

MTTOCHOHDRIOH

TRAHSCRIPTIOH

RHA BIOSYRTHETIC PROCESS

UBIOUITTH CYCLE

KEGATIVE REGULATIOH OF TRAHSCRTPTIOH

PROTEIT TRANSPORT

PROTETH PROCESSTHG

IOW CHEAKIEL ACTTVITY

CATION CHEARELL ACTTYITY

DMAUE RESPOHSE

IOH TRAHSMEMBRAKE TRAHSPORTER ACTIVITY

TRAKSL ATIOH

REGULATIOH OF TRAHSLATIOH

RHA SPLICTHG

RWA BTIDTHG

TRHA PROCESSTHG

RHA METABOLIC PROCESS

TRAHSLATIOWAL THITIATION

RIBOSOME

RIBOHUCLEOPROTETH COMPLEX

RRIA PROCESSITI

RHA PROCESSITG

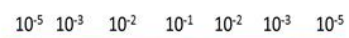

Scale

Fig. 3. Heatmap of processes significantly altered in Jurkat cells showing the overview of the effects of anisomycin (ANISO), deoxynivalenol (DON), ionomycin (ION), tributyltin oxide (TBTO) and thapsigargin (TG) on a selection of gene sets that were run in GSEA (selection; $p$ value $\leq 0.05$, FDR $\leq 0.25$ ). Each line represents one gene set. Scale indicates statistical significance (p-value) of the gene set. Green represents downregulation, red upregulation and black no effect.

Ribosome and RNA transcription

DON and anisomycin upregulated DNAJC1, NOLC1, RSL1D1 and EXOSC2 and downregulated RPL27A, FNBP1 and to lesser extent EIF2S2 (Fig. 4A). Of these genes, NOLC1 is known to support ribosome biogenesis in unstressed cells (Krastev et al., 2011). Ionomycin exerted only very minor expression changes in these genes indicating very limited effects of raised calcium levels on ribosomal function. In contrast, TBTO and to lesser extent thapsigargin downregulated EXOSC7, NOLC1, GEMIN4, RSL1D1, EXOSC2 and RPL27A. Of these, Thapsigargin downregulated NOLC1, GEMIN4 and EXOSC2. 
DON shares a similar mode of action as the ribotoxic stress inducer anisomycin while TBTO shares ER stress patterns with the ER stress inducer thapsigargin based on comparative gene expression profiling in Jurkat T cells

Thapsigargin convincingly upregulated the expression of SERP1 and PDE4DIP and induced a minor upregulation of DNAJC1 and EIF2S2. TBTO also upregulated DNAJC1 while upregulation of SERP1 and PDE4DIP was less obvious.

Genes involved in the transcription of RNA were presented in Fig. 4B. Consistent with the hypothesis that anisomycin and DON have a similar mode of action, the two compounds induced similar effects; most of the genes were upregulated by both anisomycin and DON. TBTO upregulated six genes and downregulated four genes. The reason for this mixed response of TBTO on this set of genes is unclear. The effects of ionomycin and thapsigargin on this gene set were very limited.

Legends for Figures 4-7:

Sub-selection of genes involved in ribosomal function (Fig. 4A), RNA transcription (Fig. 4B), unfolded protein response (Fig. 5), T cell activation (Fig. 6A), NRF2 activation (Fig. 6B), apoptosis (Fig. 7A) and mitochondrion function (Fig. 7B). Jurkat T cells were exposed for $6 \mathrm{~h}$ to subcytotoxic doses of anisomycin, DON, ionomycin, TBTO and thapsigargin. Selection of genes is based on $\geq 1.7$-fold up or downregulated in $\geq 3$ out of 18 arrays. Values were displayed as 2Log ratios versus the average of the controls. Green represents downregulation, red is upregulation and black means no effect.

Scale is as follows:
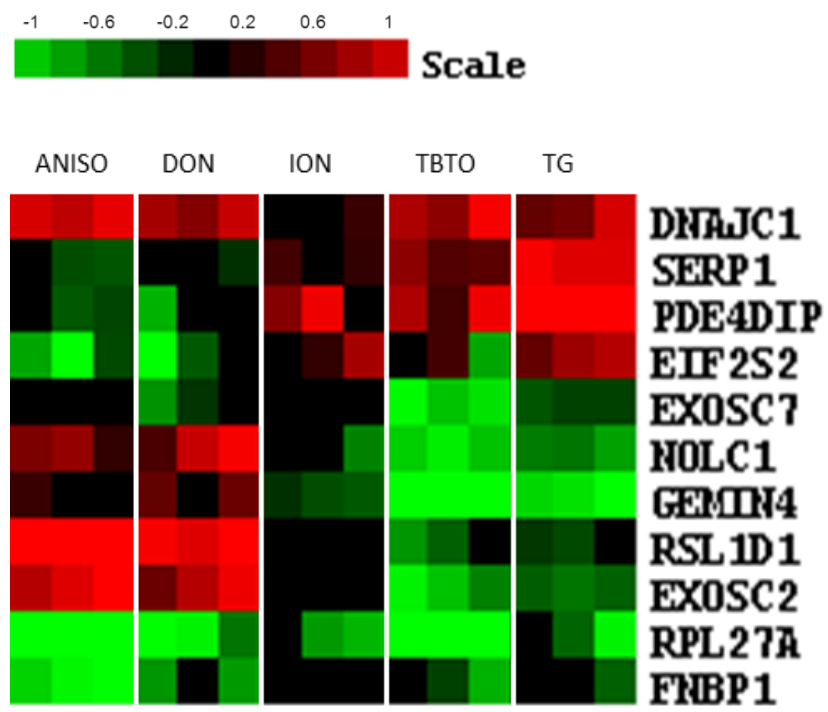

Fig. 4A. Genes involved in ribosomal function.

Anisomycin and DON upregulated genes involved in ribosomal function. TBTO and thapsigargin both downregulated more than half of the genes. Ionomycin has no effect on these genes. 11 out of 71 genes were selected. 


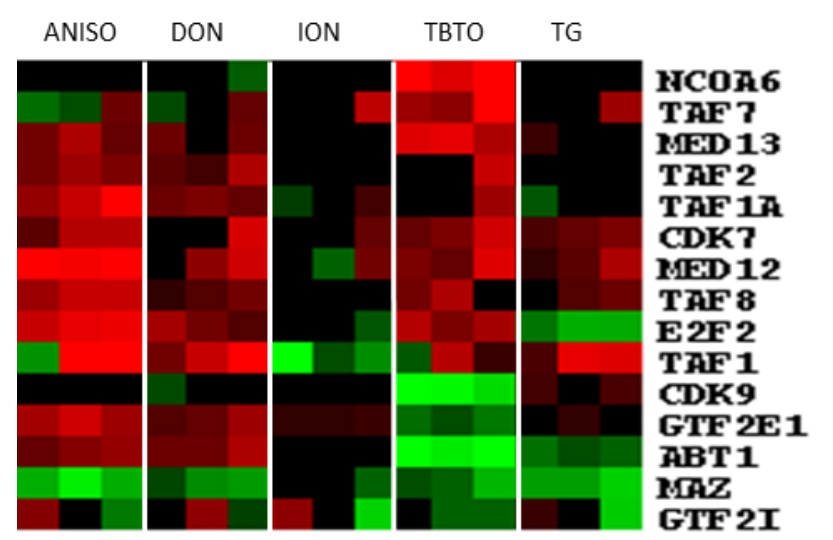

Fig. 4B. Genes involved in RNA transcription.

Genes involved in the process of transcription of RNA were upregulated by anisomycin, DON and TBTO.

Ionomycin and thapsigargin have little to no effect on these genes. 15 out of 65 genes were selected.

\section{Endoplasmic reticulum stress involved genes}

Figure 5 shows heat maps for genes that play a role within one or more processes involved in the induction of ER stress. The model compound for induction of ER stress, thapsigargin, induces the highest proportion of genes within each of the processes except induction of heat shock proteins. In this latter pathway, TBTO induces the highest number of genes. Compared to TBTO and thapsigargin, only few genes involved in the processes from ER protein folding control to ER associated protein degradation (ERAD) are upregulated by anisomycin and DON. However, anisomycin and DON induce a higher proportion of genes related to ER stress related transcription factors and apoptosis. Ionomycin induced expression of genes that encode heat shock proteins or play a role in ERAD, ER related transcription factors and ER related apoptosis. 
DON shares a similar mode of action as the ribotoxic stress inducer anisomycin while TBTO shares ER stress patterns with the ER stress inducer thapsigargin based on comparative gene expression profiling in Jurkat T cells

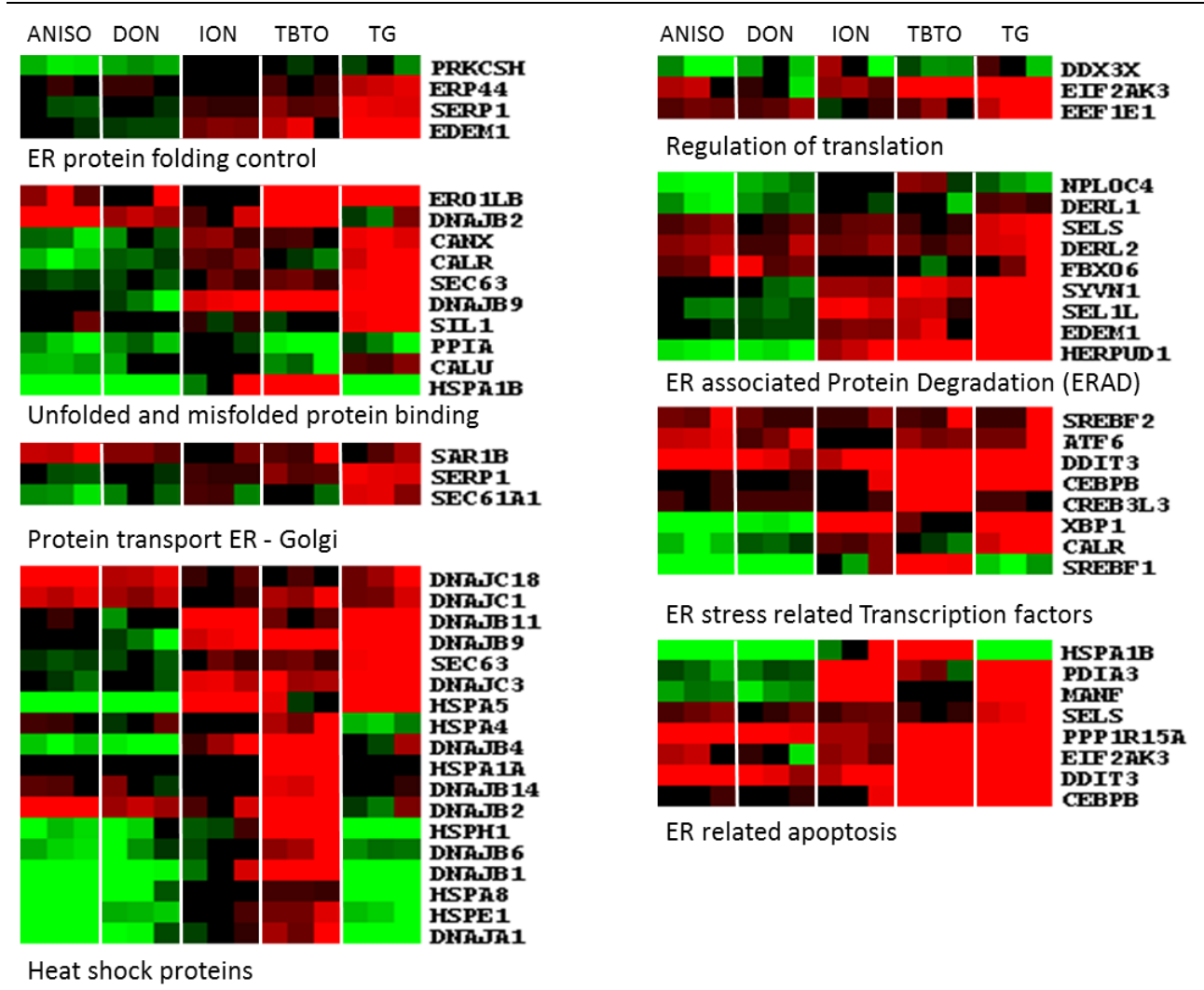

Fig. 5. Genes involved in different stages of Unfolded Protein Response.

Thapsigargin and TBTO induced most of the genes in all processes of the unfolded protein response. DON and anisomycin downregulated genes of processes early in the unfolded protein response and upregulated genes in later stages (ER stress transcription factors and ER related apoptosis). Ionomycin also induced expression of genes particularly in later stages of the unfolded protein response.

\section{T cell activation}

Many of the genes known to be upregulated during $\mathrm{T}$ cell activation were also upregulated by anisomycin, DON, ionomycin, TBTO and thapsigargin. Remarkably, the positive control for $\mathrm{T}$ cell activation ionomycin upregulated less genes than the other compounds. Almost all $\mathrm{T}$ cell activation-induced genes upregulated by thapsigargin were also upregulated by TBTO. Other $\mathrm{T}$ cell activation-related genes were, however, uniquely upregulated by TBTO (Fig 6A). Five genes (CD55, CD69, PMAIP1, BACH2 and EVI2A) were upregulated by all compounds tested in this study. TBTO upregulated the highest number of the T cell activation related genes. A subset of genes upregulated by TBTO and thapsigargin were downregulated by DON and anisomycin (such as TNFSF9 and DUSP6) and vice versa (such as MYC and $\mathrm{RHOH}$ ).

TNFSF9 induces the proliferation of activated peripheral blood T-cells (Shuford et al., 1997), while DUSP6 inactivates MAPK/ERK pathways (Muda et al., 1998). MYC activates 
the transcription of proliferation related genes (Marcu et al., 1992). RHOH is a critical regulator of thymocyte development and T-cell antigen receptor (TCR) signalling by mediating recruitment and activation of ZAP70 (Gu et al., 2006). TBTO and thapsigargin may thus activate peripheral $\mathrm{T}$ cells, whereas anisomycin and DON might act on development of $\mathrm{T}$ cells in the thymus.

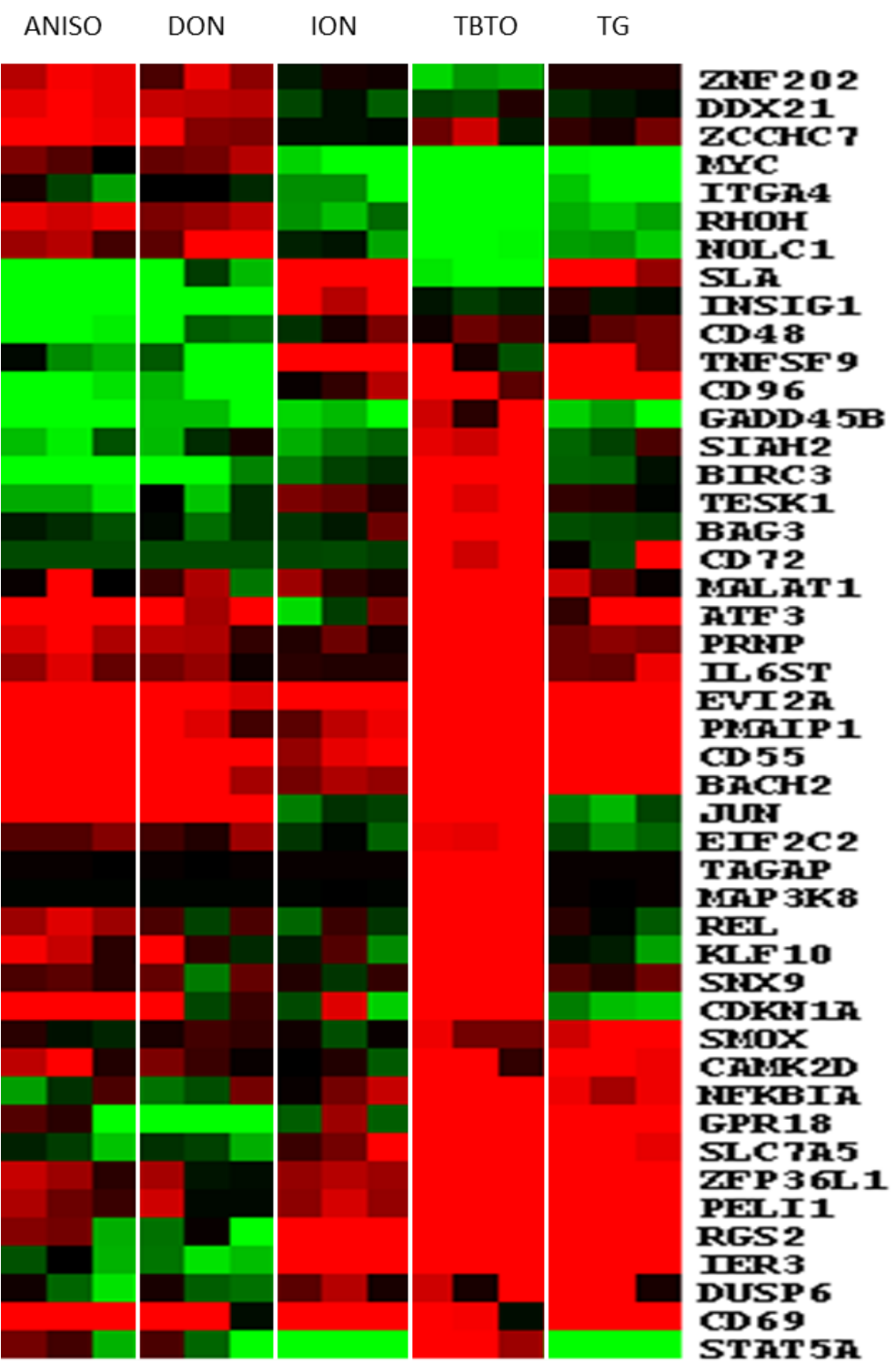

Fig. 6A. Genes involved in $T$ cell activation.

TBTO induced most of the genes involved in T cell activation. Anisomycin, DON, ionomycin and thapsigargin induced expression of half of the gene selection and repressed the expression of a few other genes. 46 out of 70 genes were selected. 
DON shares a similar mode of action as the ribotoxic stress inducer anisomycin while TBTO shares ER stress patterns with the ER stress inducer thapsigargin based on comparative gene expression profiling in Jurkat T cells

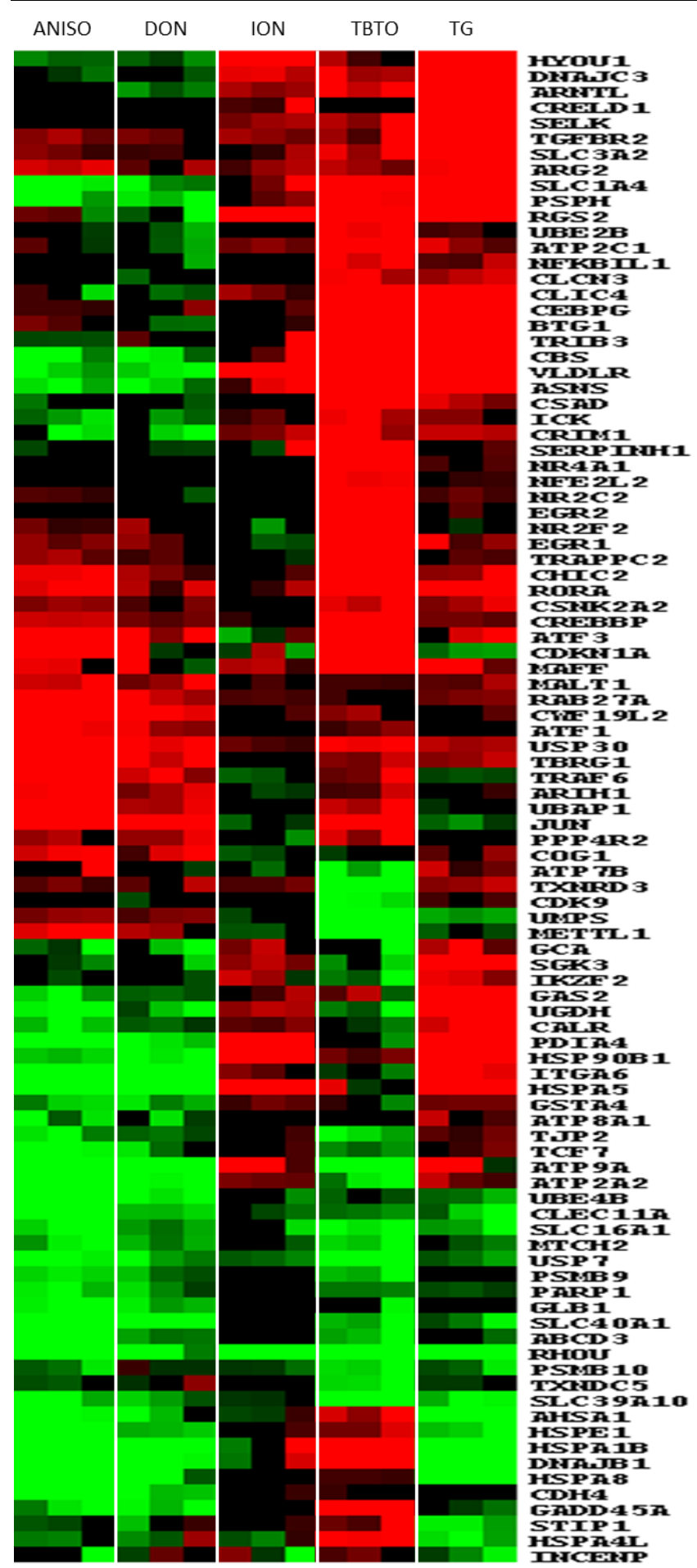


Fig. 6B. Genes involved in NRF2 activation

Genes upregulated during NRF2 activation were upregulated by ionomycin, TBTO and thapsigargin exposure. Anisomycin and DON upregulated some genes but also downregulated half of the genes. 97 genes out of 452 genes were selected.

\section{NRF2 activation and oxidative stress}

NRF2 is a transcription factor that is activated by oxidative stress. From the model compounds, thapsigargin induced the highest number of NRF2 target genes (Fig. 6B). Many of the thapsigargin induced NRF2 target genes were also upregulated by TBTO while another smaller subset was uniquely upregulated by ionomycin and thapsigargin. Anisomycin and DON downregulated a relatively high proportion of NRF2 target genes. Two well-known target genes of NRF2 are RGS2 and CREBBP (Katoh et al., 2001; Salim et al., 2011). RGS2 is upregulated by ionomycin, TBTO and thapsigargin and CREBBP is upregulated by anisomycin, DON, TBTO and thapsigargin.

\section{Apoptosis}

Many apoptosis related genes were clearly affected by TBTO, DON, thapsigargin and anisomycin (Fig. 7A). The expression patterns of anisomycin and DON were almost identical, which again fits to the hypothesis that both compounds act via the same mode of action. The majority of the thapsigargin affected genes were affected in the same direction by TBTO. Genes that were downregulated by TBTO were also downregulated by thapsigargin. Differences were observed for a group of genes that were upregulated by TBTO but not by thapsigargin (genes GADD45B - CASP8). Ionomycin induced a relatively low number of genes of which might indicate that a calcium rise alone only slightly induces apoptosis in T cells. 
DON shares a similar mode of action as the ribotoxic stress inducer anisomycin while TBTO shares ER stress patterns with the ER stress inducer thapsigargin based on comparative gene expression profiling in Jurkat T cells

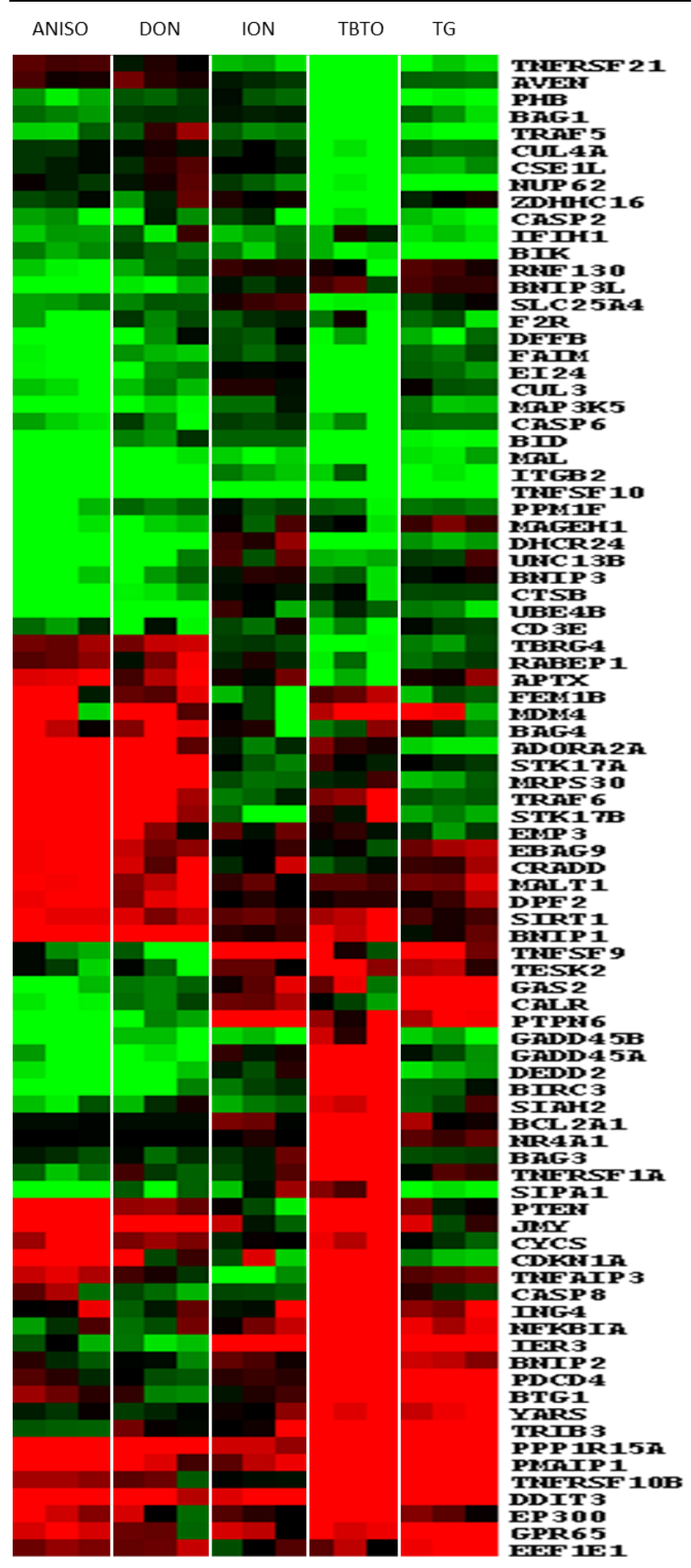


Fig 7A. Genes involved in apoptosis

Genes related to apoptosis were downregulated by anisomycin, DON and thapsigargin. A smaller portion of the genes was upregulated by these three compounds. TBTO upregulated and downregulated half of the genes. 88 genes out of 245 genes were selected.

\section{Mitochondrion proteins}

Genes encoding for mitochondrial proteins were similarly upregulated by anisomycin and DON (Fig. 7B). Nearly all genes encoding for mitochondrial proteins were downregulated by TBTO, whereas only half of these genes was downregulated by thapsigargin. Ionomycin had minimal effect on this set. The upregulation of mitochondrion proteins by DON was shown in our previous experiments on Jurkat cells (Katika et al., 2012b). On the other hand, the downregulation of these proteins by TBTO is a new finding.

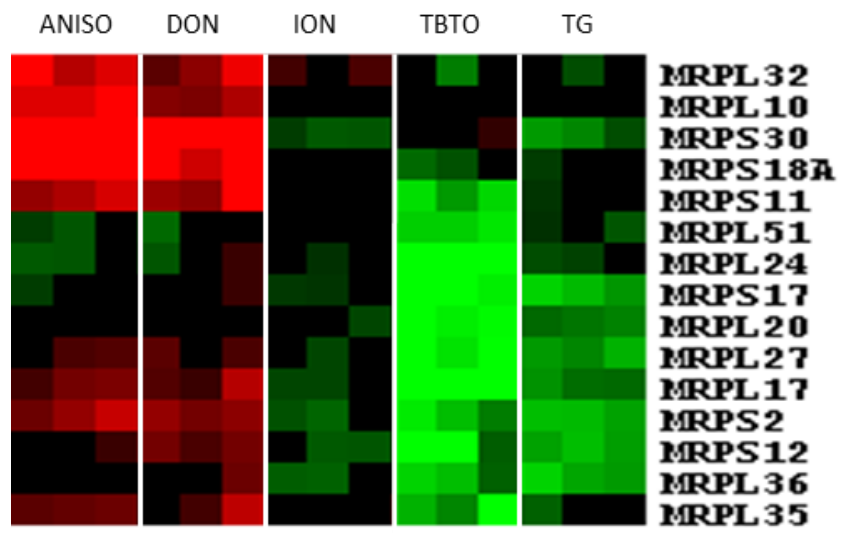

Fig. 7B. Expression of genes involved in mitochondrion protein function.

Most of the genes involved in mitochondrion function are upregulated by anisomycin and DON and downregulated by TBTO and thapsigargin. Ionomycin has no effect on these genes. In total 15 out of 63 genes were presented.

\section{Discussion}

Our previous gene expression studies indicated that DON, but not TBTO, affects gene sets related to ribosome function, RNA/protein synthesis and processing. On the other hand, DON and TBTO commonly affected processes such as ER stress, calcium mediated signalling, NFkB pathway, T cell activation, oxidative stress and apoptosis. The present study aimed to further substantiate the possible mechanisms underlying the immunotoxicity of DON and TBTO. For this, the effects of DON and TBTO on gene expression profiles in Jurkat cells were compared to those of model compounds for the induction of ribotoxic stress (anisomycin), ER stress (thapsigargin) and $T$ cell activation (ionomycin). The rationale was that compounds with similar modes of action will induce similar gene expression profiles. Genes affected by DON and TBTO that are not affected by the model compounds would indicate additional effects.

Hierarchical clustering indicated that anisomycin and DON have very similar effects in Jurkat cells, since the responses of gene expression to these compounds were almost 
DON shares a similar mode of action as the ribotoxic stress inducer anisomycin while TBTO shares ER stress patterns with the ER stress inducer thapsigargin based on comparative gene expression profiling in Jurkat T cells

identical as shown in the cluster of 2557 genes in Figure 2. The similarity was also big on gene sets that were affected by both compounds (Fig. 3). In accordance with this, DON and anisomycin also affected many genes into the same direction. The biological interpretation of the transcriptomics data indicated that anisomycin as well as DON upregulated genes involved in ribosome, RNA/protein synthesis and processing, ER stress, mitochondria, oxidative stress, $\mathrm{T}$ cell activation and apoptosis. This confirms earlier findings that both compounds bind to and damage ribosomes and activate ribosome associated kinases leading to ribotoxic stress (Iordanov et al., 1997). In addition, a recent study showed that the effects of anisomycin on ribosomal RNA cleavage were similar as observed for DON (He et al., 2012). Taken together, anisomycin and DON both elevated the expression of genes involved in the entire route of RNA and protein synthesis, which might be a compensation mechanism for the inhibiting action of anisomycin and DON on protein synthesis.

Hierarchical clustering also visualized similarities and differences between the effects of TBTO and the model compound for ER stress, thapsigargin. Most genes affected by thapsigargin were also affected in the same direction by TBTO (Fig. 2) which confirms our previous findings that TBTO induces ER stress. Moreover, both thapsigargin and TBTO induce many genes involved in ER stress, mitochondria, oxidative stress, $\mathrm{T}$ cell activation and apoptosis. In general, TBTO affected more genes of these pathways or generated higher induction values than thapsigargin. An exception were genes known to be involved in unfolded protein binding or ER stress (Fig. 5) of which more genes were affected by thapsigargin than by TBTO. In contrast to anisomycin and DON, thapsigargin and TBTO downregulated most of the gene sets involved in RNA and ribosomal function (Fig. 3) indicating that thapsigargin and TBTO do not induce a ribotoxic stress response.

Our data allow to compare two routes of ER stress induction, being ER stress induction via ribotoxic stress or via direct effects on the ER. The ribotoxic stress inducers anisomycin and DON induced only few genes and downregulated relatively many genes involved in the unfolded protein response (Fig. 5, ER protein folding, 'unfolded and misfolded protein binding', and ER associated protein degradation). In contrast, TBTO and the direct ER stress inducer thapsigargin induce a high proportion of genes involved in the unfolded protein response. This includes HERPUD1, that is well-known to be involved in the destruction of misfolded proteins during the unfolded protein response (Hori et al., 2004). This difference is likely due to that ribotoxic stress induces a stop of translation leading to less proteins entering the ER which tempers the unfolded protein response. TBTO (Katika et al., 2012a) and thapsigargin directly affect the ER which does induce the unfolded protein response. At the end, however, both anisomycin and DON as well as thapsigargin and TBTO induce ER stress related transcription factors and apoptosis inducing genes (Fig. 5).

Thapsigargin is known for its high affinity to bind and inhibit the ER Ca2+ ATPase SERCA leading to induction of ER stress, T cell activation and apoptosis (Rogers et al., 1995; Treiman et al., 1998). It has been proposed before that also TBTO induces ER stress by acting on SERCA (Kass and Orrenius, 1999; Katika et al., 2012a). In that case, all genes 
affected by thapsigargin would be expected to be affected in the same direction by TBTO as well. This is true for some groups of genes (Fig. 2, clusters B, C, E, F, H, J, K, O) but not for all genes. Particularly, the genes within Fig. 2, cluster D (also Suppl. Fig. 1), and part of cluster G, and Fig. 5 are uniquely affected by thapsigargin. The genes within cluster D are not only upregulated by thapsigargin but also by ionomycin. The induction of these genes is likely due to the release of calcium from intracellular storages which is a known effect of both thapsigargin and ionomycin (Imboden et al., 1985; Jiang et al., 1994). Therefore, the observation that induction of genes by thapsigargin and not by TBTO indicates that TBTO likely affects another target than SERCA. In addition, TBTO induces effects that are not induced by thapsigargin, for example increased expression of genes involved in DNA packaging and nucleosome assembly (Fig. 2, cluster I, Suppl. Fig 2), genes encoding for heat shock proteins (Fig. 5) and apoptosis inducing genes (Fig. 7A) and decreased expression of genes coding for mitochondrial proteins (Fig. 7B). The effect of TBTO on heat shock proteins is a new finding, although Hsp70 protein was increased in stingrays that were exposed to TBTO (Dwivedi and Trombetta, 2006). Also the downregulation of genes coding for mitochondrial proteins is a new finding. This indicates that TBTO induces more effects than those on the ER alone.

Ionomycin was included as a reference compound that increases intracellular calcium levels which in turn induces a $\mathrm{T}$ cell activation response. In accordance to the expectations, ionomycin did induce genes involved in calcium binding and T cell activation (Fig. 3 and 6A). Ionomycin had minimal effects on ribosomal genes, RNA processing and mitochondrial genes (Figs 3, 4 and 7B) but did induce genes involved in ER stress and apoptosis. This indicates that a raise of intracellular calcium levels is sufficient for induction of ER stress and apoptosis next to T cell activation in Jurkat cells. It is interesting that a group of genes (Suppl. Fig. 1) are uniquely upregulated by ionomycin and thapsigargin. This set of genes included genes involved in the unfolded protein response and $\mathrm{T}$ cell activation.

During normal $\mathrm{T}$ cell activation, calcium release from the ER is triggered by inositol-1,4,5trisphosphate (IP3) that is generated as a response to antigen binding to the T-cell receptor (Gwack et al., 2007). DON and TBTO are not expected to activate the T cell receptor but the $\mathrm{T}$ cell activation response is likely activated by the induction of calcium release from the ER. Induction of calcium influx from the ER by ionomycin (Morgan and Jacob, 1994) induced the expression of a subset of genes involved in protein folding in the ER, ER stress (UPR) and T cell activation (fig. 2, cluster D and Fig. 5). The impact of ionomycin on overall gene expression was much less than that of anisomycin, DON, TBTO and thapsigargin, indicating that direct effects on ribosomes and the ER induce many more genes than those induced by a raise of calcium ions alone.

The effects of DON on mitochondrial proteins are in accordance with our previous findings on the effect of DON on mitochondria in Jurkat cells (Katika et al., 2012b). An overview of genes coding for mitochondrial proteins showed that anisomycin and DON induced most of the mitochondrial ribosomal proteins whereas these were downregulated or not affected by 
DON shares a similar mode of action as the ribotoxic stress inducer anisomycin while TBTO shares ER stress patterns with the ER stress inducer thapsigargin based on comparative gene expression profiling in Jurkat T cells

TBTO and thapsigargin (Fig. 7B). The downregulation of mitochondrion protein genes was more pronounced for TBTO than for thapsigargin. Mitochondrion related genes such as MRPS18A and MRPS30 were upregulated by anisomycin and DON in the present study and were also upregulated by DON exposure in Jurkat T cells in a previous study (Katika et al., 2012b). Mitochondrial damage leads to oxidative stress and genes related to oxidative stress response were affected by anisomycin, DON, ionomycin, thapsigargin and TBTO. A subset of genes related to oxidative stress and NRF2 pathway were affected by anisomycin and DON and approximately half of the genes were upregulated by TBTO and thapsigargin (Fig. 6B). Some of these latter genes, such as RORA, MAFF and USP30, are also upregulated by anisomycin and DON. Overall, however, anisomycin and DON induce less genes that are known to be involved in the NRF2 pathway than TBTO and TG. In addition, TBTO and, more convincingly, thapsigargin exposure upregulated SERP1 expression, a gene which is elevated after oxidative stress leading to the accumulation of unfolded proteins (Yamaguchi et al., 1999). This suggests that TBTO and thapsigargin cause more oxidative stress than anisomycin and DON that is not caused by their effects on mitochondrial proteins. Induction of oxidative stress in Jurkat cells by DON and TBTO has also been detected in our previous studies (Katika et al., 2012b; Katika et al., 2011). Induction of oxidative stress by the production of reactive oxygen species by DON and TBTO has also been described in HepG2 cells (Zhang et al., 2009).

Although some of the gene sets were not significantly affected by anisomycin, ionomycin and thapsigargin according to GSEA analysis (Fig. 3), a number of genes that are related to ribosome, RNA biosynthesis, NRF2 pathway, T cell activation, apoptosis and mitochondria are affected by all the compounds (Fig. 4-7). This difference will be partly due to the fact that GSEA imply all genes for its significance testing while the heat maps only show genes that are at least $1.7 \mathrm{x}$ up or downregulated. In addition, gene sets for which a part is upregulated and another part downregulated will not be significantly enriched according to the GSEA statistics.

An effect found uniquely for TBTO in this study was the upregulation of genes involved in DNA packaging and nucleosome assembly (Fig. 2 cluster I; supplementary Fig. 2). Eight of these TBTO induced genes encode for histones and this reveals a mode of action of TBTO that has not been published before. Since these genes were not regulated by thapsigargin, this indicates a difference in the modes of action of both compounds.

In summary, the present study demonstrates that DON has a similar mode of action as the ribotoxic stress inducer anisomycin. DON did not affect other genes than anisomycin indicating the effect of DON to be restricted to ribotoxic stress. The similarity of gene expression profiles induced by TBTO and thapsigargin including effects on ER stress related genes confirm earlier indications that the mode of action of TBTO is induction of ER stress. TBTO also induced groups of genes that are involved in DNA packaging and heat shock response that are not affected by thapsigargin indicating an additional mode of action. DON, anisomycin, TBTO and thapsigargin induce ER stress that finally results in T cell activation, oxidative stress and apoptosis. DON and anisomycin induce ER stress via 


\section{Chapter 5}

ribotoxic stress while TBTO and thapsigargin induce ER stress independently of ribotoxic stress. Gene expression changes based on a raise in intracellular calcium alone (ionomycin) were less than those induced by DON, anisomycin, TBTO and thapsigargin but thapsigargin does induce genes involved in ER stress, T cell activation, oxidative stress and apoptosis either.

\section{Acknowledgements}

The authors like to thank Andre Boorsma for his assistance during the analysis of the microarray data. The study is supported by a grant (MFA 6809) that the University of Maastricht received from the Dutch Technology Foundation STW. 
DON shares a similar mode of action as the ribotoxic stress inducer anisomycin while TBTO shares ER stress patterns with the ER stress inducer thapsigargin based on comparative gene expression profiling in Jurkat T cells

\section{References}

Baken, K.A., Arkusz, J., Pennings, J.L., Vandebriel, R.J., van Loveren, H., 2007. In vitro immunotoxicity of bis(tri-n-butyltin)oxide (TBTO) studied by toxicogenomics. Toxicology 237, 35-48.

Chatila, T., Silverman, L., Miller, R., Geha, R., 1989. Mechanisms of T cell activation by the calcium ionophore ionomycin. J Immunol 143, 1283-1289.

Civelek, M., Manduchi, E., Riley, R.J., Stoeckert, C.J., Jr., Davies, P.F., 2009. Chronic endoplasmic reticulum stress activates unfolded protein response in arterial endothelium in regions of susceptibility to atherosclerosis. Circ Res 105, 453-461.

Dwivedi, J., Trombetta, L.D., 2006. Acute toxicity and bioaccumulation of tributyltin in tissues of Urolophus jamaicensis (yellow stingray). J Toxicol Environ Health A 69, 1311-1323.

Eisen, M.B., Spellman, P.T., Brown, P.O., Botstein, D., 1998. Cluster analysis and display of genome-wide expression patterns. P Natl Acad Sci USA 95, 14863-14868.

Ekins, S., Bugrim, A., Brovold, L., Kirillov, E., Nikolsky, Y., Rakhmatulin, E., Sorokina, S., Ryabov, A., Serebryiskaya, T., Melnikov, A., Metz, J., Nikolskaya, T., 2006. Algorithms for network analysis in systemsADME/Tox using the MetaCore and MetaDrug platforms. Xenobiotica; the fate of foreign compounds in biological systems 36, 877-901.

Fielden, M.R., Adai, A., Dunn, R.T., 2nd, Olaharski, A., Searfoss, G., Sina, J., Aubrecht, J., Boitier, E., Nioi, P., Auerbach, S., Jacobson-Kram, D., Raghavan, N., Yang, Y., Kincaid, A., Sherlock, J., Chen, S.J., Car, B., Predictive Safety Testing Consortium, C.W.G., 2011. Development and evaluation of a genomic signature for the prediction and mechanistic assessment of nongenotoxic hepatocarcinogens in the rat. Toxicol Sci 124, 54-74.

Futami, T., Miyagishi, M., Taira, K., 2005. Identification of a network involved in thapsigargin-induced apoptosis using a library of small interfering RNA expression vectors. J Biol Chem 280, 826-831.

Grollman, A.P., 1967. Inhibitors of protein biosynthesis. II. Mode of action of anisomycin. J Biol Chem 242, 3226-3233.

Grundler, W., Dirscherl, P., Beisker, W., Marx, K., Stampfl, A., Maier, K., Zimmermann, I., Nusse, M., 2001. Early functional apoptotic responses of thymocytes induced by Tri-n-butyltin. Cytometry 44, 45-56.

Gu, Y., Chae, H.D., Siefring, J.E., Jasti, A.C., Hildeman, D.A., Williams, D.A., 2006. RhoH GTPase recruits and activates Zap70 required for T cell receptor signaling and thymocyte development. Nat Immunol 7, 1182-1190. Gwack, Y., Feske, S., Srikanth, S., Hogan, P.G., Rao, A., 2007. Signalling to transcription: store-operated Ca2+ entry and NFAT activation in lymphocytes. Cell Calcium 42, 145-156.

He, K., Zhou, H.R., Pestka, J.J., 2012. Mechanisms for ribotoxin-induced ribosomal RNA cleavage. Toxicol Appl Pharmacol 265, 10-18.

Hoch, M., 2001. Organotin compounds in the environment - an overview. Appl Geochem 16, 719-743.

Hori, O., Ichinoda, F., Yamaguchi, A., Tamatani, T., Taniguchi, M., Koyama, Y., Katayama, T., Tohyama, M., Stern, D.M., Ozawa, K., Kitao, Y., Ogawa, S., 2004. Role of Herp in the endoplasmic reticulum stress response. Genes Cells 9, 457-469.

Imboden, J.B., Weiss, A., Stobo, J.D., 1985. The antigen receptor on a human T cell line initiates activation by increasing cytoplasmic free calcium. J Immunol 134, 663-665.

Iordanov, M.S., Pribnow, D., Magun, J.L., Dinh, T.H., Pearson, J.A., Chen, S.L., Magun, B.E., 1997. Ribotoxic stress response: activation of the stress-activated protein kinase JNK1 by inhibitors of the peptidyl transferase reaction and by sequence-specific RNA damage to the alpha-sarcin/ricin loop in the 28S rRNA. Mol Cell Biol 17, 3373-3381.

Jiang, S., Chow, S.C., Nicotera, P., Orrenius, S., 1994. Intracellular Ca2+ signals activate apoptosis in thymocytes: studies using the $\mathrm{Ca}(2+)$-ATPase inhibitor thapsigargin. Exp Cell Res 212, 84-92.

Kass, G.E.N., Orrenius, S., 1999. Calcium signaling and cytotoxicity. Environmental Health Perspectives 107, 2535 .

Katika, M.R., Hendriksen, P.J., de Ruijter, N.C., van Loveren, H., Peijnenburg, A., 2012a. Immunocytological and biochemical analysis of the mode of action of bis (tri-n-butyltin) tri-oxide (TBTO) in Jurkat cells. Toxicol Lett $212,126-136$. 


\section{Chapter 5}

Katika, M.R., Hendriksen, P.J., Shao, J., van Loveren, H., Peijnenburg, A., 2012b. Transcriptome analysis of the human T lymphocyte cell line Jurkat and human peripheral blood mononuclear cells exposed to deoxynivalenol (DON): New mechanistic insights. Toxicol Appl Pharmacol 264, 51-64.

Katika, M.R., Hendriksen, P.J.M., van Loveren, H., Peijnenburg, A., 2011. Exposure of Jurkat cells to bis (tri-nbutyltin) oxide (TBTO) induces transcriptomics changes indicative for ER-and oxidative stress, T cell activation and apoptosis. Toxicol Appl Pharm 254, 311-322.

Katoh, Y., Itoh, K., Yoshida, E., Miyagishi, M., Fukamizu, A., Yamamoto, M., 2001. Two domains of Nrf2 cooperatively bind CBP, a CREB binding protein, and synergistically activate transcription. Genes Cells 6, 857868 .

Kergosien, D.H., Rice, C.D., 1998. Macrophage secretory function is enhanced by low doses of tributyltin-oxide (TBTO), but not tributyltin-chloride (TBTCl). Arch Environ Contam Toxicol 34, 223-228.

Krastev, D.B., Slabicki, M., Paszkowski-Rogacz, M., Hubner, N.C., Junqueira, M., Shevchenko, A., Mann, M., Neugebauer, K.M., Buchholz, F., 2011. A systematic RNAi synthetic interaction screen reveals a link between p53 and snoRNP assembly. Nature cell biology 13, 809-818.

Kuny, S., Gaillard, F., Sauve, Y., 2012. Differential gene expression in eyecup and retina of a mouse model of Stargardt-like macular dystrophy (STGD3). Investigative ophthalmology \& visual science 53, 664-675.

Lamb, J., Crawford, E.D., Peck, D., Modell, J.W., Blat, I.C., Wrobel, M.J., Lerner, J., Brunet, J.P., Subramanian, A., Ross, K.N., Reich, M., Hieronymus, H., Wei, G., Armstrong, S.A., Haggarty, S.J., Clemons, P.A., Wei, R., Carr, S.A., Lander, E.S., Golub, T.R., 2006. The Connectivity Map: using gene-expression signatures to connect small molecules, genes, and disease. Science 313, 1929-1935.

Liu, W., Youn, H.D., Liu, J.O., 2001. Thapsigargin-induced apoptosis involves Cabin1-MEF2-mediated induction of Nur77. Eur J Immunol 31, 1757-1764.

Marcu, K.B., Bossone, S.A., Patel, A.J., 1992. myc function and regulation. Annual review of biochemistry 61, 809-860.

Mason, M.J., Mahaut-Smith, M.P., Grinstein, S., 1991. The role of intracellular Ca2+ in the regulation of the plasma membrane Ca2+ permeability of unstimulated rat lymphocytes. J Biol Chem 266, 10872-10879.

Middlebrook, J.L., Leatherman, D.L., 1989. Binding of T-2 toxin to eukaryotic cell ribosomes. Biochem Pharmacol 38, 3103-3110.

Morgan, A.J., Jacob, R., 1994. Ionomycin enhances Ca2+ influx by stimulating store-regulated cation entry and not by a direct action at the plasma membrane. The Biochemical journal 300 ( Pt 3), 665-672.

Muda, M., Theodosiou, A., Gillieron, C., Smith, A., Chabert, C., Camps, M., Boschert, U., Rodrigues, N., Davies, K., Ashworth, A., Arkinstall, S., 1998. The mitogen-activated protein kinase phosphatase-3 N-terminal noncatalytic region is responsible for tight substrate binding and enzymatic specificity. J Biol Chem 273, 93239329.

Nollen, E.A., Brunsting, J.F., Roelofsen, H., Weber, L.A., Kampinga, H.H., 1999. In vivo chaperone activity of heat shock protein 70 and thermotolerance. Mol Cell Biol 19, 2069-2079.

Osman, A.M., Pennings, J.L.A., Blokland, M., Peijnenburg, A., van Loveren, H., 2010. Protein expression profiling of mouse thymoma cells upon exposure to the trichothecene deoxynivalenol (DON): Implications for its mechanism of action. Journal of Immunotoxicology 7, 147-156.

Osman, A.M., van Loveren, H., 2012. Phosphoproteomic Analysis of Mouse Thymoma Cells Treated With Tributyltin Oxide: TBTO Affects Proliferation and Energy Sensing Pathways. Toxicol Sci 126, 84-100. Pestka, J.J., Zhou, H.-R., Moon, Y., Chung, Y.J., 2004. Cellular and molecular mechanisms for immune modulation by deoxynivalenol and other trichothecenes: unraveling a paradox. Toxicology Letters 153, 61-73. Pino, S.C., O'Sullivan-Murphy, B., Lidstone, E.A., Thornley, T.B., Jurczyk, A., Urano, F., Greiner, D.L., Mordes, J.P., Rossini, A.A., Bortell, R., 2008. Protein kinase C signaling during T cell activation induces the endoplasmic reticulum stress response. Cell stress \& chaperones 13, 421-434.

Reich, M., Liefeld, T., Gould, J., Lerner, J., Tamayo, P., Mesirov, J.P., 2006. GenePattern 2.0. Nat Genet 38, 500501 .

Rodriguez-Fonseca, C., Amils, R., Garrett, R.A., 1995. Fine structure of the peptidyl transferase centre on 23 Slike rRNAs deduced from chemical probing of antibiotic-ribosome complexes. Journal of molecular biology 247 , 224-235. 
DON shares a similar mode of action as the ribotoxic stress inducer anisomycin while TBTO shares ER stress patterns with the ER stress inducer thapsigargin based on comparative gene expression profiling in Jurkat T cells

Rogers, T.B., Inesi, G., Wade, R., Lederer, W.J., 1995. Use of thapsigargin to study Ca2+ homeostasis in cardiac cells. Bioscience reports 15, 341-349.

Rotter, B.A., Prelusky, D.B., Pestka, J.J., 1996. Toxicology of deoxynivalenol (vomitoxin). Journal of toxicology and environmental health 48, 1-34.

Salim, S., Asghar, M., Taneja, M., Hovatta, I., Wu, Y.L., Saha, K., Sarraj, N., Hite, B., 2011. Novel role of RGS2 in regulation of antioxidant homeostasis in neuronal cells. FEBS Lett 585, 1375-1381.

Scheuner, D., Kaufman, R.J., 2008. The unfolded protein response: a pathway that links insulin demand with betacell failure and diabetes. Endocrine reviews 29, 317-333.

Schmeits, P.C., Volger, O.L., Zandvliet, E.T., van Loveren, H., Peijnenburg, A.A., Hendriksen, P.J., 2013.

Assessment of the usefulness of the murine cytotoxic T cell line CTLL-2 for immunotoxicity screening by transcriptomics. Toxicol Lett 217, 1-13.

Shaffer, A.L., Rosenwald, A., Hurt, E.M., Giltnane, J.M., Lam, L.T., Pickeral, O.K., Staudt, L.M., 2001.

Signatures of the immune response. Immunity 15, 375-385.

Shuford, W.W., Klussman, K., Tritchler, D.D., Loo, D.T., Chalupny, J., Siadak, A.W., Brown, T.J., Emswiler, J., Raecho, H., Larsen, C.P., Pearson, T.C., Ledbetter, J.A., Aruffo, A., Mittler, R.S., 1997. 4-1BB costimulatory signals preferentially induce $\mathrm{CD} 8+\mathrm{T}$ cell proliferation and lead to the amplification in vivo of cytotoxic $\mathrm{T}$ cell responses. J Exp Med 186, 47-55.

Subramanian, A., Tamayo, P., Mootha, V.K., Mukherjee, S., Ebert, B.L., Gillette, M.A., Paulovich, A., Pomeroy, S.L., Golub, T.R., Lander, E.S., Mesirov, J.P., 2005. Gene set enrichment analysis: a knowledge-based approach for interpreting genome-wide expression profiles. P Natl Acad Sci USA 102, 15545-15550.

Treiman, M., Caspersen, C., Christensen, S.B., 1998. A tool coming of age: thapsigargin as an inhibitor of sarcoendoplasmic reticulum Ca(2+)-ATPases. Trends in pharmacological sciences 19, 131-135.

van Kol, S.W., Hendriksen, P.J., van Loveren, H., Peijnenburg, A., 2011. The effects of deoxynivalenol on gene expression in the murine thymus. Toxicol Appl Pharmacol 250, 299-311.

van Kol, S.W., Hendriksen, P.J., van Loveren, H., Peijnenburg, A., 2012. Transcriptomics analysis of primary

mouse thymocytes exposed to bis(tri-n-butyltin)dioxide (TBTO). Toxicology 296, 37-47.

Van Loveren, H., Krajnc, E.I., Rombout, P.J., Blommaert, F.A., Vos, J.G., 1990. Effects of ozone,

hexachlorobenzene, and bis(tri-n-butyltin)oxide on natural killer activity in the rat lung. Toxicol Appl Pharmacol 102, 21-33.

Vos, J.G., De Klerk, A., Krajnc, E.I., Van Loveren, H., Rozing, J., 1990. Immunotoxicity of bis(tri-nbutyltin)oxide in the rat: effects on thymus-dependent immunity and on nonspecific resistance following long-term exposure in young versus aged rats. Toxicol Appl Pharmacol 105, 144-155.

Yamaguchi, A., Hori, O., Stern, D.M., Hartmann, E., Ogawa, S., Tohyama, M., 1999. Stress-associated endoplasmic reticulum protein 1 (SERP1)/Ribosome-associated membrane protein 4 (RAMP4) stabilizes membrane proteins during stress and facilitates subsequent glycosylation. J Cell Biol 147, 1195-1204.

Zhang, X., Jiang, L., Geng, C., Cao, J., Zhong, L., 2009. The role of oxidative stress in deoxynivalenol-induced DNA damage in HepG2 cells. Toxicon 54, 513-518. 



\section{Chapter 6}

\section{Successful validation of genomic biomarkers for human immunotoxicity in Jurkat $\mathrm{T}$ cells in vitro}

Peter C J Schmeits, Jia Shao, Danique A van der Krieken, Oscar L Volger, Henk van Loveren, Ad A C M Peijnenburg and Peter J M Hendriksen Journal of applied Toxicology. 11/2014

Supplementary material can be found at:

http://onlinelibrary.wiley.com/doi/10.1002/jat.3079/suppinfo 


\begin{abstract}
Previously, we identified 25 classifier genes that were able to assess immunotoxicity using human Jurkat $\mathrm{T}$ cells. The present study aimed to validate these classifiers. For that purpose, Jurkat cells were exposed for $6 \mathrm{~h}$ to subcytotoxic doses of nine immunotoxicants, five non-immunotoxicants, and four compounds for which human immunotoxicity has not yet been fully established. RNA was isolated and subjected to Fluidigm qRT-PCR analysis. The sensitivity, specificity and accuracy of the screening assay as based on the nine immunotoxicants and five non-immunotoxicants used in this study were $100 \%, 80 \%$ and $93 \%$, respectively, which is better than the performance in our previous study. Only one compound was classified as false positive (benzo-e-pyrene). Of the four potential (non)immunotoxicants, chlorantraniliprole and Hidrasec were classified immunotoxic and sunset yellow and imidacloprid as non-immunotoxic. ToxPi analysis of the PCR data provided insight in the molecular pathways that were affected by the compounds. The immunotoxicants 2,3-dichloro-propanol and cypermethrin, although structurally different, affected protein metabolism and cholesterol biosynthesis and transport. In addition, four compounds, i.e. chlorpyrifos, aldicarb, benzo-e-pyrene and anti-CD3, affected genes in cholesterol metabolism and transport, protein metabolism and transcription regulation. qRT-PCR on eight additional genes coding for similar processes as defined in ToxPi analyses, supported these results. In conclusion, the 25 immunotoxic classifiers performed very well in a screening with new non-immunotoxic and immunotoxic compounds. Therefore, the Jurkat screening assay has great promise to be applied within a tiered approach for animal free testing of human immunotoxicity.
\end{abstract}




\section{Introduction}

Direct immunotoxicity is defined as the action of a compound on components of the immune system that lead to either immunostimulation or immunosuppression. The assessment of direct immunotoxicity is an important part of the overall toxicological investigation of chemicals (Lankveld, et al. 2010). Several authorities including the European Medicines Agency (EMEA 2006) and the US Food and Drug Administration (FDA 2002) emphasize the need to evaluate immunotoxic effects during the preclinical phase of drug development. Other authorities such as the Organisation for Economic Cooperation and Development (OECD) (Institoris, et al. 1998) and the Environmental Protection Agency (EPA 2013) stress the need for safety assessment of food contaminants and environmental pollutants. Current immunotoxicity screening still focuses on rodent in vivo models. Since the implementation of $\mathrm{REACH}$, that requires the evaluation of chemical hazards for chemicals of which the yearly production exceeds one tonne, progress has been made towards development of in vitro alternatives for immunotoxicity testing (EC 2006).

In our previous work, using the in vitro Jurkat $\mathrm{T}$ cell model, we identified and validated 25 biomarker genes representative for different mechanisms underlying direct immunotoxicity (Shao, et al. 2014, Shao, et al. 2013) (Table 1). Jurkat T cells were chosen since they are easy to work with, cheap, readily available and of human origin, making extrapolation to human hazard easier than an animal cell model. Jurkat cells have also been applied in assessing the effect of compounds on mitogen-induced proliferation and migration (Fernandez-Riejos, et al. 2008, Fischer, et al. 2004).

On the basis of the outcome of the previous study, two important questions were raised. Firstly, how does the screening system perform towards new classes of immunotoxicants that have not been tested yet? This question is relevant because the biomarkers are based on a set of chemicals belonging to a variety of compound classes such as metals, mycotoxins, herbicides, insecticides, fungicides. Therefore, how this biomarker based system will perform when exposing to a compound from a class that has not been tested should be further investigated. Secondly, only a limited number of non-immunotoxic compounds has been tested, which resulted in a less satisfactory specificity. How will this screening system perform when more non-immunotoxicants are included? To answer these important issues, new compounds were searched for in literature and reports.

In total we selected nine known immunotoxicants, five known non-immunotoxicants and four compounds for which it was not fully established whether they are immunotoxic or not (Table 2). Known immunotoxicants from new compound classes include the chloropropanol food contaminant 2,3-dichloro-1-propanol (2,3-DCP) (Lu, et al. 2013), the biological anti-CD3 (Ishiguro and Xavier 2004, Weetall, et al. 2002), the organophosphorus pesticide chlorpyrifos which causes immunotoxicity in T cells and NK cells (Dunier, et al. 1991, Noworyta-Glowacka, et al. 2012), the lectin phytohaemagglutinin (PHA-L) (Mitsuishi, et al. 1986) and the poly-brominated flame retardant tetrabromobisphenol A (TBBPA) (Birnbaum and Staskal 2004, Pullen, et al. 2003). In addition, immunotoxic compounds from classes tested before were included: the insecticides cypermethrin and 
aldicarb (Jin, et al. 2011), and the mycotoxin zearalenone (Abbes, et al. 2013).The insecticide aldicarb increased $\mathrm{T}$ cell populations in women drinking contaminated water (Mirkin, et al. 1990), however aldicarb was assessed to be non-immunotoxic in mice (Thomas, et al. 1987). Arsenic trioxide was already tested before in the Jurkat screening model and is tested again as a positive control as it showed the largest effects on the biomarker genes (Shao, et al. 2013).

Since the results of compounds that have been tested as non-immunotoxic are less likely to be published, a publication bias exists for non-immunotoxic compounds. Therefore, searches for non immunotoxicants also concerned governmental reports like those from the European CHemicals Agency (ECHA) and the Australian Pesticides and the Veterinary Medicines Authority (APVMA). Known non-immunotoxicants selected in this study were ametoctradin (APVMA), arsenobetaine (Borak and Hosgood 2007, Sakurai, et al. 2004), carbon tetrachloride (CCL4) (Smialowicz, et al. 1991), diuron (ECHA 2014) and benzo-epyrene (White, et al. 2012).

A third category contains compounds of which immunotoxicity has not been definitively been observed. Four compounds were included being sunset yellow FCF, racecadotril (Hidrasec), chlorantraniliprole (trade name Rynaxypyr) and imidacloprid. Sunset yellow FCF is a food contaminant that was tested immunotoxic in mice (Hashem, et al. 2010, Yadav, et al. 2013). Sunset yellow FCF reduced the number of monocytes to $50 \%$ in mice in vivo without affecting other immune cells (Hashem, et al. 2010). Hidrasec, which is used as treatment for diarrhoea, was assessed to be non-immotoxic in rodents (non-peer reviewed publications). Though, the information leaflet mentions that up to $1 \%$ of the users suffered from rash and erythema, that are clinical signs of hypersensitivity of the human skin to chemicals. Also chlorantraniliprole was evaluated as non-immunotoxic in rodents (non-peer reviewed publications). However, chlorantraniliprole is suspected to act on release of calcium from intracellular calcium stores (Lahm, et al. 2005) which is an important process in $\mathrm{T}$ cell activation. Therefore it was decided to include this drug in the present study as well. Imidacloprid is a neonicotinoid insecticide and is tested immunotoxic in rats and mice (Badgujar, et al. 2013, Gawade, et al. 2013). Nevertheless, there is little known about the effects of this compound on the human immune system and on humanderived immune cells in vitro.

The aim of this study is twofold. The first aim is to validate the 25 biomarkers previously identified by screening new immunotoxic and non-immunotoxic compounds. In our previous study the sensitivity, specificity and accuracy were 88, 67 and $85 \%$ (Shao, et al. 2014). The low specificity was likely due to the fact that only three non immunotoxic controls were examined. Therefore, in the present work, the performance of the classifier genes is tested using an extended set of non-immunotoxic controls. The second aim is to predict the immunotoxicity of five compounds for which insufficient data is available. Next to the 25 marker genes identified before, we selected eight additional genes that are known to be biomarkers for specific processes including $\mathrm{T}$ cell activation, ER stress, cholesterol homeostasis and cell cycle (Table 4). It was envisaged that the response of these genes in 
combination with the 25 markers for immunotoxicity will provide insight in the mechanisms of action of the compounds. For assessing the mRNA expression response of the 33 genes to the 19 compounds in Jurkat cells, we used a Fluidigm high-throughput PCR system, which has proven to be a fast and reliable system to study gene expression (Shao, et al. 2014). The set of 25 biomarkers yielded a sensitivity of $100 \%$, specificity of $80 \%$ and accuracy of $93 \%$. This performance was better than that obtained in the previous validation experiment (Shao, et al. 2014).

Table 1. Overview of 28 primers that were used as classifiers of immunotoxicity. The latter three primers (italics) were used as reference genes.

\begin{tabular}{|c|c|c|c|}
\hline Gene Symbol & Description & mRNA accession & Taqman assay \\
\hline ABCA1 & $\begin{array}{l}\text { ATP-binding cassette, sub-family A } \\
\text { (ABC1), member } 1\end{array}$ & NM_005502 & Hs01059118_m1 \\
\hline ABCG1 & $\begin{array}{l}\text { ATP-binding cassette, sub-family G } \\
\text { (WHITE), member } 1\end{array}$ & NM_004915 & Hs00245154_m1 \\
\hline AK4 & adenylate kinase 4 & NM_001005353 & Hs03405743_g1 \\
\hline ALDH8A1 & $\begin{array}{c}\text { aldehyde dehydrogenase } 8 \text { family, } \\
\text { member A1 }\end{array}$ & NM_001193480 & Hs00988965_m1 \\
\hline ARRDC3 & arrestin domain containing 3 & NM_020801 & Hs00385845_m1 \\
\hline BZRAP1 & $\begin{array}{l}\text { benzodiazapine receptor (peripheral) } \\
\text { associated protein } 1\end{array}$ & NM_004758 & Hs00270490_m1 \\
\hline $\mathrm{CCNG} 2$ & cyclin $\mathrm{G} 2$ & NM_004354 & Hs00171119_m1 \\
\hline CEBPB & $\begin{array}{l}\text { CCAAT/enhancer binding protein } \\
\text { (C/EBP), beta }\end{array}$ & NM_005194 & Hs00270923_s1 \\
\hline CHAC1 & $\begin{array}{l}\text { ChaC, cation transport regulator } \\
\text { homolog } 1 \text { (E. coli) }\end{array}$ & NM_001142776 & Hs00225520_m1 \\
\hline CRIM1 & $\begin{array}{l}\text { cysteine rich transmembrane BMP } \\
\text { regulator } 1 \text { (chordin-like) }\end{array}$ & NM_016441 & Hs00212750_m1 \\
\hline FBXO32 & F-box protein 32 & NM_001242463 & Hs01041408_m1 \\
\hline GPR18 & G protein-coupled receptor 18 & NM_001098200 & Hs00245542_m1 \\
\hline HMGCS1 & $\begin{array}{l}\text { 3-hydroxy-3-methylglutaryl-CoA } \\
\text { synthase } 1 \text { (soluble) }\end{array}$ & NM_001098272 & Hs00940429_m1 \\
\hline HSPA1B & heat shock $70 \mathrm{kDa}$ protein $1 \mathrm{~B}$ & NM_005346 & Hs01040501-sH \\
\hline
\end{tabular}




\section{Chapter 6}

\begin{tabular}{|c|c|c|c|}
\hline HSPA5 & $\begin{array}{l}\text { heat shock } 70 \mathrm{kDa} \text { protein } 5 \text { (glucose- } \\
\text { regulated protein, } 78 \mathrm{kDa})\end{array}$ & NM_005347 & Hs00946084_g1 \\
\hline ID1 & $\begin{array}{l}\text { inhibitor of DNA binding 1, dominant } \\
\text { negative helix-loop-helix protein }\end{array}$ & NM_002165 & Hs00357821_g1 \\
\hline ID2 & $\begin{array}{l}\text { inhibitor of DNA binding 2, dominant } \\
\text { negative helix-loop-helix protein }\end{array}$ & NM_002166 & Hs00747379_m1 \\
\hline KLF2 & Kruppel-like factor 2 (lung) & NM_016270 & Hs00360439_g1 \\
\hline KLHL24 & kelch-like 24 (Drosophila) & NM_017644 & Hs00214210_m1 \\
\hline NQO1 & $\mathrm{NAD}(\mathrm{P}) \mathrm{H}$ dehydrogenase, quinone 1 & NM_000903 & Hs01045995_m1 \\
\hline SLC7A11 & $\begin{array}{c}\text { solute carrier family } 7 \text { (anionic amino } \\
\text { acid transporter light chain, xc- system), } \\
\text { member } 11\end{array}$ & NM_014331 & Hs00921938_m1 \\
\hline SRXN1 & sulfiredoxin 1 & NM_080725 & Hs00607800_m1 \\
\hline TM6SF1 & transmembrane 6 superfamily member 1 & NM_001144903 & Hs00224823_m1 \\
\hline VLDLR & very low density lipoprotein receptor & NM_001018056 & Hs01047538_m1 \\
\hline VPREB1 & pre-B lymphocyte 1 & NM_007128 & Hs00356766_g1 \\
\hline$B 2 M$ & $\begin{array}{l}\text { B2 microglobulin, present on all } \\
\text { nucleated cells }\end{array}$ & NM_004048 & H2000984230_m \\
\hline GET4 & Golgi To ER Traffic Protein 4 Homolog & NM_015949.2 & Hs00944514_m1 \\
\hline$P I G G$ & $\begin{array}{c}\text { Phosphatidylinositol Glycan Anchor } \\
\text { Biosynthesis, Class } G\end{array}$ & NM_017733.3 & Hs01107608_m1 \\
\hline
\end{tabular}


Successful validation of genomic biomarkers for human immunotoxicity in Jurkat $\mathrm{T}$ cells in vitro

Table 2. Overview of the compounds, classes and concentrations used. Compounds $(n=18)$ are divided in immunotoxic ( $n=9$, top), non-immunotoxic $(n=5$, middle) and unknowns ( $n=4$, bottom).

\begin{tabular}{|c|c|c|c|}
\hline Compound name & Class & $\begin{array}{c}\text { Concentration }(\mu \mathrm{M}) \\
\text { CV80 }\end{array}$ & $\begin{array}{l}\text { Immuno- } \\
\text { toxicity }\end{array}$ \\
\hline $\begin{array}{l}\text { 2,3-dichloro-1- } \\
\text { propanol }\end{array}$ & Food contaminant, chloropropanol & 6000 & Yes \\
\hline Aldicarb & Insecticide & 1000 & Yes \\
\hline Anti-CD3 & Biological & $2.5 \mathrm{ng} / \mu \mathrm{l}$ & Yes \\
\hline Arsenic trioxide & Metal & 3 & Yes \\
\hline Chlorpyrifos & Organophosphorous pesticide & 1000 & Yes \\
\hline Cypermethrin & Insecticide & 1000 & Yes \\
\hline Phytohaemmagluttinin & Lectin & $100 \mathrm{ng} / \mathrm{ml}$ & Yes \\
\hline Tetrabromobisphenol A & Flame retardant & 75 & Yes \\
\hline Zearalenone & Fungal mycotoxin & 50 & Yes \\
\hline Ametoctradin & Fungicide & 25 & No \\
\hline Arsenobetaine & Organoarsenic compound & 20 & No \\
\hline Benzo[e]pyrene & Polyaromatic hydrocarbon & 250 & No \\
\hline Carbon tetrachloride & Organic compound & 1000 & No \\
\hline Diuron & Herbicide & 100 & No \\
\hline Chlorantraniliprole & Insecticide & 100 & $?$ \\
\hline Imidacloprid & Pesticide/insecticide, endocrine disrupter & 1000 & $?$ \\
\hline Hidrasec & Antidiarrheal drug & 500 & $?$ \\
\hline Sunset yellow - FCF & Food additive & 500 & $?$ \\
\hline
\end{tabular}

\section{Materials and Methods}

\section{Chemicals}

All chemicals were ordered from Sigma-Aldrich (Zwijndrecht, the Netherlands), except anti-CD3 and IgG isotype control (Abcam, Cambridge, UK).

\section{Cell culture}

The human T-lymphocyte cell line (Jurkat) was obtained from the American Type Culture Collection (ATCC). Jurkat cells were cultured in RPMI-1640 medium supplemented with 10\% Fetal Calf Serum, $2 \mathrm{mM}$ glutamine, $1 \mathrm{mM}$ sodium pyruvate, $1 \mathrm{mM}$ nonessential amino acids, $100 \mathrm{U} / \mathrm{ml}$ penicillin, and $100 \mu \mathrm{g} / \mathrm{ml}$ streptomycin (Invitrogen Life Science, Breda, the Netherlands). Cells were cultured at $37{ }^{\circ} \mathrm{C}$ with $5 \% \mathrm{CO} 2$ in a humidified atmosphere. The medium was refreshed three times a week. 
ATPlite assay

Cell viability was tested using the ATPlite assay (Perkin Elmer, Oosterhout, the Netherlands) which is based on the production of light caused by the reaction of ATP with luciferase and D-luciferin. The emitted light is proportional to the amount of ATP, which is a marker for cell viability. Jurkat cells were plated $20 \mathrm{~h}$ before exposure in a 96 well plate (220,000 cells/well). Exposure was done in triplicate in $100 \mu \mathrm{l}$ medium in 96 well plates for 24 hours to increasing concentrations of compounds, or to the vehicle controls. After exposure, the assay was performed according the manufacturer's protocol.

\section{Exposures}

Jurkat cells (passage number between 15 and 19) were seeded in 6-well plates containing $2.7 \mathrm{ml}(750,000$ cells/well) per well. After growing the cells for 20 hours, exposure was initiated by adding $0.3 \mathrm{ml}$ medium containing non-cytotoxic concentration of the compounds or vehicle controls. Subsequently, cells were exposed to the compounds for $6 \mathrm{~h}$. The maximum final DMSO concentration in the medium was $0.1 \%(\mathrm{v} / \mathrm{v})$ for all the samples which had no effect on viability. For each compound, exposures were performed on three different days. IgG was used as a control for the anti-CD3 exposures. DMSO was not present in either anti-CD3 or IgG treatments.

\section{RNA isolation and quality control.}

After exposure, the culture medium was removed after centrifugation of the cell suspension (5 min at $300 \mathrm{~g}, 4{ }^{\circ} \mathrm{C}$ ). The resulting cell pellet was homogenized in $600 \mu$ lysis buffer (RLT) (Qiagen, Venlo, Netherlands) supplemented with $10 \% \beta$-mercaptoethanol and stored at $-80{ }^{\circ} \mathrm{C}$ until further processing. RNA was isolated with the QIAshredder kit (Qiagen) according to the manufacturer's protocol. Subsequently, RNA was purified using the mRNeasy kit (Qiagen) including DNase treatment according to the manufacturer's protocol. RNA yield was assessed spectrophotometrically (NanoDrop 2000, Isogen Life Science, De Meern, the Netherlands).

\section{Quantitative Real-Time PCR verification.}

Detection of biomarker gene expression changes was performed at ServiceXS (ServiceXS B.V., Leiden, The Netherlands) using the 96.96 BioMark ${ }^{\text {TM }}$ Dynamic Array for Real-Time PCR (Fluidigm Corporation, San Francisco, CA), according to the manufacturer's instructions. cDNA samples were synthesized using miScript Reverse Transcription kit according to the manufacturer's protocol (Qiagen). Before use on the BioMark ${ }^{\mathrm{TM}}$ array, the cDNA was first subjected to 14 cycles of Specific Target Amplification (STA) using a $0.2 \mathrm{x}$ mixture of all Taqman Gene Expression assays in combination with the Taqman PreAmp Master Mix (Applied Biosystems), followed by 5-fold dilution. Water was included as No Template Control (NTC) at the indicated positions. The No Template Controls were also included in the STA reaction, to serve as a true negative control for the entire procedure. After the $5 \mathrm{x}$ dilution, thermal cycling and real-time imaging of the BioMark ${ }^{\mathrm{TM}}$ array was 
done on the BioMark ${ }^{\mathrm{TM}}$ instrument, and threshold cycle $(\mathrm{Ct})$ values were extracted using the BioMark ${ }^{\mathrm{TM}}$ Real-Time PCR analysis software. Ct values were used to determine compound effects on mRNA expression levels. Pair-wise combinations of all samples were made with each of the assays in duplicate on the array. The empty assay positions were filled with No Assay Controls, in which the $20 \mathrm{x}$ assay mix was substituted with water). The default Taqman PCR protocol was used on the BioMark ${ }^{\mathrm{TM}}$ instrument with an annealing temperature of $60^{\circ} \mathrm{C}$ and a total of 35 cycles of PCR.

\section{Analyses of QRT-PCR data.}

At the end of each PCR cycle, data was collected from the 9216 reaction chambers on each array, and $\mathrm{Ct}$ values were extracted using the BioMark ${ }^{\mathrm{TM}}$ Real-Time PCR analysis software version 3.0.2. The quality threshold was set at 0.65 (default value).

The relative mRNA expression levels were calculated for each individual sample by applying the delta-delta-CT method. Three genes were selected as reference genes, based on the low variability of the relative mRNA expression levels quantified by the microarrays performed before (Shao, et al. 2013), being beta-2-macroglobulin (B2M, highly abundant), Golgi to ER traffic protein 4 (GET4, lowly abundant), and phosphatidylinositol glycan anchor biosynthesis class G1 (PIGG). Compounds are considered immunotoxic when one or more of the classifier genes are affected by factor $\geq 2$ vs. the control in at least two out of three replicates. Clustering of genes was performed using Cluster v3.0 (uncentered correlation; average linkage clustering) developed by Stanford University. Treeview was used for visualisation of the clustering analysis.

\section{Functional interpretation based on ToxPi analysis}

The 25 classifiers were divided into eight functional classes (Table 3). The effects of each compound on these functional themes were visualized using ToxPi software from the US EPA (Reif, et al. 2013). The mRNA levels of the 25 classifier genes of the 16 compounds were used as the input for ToxPi software. ToxPi calculates a ToxPi score for each compound on each functional theme, and ranks the compounds by their overall ToxPi scores. The ToxPi score (between 0 to 1 ) is calculated by dividing the results of each chemical on the genes that are involved in this functional theme by the maximum results on the same genes from the 16 compounds. 


\section{Chapter 6}

Table 3. Functional themes in which the 25 classifiers are involved.

\begin{tabular}{c|l}
\multicolumn{1}{c|}{ Category } & \multicolumn{1}{c}{ Genes } \\
\hline Regulation of cell cycle and apoptosis & CCNG2, CRIM1, CHAC1, HSPA1B, ID1, ID2 \\
Metabolism and transport of cholesterol & HMGCS1, ABCA1, ABCG1 \\
Cellular signal transduction & BZRAP1, ARRDC3, CRIM1, GPR18, KLHL24, CHAC1 \\
Cellular stress responses & $\begin{array}{l}\text { KLF2, CHAC1, HSPA1B, HSPA5, NQO1, SRXN1, AK4, } \\
\text { SLC7A11, VLDLR, TM6SF1, ABCA1, ABCG1 } \\
\text { Immune regulation } \\
\text { Protein metabolism } \\
\text { Retinoic acid metabolism } \\
\text { Regulation of transcription }\end{array}$ \\
& FBXO32, CRIM1, AK4 \\
& ID1, ID2 \\
\hline
\end{tabular}

QRT-PCR on additional genes for functional confirmation

Eight genes were selected for additional QRT-PCR experiments to confirm the functional themes that were used in ToxPi analyses. These genes were involved in processes such as $\mathrm{T}$ cell activation, apoptosis, ER stress, cholesterol homeostasis, immune regulation, cell cycle and regulation of transcription (Table 4). QRT-PCR procedure was identical to the methods described above.

\section{Hierarchical clustering}

Hierarchical clustering was performed with the programs Cluster (uncentered correlation; average linkage clustering) and Treeview (Eisen, et al. 1998). Red and green indicate upand downregulation vs. average expression of control samples. 
Successful validation of genomic biomarkers for human immunotoxicity in Jurkat $\mathrm{T}$ cells in vitro

Table 4. Overview of eight gene markers for investigating possible modes of action

\begin{tabular}{|c|c|c|c|c|}
\hline $\begin{array}{c}\text { Gene } \\
\text { Symbol }\end{array}$ & Description & Process & $\begin{array}{c}\text { mRNA } \\
\text { accession }\end{array}$ & $\begin{array}{l}\text { Taqman } \\
\text { assay }\end{array}$ \\
\hline CD69 & Cluster of Differentiation 69 & $\mathrm{~T}$ cell activation & NM_001781 & $\begin{array}{c}\text { hs00934033_ } \\
\text { m1 }\end{array}$ \\
\hline DDIT3 & $\begin{array}{l}\text { DNA damage inducible } \\
\text { transcript } 3\end{array}$ & $\begin{array}{l}\text { DNA damage, } \\
\text { apoptosis }\end{array}$ & NM_001195053 & $\begin{array}{c}\text { Hs00358796_ } \\
\text { g1 }\end{array}$ \\
\hline DDIT4 & $\begin{array}{l}\text { DNA damage inducible } \\
\text { transcript } 4\end{array}$ & Immune regulation & NM_019058 & $\begin{array}{c}\text { Hs01111686_ } \\
\text { g1 }\end{array}$ \\
\hline HERPUD1 & $\begin{array}{l}\text { Homocysteine-responsive } \\
\text { endoplasmic reticulum-resident } \\
\text { ubiquitin-like domain member } \\
1\end{array}$ & $\begin{array}{l}\text { ER stress / Unfolded } \\
\text { protein response }\end{array}$ & NM_001010989 & $\begin{array}{c}\text { Hs01124269_ } \\
\text { m1 }\end{array}$ \\
\hline LGALS1 & Galectin-1 & Apoptosis, cell cycle & NM_002305 & $\begin{array}{l}\text { Hs00355202_- } \\
\text { m1 }\end{array}$ \\
\hline SGK1 & $\begin{array}{c}\text { Serine/threonine-protein kinase } \\
1\end{array}$ & $\begin{array}{l}\text { Regulation of } \\
\text { transcription }\end{array}$ & NM_001143676 & $\begin{array}{c}\text { Hs00985033_ } \\
\text { g1 }\end{array}$ \\
\hline SQLE & squalene epoxidase & $\begin{array}{l}\text { Cholesterol } \\
\text { homeostasis }\end{array}$ & NM_003129 & $\begin{array}{c}\text { Hs01123768_ } \\
\text { m1 }\end{array}$ \\
\hline TRIB3 & Tribbles homolog 3 & Apoptosis, ER stress & NM_021158 & $\begin{array}{c}\text { hs01082394_ } \\
\text { m1 }\end{array}$ \\
\hline
\end{tabular}

\section{Results}

\section{ATPlite assay}

The viability of Jurkat cells that were exposed to the different compounds was assessed by means of the ATPlite assay. Compound concentrations that lead to a decrease in viability of $20 \%$ or less after $24 \mathrm{~h}$ incubation (CV80) were selected for gene expression analysis, as published before (Schmeits, et al. 2013). For some compounds, the viability did not decrease after exposure to the highest concentration not giving rise to precipitation. In that case, this highest concentration was taken for further analysis. An overview of the viability data is presented in Figure 1. The concentrations that were selected for exposures are listed in Table 2. 


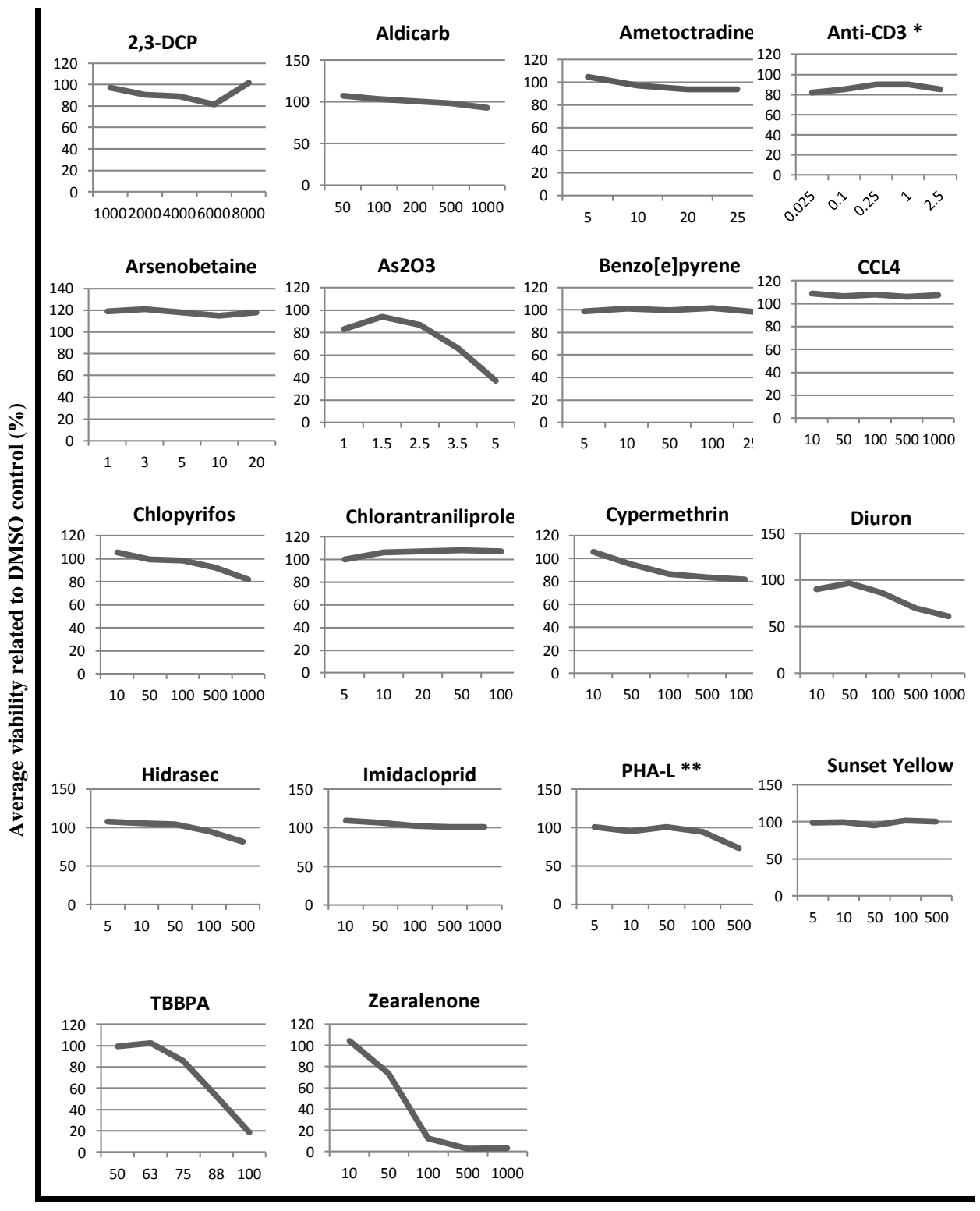

\section{Concentration $(\mu \mathrm{M})$}

Figure 1. Average viability of compounds as measured by ATPlite assay. Results are based on at least 3 biological replicates of Jurkat cells and viability is corrected for solvent control DMSO. Average viability is shown on Y-axis as percentage to DMSO, compound concentrations are present on $\mathrm{X}$-axis in $\mu \mathrm{M}$. Exceptions *Anti CD3 was dosed in $\mathrm{ng} / \mathrm{\mu l}$ and was corrected for IgG control. ** PHA-L was dosed in $\mathrm{ng} / \mathrm{ml}$. 


\section{Biomarker characteristics}

The QRT-PCR data were subjected to hierarchical clustering analysis (the outcome is visualized in the heat-map in Figure 2). The results of the QRT-PCR analysis are also shown in Supplementary Figure 1. All nine known immunotoxicant are classified as immunotoxic based on the 25 gene markers. The sensitivity is therefore $100 \%$. For the known non-immunotoxicants, four out of five were correctly classified as nonimmunotoxic. Benzo-e-pyrene downregulated one gene (HMGCS1) and is consequently classified as false positive. The specificity of this set is therefore $80 \%$. The overall accuracy is $93 \%$. The performance characteristics of the present analysis are also shown in supplementary table 1 .

\section{Immunotoxic Not Immunotoxic Unknown}

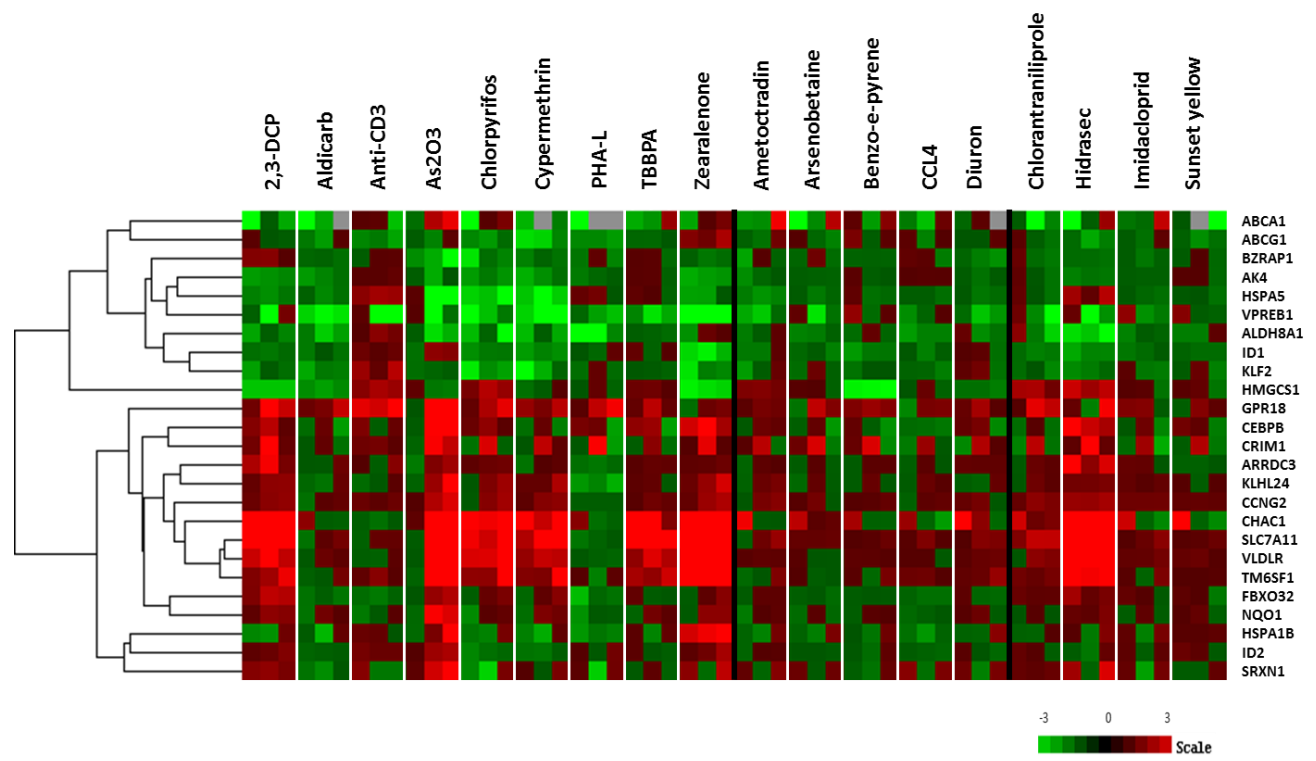

Figure 2. Average expression of $n=25$ classifier genes in human Jurkat T cells exposed to 19 different compounds. Values represent the average \pm SD of technical duplicates. Each compound is tested in three independent biological replicates. The order of the genes were determined by hierarchical clustering. Red indicates that the particular gene is upregulated, green indicates a downregulation, grey represents missing values. Colour scale represents $2 \log$ ratios vs. vehicle control.

\section{Compounds with unknown immunotoxic properties}

This study included four compounds for which the immunotoxic properties have not been precisely described. The reason for including these compounds was to verify whether the expression profiles of these 25 marker genes can provide more insight into the modes of action and point towards possible immunotoxic properties of these compounds. Chlorantraniliprole upregulates two genes (GPR18 and SLC7A11) and is classified as immunotoxic. Hidrasec upregulates seven genes and downregulates one and is also 
classified as immunotoxic. Imidacloprid and Sunset yellow do not affect any of the genes and are therefore considered not immunotoxic

\section{ToxPi analyses}

We categorized the 25 candidate classifier genes into eight functional themes, based on the major GO processes and molecular functions that these genes are involved in (Table 3). The ToxPi tool was then used to gain insight into the modes of action of the compounds. Results of this analysis are shown in pie graphs in Figure 3. A first observation is that all compounds affected protein metabolism to an almost similar degree. Based on similarities in ToxPi results, the compounds could be classified into three groups. The first group was formed by zearalenone, Hidrasec and As2O3 which all affected genes in cellular signal transduction and cellular stress responses (panel A). Next to these similarities, zearalenone affects immune regulation and Hidrasec affects retinoic acid metabolism which are processes that are hardly affected by the other two compounds.

Two compounds with almost similar pie graph, but no similarities in structure are 2,3-DCP and cypermethrin (panel B). Both compounds affect protein metabolism and cholesterol metabolism \& transport. In addition, cypermethrin affects immune regulation and transcription regulation that are not or to a lesser extent regulated by 2,3-DCP. ToxPi analysis of four compounds, chlorpyrifos, benzo-e-pyrene, aldicarb and anti-CD3, resulted in similar pie graphs (panel C). These four compounds all affect cholesterol metabolism and transport, protein metabolism and transcription regulation, and to a lesser extent retinoic acid metabolism and immune regulation.

\begin{tabular}{c|c|c}
\hline Color & Category & $\begin{array}{c}\text { Genes } \\
\text { (N) }\end{array}$ \\
\hline$\square$ & $\begin{array}{c}\text { Regulation cell } \\
\text { cycle \& apoptosis } \\
\text { Cholesterol } \\
\text { metabolism \& } \\
\text { transport } \\
\text { Cellular signal } \\
\text { transduction }\end{array}$ & 6 \\
$\begin{array}{c}\text { Cellular stress } \\
\text { responses }\end{array}$ & 12 \\
\hline & $\begin{array}{c}\text { Immune regulation } \\
\text { Protein metabolism } \\
\text { Retinoic acid } \\
\text { metabolism } \\
\text { Regulation } \\
\text { transcription }\end{array}$ & 3 \\
\hline
\end{tabular}

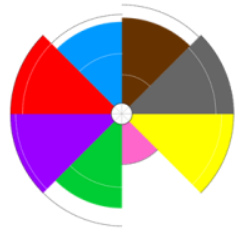

Zearalenone

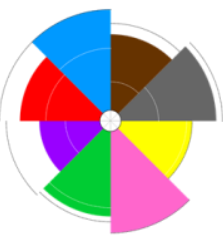

Hidrasec

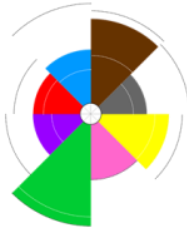

2,3-DCP

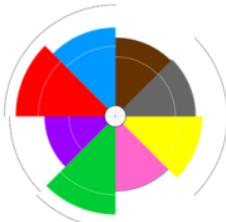

As203

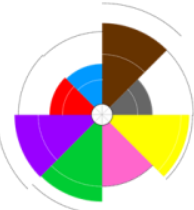

Cypermethrin 


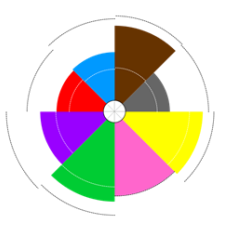

Chlorpyrifos

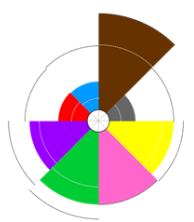

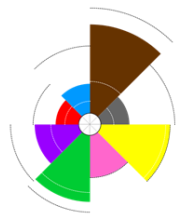

C

\begin{abstract}
Aldicarb
Figure 3. Visualization of the effects of example compounds on eight functional themes. The pie graphs visualize the effects of each compound on the functional themes as listed in the table (left side of Fig. 3A). Each pie represents one compound. Each piece of the pie represents one single functional theme. The eight functional themes were weighted equally, so the graphic widths of all slices are equal. The size of each piece (the distance to the centre, between 0 to 1 ) shows the ToxPi score that was calculated by the ToxPi software. Pie graphs are shown for the following compounds: A) Zearalenone, Hidrasec and As2O3. B) 2.3-DCP and cypermethrin. C) Chlorpyrifos, benzo-e-pyrene, aldicarb and anti-CD3.
\end{abstract}

\title{
Effects on mode of action (MOA) signature genes
}

In order to validate the MOAs identified with the present study, we also performed qRTPCR for all compounds on eight additional genes with known functions. An overview of the primers for these genes is given in Table 4. Seven compounds resulted in significantly altered expression of at least one of the eight genes. The results of the PCR experiments for these seven compounds are visualised as bar graphs in Figure 4. PHA-L upregulated the early T cell activation marker CD69 (Ziegler, et al. 1994), which corresponds to the mechanism of action of T cell activation. CD69 was also upregulated by TBBPA which indicates that this compound induces $\mathrm{T}$ cell activation as well. TBBPA also induced expression of HERPUD1, a known marker for an induced unfolded protein response that may lead to ER stress (Hori, et al. 2004). Other compounds that increased the expression of HERPUD1 and are thus likely to induce ER stress are Hidrasec and 2,3-DCP. 2,3-DCP downregulated SQLE, which is involved in cholesterol metabolism and transport (Bonne, et al. 2002). This decrease of cholesterol metabolism support the biological interpretation based on the 25 classifier genes for 2,3-DCP in Figure 3A. SQLE was also downregulated by anti-CD3 and zearalenone, and upregulated by chlorpyrifos and hidrasec which is in agreement with the results shown in Figures 3A and 3B. SGK1 codes for a protein that is involved in cell growth, survival, migration and cellular stress response (Amato, et al. 2009). SGK1 was upregulated by anti-CD3 and chlorpyrifos. Hidrasec downregulated LGALS1, a gene that is involved in cell cycle and apoptosis, which also supports the 
outcome of the ToxPi analysis. LGALS1 was also downregulated by chlorpyrifos and upregulated by anti-CD3, however, regulation of cell cycle and apoptosis was not obvious from the pie-graphs for these compounds (Fig.3).

Of the compounds that were immunotoxic based on the classifiers, As2O3, aldicarb and cypermethrin did not affect any of the additional genes. Furthermore, benzo-e-pyrene, the false positive as based on the 25 identifiers had also no effect on these additional genes. Moreover, the compounds selected as non-immunotoxic did not change the expression of any of the eight additional genes.
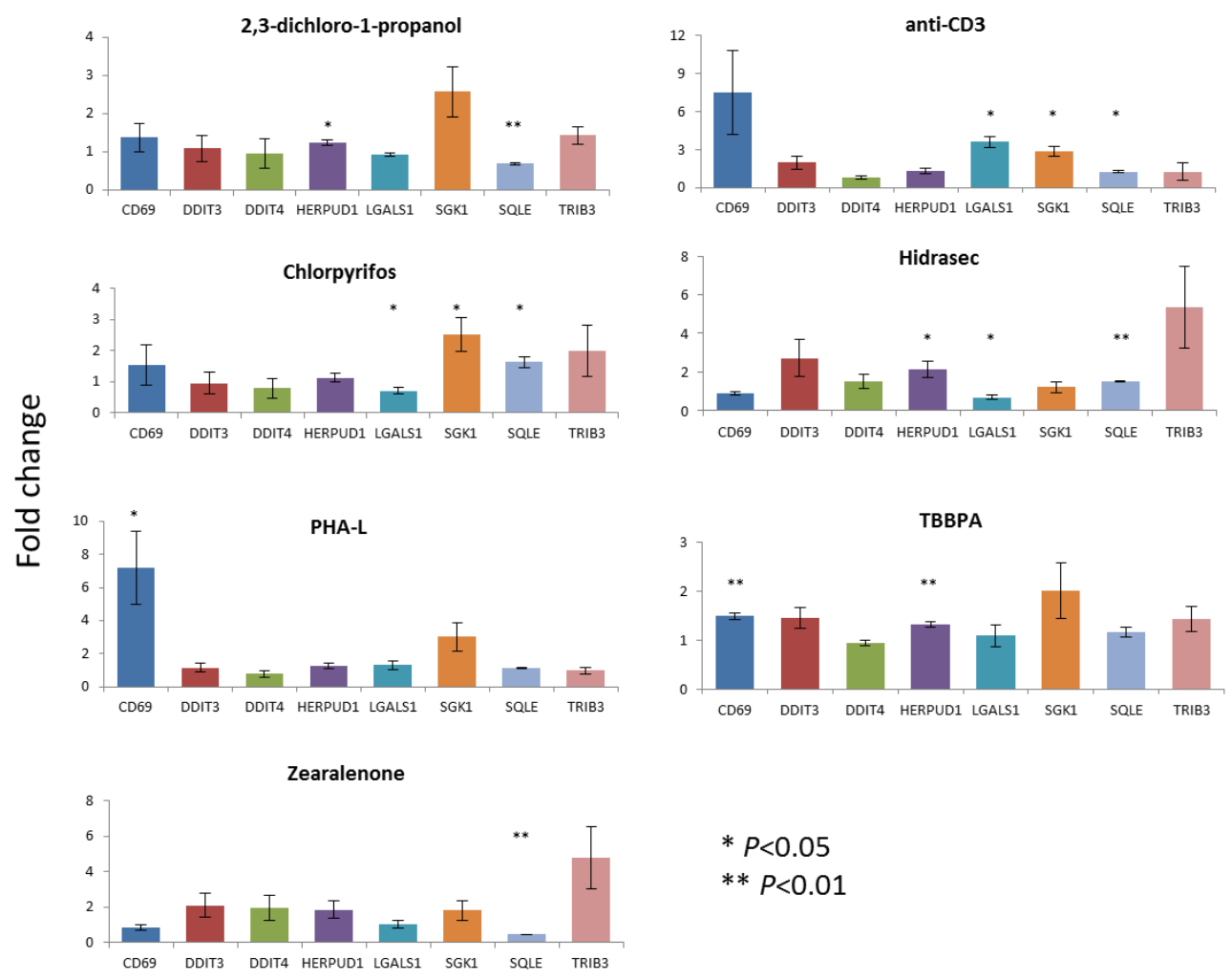

Figure 4. Average expression of genes indicating modes of action. Performance of eight QRT-PCR genes that are involved in T cell activation and proliferation (CD69 and LGALS1), DNA damage and apoptosis (DDIT3, DDIT4, TRIB3), ER stress induction (HERPUD1), cellular stress response (SGK1) and sterol biosynthesis (SQLE). Data is based on three independent biological replicates. ${ }^{*} P<0.05$ and ${ }^{* *} P<0.01$ compared to control (Student's $T$ test). Y-axis: Fold change as corrected by DMSO and reference genes.

\section{Discussion}

The identification and validation of the 25 classifier genes was performed previously on a training set of 36 immunotoxic and 8 non-immunotoxic compounds, and an external verification set of 17 immunotoxic and 3 non-immunotoxic compounds (Shao, et al. 2014). 
The classifiers were chosen in such a way that they covered a broad range of molecular mechanisms of action.

The present study was designed for two purposes, being 1) further validation of the 25 classifiers with additional immunotoxicants and non-immunotoxic control compounds, and 2) application of the classifiers to screen a group of compounds for which human immunotoxicity has not yet been fully established. For the first purpose, we exposed Jurkat cells to nine known immunotoxicants and five known non-immunotoxicants. These compounds included new compound classes that were not tested before, such as the polybrominated flame retardant TBBPA and the biological anti-CD3. The four compounds selected for the second purpose were the neonicotinoid imidacloprid, the insecticide chlorantraniliprole, the antidiarrheal drug hidrasec and the food additive sunset yellow FCF. In this second round of validation, the 25 classifiers generated a higher sensitivity (100 vs. $88 \%$ ), specificity (80 vs. $67 \%$ ) and overall accuracy (93 vs. $85 \%$ ) than obtained in our previous validation (Shao, et al. 2014). When results of our present study were combined with those of Shao et. al. (2014), the sensitivity, specificity and accuracy would be $91 \%, 71$ $\%$ and $85 \%$, respectively. In addition, we show that the 25 classifiers correctly predicted the immunotoxicity of compounds from classes not tested before in the Jurkat assay including TBBPA, anti CD3, chlorpyrifos, PHA-L and 2,3-DCP.

This current exercise resulted in only one false positive (benzo-e-pyrene). Benzo-e-pyrene is a structural analogue of benzo-a-pyrene which is a known immunotoxicant (Boorman, et al. 1982). Although benzo-e-pyrene is used as a non-immunosuppressive control for polyaromatic hydrocarbon (PAH) exposure (Davila, et al. 1999), some studies indicate slight immunotoxic effects of benzo-e-pyrene (Davila, et al. 1996, Krieger, et al. 1995). The only gene that was regulated by benzo-e-pyrene was HMGCS1, which is regulated in cholesterol metabolism and transport (Horton, et al. 2002).

We investigated possible mode of actions of the test compounds by using ToxPi analysis based on the expression of the 25 classifier genes. In addition, we performed PCR on eight additional genes, in order to support the putative MOAs we identified with the 25 classifiers. None of the non-immunotoxic compounds in the present study affected the expression of the eight additional genes tested. We determined the fold changes in expression of these eight additional genes regarding the 31 compounds of the previous study (Shao, et al. 2014). Also in this study the non-immunotoxic compounds didn't alter the expression of any of the eight additional genes (results not shown).

TBBPA is known to induce oxidative stress followed by DNA damage (Choi, et al. 2011) and stimulate immune cells (Koike, et al. 2013). In our study, TBBPA induced expression of T cell activation marker CD69, which corresponds to the results of Koike et. al., but also upregulates ER stress/UPR gene HERPUD1 (Hori, et al. 2004), which is a new finding (Fig. 4). In addition, TBBPA upregulated the pro-apoptosis marker CHAC1 (Mungrue, et al. 2009) almost 4 times. Furthermore, TBBPA is known to induce cell death (in Sertoli cells) by affecting calcium homeostasis (Ogunbayo, et al. 2008). Disruption of calcium 
homeostasis in T cells may lead to ER stress (Gwack, et al. 2007, Katika, et al. 2012). Cells that do not recover from ER stress will undergo apoptotic events.

Induction of ER stress is not limited to immune cells, however, immune cells are more sensitive to ER stress inducing compounds such as deoxynivalenol and tributyltin oxide. Previously we demonstrated that $\mathrm{T}$ cells are more sensitive because of the fact that ER stress leads to a leakage of calcium ions from the ER, leading to a calcium signal that in turn generates a $\mathrm{T}$ cell activation response, which is a measure for immunotoxicity (Katika, et al. 2012, Katika, et al. 2012, Schmeits, et al. 2013). Although ER stress may occur in other cells as well (at higher concentrations than in immune cells), in those cells this will not lead to a $\mathrm{T}$ cell activation response.

Currently, the mechanism by which the mycotoxin zearalenone exerts its immunotoxicity is not clear. We show that zearalenone affects genes in cellular stress responses, cholesterol metabolism/transport, immune regulation, cellular signal transduction, cell cycle and apoptosis and transcription. In addition, zearalenone downregulated one of the eight additional genes tested, SQLE, which is involved in cholesterol metabolism. The fact that some of the immunotoxic compounds affect genes involved in cholesterol metabolism might very well reflect the cellular response to disruption of cholesterol homeostasis.

Based on our results obtained with the 25 classifier genes, 2,3-DCP mainly affects cholesterol metabolism and transport and protein metabolism. PCR analysis of additional genes, such as HERPUD1 and SQLE, supported these findings. A previous study indicated that 2,3-DCP inhibits $\mathrm{T}$ cell activation and downregulates activation of transduction pathways in vitro (mouse $\mathrm{T}$ cells purified from splenocytes) and mice in vivo (Lu, et al. 2013). However, 2,3-DCP did not significantly affect expression of the $\mathrm{T}$ cell activation marker CD69 in the present study. This is most likely caused by the fact that Jurkat cells generally were cultured without stimulus (PHA/LPS). An inhibition of T cell activation is therefore hard to detect.

In the present study chlorpyrifos induces cellular stress responses and cholesterol biosynthesis in Jurkat $\mathrm{T}$ cells. Previous studies found that chlorpyrifos induced oxidative stress (Ambali, et al. 2007, Gultekin, et al. 2001). Also, chlorpyrifos induces hyperlipidaemia, a state in which cholesterol synthesis is elevated in rats (Acker and Nogueira 2012) which is in line with the results obtained in our study.

Of the four compounds that might be immunotoxic, chlorantraniliprole and Hidrasec were classified as immunotoxic, and the other two (imidacloprid and sunset yellow) as non immunotoxic, as based on the genetic markers used in this Jurkat study. Imidacloprid has been tested immunotoxic in rats and mice in vivo (Badgujar, et al. 2013, Gawade, et al. 2013). No data was available on human immune cells. Imidacloprid does not affect any of the 25 classifiers or eight additional genes tested in this study. Sunset yellow is known to affect monocytes but no other blood cells in mice in vivo (Hashem, et al. 2010). Apparently, sunset yellow is also not toxic for human Jurkat $\mathrm{T}$ cells. This result points to the limitation of the current assay that compounds targeting types of immune cells other than $\mathrm{T}$ cells might be not detected. Both chlorantraniliprole and Hidrasec were assessed non- 
immunotoxic in rodent immunotoxicity studies. The discrepancy between the outcome of the animal studies and the current Jurkat study with these compounds might be due to interspecies differences. It is generally recognised that the predictability of rodent studies for human toxicity is rather low (Shanks, et al. 2009). For this reason, the US National Research Council (2007), and other organisations, developed a future vision in which animal models are being replaced by human in vitro models. Chlorantraniliprole is suspected to act on release of calcium from intracellular calcium stores (Lahm, et al. 2005) that is known to lead to T cell activation in T cells (Gwack, et al. 2007, Katika, et al. 2012). Chlorantraniliprole mainly affects cellular stress and signal response pathways in our present experiments. One of the genes upregulated by chlorantraniliprole is SLC7A11 (alias XCT). SLC7A11 represents the rate limiting step of glutathione synthesis, and overexpression of SLC7A11 reduces the need for calcium for early cell cycle progression in early cell cycle (Lastro, et al. 2008).

In conclusion we have proven the good prediction performance of Jurkat $\mathrm{T}$ cell screening system based on 25 classifiers when challenged by new classes of immunotoxicants. The sensitivity, specificity and accuracy were even slightly higher in the present study as compared to the previous study. In addition to its use for predicting direct immunotoxicity, this set of genes can be exploited to give indications for the modes of action of compounds. This system however may not detect compounds that exert immunotoxic action on other immune cells than $\mathrm{T}$ cells, which likely is the case for sunset yellow. Therefore, the Jurkat $\mathrm{T}$ cell line is a valuable model for immunotoxicity screening not on itself but as part of an integrated testing strategy.

\section{Acknowledgements}

This study was financially supported by the Netherlands Genomics Initiative, the Netherlands Toxicogenomics Centre (grant 05060510). 


\section{Chapter 6}

References

2007. Toxicity Testing in the 21st Century: A Vision and a Strategy. The National Academies Press

Abbes S, Ben Salah-Abbes J, Sharafi H, Oueslati R, Noghabi KA. 2013. Lactobacillus paracasei BEJ01 prevents immunotoxic effects during chronic zearalenone exposure in Balb/c mice. Immunopharmacol Immunotoxicol 35:341-348. DOI: 10.3109/08923973.2013.772194.

Acker CI, Nogueira CW. 2012. Chlorpyrifos acute exposure induces hyperglycemia and hyperlipidemia in rats. Chemosphere 89:602-608. DOI: 10.1016/j.chemosphere.2012.05.059.

Amato R, D'Antona L, Porciatti G, Agosti V, Menniti M, Rinaldo C, Costa N, Bellacchio E, Mattarocci S, Fuiano G, Soddu S, Paggi MG, Lang F, Perrotti N. 2009. Sgk1 activates MDM2-dependent p53 degradation and affects cell proliferation, survival, and differentiation. J Mol Med (Berl) 87:1221-1239. DOI: 10.1007/s00109-009-05255 .

Ambali S, Akanbi D, Igbokwe N, Shittu M, Kawu M, Ayo J. 2007. Evaluation of subchronic chlorpyrifos poisoning on hematological and serum biochemical changes in mice and protective effect of vitamin $\mathrm{C}$. $\mathrm{J}$ Toxicol Sci 32:111-120.

Badgujar PC, Jain SK, Singh A, Punia JS, Gupta RP, Chandratre GA. 2013. Immunotoxic effects of imidacloprid following 28 days of oral exposure in BALB/c mice. Environ Toxicol Pharmacol 35:408-418. DOI:

10.1016/j.etap.2013.01.012.

Birnbaum LS, Staskal DF. 2004. Brominated flame retardants: cause for concern? Environ Health Perspect 112:917.

Bonne AC, den Bieman MG, Gillissen GF, van Lith HA, van Zutphen LF. 2002. Chromosomal localization of genes involved in biosynthesis, metabolism or transport of cholesterol in the rat. Cytogenet Genome Res 97:183186. DOI: 66606.

Boorman GA, Luster MI, Dean JH, Campbell ML. 1982. Assessment of myelotoxicity caused by environmental chemicals. Environ Health Perspect 43:129-135.

Borak J, Hosgood HD. 2007. Seafood arsenic: implications for human risk assessment. Regul Toxicol Pharmacol 47:204-212. DOI: 10.1016/j.yrtph.2006.09.005.

Choi JS, Lee YJ, Kim TH, Lim HJ, Ahn MY, Kwack SJ, Kang TS, Park KL, Lee J, Kim ND, Jeong TC, Kim SG, Jeong HG, Lee BM, Kim HS. 2011. Molecular Mechanism of Tetrabromobisphenol A (TBBPA)-induced Target Organ Toxicity in Sprague-Dawley Male Rats. Toxicol Res 27:61-70. DOI: 10.5487/TR.2011.27.2.061.

Davila DR, Lane JL, Lauer FT, Burchiel SW. 1999. Protein tyrosine kinase activation by polycyclic aromatic hydrocarbons in human HPB-ALL T cells. J Toxicol Environ Health A 56:249-261. DOI:

10.1080/009841099158097.

Davila DR, Romero DL, Burchiel SW. 1996. Human T cells are highly sensitive to suppression of mitogenesis by polycyclic aromatic hydrocarbons and this effect is differentially reversed by alpha-naphthoflavone. Toxicol Appl Pharmacol 139:333-341. DOI: 10.1006/taap.1996.0173.

Dunier M, Siwicki AK, Demael A. 1991. Effects of organophosphorus insecticides: effects of trichlorfon and dichlorvos on the immune response of carp (Cyprinus carpio). III. In vitro effects on lymphocyte proliferation and phagocytosis and in vivo effects on humoral response. Ecotoxicol Environ Saf 22:79-87.

EC. 2006. Regulation (EC) No 1907/2006 of the European Parliament and of the Council of 18 December 2006 concerning the Registration, Evaluation, Authorisation and Restriction of Chemicals (REACH), establishing a European Chemicals Agency, amending Directive 1999/45/EC and repealing Council Regulation (EEC) No 793/93 and Commission Regulation (EC) No 1488/94 as well as Council Directive 76/769/EEC and Commission Directives 91/155/EEC, 93/67/EEC, 93/105/EC and 2000/21/EC. EC (ed). OJ L; 1-849

diuron Immunotoxicity. http://apps.echa.europa.eu/registered/data/dossiers/DISS-9d864497-d81a-5ced-e04400144f67d249/AGGR-ad88c783-e215-4ee3-8ac8-7fe393b61600_DISS-9d864497-d81a-5ced-e044-

00144f67d249.html

Eisen MB, Spellman PT, Brown PO, Botstein D. 1998. Cluster analysis and display of genome-wide expression patterns. Proc Natl Acad Sci U S A 95:14863-14868.

EMEA. 2006. NOTE FOR GUIDANCE ON IMMUNOTOXICITY STUDIES FOR HUMAN

PHARMACEUTICALS. In ICH Topic S 8 Immunotoxicity Studies for Human Pharmaceuticals, Agency EM (ed). 13 
EPA. 2013. Part 158 Toxicology Data Requirements: Guidance for Neurotoxicity Battery, Subchronic Inhalation, Subchronic Dermal and Immunotoxicity Studies. Office of Pesticide Programs USEPA (ed). 11

FDA. 2002. Guidance for Industry - Immunotoxicology Evaluation of Investigational New Drugs. (CDER) USDoHaHSFaDACfDEaR (ed). ICCVAM; 35

Fernandez-Riejos P, Goberna R, Sanchez-Margalet V. 2008. Leptin promotes cell survival and activates Jurkat T lymphocytes by stimulation of mitogen-activated protein kinase. Clin Exp Immunol 151:505-518. DOI: 10.1111/j.1365-2249.2007.03563.x.

Fischer AM, Mercer JC, Iyer A, Ragin MJ, August A. 2004. Regulation of CXC chemokine receptor 4-mediated migration by the Tec family tyrosine kinase ITK. J Biol Chem 279:29816-29820. DOI: 10.1074/jbc.M312848200. Gawade L, Dadarkar SS, Husain R, Gatne M. 2013. A detailed study of developmental immunotoxicity of imidacloprid in Wistar rats. Food Chem Toxicol 51:61-70. DOI: 10.1016/j.fct.2012.09.009.

Gultekin F, Delibas N, Yasar S, Kilinc I. 2001. In vivo changes in antioxidant systems and protective role of melatonin and a combination of vitamin $\mathrm{C}$ and vitamin $\mathrm{E}$ on oxidative damage in erythrocytes induced by chlorpyrifos-ethyl in rats. Arch Toxicol 75:88-96.

Gwack Y, Feske S, Srikanth S, Hogan PG, Rao A. 2007. Signalling to transcription: store-operated Ca2+ entry and NFAT activation in lymphocytes. Cell Calcium 42:145-156. DOI: 10.1016/j.ceca.2007.03.007.

Hashem MM, Atta AH, Arbid MS, Nada SA, Asaad GF. 2010. Immunological studies on Amaranth, Sunset Yellow and Curcumin as food colouring agents in albino rats. Food Chem Toxicol 48:1581-1586. DOI: 10.1016/j.fct.2010.03.028.

Hori O, Ichinoda F, Yamaguchi A, Tamatani T, Taniguchi M, Koyama Y, Katayama T, Tohyama M, Stern DM, Ozawa K, Kitao Y, Ogawa S. 2004. Role of Herp in the endoplasmic reticulum stress response. Genes Cells 9:457-469. DOI: 10.1111/j.1356-9597.2004.00735.x.

Horton JD, Goldstein JL, Brown MS. 2002. SREBPs: activators of the complete program of cholesterol and fatty acid synthesis in the liver. J Clin Invest 109:1125-1131. DOI: 10.1172/JCI15593.

Institoris L, Siroki O, Desi I, Lesznyak J, Serenyi P, Szekeres E, Petri I. 1998. Extension of the protocol of OECD guideline 407 (28-day repeated dose oral toxicity test in the rat) to detect potential immunotoxicity of chemicals. Hum Exp Toxicol 17:206-211.

Ishiguro K, Xavier R. 2004. Homer-3 regulates activation of serum response element in T cells via its EVH1 domain. Blood 103:2248-2256. DOI: 10.1182/blood-2003-08-2671.

Jin Y, Zheng S, Fu Z. 2011. Embryonic exposure to cypermethrin induces apoptosis and immunotoxicity in zebrafish (Danio rerio). Fish Shellfish Immunol 30:1049-1054. DOI: 10.1016/j.fsi.2011.02.001.

Katika MR, Hendriksen PJ, de Ruijter NC, van Loveren H, Peijnenburg A. 2012. Immunocytological and biochemical analysis of the mode of action of bis (tri-n-butyltin) tri-oxide (TBTO) in Jurkat cells. Toxicol Lett 212:126-136. DOI: 10.1016/j.toxlet.2012.05.010.

Katika MR, Hendriksen PJ, Shao J, van Loveren H, Peijnenburg A. 2012. Transcriptome analysis of the human T lymphocyte cell line Jurkat and human peripheral blood mononuclear cells exposed to deoxynivalenol (DON):

New mechanistic insights. Toxicol Appl Pharmacol 264:51-64. DOI: 10.1016/j.taap.2012.07.017.

Koike E, Yanagisawa R, Takigami H, Takano H. 2013. Brominated flame retardants stimulate mouse immune cells in vitro. J Appl Toxicol 33:1451-1459. DOI: 10.1002/jat.2809.

Krieger JA, Davila DR, Lytton J, Born JL, Burchiel SW. 1995. Inhibition of sarcoplasmic/endoplasmic reticulum calcium ATPases (SERCA) by polycyclic aromatic hydrocarbons in HPB-ALL human T cells and other tissues.

Toxicol Appl Pharmacol 133:102-108. DOI: 10.1006/taap.1995.1131.

Lahm GP, Selby TP, Freudenberger JH, Stevenson TM, Myers BJ, Seburyamo G, Smith BK, Flexner L, Clark CE, Cordova D. 2005. Insecticidal anthranilic diamides: a new class of potent ryanodine receptor activators. Bioorg Med Chem Lett 15:4898-4906. DOI: 10.1016/j.bmcl.2005.08.034.

Lankveld DP, Van Loveren H, Baken KA, Vandebriel RJ. 2010. In vitro testing for direct immunotoxicity: state of the art. Methods Mol Biol 598:401-423. DOI: 10.1007/978-1-60761-401-2_26.

Lastro M, Kourtidis A, Farley K, Conklin DS. 2008. xCT expression reduces the early cell cycle requirement for calcium signaling. Cell Signal 20:390-399. DOI: 10.1016/j.cellsig.2007.10.030.

Lu J, Huang G, Zhang S, Song B, Wang Z, Xu L, Zhang S, Guan S. 2013. The inhibition of 2,3-dichloro-1propanol on T cell in vitro and in vivo. Int Immunopharmacol 17:321-328. DOI: 10.1016/j.intimp.2013.06.026. 


\section{Chapter 6}

Mirkin IR, Anderson HA, Hanrahan L, Hong R, Golubjatnikov R, Belluck D. 1990. Changes in T-lymphocyte distribution associated with ingestion of aldicarb-contaminated drinking water: a follow-up study. Environ Res 51:35-50.

Mitsuishi Y, Falkenrodt A, Urlacher A, Tongio MM, Mayer S. 1986. New human MHC class I antigens segregating with HLA-A antigens detected on some lymphocyte subpopulations. Hum Immunol 15:175-197. Mungrue IN, Pagnon J, Kohannim O, Gargalovic PS, Lusis AJ. 2009. CHAC1/MGC4504 is a novel proapoptotic component of the unfolded protein response, downstream of the ATF4-ATF3-CHOP cascade. J Immunol 182:466476.

Noworyta-Glowacka J, Bankowski R, Siennicka J, Wiadrowska B, Ludwicki JK. 2012. Influence of chlorpyrifos on the profile of subpopulations of immunoactive cells and their phagocytic activity in an experimental in vivo model. Ann Agric Environ Med 19:483-486.

Ogunbayo OA, Lai PF, Connolly TJ, Michelangeli F. 2008. Tetrabromobisphenol A (TBBPA), induces cell death in TM4 Sertoli cells by modulating $\mathrm{Ca} 2+$ transport proteins and causing dysregulation of $\mathrm{Ca} 2+$ homeostasis. Toxicol In Vitro 22:943-952. DOI: 10.1016/j.tiv.2008.01.015.

Pullen S, Boecker R, Tiegs G. 2003. The flame retardants tetrabromobisphenol A and tetrabromobisphenol Abisallylether suppress the induction of interleukin-2 receptor alpha chain (CD25) in murine splenocytes. Toxicology 184:11-22.

Reif DM, Sypa M, Lock EF, Wright FA, Wilson A, Cathey T, Judson RR, Rusyn I. 2013. ToxPi GUI: an interactive visualization tool for transparent integration of data from diverse sources of evidence. Bioinformatics 29:402-403. DOI: 10.1093/bioinformatics/bts686.

Sakurai T, Kojima C, Ochiai M, Ohta T, Fujiwara K. 2004. Evaluation of in vivo acute immunotoxicity of a major organic arsenic compound arsenobetaine in seafood. Int Immunopharmacol 4:179-184. DOI:

10.1016/j.intimp.2003.11.004.

Schmeits PC, Katika MR, Peijnenburg AA, van Loveren H, Hendriksen PJ. 2013. DON shares a similar mode of action as the ribotoxic stress inducer anisomycin while TBTO shares ER stress patterns with the ER stress inducer thapsigargin based on comparative gene expression profiling in Jurkat T cells. Toxicol Lett,

10.1016/j.toxlet.2013.11.005. DOI: 10.1016/j.toxlet.2013.11.005.

Schmeits PC, Volger OL, Zandvliet ET, van Loveren H, Peijnenburg AA, Hendriksen PJ. 2013. Assessment of the usefulness of the murine cytotoxic T cell line CTLL-2 for immunotoxicity screening by transcriptomics. Toxicol Lett 217:1-13. DOI: 10.1016/j.toxlet.2012.12.005.

Shanks N, Greek R, Greek J. 2009. Are animal models predictive for humans? Philos Ethics Humanit Med 4:2. DOI: $10.1186 / 1747-5341-4-2$.

Shao J, Berger LF, Hendriksen PJ, Peijnenburg AA, van Loveren H, Volger OL. 2014. Transcriptome-based functional classifiers for direct immunotoxicity. Arch Toxicol 88:673-689. DOI: 10.1007/s00204-013-1179-1. Shao J, Katika MR, Schmeits PC, Hendriksen PJ, van Loveren H, Peijnenburg AA, Volger OL. 2013. Toxicogenomics-based identification of mechanisms for direct immunotoxicity. Toxicol Sci 135:328-346. DOI: 10.1093/toxsci/kft151.

Smialowicz RJ, Simmons JE, Luebke RW, Allis JW. 1991. Immunotoxicologic assessment of subacute exposure of rats to carbon tetrachloride with comparison to hepatotoxicity and nephrotoxicity. Fundam Appl Toxicol 17:186-196.

Thomas PT, Ratajczak HV, Eisenberg WC, Furedi-Machacek M, Ketels KV, Barbera PW. 1987. Evaluation of host resistance and immunity in mice exposed to the carbamate pesticide aldicarb. Fundam Appl Toxicol 9:82-89. Weetall M, Digan ME, Hugo R, Mathew S, Hopf C, Tart-Risher N, Zhang J, Shi V, Fu F, Hammond-McKibben D, West S, Brack R, Brinkmann V, Bergman R, Neville D, Jr., Lake P. 2002. T-cell depletion and graft survival induced by anti-human CD3 immunotoxins in human CD3epsilon transgenic mice. Transplantation 73:1658-1666. White KL, Jr., McLoughlin CE, Auttachoat W, Smith MJ. 2012. Validation of the Candida albicans delayed-type hypersensitivity (DTH) model in the female $\mathrm{B}(6) \mathrm{C}(3) \mathrm{F}(1)$ mouse for use in immunotoxicological investigations. J Immunotoxicol 9:141-147. DOI: 10.3109/1547691X.2011.636768.

Yadav A, Kumar A, Tripathi A, Das M. 2013. Sunset yellow FCF, a permitted food dye, alters functional responses of splenocytes at non-cytotoxic dose. Toxicol Lett 217:197-204. DOI: 10.1016/j.toxlet.2012.12.016.

Ziegler SF, Ramsdell F, Alderson MR. 1994. The activation antigen CD69. Stem Cells 12:456-465. DOI: 10.1002/stem.5530120502. 


\section{Chapter 7}

Summary, general discussion and future perspectives 
Two main objectives were addressed in this thesis, being (1) to assess the usefulness of two mouse cell lines (EL-4 and CTLL-2) and one human cell line (Jurkat) for immunotoxicity testing, and (2) to validate genomic biomarkers for human immunotoxicity using a high throughput set up. An overview of the immune system, current methods for testing immunotoxicity and an explanation of 'omics' technologies is given in Chapter 1. Over the past decade, the focus within toxicity testing has been moving slowly towards the use of less animals. This is emphasized in a number of American and European guidelines and regulations (EC 2006; Firestone et al. 2010; Krewski et al. 2010; Krewski et al. 2009). Parallel to the introduction of these regulations and guidelines was the rise of toxicogenomics techniques, such as whole genome mRNA expression analysis, for generating a larger amount of data out of smaller sample volumes. These techniques aided in the understanding of modes of actions of marketed and newly synthesized chemicals. Although progress has been made towards animal free immunotoxicity screening, the contribution of genomics techniques to the development of these alternative tests was limited so far. In this thesis, a toxicogenomics approach was used to assess the suitability of various mouse cell models, i.e. the CTLL-2 and EL-4 cell lines and murine primary cells, for immunotoxicity testing. In addition, work was performed with the human Jurkat $\mathrm{T}$ cell line. This thesis studied the performance of omics-based classifiers of immunotoxicity in the Jurkat cell line and verified the mechanisms of action of the immunotoxicants TBTO and DON previously identified in transcriptomics studies using latter cell line (Katika et al. 2012a; Katika et al. 2012b; Shao et al. 2014).

\section{Standardisation of exposure}

To optimise a testing strategy for screening immunotoxicity of compounds, one of the first requirements is to define an exposure set up that is similar in all experiments. Since toxicity is achieved for every compound as long as the dose is high enough, conditions were selected to assure that compound specific effects can be investigated rather than the general cytotoxicity response leading to cell death via necrosis (as a loss of membrane integrity resulting in cell lysis) or apoptosis (controlled or programmed cell death). occurring at higher doses. For each compound tested in this thesis, viability data were generated by exposing cells for $24 \mathrm{~h}$. Many assays are available to test cellular viability or cytotoxicity. Two assays were extensively used in this thesis, being the Water-Soluble Tetrazolium assay (WST-1) and the ATPlite assay. The WST-1 assay is a colorimetric assay in which the tetrazolium salt WST-1 that is added to the cells will be converted by mitochondrial dehydrogenases resulting in a change of colour of the medium. The change in colour can be quantified measuring the absorbance using a microplate spectrophotometer. The ATPlite assay is luminescence bases and this assay the cells are first lysed and then a substrate containing luciferase and d-luciferin is added. ATP that is present will react with dluciferin, oxygen and luciferase and converted to AMP. With this reaction, light is emitted and the emitted light is proportional to the ATP concentration in the sample. For both the 
WST-1 and the ATPlite assay, a concentration range of (non-)immunotoxic compound is tested, and the viability (in \%) is calculated against the solvent control DMSO.

The concentrations for microarray exposure were selected in such a way that they induced a decrease in cell viability of maximally $20 \%$ after $24 \mathrm{~h}$. This threshold was chosen to ensure that effects observed would not be the result of general toxicity events leading to cell death. These concentrations were then applied in $6 \mathrm{~h}$ exposures that were used for microarray hybridisations or high-throughput PCR reactions. For primary mouse cells (thymocytes, splenocytes) the dose optimisation was a little different. Since the viability of these primary cells declines from the moment of isolation, the doses for exposure of these primary cells were based on viability results obtained with the mouse EL-4 or CTLL- 2 cell lines. The viability of primary cells was determined after $6 \mathrm{~h}$ of exposure. This method for assessing an optimal test concentration and the method for exposure was used for each chemical described in this thesis, making comparisons between different experiments valid.

\section{Suitability of mouse cell models in detecting the mode of action of immunotoxic compounds}

To examine the suitability of two mouse cell line models for immunotoxicity testing, these were exposed to three model immunotoxic/immunosuppressive compounds and subjected to DNA microarray analysis. The first compound concerns Cyclosporine A (CsA) which is an immunosuppressive drug used in organ transplant patients to prevent organ rejection and prevents graft-versus-host disease in bone marrow recipients. This drug was used as the mode of action is clear and the effect on the immune system is evident. CsA inhibits the $\mathrm{T}$ cell activation response and induces ER stress and oxidative stress leading to apoptosis in $\mathrm{T}$ cells (Hama et al. 2013; Ho et al. 1996; O'Connell et al. 2012; Stepkowski and Kirken 2000). The experiments performed with CsA are described in Chapter 2 of this thesis. Transcriptomics was used to compare the effects of CsA in mouse CTLL-2 cells, mouse EL-4 cells, primary mouse splenocytes (in vitro) and mouse spleens in vivo. The objective was to find the model that best represented the mode of action of CsA. In addition, comparisons were made with CsA exposures in human T lymphocyte (Jurkat), human liver (HepG2) and human kidney (RPTEC/TERT1) cell lines. The effects on pathway level as well as on individual gene expression level were quite similar for CTLL-2 and EL-4 cells. Both cell lines upregulated genes in oxidative stress, ER stress and XBP1 target genes, and downregulated genes involved in apoptosis. Genes upregulated by CsA in human Jurkat $\mathrm{T}$ cell, HepG2 cells and renal proximal tubular cells were also upregulated in EL-4, CTLL-2 and primary mouse splenocytes cells, but this was not the case for genes downregulated by CsA in those human cell lines. Spleens of mice exposed in vivo did not result in a high number of genes affected, except a set of genes that were downregulated and linked to cell cycle. This was probably caused by the fact that $\mathrm{T}$ cells are removed from the site of action when affected in vivo. This was shown by the higher number of genes expressed in monocytes and NK cells in the in vivo mouse spleen samples as compared to the in vitro models. After analysis of the different pathways and comparisons to various data sets, CTLL-2 cells appeared to reflect the known CsA affected pathways best, although $\mathrm{T}$ cell 
activation was not clearly downregulated in CTLL-2 cells. EL-4 cells were even less suitable in detecting inhibition of $\mathrm{T}$ cell activation. One of the characteristics of the CTLL-2 cell line is that it has to be cultured in the presence of a T cell stimulant, such as IL-2. Due to this, CTLL-2 cells were able to detect the T cell inhibition that is caused by CsA after exposure to T cells (Chapter 2), while EL-4 cells were not. Standard procedures of the other models do not include culturing in the presence of a $\mathrm{T}$ cell stimulant.

The two immunotoxicants deoxynivalenol (DON) and tributyltin-oxide (TBTO) were used in Chapters 3 and 4. DON is a mycotoxin that is produced by Fusarium species that grows on agricultural products such as wheat and corn. As DON is stable during heating and cooking processes, humans are continuously exposed to low levels of this mycotoxin (Bimczok et al. 2007; Rasmussen et al. 2003; Severino et al. 2006). DON is known to cause a process of ribotoxic stress leading to ER stress and $\mathrm{T}$ cell activation and specifically affects the thymus and bone marrow, as these are rapid dividing cells (Iordanov et al. 1997; Pestka et al. 2005). TBTO is an organotin compound that was used in a variety of industrial processes. TBTO was applied in ship paints to prevent the growth of molluscs species at the outside of vessels, but also employed in plastic floor tiles and as a wood preservative, making it a wide spread contaminant of the environment (Hoch 2001). The mode of action of TBTO is quite similar to that of DON; TBTO induces an ER stress response leading to T cell activation (Katika et al. 2011; van Kol et al. 2012) and in vivo also specifically affects the thymus (van Kol et al. 2011). TBTO, in contrast to DON, does not cause a ribotoxic stress response. Since both DON and TBTO were extensively studied before in in vitro and in vivo immunotoxicity studies, they were used as model compounds to further test the suitability of mouse EL-4 cells (Chapter 3) and CTLL-2 cells (Chapter 4) in this thesis. Results of the exposures of EL-4 cells to DON were compared to mouse CTLL-2 cells (in vitro), mouse thymocytes (in vitro), mouse thymuses (in vivo) and human Jurkat T cells (in vitro). Gene sets and individual genes important in the modes of action of DON that were compared included ribosomes, ER stress, T cell activation and apoptosis. Although EL-4 cells induced genes in ribosome biogenesis and assembly and RNA processing, the induction values were lower than observed in human Jurkat T cells. CTLL-2 cells also upregulated some genes involved in ribosome biogenesis, though the induction values were less convincing than for EL-4 cells. Next to the ribotoxic action of DON, the induction of genes in ER stress, T cell activation and apoptosis could not be detected in EL-4 cells or in CTLL-2 cells. Genes in those processes were upregulated in human Jurkat T cells, as expected. It is conceivable that the lack of induction of ER stress, T cell activation and apoptosis might be caused by a lack of genes or non-functionality of genes involved in the link between ribotoxic and ER stress in both the EL-4 cell line and the CTLL-2 cell line. The mode of action of TBTO (induction of ER stress, T cell activation and apoptosis) could only partly be detected for EL-4 cells exposed to TBTO. ER stress was induced in EL-4 cells but this did not result in subsequent $\mathrm{T}$ cell activation and apoptosis. Due to a mutation in a calcineurin gene EL-4 cells have a constitutively activated T cell activation response (Fruman et al. 1995), which makes it more difficult to detect further induction of the T cell 
activation response on top of the genetically driven activation. The upregulation of genes in ER stress, T cell activation and apoptosis was however clearly detected in CTLL-2 cells exposed to TBTO. The comparisons on gene sets and processes that are important in the immunotoxic action of TBTO made clear that these were better reflected in CTLL-2, Jurkat or mice primary thymocytes than in EL-4 cells. For DON, these processes were best reflected in Jurkat or mice thymus in vivo rather than in EL-4 cells or CTLL-2 cells. As neither EL-4 cells nor CTLL-2 cells were able to detect the modes of action of all three tested compounds (CsA, TBTO and DON), it was concluded not to use these cell lines for follow-up immunotoxicity experiments.

\section{Direct comparison of the modes of action of DON and TBTO in human Jurkat T cells}

Since previous transcriptomics experiments on the effects of DON and TBTO in the human $\mathrm{T}$ cell line Jurkat pointed towards the mechanisms of action of these compounds, a comparative microarray study was set up. To verify the results obtained with DON and TBTO, compounds with suspected similar modes of action were used, i.e. anisomycin, ionomycin and thapsigargin (Chapter 5). The rationale for this study was that compounds which have similar mode of action will have a similar gene expression profile. These direct comparisons on microarray level result in clear insights in the similarities and differences of suspected similar acting compounds. These types of read-across experiments are also performed on a larger scale. The connectivity map (cmap), for instance, is a systematic approach to connect the effects of compounds in human cells (Lamb et al. 2006). Using standardised culture and exposure procedures within the same cell line, microarray data of different compounds generated in labs throughout the world can be compared to each other. The outcome of such comparison is a list of compounds that generated similar microarray expression profiles as the study compound. In addition, a list is generated including compounds that generate opposite effects. The more data stored in the cmap database, the more powerful the approach of comparing microarray data (Toyoshiba et al. 2009).

Thapsigargin was used as a positive control for ER stress induction by calcium efflux from the ER eventually leading to apoptosis (Rogers et al. 1995; Scheuner and Kaufman 2008). Ionomycin is known to raise calcium levels via release of calcium from intracellular pools and subsequently acts as a T cell activator (Imboden et al. 1985). Anisomycin is a wellknown protein synthesis inhibitor (Grollman 1967). It binds to the 28S rRNA and induces a ribotoxic stress response (Iordanov et al. 1997). Based on the microarray comparisons described in Chapter 5 it became apparent that anisomycin and DON generated gene expression profiles that almost exactly matched. Therefore, we can state that these compounds have a similar mode of action. TBTO induced effects in processes similar to the processes effected by thapsigargin and ionomycin, such as T cell activation, ER stress induction and apoptosis. In addition, a set of genes involved in DNA packaging and nucleosome assembly was affected by TBTO that was not shared by the other study compounds. Also, this study showed that toxicogenomics can aid in detecting similarities and differences in modes of action of compounds. 
Progress towards animal free in vitro immunotoxicity testing

Parallel to the experiments described above and in Chapters 2-5, larger microarray exposure studies were performed by Shao et al using Jurkat $\mathrm{T}$ cells and sets of immunotoxic, non-immunotoxic and vehicle compounds (Shao et al. 2014; Shao et al. 2013). The goal of these experiments was to identify possible modes of action underlying immunotoxicity and classifier genes that can serve as in vitro biomarkers for direct human immunotoxicity. In these studies, Jurkat cells were exposed to 44 different compounds resulting in 28 genes that were selected as potential classifiers of immunotoxicity. A highthroughput PCR method (Fluigidm) was used to validate the expression of these genes. Pearson's correlation $(\mathrm{R} \geq 0.69)$ that was found for 27 out of the 28 genes. A redundancy analysis was performed resulting in a final set of 25 classifiers. The performance of these genes was externally validated by exposing Jurkat cells to an additional set of 20 compounds followed by high-throughput PCR (Fluidigm). This gave a good sensitivity (88\%), specificity $(67 \%)$ and accuracy $(85 \%)$. Although the performance characteristics were promising, several questions and issues remained unanswered. One such question concerns: "How does this screening system perform with compounds of classes that have not been tested before?" Another issue is the low number of non-immunotoxic controls that were included in the studies of Shao et al. Therefore, in Chapter 6 Jurkat $\mathrm{T}$ cells were exposed to a new set of 14 chemicals of which some belong to classes that were not tested before. Five of these compounds were known non-immunotoxicants. The imbalance between tested immunotoxicants and non immunotoxicants will always be present as the search for known non immunotoxicants is difficult. This is because immunotoxicity studies on compounds that are suspected to be not immunotoxic are not often performed and the fact that microarray studies on compounds not leading to immunotoxicity are less likely to be published (publication bias). Since a limited set of genes was identified by Shao et al as classifiers of human immunotoxicity, we opted for the use of Fluidigm analysis over microarray analysis, ensuring quick results that are easier to analyse as compared to whole genome microarrays. Of the 14 compounds used in the Fluidigm study, 13 were correctly classified and sensitivity, specificity and accuracy of 100\%, 80\% and 93\%, respectively. Combining the results obtained in Chapter 6 with previous studies of Shao et al. generated $91 \%$ sensitivity, $71 \%$ specificity and $83 \%$ accuracy.

The US EPA ToxPi (Toxicological Priority Index) tool that was used in Chapter 6, provides additional information on compounds affecting genes from a similar process or pathway. In this way, it becomes clear that chemicals that are structurally very different can have similar effects, whereas chemicals that are quite similar in structure might not. Since this tool can be used combining multiple domains of knowledge, the EPA has proposed to apply this tool for chemical priority setting in the framework of the ToxCast program (Reif et al. 2010). 


\section{Towards changing guidelines}

The research performed in the present thesis yields a set of biomarkers with high sensitivity, specificity and accuracy to predict immunotoxicity. As convincing as the results may be, this does not mean animal experiments for immunotoxicity are quickly going to be replaced by in vitro screening of chemicals using Jurkat cells. When submitting our work to journals, reviewers often ask to validate our findings by performing animal experiments as it is clear that the current in vitro tests for immunotoxicity lack the structures of a complete organ and the cooperation between different (immune) cells and different (immune) organs. The aim of (immuno)toxicity testing, including testing using in vitro technologies, is to protect humans from adverse effects associated with chemical exposure and animal experiments should not be seen as golden standard for effects that occur in humans. For that reason validating the extrapolation step from human in vitro to in vivo effects in humans using animal studies may not be ideal. Yet animal experiments will serve as a proxy for humans if no suitable human alternative is available. In 2011, Archibald et. al. conjured the UK prime minister and health secretary of the government to "initiate a comparison of a set of human-biology-based tests with those currently used" to find out which models are more predictive for human endpoints (Archibald et al. 2011a; Archibald et al. 2011b). Some initiatives, such as ASAT (Assuring Safety without Animal Testing), aim to make use of human databases that allow to compare newly generated data with gene expression data related to particular diseases in humans. The ASAT initiative focuses on the search for disease pathways that will aid putting findings generated with in vitro testing in their proper context and thus help to validate such in vitro test systems for assessing the risk of adverse effects associated with exposure to chemical substances. In that sense the ASAT approach is different from more classical approaches for validation, as it does not rely on effects in laboratory animals for the purpose of validation. Because of issues of validation and the urge for confidence in the validity of (immuno)toxicity testing by regulators, as in the end they will be held liable for any consequence the assessments may have, the process of amending regulatory guidelines and laws to implement new in vitro alternatives for (immuno)toxicity testing is long and can take several years before universally acceptance has been achieved (Schiffelers et al. 2012). Until that moment, producers of new chemicals and drugs will have to apply to the current laws that include animal experiments to screen for immunotoxic effects.

To speed up the process for in vitro tests to be generally accepted, several institutes in the US gathered their plans in a vision document entitled "Toxicity Testing in the 21st Century: A Vision and a Strategy" which was published by the National Academic Press in 2007 (2007). This vision states that research should shift towards using predictive highthroughput assays based on cells or cell lines, preferably of human origin. In addition, the document "envisions a new toxicity-testing system that evaluates biologically significant perturbations in key toxicity pathways by using new methods in computational biology and a comprehensive array of in vitro tests based on human biology." These two points (using human in vitro cells and biological interpretation of toxicity pathways) are clearly covered 
in this thesis as we performed experiments on human Jurkat T cells and used whole genome microarrays in combination with tools such as gene set enrichment analysis or MetaCore to study effects on biological processes.

\section{Limitations and future research perspectives}

The results presented in Chapter 6 of this thesis point out that the set of 25 classifiers can be used as a screening model for direct immunotoxicity. However, as is the case in any model, the $\mathrm{T}$ cell based screening model has some limitations. First of all, because the human immune system consists of many different organs and cells, screenings in $\mathrm{T}$ cells might miss some of the compounds whose action is only detectable in cells other than $\mathrm{T}$ cells. One such case was sunset yellow (Chapter 6), but other cases cannot be excluded. To solve this issue, similar exercises as performed in this thesis should be executed for B cells and monocytes and be combined in a battery of screening assays with the human Jurkat $\mathrm{T}$ cells.

It is expected that the understanding of the effects of chemicals on human organs will accelerate in the coming years with the introduction of organ-on-a-chip methods (Huh et al. 2010). These methods can use human cells to grow miniature organs such as lungs, gut or heart. Unfortunately, as the immune system is a complex cooperation of multiple organs and cells, this progress does not include immunotoxicity (yet). A second concern is the relatively low amount of negative controls that has been tested. Far more immunotoxic compounds have been used in this thesis as compared to the number of non immunotoxic controls. In future experiments the search for these true non-immunotoxic controls should be extended and the overall ratio between immunotoxicants and non immunotoxic controls should be more balanced. Third, the Jurkat screening method described in this thesis focuses on the direct effects in T cell, as the effects on the gene level were measured 6 hours after exposure in vitro. Different from the in vivo situation is the lack of a memory $\mathrm{T}$ cell immune response in cell cultures. This is a point of concern that could be solved when further improvements can be made in co culturing different human immune cells with other cell types, for instance in an organ-on-a-chip setting.

\section{Conclusion}

This thesis focused on testing the suitability of two mouse cell lines and one human cell line for their applicability in immunotoxicity screenings. Our data clearly indicate some disadvantages of the EL-4 and CTLL-2 cells, as important immunotoxicological processes such as ribotoxic stress and ER stress could not be detected well. The suspected lack of genes or non-functionality of genes important in the pathway interconnecting ribotoxic stress, ER stress and $\mathrm{T}$ cell activation makes these cell lines less suitable for immunotoxicity testing as compared to the human Jurkat T cell line. Previous studies in the human Jurkat cell line resulted in a set of immunotoxic biomarkers that were further validated in this thesis showing high sensitivity, specificity and accuracy. Altogether, the 
Summary, general discussion and future perspectives

results in this thesis provided a suitable set of genetic markers that can be used to predict immunotoxicity in humans of new chemicals. 


\section{Chapter 7}

References

(2007) Toxicity Testing in the 21st Century: A Vision and a Strategy. The National Academies Press

Archibald K, Baxter AD, BeruBe K, et al. (2011a) Safety of medicine and the use of animals in research. Lancet 378(9802):e2 doi:10.1016/S0140-6736(11)61669-3

Archibald K, Coleman R, Foster C (2011b) Open letter to UK Prime Minister David Cameron and Health Secretary Andrew Lansley on safety of medicines. Lancet 377(9781):1915 doi:10.1016/S0140-6736(11)60802-7 Bimczok D, Doll S, Rau H, et al. (2007) The Fusarium toxin deoxynivalenol disrupts phenotype and function of monocyte-derived dendritic cells in vivo and in vitro. Immunobiology 212(8):655-66 doi:S0171-2985(07)00068-X [pii] 10.1016/j.imbio.2007.05.002

EC (2006) Regulation (EC) No 1907/2006 of the European Parliament and of the Council of 18 December 2006 concerning the Registration, Evaluation, Authorisation and Restriction of Chemicals (REACH), establishing a European Chemicals Agency, amending Directive 1999/45/EC and repealing Council Regulation (EEC) No 793/93 and Commission Regulation (EC) No 1488/94 as well as Council Directive 76/769/EEC and Commission Directives 91/155/EEC, 93/67/EEC, 93/105/EC and 2000/21/EC. In: EC (ed). OJ L, p 1-849

Firestone M, Kavlock R, Zenick H, Kramer M, Testing USEPAWGotFoT (2010) The U.S. Environmental Protection Agency strategic plan for evaluating the toxicity of chemicals. Journal of toxicology and environmental health Part B, Critical reviews 13(2-4):139-62 doi:10.1080/10937404.2010.483178

Fruman DA, Pai SY, Burakoff SJ, Bierer BE (1995) Characterization of a mutant calcineurin A alpha gene expressed by EL4 lymphoma cells. Molecular and cellular biology 15(7):3857-63

Grollman AP (1967) Inhibitors of protein biosynthesis. II. Mode of action of anisomycin. The Journal of biological chemistry 242(13):3226-33

Hama T, Nakanishi K, Mukaiyama H, et al. (2013) Endoplasmic reticulum stress with low-dose cyclosporine in frequently relapsing nephrotic syndrome. Pediatric nephrology doi:10.1007/s00467-012-2403-6

Ho S, Clipstone N, Timmermann L, et al. (1996) The mechanism of action of cyclosporin A and FK506. Clinical immunology and immunopathology 80(3 Pt 2):S40-5

Hoch M (2001) Organotin compounds in the environment - an overview. Appl Geochem 16(7-8):719-743

Huh D, Matthews BD, Mammoto A, Montoya-Zavala M, Hsin HY, Ingber DE (2010) Reconstituting organ-level lung functions on a chip. Science 328(5986):1662-8 doi:10.1126/science.1188302

Imboden JB, Weiss A, Stobo JD (1985) The antigen receptor on a human T cell line initiates activation by increasing cytoplasmic free calcium. Journal of immunology 134(2):663-5

Iordanov MS, Pribnow D, Magun JL, et al. (1997) Ribotoxic stress response: activation of the stress-activated protein kinase JNK1 by inhibitors of the peptidyl transferase reaction and by sequence-specific RNA damage to the alpha-sarcin/ricin loop in the 28S rRNA. Molecular and cellular biology 17(6):3373-81

Katika MR, Hendriksen PJ, de Ruijter NC, van Loveren H, Peijnenburg A (2012a) Immunocytological and biochemical analysis of the mode of action of bis (tri-n-butyltin) tri-oxide (TBTO) in Jurkat cells. Toxicology letters 212(2):126-36 doi:10.1016/j.toxlet.2012.05.010

Katika MR, Hendriksen PJ, Shao J, van Loveren H, Peijnenburg A (2012b) Transcriptome analysis of the human T lymphocyte cell line Jurkat and human peripheral blood mononuclear cells exposed to deoxynivalenol (DON): New mechanistic insights. Toxicology and applied pharmacology 264(1):51-64 doi:10.1016/j.taap.2012.07.017 Katika MR, Hendriksen PJ, van Loveren H, Peijnenburg A (2011) Exposure of Jurkat cells to bis (tri-n-butyltin) oxide (TBTO) induces transcriptomics changes indicative for ER- and oxidative stress, T cell activation and apoptosis. Toxicology and applied pharmacology 254(3):311-22 doi:10.1016/j.taap.2011.04.021

Krewski D, Acosta D, Jr., Andersen M, et al. (2010) Toxicity testing in the 21st century: a vision and a strategy. Journal of toxicology and environmental health Part B, Critical reviews 13(2-4):51-138 doi:10.1080/10937404.2010.483176

Krewski D, Andersen ME, Mantus E, Zeise L (2009) Toxicity testing in the 21st century: implications for human health risk assessment. Risk analysis : an official publication of the Society for Risk Analysis 29(4):474-9 doi:10.1111/j.1539-6924.2008.01150.x

Lamb J, Crawford ED, Peck D, et al. (2006) The Connectivity Map: using gene-expression signatures to connect small molecules, genes, and disease. Science 313(5795):1929-35 doi:10.1126/science.1132939 
O'Connell S, Tuite N, Slattery C, Ryan MP, McMorrow T (2012) Cyclosporine A--induced oxidative stress in human renal mesangial cells: a role for ERK 1/2 MAPK signaling. Toxicological sciences : an official journal of the Society of Toxicology 126(1):101-13 doi:10.1093/toxsci/kfr330

Pestka JJ, Uzarski RL, Islam Z (2005) Induction of apoptosis and cytokine production in the Jurkat human T cells by deoxynivalenol: role of mitogen-activated protein kinases and comparison to other 8-ketotrichothecenes.

Toxicology 206(2):207-19 doi:S0300-483X(04)00566-9 [pii]

10.1016/j.tox.2004.08.020

Rasmussen PH, Ghorbani F, Berg T (2003) Deoxynivalenol and other Fusarium toxins in wheat and rye flours on the Danish market. Food Addit Contam 20(4):396-404 doi:10.1080/0265203031000082495

W2C0DNRN91MGQP2E [pii]

Reif DM, Martin MT, Tan SW, et al. (2010) Endocrine profiling and prioritization of environmental chemicals using ToxCast data. Environmental health perspectives 118(12):1714-20 doi:10.1289/ehp.1002180

Rogers TB, Inesi G, Wade R, Lederer WJ (1995) Use of thapsigargin to study Ca2+ homeostasis in cardiac cells. Bioscience reports 15(5):341-9

Scheuner D, Kaufman RJ (2008) The unfolded protein response: a pathway that links insulin demand with betacell failure and diabetes. Endocrine reviews 29(3):317-33 doi:10.1210/er.2007-0039

Schiffelers MJ, Blaauboer BJ, Hendriksen CF, Bakker WE (2012) Regulatory acceptance and use of 3R models: a multilevel perspective. Altex 29(3):287-300

Severino L, Luongo D, Bergamo P, Lucisano A, Rossi M (2006) Mycotoxins nivalenol and deoxynivalenol differentially modulate cytokine mRNA expression in Jurkat T cells. Cytokine 36(1-2):75-82 doi:S1043-

4666(06)00314-0 [pii]

10.1016/j.cyto.2006.11.006

Shao J, Berger LF, Hendriksen PJ, Peijnenburg AA, van Loveren H, Volger OL (2014) Transcriptome-based functional classifiers for direct immunotoxicity. Archives of toxicology 88(3):673-89 doi:10.1007/s00204-0131179-1

Shao J, Katika MR, Schmeits PC, et al. (2013) Toxicogenomics-based identification of mechanisms for direct immunotoxicity. Toxicological sciences : an official journal of the Society of Toxicology doi:10.1093/toxsci/kft151

Stepkowski SM, Kirken RA (2000) The role of IL-2 in allograft rejection--a lesson learned from experimental work. Transplantation 69(12):2480-2

Toyoshiba H, Sawada H, Naeshiro I, Horinouchi A (2009) Similar compounds searching system by using the gene expression microarray database. Toxicology letters 186(1):52-7 doi:10.1016/j.toxlet.2008.08.009

van Kol SW, Hendriksen PJ, van Loveren H, Peijnenburg A (2012) Transcriptomics analysis of primary mouse thymocytes exposed to bis(tri-n-butyltin)dioxide (TBTO). Toxicology 296(1-3):37-47

doi:10.1016/j.tox.2012.03.002

van Kol SWM, Hendriksen PJM, van Loveren H, Peijnenburg A (2011) The effects of deoxynivalenol on gene expression in the murine thymus. Toxicology and applied pharmacology 250(3):299-311 

Chapter 8

Nederlandse samenvatting 
In dit proefschrift staan twee hoofdonderwerpen centraal. Ten eerste, het bepalen van de geschiktheid van twee muizen cellijnen (EL-4 en CTLL-2) en één humane cellijn (Jurkat) voor detectie van mechanismes van immunotoxiciteit. Ten tweede, het uitvoeren van een (pre)validatie van biomerkers voor detectie van humane immunotoxiciteit. Daarnaast werd met behulp van microarrays meer inzicht verschaft in het werkingsmechanisme van immunotoxische stoffen. Een overzicht van het immuunsysteem, de huidige testmethoden voor immunotoxiciteit, het werkingsmechanisme van de immunotoxische modelstoffen en een uitleg van verschillende 'omics' technologieën wordt gegeven in Hoofdstuk 1 van dit proefschrift. Het afgelopen decennium verschoof de aandacht met betrekking tot immunotoxiciteitstesten langzaam richting het gebruik van minder proefdieren. Dit komt onder andere tot uitdrukking in diverse Amerikaanse en Europese richtlijnen en regelgevingen. Parallel aan de introductie van deze richtlijnen en regelgevingen was de opkomst van toxicogenomics technieken, zoals microarrays. Hiermee wordt de respons in boodschapper RNA (mRNA) van het gehele genoom gemeten. Op deze wijze kunnen grote hoeveelheden data verkregen worden uit relatief kleine samples. Deze technieken geven meer inzicht in de werkingsmechanismen van nieuwe en bestaande stoffen en dragen bij aan de identificatie van biomerkers. Ondanks de geboekte vooruitgang met de ontwikkeling van proefdiervrije immunotoxiciteitstesten zoals de lymfocyt proliferatie test en cytokine release test, was de bijdrage van genomics technieken bij de totstandkoming van alternatieve testen beperkt. In dit proefschrift wordt een toxicogenomics benadering gevolgd voor het bepalen van de geschiktheid van verschillende cel modellen als alternatieve testen voor directe immunotoxiciteit. Cel modellen die gebruikt werden betroffen de muizen CTLL-2, muizen EL-4 en humane Jurkat T cellijnen. Verder beschrijft dit proefschrift onderzoek naar het werkingsmechanisme van de immunotoxische stoffen TBTO en DON in de Jurkat cellijn en de geschiktheid van eerder geïdentificeerde biomerkers voor het opsporen van immunotoxiciteit in deze cellijn.

\section{Standaardisering van blootstellingsexperimenten}

Een eerste voorwaarde voor een optimale teststrategie is het gebruiken van een methode die in elk experiment hetzelfde is. Omdat elke stof toxiciteit kan veroorzaken zolang de dosis hoog genoeg is, werden in de experimenten in dit proefschrift condities geselecteerd die het mogelijk maken om stof-specifieke effecten te detecteren. Hoge concentraties induceren een algemene cytotoxiciteitsrespons, leidend tot celdood via necrose (door verlies van membraan integriteit resulterend in cel lysis) of apoptose (gecontroleerde celdood). De stof specifieke effecten van een stof zijn dan niet meer te detecteren. Voor elke stof getest in dit proefschrift werden viabiliteitsdata gegenereerd na 24 uur blootstellingen. De criteria voor het selecteren van de concentraties voor microarray blootstellingen werd bepaald op een afname van maximaal $20 \%$ in cel viabiliteit na 24 uur. De gekozen concentraties werden vervolgens gebruikt in 6 uur blootstellingen voor microarray of high-throughput PCR reacties. Voor primaire muizencellen (thymus- en miltcellen) werd een iets andere doseringsbepaling gevolgd. Omdat de viabiliteit van deze primaire cellen afneemt vanaf het moment van isolatie, werden de doseringen van deze cellen gebaseerd op de 
viabiliteitsexperimenten van muizen EL-4 en CTLL-2 cellijnen. De viabiliteit van primaire cellen werd bepaald na 6 uur in plaats van 24 uur blootstelling. Deze methodes voor het bepalen van een optimale testconcentratie werden bij elke stof gebruikt, waardoor de vergelijking tussen verschillende experimenten valide is.

Geschiktheid van muizen cellijnen in het detecteren van de werkingsmechanismes van immunotoxische stoffen

Om de geschiktheid van de CTLL-2 en EL-4 cellijnen voor immunotoxiciteitstesten te bestuderen werden beide muizencellijnen blootgesteld aan drie model immunotoxische of immunosuppressieve stoffen en werden de effecten van deze stoffen op genexpressie geanalyseerd met behulp van microarrays (transcriptomics). Daarnaast werd gebruik gemaakt van primaire muizen cellen (milt/thymus) en muizenorganen van in vivo experimenten. Transcriptomics werd gebruikt om de verschillen tussen muizen CTLL-2 cellen, muizen EL-4 cellen, primaire cellen (in vitro) en muizen milt (in vivo) te vergelijken. De uitdaging was om te bepalen welke van de cellijnen een transcriptomics respons geeft die het beste overeenkomt met het verwachte werkmechanisme. Voor de blootstelling werden stoffen geselecteerd waarvan het werkingsmechanisme al bekend was. De eerste stof betrof Ciclosporine A (CsA), een immunosuppressief medicament welke bij orgaantransplantaties gebruikt wordt om afstoting te voorkomen en beschermt tegen graftversus-host ziekte. CsA verlaagt de T cel activatie respons en induceert Endoplasmatisch Reticulum (ER) stress en oxidatieve stress, wat uiteindelijk leidt tot apoptose in $\mathrm{T}$ cellen. De experimenten uitgevoerd met CsA staan beschreven in Hoofdstuk 2 van dit proefschrift. Ook werden soort-overstijgende (muis - mens) vergelijkingen gemaakt met transcriptomics responsen op CsA blootstellingen in de humane T cellijn (Jurkat), humane lever cellijn (HepG2) en humane nier (RPTEC/TERT1) cellijn, gepubliceerd door anderen. De effecten op procesniveau en op individuele genexpressie waren bijna gelijk voor CTLL2 en EL-4 cellen. CsA induceerde in beide cellijnen een verhoogde mRNA expressie van genen betrokken bij oxidatieve stress, ER stress en apoptose. Genen waarvan CsA de expressie in de humane cellijnen Jurkat, HepG2 en RPTEC/TERT1 cellen verhoogt, werden ook door CsA in de muizen cellen (EL-4, CTLL-2 en primaire miltcellen) verhoogd tot expressie gebracht. Genen waarvan de expressie in humane cellen verlaagd werd door CsA, werden daarentegen niet in muizencellen verlaagd.

Milten van muizen die in vivo blootgesteld werden aan CsA lieten slechts weinig verandering in genexpressie zien, met uitzondering van een groepje celcyclus-gerelateerde genen waarvan de expressie verlaagd werd. De oorzaak van deze geringe respons ligt waarschijnlijk in het feit dat apoptotische $\mathrm{T}$ cellen uit de milt verwijderd worden door monocyten en Natural Killer cellen. Dit was in overeenstemming met de verhoogde expressie van monocyt en Natural Killer cel specifieke genen in met CsA blootgestelde milten. $\mathrm{Na}$ analyse van verschillende mechanismen en vergelijkingen tussen bestaande datasets bleken CTLL-2 cellen het beste de effecten op de voor CsA relevante processen weer te geven. $\mathrm{T}$ cel activatie was verminderd in CTLL-2 cellen, echter, deze vermindering 
was niet overtuigend. EL-4 cellen waren nog minder geschikt om de remming van T cel activatie te detecteren. Eén van de karakteristieken van de CTLL-2 cellijn is dat deze gekweekt moet worden in de aanwezigheid van een T cel stimulans, zoals IL-2, waarmee T cel activatie wordt gestimuleerd. Hierdoor zijn CTLL-2 cellen beter in het detecteren van door CsA veroorzaakte T cel inhibitie (Hoofdstuk 2) dan EL-4 cellen. In de andere gebruikte cellijnen werd geen $\mathrm{T}$ cel activatie tijdens kweek gebruikt.

Twee immunotoxische stoffen deoxynivalenol (DON) en tributyltin oxide (TBTO) werden gebruikt in Hoofdstuk 3 en 4. DON is een schimmeltoxine (mycotoxine) dat op landbouwproducten zoals mais en tarwe gevonden kan worden. Omdat DON stabiel blijft tijdens verhitting en koken, worden mensen continu blootgesteld aan lage hoeveelheden van dit mycotoxine. Het is bekend dat DON ribotoxische stress induceert, wat leidt tot ER stress en $\mathrm{T}$ cel activatie en specifiek aangrijpt op cellen in de thymus en beenmerg. TBTO is een organotin verbinding die gebruikt werd in verschillende industriële processen. TBTO werd verwerkt in scheepsverf om de groei van weekdieren aan de buitenkant van schepen tegen te gaan, maar TBTO werd ook gebruikt in plastic vloertegels en als houtbeschermer, waardoor TBTO wereldwijd in het milieu verspreid werd. Het werkingsmechanisme van TBTO heeft overeenkomsten met dat van DON. TBTO induceert een ER stress respons leidend tot $\mathrm{T}$ cel activatie en grijpt daarnaast in vivo ook specifiek aan op de thymus. Een verschil tussen DON en TBTO is dat DON ER stress induceert via ribotoxische stress inductie, waar TBTO een direct effect heeft op het ER. Omdat zowel DON als TBTO reeds uitgebreid bestudeerd zijn in in vitro en in vivo immunotoxiciteitsstudies, werden beide als modelstoffen gebruikt om de geschiktheid van muizen EL-4 cellen (Hoofdstuk 3) en CTLL-2 cellen (Hoofdstuk 4) te testen. Resultaten van de blootstellingen van EL-4 cellen aan DON werden vergeleken met muizen CTLL-2 cellen (in vitro), muizen thymocyten (in vitro), muizen thymocyten (in vivo) en humane Jurkat T cellen (in vitro). DON blootstelling in EL-4 cellen zorgde voor een verhoging van genexpressie in genen uit ribosoom biogenese en RNA processing. Deze verhoging van expressie was echter lager dan in humane Jurkat $\mathrm{T}$ cellen. DON induceerde ook een verhoogde expressie van genen betrokken bij ribosoom biogenese in CTLL-2 cellen, maar deze inductie werd overtuigender waargenomen in EL-4 cellen. Zowel CTLL-2 cellen als EL-4 cellen veroorzaakten geen verhoging van de overige processen behorende tot het werkingsmechanisme van DON (ER stress, T cel activatie en apoptose). Zoals verwacht werd de expressie van genen in deze processen wel verhoogd in Jurkat T cellen. De EL-4 en CTLL-2 cellijn zijn mogelijk niet in staat om ER stress, T cel activatie en apoptose te induceren door het ontbreken van genen (of functionaliteit van genen) die betrokken zijn in de link tussen ribotoxische stress en ER stress.

Het werkingsmechanisme van TBTO (inductie van ER stress, T cel activatie en apoptose) werd slechts gedeeltelijk gerepresenteerd in EL-4 cellen. ER stress werd geïnduceerd in EL-4 cellen, maar dit leidde niet tot een daarop volgende $\mathrm{T}$ cel activatie en apoptose. Door een mutatie in het calcineurine-gen is de $\mathrm{T}$ cel activatie respons al continu in EL-4 cellen geactiveerd, en kan mogelijk niet nog verder geactiveerd worden. De expressie van genen 
betrokken bij de processen ER stress, T cel activatie en apoptose werden wel duidelijk door TBTO verhoogd in CTLL-2. De vergelijkingen op basis van genen en processen, welke belangrijk zijn in de immunotoxische actie van TBTO, maakten duidelijk dat deze beter gedetecteerd werden in CTLL-2 cellen, Jurkat T cellen en muis primaire thymocyten dan in EL-4 cellen. De processen behorende bij het werkingsmechanisme van DON werden beter gerepresenteerd in Jurkat T cellen en muis thymus in vivo dan in CTLL-2 cellen of EL-4 cellen. Omdat zowel EL-4 cellen als CTLL-2 cellen niet in staat waren om de werkingsmechanismen van elk van de drie de geteste stoffen (CsA, TBTO en DON) op te pikken, werd besloten deze cellijnen niet meer te gebruiken in toekomstige immunotoxische experimenten.

Directe vergelijking van de werkingsmechanismen van DON en TBTO in humane Jurkat T cellen

Omdat eerdere transcriptomics experimenten naar de effecten van DON en TBTO in de humane $\mathrm{T}$ cellijn Jurkat het werkingsmechanisme van beide stoffen verhelderden, werden deze stoffen in een microarray vergelijkingsexperiment gebruikt. Om de resultaten die verkregen zijn met DON en TBTO te verifiëren werden modelstoffen met een verwacht (deels) gelijk werkingsmechanisme gebruikt, zoals anisomycin, ionomycin en thapsigargin (Hoofdstuk 5). De rationale achter deze studie is dat stoffen welke werken volgens eenzelfde mechanisme ook eenzelfde genexpressie profiel zullen veroorzaken.

Thapsigargin werd gebruikt als positieve controle voor ER stress inductie geïnduceerd door vrijgifte van calcium ionen vanuit het ER naar het cytoplasma leidend tot apoptose. Ionomycin staat bekend om zijn calcium verhogend effect door het vrijmaken van calcium uit intracellulaire opslag en werkt vervolgens als T cel activator. Van anisomycin is bekend dat het de eiwit synthese remt. Anisomycin hecht aan 28s rRNA en veroorzaakt een ribotoxische stress respons. Op basis van de microarray data beschreven in Hoofdstuk 5 werd duidelijk dat anisomycin en DON genexpressie profielen veroorzaakten, welke bijna identiek aan elkaar waren. Daardoor kunnen we stellen dat deze stoffen een gelijk werkingsmechanisme hebben. TBTO verhoogde de genen in T cel activatie, ER stress inductie en apoptose, welke ook verhoogd werden door thapsigargin en ionomycin. Daarnaast werd een set genen geïdentificeerd waar alleen TBTO op aangreep. Deze genen waren betrokken bij efficiënte vouwing van DNA rondom histonen. Deze studie liet nogmaals zien dat toxicogenomics een toegevoegde waarde heeft bij het detecteren van overeenkomsten en verschillen in de werkingsmechanismen van verschillende stoffen.

\section{Voortgang richting proefdiervrije immunotoxiciteitstesten}

Parallel aan de experimenten beschreven in Hoofdstuk 2-5 werden grootschalige microarray blootstellingsstudies uitgevoerd door Shao et. al., gebruikmakend van Jurkat T cellen en sets van immunotoxische en niet-immunotoxische stoffen. Het doel van deze experimenten was het identificeren van mogelijke immunotoxische werkingsmechanismen en identificatie van classificatiegenen die als in vitro biomerkers voor humane 
immunotoxiciteit kunnen dienen. De uitkomst van de studies van Shao et. al. was een set van 25 genen die met hoge sensitiviteit (88\%), specificiteit (67\%) en nauwkeurigheid $(85 \%)$ de immunotoxiciteit van stoffen kunnen voorspellen. Ondanks deze veelbelovende resultaten bleven een aantal vragen en kwesties onbeantwoord. Eén van deze vragen is: "Hoe zijn de prestaties van dit screeningsmodel wanneer stoffen worden getest van klassen die nog niet eerder getest zijn?". Een andere kwestie is het geringe aantal nietimmunotoxische stoffen in de studies van Shao et. al. Daarom werden Jurkat T cellen in Hoofdstuk 6 blootgesteld aan een nieuwe set van 14 stoffen waarvan enkele tot klassen behoren welke nog niet eerder zijn getest. Vijf van de 14 stoffen waren bekende niet immunotoxische stoffen. De onbalans tussen geteste immunotoxische en niet immunotoxische stoffen zal altijd aanwezig zijn omdat er van weinig stoffen beschreven is dat ze bewezen niet-immunotoxische stoffen zijn. Dit komt doordat immunotoxiciteitsstudies in het algemeen niet worden uitgevoerd op stoffen waarvan geen immunotoxiciteit wordt verwacht. Een tweede reden is dat richtlijnen doorgaans weinig of geen informatie verlangen over mogelijke immunotoxiciteit van stoffen. Omdat een gelimiteerde set genen reeds was geïdentificeerd als classificatie genen voor humane immunotoxiciteit door Shao et al., werd gekozen voor een Fluidigm analyse in plaats van microarray analyse. Dit zorgde voor snelle resultaten die gemakkelijker te analyseren zijn in vergelijking met microarray data analyse. Van de 14 stoffen die gebruikt zijn in de Fluidigm studie werden er 13 correct geclassificeerd. Sensitiviteit, specificiteit en nauwkeurigheid waren respectievelijk 100\%, $80 \%$ en 93\%. Wanneer deze resultaten gecombineerd worden met de resultaten van de studies van Shao et. al. komt men tot $91 \%$ sensitiviteit, $71 \%$ specificiteit en $83 \%$ nauwkeurigheid voor de 25 biomerkers.

\section{Toekomstige verandering in richtlijnen}

Het onderzoek dat uitgevoerd werd in dit proefschrift leverde uiteindelijk een set biomerkers op met hoge specificiteit, sensitiviteit en nauwkeurigheid voor immunotoxische voorspellingen. Hoe overtuigend de resultaten ook mogen zijn, dit betekent niet dat dierproeven voor immunotoxiciteitstesten snel vervangen zullen worden door in vitro screenings met chemicaliën in Jurkat $\mathrm{T}$ cellen. Dierproeven zouden echter niet als gouden standaard gezien moeten worden voor de effecten die optreden in mensen. Om die reden is de validatie van de extrapolatie van effecten op mens in vitro naar mens in vivo door middel van dierproeven niet ideaal. Gebruik maken van humane cellijnen en weefsels blootgesteld aan dezelfde stof en identificatie van de werkingsmechanismen in humane systemen zou een betere opzet zijn. Echter, de complexiteit van het immuunsysteem (meerdere organen, weefsels en cellen) is beperkend om deze strategie toe te passen voor immunotoxiciteit. Sommige initiatieven, zoals ASAT (Assuring Safety without Animal Testing), doelen op het gebruik van humane data van blootstellingsexperimenten, gerelateerd aan specifieke menselijke ziektes, om vergelijkingen mogelijk te maken. In die zin is de ASAT benadering anders dan de meeste klassieke validatie benaderingen omdat het niet berust op de resultaten van dierproeven voor de validatie. Het veranderproces in de richtlijnen en wetten 
om nieuwe in vitro alternatieven voor immunotoxiciteitstesten te implementeren is een lange weg. Dit komt door de behoefte aan betrouwbare en gevalideerde (immuno)toxiciteitstesten door de overkoepelende organisaties. Het kan meerdere jaren duren voordat een bewezen alternatief algemeen geaccepteerd wordt. Tot dat moment zullen producenten van nieuwe stoffen en medicijnen zich moeten conformeren aan de huidige wetten die voorschrijven dat de stoffen in dierproeven getest moeten zijn op immunotoxiciteit.

Om sneller tot algemene acceptatie voor in vitro testen te komen, verzamelden verscheidene instituten in de VS hun plannen in een visiedocument getiteld "Toxicity Testing in the 21st Century: A Vision and a Strategy", welke gepubliceerd werd door de National Academic Press in 2007. Deze visie behelst het verplaatsen van onderzoek richting het gebruik van meer high-throughput methoden gebaseerd op cellen of cellijnen, bij voorkeur van humane oorsprong. Daarnaast meldt het document dat nieuwe toxiciteit testsystemen gebruikt moeten worden om de biologisch relevante veranderingen in de belangrijkste toxiciteit pathways te evalueren gefocust op humane biologie. Deze twee punten (gebruik maken van humane in vitro celsystemen en kennis m.b.t. toxiciteit pathways) zijn duidelijk behandeld in dit proefschrift daar experimenten zijn uitgevoerd in humane Jurkat $\mathrm{T}$ cellen en gebruik werd gemaakt van microarrays in combinatie met tools zoals GSEA of MetaCore om de biologische respons te bestuderen.

\section{Conclusie}

Dit proefschrift richtte zich op het testen van de bruikbaarheid van twee muizen cellijnen en één humane cellijn voor toepassing in immunoxiciteitstesten. De experimenten toonden enkele duidelijke nadelen van de muizen EL-4 en CTLL-2 cellijnen aan. Beide cellijnen waren, in tegenstelling tot de Jurkat cellijn, niet in staat om de belangrijke immunotoxische processen van CsA, DON en TBTO te detecteren. Enerzijds is de T cel activatie respons maximaal geactiveerd in zowel de CTLL-2 cellijn (door standaard kweek procedures) als de EL-4 cellijn (door genetische activatie van calcineurine gen). Anderzijds is de verwachte afwezigheid van (functionele) genen die belangrijk zijn in de link tussen ribotoxische stress, ER stress en T cel activatie. Beide redenen maken de CTLL-2 en EL-4 cellen minder geschikt voor immunotoxiciteitsstudies in vergelijking met humane Jurkat cellen. De progressie die geboekt werd met Jurkat cellen resulteerde in een set op mechanisme gebaseerde immunotoxische biomerkers welke verder gevalideerd werden in dit proefschrift. Dit resulteerde in een hoge sensitiviteit, specificiteit en nauwkeurigheid. Alles bij elkaar leverde de resultaten van dit proefschrift een bruikbare set genetische merkers op, welke gebruikt kunnen worden in in vitro onderzoek met bestaande en nieuwe stoffen om voorspellingen te doen over de immunotoxiciteit en werkingsmechanismen in mensen. 

Chapter 9

\section{Valorisation Addendum}




\section{Introduction}

Chemicals with direct immunotoxic characteristics may cause a risk to human health, as humans can be exposed to these chemicals via food, drinking water, and the environment. These direct immunotoxic properties are evaluated in the safety assessment of new and existing chemicals and food additives (EPA 1998; Institóris et al. 1998), and during the preclinical phase of pharmaceutical development (EMA 2000; FDA 2002). Currently, immunotoxicity tests are mainly based on changes in organ weights in animal experiments, histopathology of those organs (spleen, thymus, bone marrow, lymph nodes) or by measuring serum parameters (FDA 2002). Disadvantages of animal tests are related to the high costs and long time needed as well as to ethical issues (Corsini and Roggen 2009). In addition, animal studies rely mostly on apical endpoints, do not sufficiently yield insights into the molecular mechanisms of direct immunotoxicity and often have limited prediction towards the human situation. Thus, animal free alternatives are urgently needed. The latter is a key element in a report from the National Research Council (NRC) of the U.S. National Academy of Science entitled "Toxicity testing in the 21st Century: A Vision and A Strategy"(2007). In this report, the NRC supports the shifts from animal testing to (preferably human-based) in vitro testing and from single endpoint studies to studies addressing toxicity pathways. This support for omics approaches in defining new endpoints was also shared by the European Centre for the Validation of Alternative Methods (ECVAM) (Bouvier d'Yvoire et al. 2012). The application of transcriptomics provides mechanistic insights into the mode of action of the chemical and can also yield biomarkers that represent a specific toxicological endpoint.

\section{Innovation and social relevance of the research results}

Recently, in vitro transcriptomics studies using human and rodent $\mathrm{T}$ cell lines and primary cells have led to a better insight into the mechanism of action of a limited set of immunotoxicants. The question which of the available models would be most suitable to screen compounds for immunotoxicity was however not yet answered. Therefore, the work described in the present thesis started with a comparative assessment of several models using three different model immunotoxicants (CsA, TBTO and DON). As it became apparent that the in vitro mouse models (CTLL-2 and EL-4 cell lines) as compared to the human Jurkat $\mathrm{T}$ cell line lacked some important features to detect the immunotoxicity of these immunotoxicants, a larger set of chemicals was studied by using the human Jurkat $\mathrm{T}$ cell line. These studies were performed by colleagues and resulted in the identification of a set of mechanism-based biomarkers that allowed to distinguish immunotoxicants from non immunotoxicants with a relatively high accuracy $85 \%$. As some questions remained unanswered, such as: "How does this model perform when challenged with chemicals that were not tested before?" the set of biomarkers was further tested with a new set of compounds in this thesis. This additional pre-validation of the biomarkers resulted in excellent sensitivity (100\%), specificity (80\%) and accuracy (93\%). In addition, the immunotoxicity of chemicals originating from classes that were not tested before could also be confirmed. It was concluded that the Jurkat $\mathrm{T}$ cell model in combination with the 
biomarker gene set promises to be a useful module within a battery of tests to screen new and existing chemicals for immunotoxicity. Besides assessments on immunotoxicity of chemicals, one study was set up using known immunotoxicants in one microarray experiments. This allowed a direct comparison between the gene expression profiles of compounds with suspected similar modes of action.

Taken together, the results of this thesis showed that of the models assessed, the Jurkat T cell line gave the best prediction for immunotoxicity testing. Using this cell line in a toxicogenomics setting resulted in valuable mechanistic information and biomarkers for immunotoxicity were pre validated in a second experiment with another set of immunotoxicants and non-immunotoxicants. The research performed was in line of the framework of US NRC, US FDA and ECVAM contributing to the development of animal free screening models.

\section{Concrete product}

The set of biomarkers that were pre-validated in this thesis can be used in a high-throughput setting allowing screening of large sets of chemicals in a short time. In the present thesis a Fluidigm high-throughput PCR system was used, however, other possibilities exist. Biomarkers could also be tested using a Luminex setting, which has the advantage that the quantification of mRNA is done directly on lysates of cultured cells, so no RNA isolation and purification steps are required (Zheng et al. 2006). Though this makes the Luminex system more high throughput, the Fluidigm setting is fast, cheaper than the Luminex system, and has already proven itself in Jurkat immunotoxicity experiments.

\section{Potential applications}

An assay that is created on the basis of the outcome of this thesis can be used for several purposes. First, it can be used within drug development to screen for potential immunotoxic properties of newly developed pharmaceuticals. Second, within the framework of REACH, an assay could be used in the safety evaluation of existing chemicals and the presence of immunotoxicants in food, feed and water.

\section{Implementation schedule}

The present thesis proved the value of the identified biomarkers, however, some improvements are still to be investigated. To generate a more powerful validation, more non-immunotoxicants need to be used in this screening set up to balance the large number of known immunotoxicants with the low number of known non-immunotoxicants. A next step will be the submission of the results of the Jurkat screening assay to ECVAM for independent further validation. Because the cell line (Jurkat $\mathrm{T}$ cell line) and the primers in RT-PCR (Taqman) are both commercially available, this will shorten the time for validation by ECVAM. Parallel to this, similar exercises as done in this thesis could be performed for other immune cell lines, such as a macrophage cell line or a Natural Killer cell line. When compounds can be screened in three cell lines (T cell, NK and macrophage) 


\section{Chapter 9}

with the same set of biomarkers, this will increase the power of the assay, as immunotoxic chemicals might specifically affect NK cells or macrophages and do not affect T cells. 
References

(2007) Toxicity Testing in the 21st Century: A Vision and a Strategy. The National Academies Press Bouvier d'Yvoire M, Bremer S, Casati S, et al. (2012) ECVAM and new technologies for toxicity testing. Advances in experimental medicine and biology 745:154-80 doi:10.1007/978-1-4614-3055-1_10

Corsini E, Roggen EL (2009) Immunotoxicology: opportunities for non-animal test development. Alternatives to laboratory animals : ATLA 37(4):387-97

EMA (2000) Note for Guidance on Repeated Dose Toxicity, CPMP/SWP/1042/99.

EPA (1998) Health Effects Test Guidelines, Immunotoxicity, OPPTS 870. 7800.

FDA (2002) Guidance for Industry: Immunotoxicology Evaluation of Investigational New Drugs.

Institóris L, Siroki O, Dési I, et al. (1998) Extension of the protocol of OECD guideline 407 (28-day repeated dose oral toxicity test in the rat) to detect potential immunotoxicity of chemicals. Human \& Experimental Toxicology 17(4):206-211 doi:10.1177/096032719801700402

Zheng Z, Luo Y, McMaster GK (2006) Sensitive and Quantitative Measurement of Gene Expression Directly from a Small Amount of Whole Blood. Clinical Chemistry 52(7):1294-1302 doi:10.1373/clinchem.2005.065078 

Dankwoord 
Op de kaft van een proefschrift pronkt altijd alleen de naam van de promovendus. Gelukkig stond ik er tijdens mijn promotietraject niet alleen voor. Dit (waarschijnlijk) meest gelezen deel van mijn proefschrift biedt dan ook ruimte om eenieder te bedanken die op welke wijze dan ook een bijdrage heeft geleverd aan de in- of ontspanningen tijdens mijn promotietraject.

Henk, ondanks de fysieke afstand tussen Wageningen en Bilthoven (of Maastricht) stond dit een uitstekende begeleiding niet in de weg. In regelmatige besprekingen wist je steeds de nadruk te leggen op de hoofdlijn en me kritisch na te laten denken over gemaakte keuzes. Jouw bijdrage aan met name de structuur in mijn proefschrift is onmiskenbaar. Bedankt voor je waardevolle begeleiding en advies de afgelopen jaren.

Ad, de fysieke afstand tot jou bleef beperkt tot één verdieping en omdat je deur altijd open stond was je te allen tijden bereikbaar voor korte discussies. Jij hield de uitgezette lijn in wekelijkse besprekingen in het oog en stuurde bij waar noodzakelijk. Ook buiten het werk om was je beschikbaar voor een praatje. Dank voor de goede begeleiding.

Peter Hendriksen, jij zat nog dichter op het vuur dan Ad en Henk. De volledige vier jaar van mijn RIKILT-tijd was ik je kamergenoot en mocht ik je storen voor alle vragen. Met name je gestructureerde manier van microarray data analyse was erg prettig. Ook had je een belangrijke stem(pel) in het reviewen van mijn schrijfwerk. Ik wil je bedanken voor de nuttige discussies en alle tijd die je hebt gestoken in mijn begeleiding.

Oscar, jij was degene die mijn experimenten in gang zette in mijn begintijd. Ik bewonder je kracht om altijd alternatieve mogelijkheden aan te dragen, waardoor voor elk probleem al snel meerdere oplossingen gevonden werden.

Jia, you started your $\mathrm{PhD}$ a month or two earlier than I did and therefore you took me by the hand in the world of Jurkat cell cultures and all relevant techniques on the RIKILT labs. Together we shared knowledge, experiences, two journal papers and two book chapters. I admire your passion for research and I think you can be very proud of your work. I was very happy to have you as a colleague and I wish you all the best in your career.

Danique, je kwam binnen als voluntair op een project van Geert, maar draaide in de vrije uurtjes mee op onderzoeksprojecten van anderen. Ik heb daar gelukkig dankbaar gebruik van mogen maken wat resulteerde in een prettige samenwerking en een mooi artikel. Ik ben blij dat je een leuke baan hebt gevonden en dat we nog regelmatig contact hebben en voel me vereerd met jou als mijn paranimf.

Meike, met name onze gezamenlijke interesse in films en series zorgden voor genoeg gespreksstof tijdens de pauzes. Je bood regelmatig hulp bij de opmaak van figuren of 
posters en daarnaast zorgde je voor een mooi ontwerp voor dit boekje, waar ik je erg dankbaar voor ben. Ik ben blij dat jij me wilt bijstaan als paranimf.

Een speciaal woord van dank aan Evelien en Geert. Jullie stonden altijd klaar voor hulp op het lab of voor een praatje. Onze CD collecties werden regelmatig uitgewisseld en na enig aandringen waren jullie overtuigd om mee te gaan naar een concert van Jonathan Jeremiah, waar jullie hopelijk net zo van hebben genoten als ik.

Toine, ik waardeer enorm je betrokkenheid bij mijn onderzoek, terwijl je daar niet eens verplicht toe was. In pauzes wist je altijd het gesprek aan de gang te houden, desnoods door iets een keer te herhalen. Ook was ik blij verrast met jou in het beachvolleybalteam op de RIKILT-dag, waar we pas in de finale moesten buigen.

Ook een groot dankjewel aan alle overige collega's van RIKILT: Hendrik, Richard, Gerlof, Liza, Astrid, Si, Ewa, Agata, Lonneke, Hans, Jeroen R, Marleen, Jeroen van D, Madhu, Corina, Marcia, Jonathan.

Als promovendus heb je ook het voorrecht zo af en toe een student te mogen begeleiden. Ik wil zowel Tanisha Guy als Tamara Zandvliet bedanken voor hun inzet en bijdrage aan de validatie van mijn eerste resultaten.

Jean Conemans en ook Mirjam Hermans, jullie bijdrage aan dit proefschrift is beperkt, maar ik ben er van overtuigd dat het de stage bij de ZANOB en JBZ is geweest die er voor heeft gezorgd dat ik ben aangenomen op het promotietraject bij RIKILT. Jean en Mirjam, jullie waren topbegeleiders tijdens mijn studie en stonden na afloop van mijn promotietraject nog steeds voor me klaar. Ontzettend bedankt voor alle steun.

Vincent en Jorn, mijn beste vrienden stonden altijd klaar voor de nodige ontspanning, zoals een filmavondje of een weekendje "Center Parcs". Ik ben blij dat we dezelfde humor hebben al is het voor anderen soms minder leuk als we ons met zijn drieën in dezelfde ruimte bevinden. Ook een dankjewel aan Pim, omdat je altijd beschikbaar was voor een afleidend "koffiepraatje".

Anita en Hanneke, ik leerde jullie kennen tijdens de masterfase van onze studie Biomedische wetenschappen en we zijn sindsdien met onregelmatige tussenpozen te vinden in de restaurants in Uden, Oss of Nijmegen. Deze avonden zijn altijd gezellig en moeten we zeker blijven doen. Ik kon mooi profiteren van alle kennis van de randzaken rondom een promotietraject die jullie opdeden en deelden en daar ben ik jullie dankbaar voor.

Met ouders die werkzaam waren in het geneesmiddelenonderzoek en op een röntgenafdeling, werd mijn interesse voor de medische en biologische wereld al vroeg aangezwengeld. Ik ben er zeker van dat de vele korte gesprekjes (colleges) tijdens de afwas bij hebben gedragen aan mijn nieuwsgierigheid voor het menselijk lichaam en ik mede 
daardoor de juiste keuzes heb gemaakt. Ondanks dat mijn moeder het begin van mijn promotieonderzoek niet meer mee heeft mogen maken, weet ik zeker dat ze trots zou zijn geweest. Pa en ma, ontzettend bedankt voor de goede zorgen.

Bart, er kan nooit genoeg over volleybal gezegd worden! En daarom hebben we ook altijd wat te vertellen. Ik bewonder enorm dat je doet wat je leuk vindt en dat je daarin ook nog eens ontzettend georganiseerd en gestructureerd bent. Kwaliteiten die wel eens goed van pas kunnen komen als je nog eens een promotieonderzoek zou gaan doen.

Mieke, als jongste met twee oudere broers had je het niet altijd makkelijk. Je wist je echter toch succesvol door je opleiding heen te manoeuvreren. Net als bij een promotieonderzoek weet je tegenslagen te overwinnen en je uiteindelijke doel te behalen. Ik hoop echter dat je over je nieuwste uitdaging niet zo lang doet als ik deed over mijn promotieonderzoek :)

Ook een woord van dank aan mijn schoonfamilie voor de interesse tijdens en de zoektocht naar werk na afloop van mijn promotieonderzoek. Ton en Betsie, Imke, Sanne en Michel: Bedankt voor jullie betrokkenheid.

Naast de drukke dagen op het lab of achter de pc was er gelukkig tijd genoeg voor ontspanning. De afgelopen jaren vond ik die ontspanning met name bij mijn volleybalteams (TFC en Nuvoc), actief als speler, maar ook als assistent bij een damesteam van TFC. Iedereen waar ik mee heb samengespeeld of samengewerkt: Dank jullie voor de gezelligheid!

Ko, dank dat je me een kans geeft om bij Deventer Ziekenhuis in een werkveld te werken dat niet direct aansluit op mijn vooropleiding. Bedankt voor het vertrouwen.

Ook de voormalig collega's van Ross Health, Inge, Dedmer, Hendrik, Leonie, Rob, Iris, Manon, Erik, Edwin, Saide, Niek en Stephanie: dank voor de gezellige werksfeer in Soest.

Dit laatste plekje is gereserveerd voor de belangrijkste persoon in mijn leven. Lieve Maartje, bedankt voor alle steun in de afgelopen jaren. Je was er voor me als het even tegen zat met mijn onderzoek of schrijfwerk. Je stond me bij in de zoektocht naar een nieuwe baan en zorgde voor de nodige ontspanning tijdens filmavondjes of concerten. Ik ben ontzettend gelukkig met jou in mijn leven en ben iedere dag dankbaar die we samen door kunnen brengen. 
About the author 


\section{Curriculum vitae}

Na de middelbare school volgde Peter Schmeits de universitaire opleiding Biomedische Wetenschappen aan de Radboud Universiteit te Nijmegen. Tijdens de masterfase van deze opleiding koos hij voor het hoofdvak toxicologie en het bijvak geneesmiddelenonderzoek. In het kader van het bijvak liep hij een gecombineerde onderzoeksstage bij de ziekenhuisapotheek Noordoost Brabant (ZANOB) en het laboratorium moleculaire diagnostiek van het Jeroen Bosch Ziekenhuis te 's-Hertogenbosch onder begeleiding van drs. Jean Conemans en dr. Mirjam Hermans. Het onderzoek richtte zich op genetische variaties van het VKORC1 gen, welke een resistentie kunnen veroorzaken tegen orale anticoagulantia. De hoofdvakstage werd uitgevoerd bij Shering-Plough (later MSD) onder begeleiding van dr. Sjeng Horbach en was gericht op het opzetten van een foto-Ames test binnen de afdeling Toxicology \& Drug Disposition. $\mathrm{Na}$ het behalen van het doctoraaldiploma in 2009 begon Peter met een promotietraject aan de afdeling Toxicogenomics van de Universiteit Maastricht onder begeleiding van dr. Peter J.M. Hendriksen, dr. Ad A.C.M. Peijnenburg en prof. Dr. Henk van Loveren. De resultaten van dat traject staan beschreven in dit proefschrift. Parallel aan het promotieonderzoek volgde Peter de postdoctorale opleiding tot toxicoloog. Na zijn promotietraject werkte Peter een jaar als consultant bij Ross Health te Soest. Vanaf juli 2015 is hij werkzaam als projectleider ICT in Deventer Ziekenhuis. 


\section{List of publications}

\section{Journal articles}

Peter C J Schmeits, Jia Shao, Danique A van der Krieken, Oscar L Volger, Henk van Loveren, Ad A C M Peijnenburg, Peter J M Hendriksen: Successful validation of genomic biomarkers for human immunotoxicity in Jurkat T cells in vitro. Journal of applied Toxicology. 11/2014

Peter C J Schmeits, Mirjam M Schaap, Mirjam Luijten, Eugene van Someren, André Boorsma, Henk van Loveren, Ad A C M Peijnenburg, Peter J M Hendriksen: Detection of the mechanism of immunotoxicity of cyclosporine A in murine in vitro and in vivo models. Archives of toxicology. 09/2014;

Peter C J Schmeits, Sandra van Kol, Henk van Loveren, Ad Peijenburg, Peter Hendriksen: The effects of tributyltin oxide and deoxynivalenol on the transcriptome of the mouse thymoma cell line EL-4. Toxicology Research. 02/2014;

Peter C J Schmeits, Madhumohan R Katika, Ad A C M Peijnenburg, Henk van Loveren, Peter J M Hendriksen: DON shares a similar mode of action as the ribotoxic stress inducer anisomycin while TBTO shares ER stress patterns with the ER stress inducer thapsigargin based on comparative gene expression profiling in Jurkat T cells. Toxicology Letters 11/2013;

Jia Shao, Madhumohan R Katika, Peter C J Schmeits, Peter J M Hendriksen, Henk van Loveren, Ad A C M Peijnenburg, Oscar L Volger: Toxicogenomics-based identification of mechanisms for direct immunotoxicity. Toxicological Sciences 07/2013;

Peter C J Schmeits, Oscar L Volger, Ella T Zandvliet, Henk van Loveren, Ad A C M Peijnenburg, Peter J M Hendriksen: Assessment of the usefulness of the murine cytotoxic T cell line CTLL-2 for immunotoxicity screening by transcriptomics. Toxicology Letters 12/2012;

Peter C J Schmeits, Mirjam H A Hermans, Johanna H H van Geest-Daalderop, Jeroen Poodt, Pernette R W de Sauvage Nolting, Jean M H Conemans: VKORC1 mutations in patients with partial resistance to phenprocoumon. British Journal of Haematology 11/2009; 148(6):955-7.

Peter C J Schmeits, N C V Péquériaux, J H H van Geest-Daalderop, M E Ouwehand, A M J Coremans, M H A Hermans, J M H Conemans: Investigating unexpected INRs: in search of the culprit--adherence, interactions, genetics, and superwarfarin. The Netherlands Journal of Medicine 03/2009; 67(2):76-8. 
Book chapters

Molecular immunotoxicology: Chapter 15: Mode of action of organotins in immune cells. Peter J.M. Hendriksen, Peter C.J. Schmeits, Henk van Loveren, Jia Shao, Ad A.C.M. Peijnenburg. Wiley-VCH 2014

Toxicoinformatics: Chapter 6.2: Toxicogenomics and systems toxicology databases and resources: 'Chemical Effects in Biological Systems' (CEBS) and 'Data Integration by Applying Models On Design \& Safety’ (DIAMONDS). Jennifer Fostel, Eugene van Someren, Tessa Pronk, Jeroen Pennings, Peter Schmeits, Jia Shao, Dinant Kroese, Rob Stierum. Elsevier Sciences 2013 


\section{Overview of completed training activities}

\section{Conferences and research meetings}

Annual meeting of the NVT, Zeist, the Netherlands, 2011 - 2013

$48^{\text {th }}$ Congress of the European Society of Toxicology (EUROTOX), Stockholm, Sweden, 2012

$52^{\text {nd }}$ Annual meeting of the Society of Toxicology (SOT), San Antonio, USA, 2013

$1^{\text {st }}-4^{\text {th }}$ Annual meetings of the Netherlands Toxicogenomics Center, Amsterdam, the Netherlands, 2010-2013

NUTRIM annual meeting, Maastricht, the Netherlands, 2011

Discipline specific courses (All part of Postgraduate Education in Toxicology in the Netherlands)

Toxicogenomics, Maastricht, 2011,

Molecular Toxicology, Amsterdam, 2012

Epidemiology, Utrecht, 2012

Cellular Toxicology, Leiden, 2013

Ecotoxicology, Utrecht/Wageningen, 2013

Risk Assessment, Wageningen, 2013

\section{General courses}

Writing for Academic Publication, Wageningen, the Netherlands, 2010

Statistical analysis of microarray data, Leiden, the Netherlands, 2010

Mini-symposium "How to write a world class paper", Wageningen, the Netherlands, 2011 
This research was financially supported by the Netherlands Toxicogenomics Centre, the Netherlands Genomics Initiative.

Cover design: Meike van der Zande

Thesis Lay out: Peter Schmeits

Printed by Proefschriftmaken.nl || Uitgeverij BOXPress

Peter Schmeits, 2015 